RESOURCE EXTRACTION, RESISTANCE, AND RELIGION IN NICARAGUA

A Dissertation

Presented to

the Faculty of the Graduate School

at the University of Missouri-Columbia

In Partial Fulfillment

Of the Requirements for the Degree

Doctor of Philosophy

by

MICHAEL HENDRICKS

Dr. Moisés Arce, Dissertation Supervisor

May 2019 
(C) Copyright by Michael Hendricks 2019

All Rights Reserved 
The undersigned, appointed by the dean of the Graduate School, have examined the dissertation entitled

RESOURCE EXTRACTION, RESISTANCE, AND RELIGION IN NICARAGUA presented by MICHAEL HENDRICKS, a candidate for the degree of Doctor of Philosophy of Political Science, and hereby certify that, in their opinion, it is worthy of acceptance.

Professor Moisés Arce

Professor Jonathan Krieckhaus

Professor Bryce Reeder

Professor Jere Gilles 


\section{DEDICATION}

I would like to dedicate my dissertation to my wife, Carly Hendricks, for all of her support and love during the past five years. I could not have done it without you. Thank you! I love you! Here is to our next adventure.

I would also like to thank my son Walter. You bring joy to me every day. I love you!

I would also like to thank my mother and father for all of their help and love during my studies and throughout my life. Thank you. Love you both.

I would also like to thank the Nicaraguan people. You welcomed me as one of your own during my Peace Corps experience, as well as my numerous field research trips. Nicaragua will always be my second home. 


\section{ACKNOWLEDGEMENTS}

I would like to thank my advisor Dr. Moisés Arce because without him, I would not have made it this far in a $\mathrm{PhD}$ program. Moisés has been invaluable to my doctoral training at the University of Missouri. He developed me into the scholar that I am today. He worked closely with me for five years on course work, research training as a research assistant, teacher training as a teaching assistant, collaborative research projects, academic grant writing, survey design, and numerous tasks that taught me to be a better teacher and a better scholar. I see Moisés not only as my advisor and my mentor, but as a close friend. While preparing me to be the best academic and scholar possible, we developed a close relationship that will last a lifetime. I look forward to continuing our professional relationship with collaborative research projects, but I also look forward to continuing our lasting friendship. I appreciate everything that you have taught me, and I am excited to learn more from you. Thank you!

I would also like to thank Dr. Vanya Krieckhaus for teaching me about what political science is and encouraging me to be a better writer. I really appreciate Vanya's bluntness and always asking the "so what" question. He made me think critically about every aspect of political science research, including my own. Vanya has definitely made me a better scholar and a better writer. Vanya is also responsible for the majority of my statistical training, which has helped me advance my research agenda. Overall, I believe Vanya, from the start of my graduate training, played a large role in teaching me what a political scientist is and what a political scientist does. Thank you for valuable encouragement, and I look forward to continuing our collaborative work together. 
I also need to thank Dr. Bryce Reeder. I did not start working with Bryce until my third year of graduate school. I am very glad that I did. Bryce opened my eyes to an entire field in international relations (peacekeeping effectiveness) that I had never invested time in before taking Bryce's class. I now have four manuscripts on peacekeeping effectiveness, three of which are with Bryce. Researching peacekeeping effectiveness has now become one of my favorite research agendas. I also want to thank Bryce for keeping me grounded and always offering insightful perspectives on research, teaching, the field of political science, the job market, the dissertation, and everything and anything related to being a political scientist. Thank you for always putting a positive perspective on things and allowing me to smile and laugh.

I also want to thank Dr. Jere Gilles. Dr. Gilles served as my outside committee member for my dissertation. I met Dr. Gilles during my second year of graduate school. I took his course "Social Change and Development" in the Rural Sociology Department. I learned from this course and from Dr. Gilles' advising new perspectives and different alternatives to include in my research. I also enjoyed my many conversations with Dr. Gilles about our Peace Corps experiences and our research. It was a pleasure to work with Dr. Gilles, and I want to thank him for serving on my committee.

I also need to thank Mario Sanchez, the Director of the Socio-Cultural Analysis Center at La Universidad Centroamericana (UCA) in Managua, Nicaragua. I began communicating with Mario in February 2016 to work on my dissertation project. Mario has been indispensable in this dissertation journey. Mario sent me countless resources related to my research. He helped me get in touch with different social movement actors, researchers, academics, and environmental and agricultural NGOs for my field research 
in January 2017. He advised me on my survey design and even provided me with edits until the survey was complete. He organized a research team to administer the survey in April 2018. He hired statisticians to input the data in to Stata. Working with Mario over the past three years has been a pleasure, and I can truly say that I have gained a valuable friendship in the process. Thank you for everything, Mario!

I also need to thank my fellow graduate students in the department and outside the department. I thank those that have moved on and those that are still here. Going through the struggles of graduate school without them would have made completing this $\mathrm{PhD}$ nearly impossible. They were there for me when I struggled and failed to listen and offer me advice. They also celebrated my achievements and encouraged me to do better. Having my fellow graduate students as colleagues but more importantly as friends, made graduate school an experience worth pursuing. Thank you and good luck to you all! I am here if you need me.

Thank you to Audra Jenkins. Audra without you, the Department of Political Science would not function. You are what makes this department complete. I thank you for always taking the time to listen to me and encourage me throughout my time at Mizzou. You truly care about the students and faculty in our department, which made working in the Department of Political Science a very enjoyable experience. I will miss you very much, but for now I will see you at the Annex! Thank you again for everything!

I thank other faculty and staff in the Department of Political Science. Thank you for teaching me, offering me guidance and advice when needed, and simply being excellent role models to look up to. The collegial atmosphere that you instill in our department has made studying and working here a pleasurable experience. I will miss 
seeing you on a daily basis and our interactions together. Good luck in your future endeavors and I wish you all the best. Thank you again for everything!

I thank University of Missouri Research Council, University of Missouri's Kinder Institute on Constitutional Democracy, and the University of Missouri's Office of Graduate Studies for providing me the funding necessary to complete my dissertation research. Thank you to the University of Missouri Research Council for the $\$ 10,000$ to complete my survey research in Nicaragua, which was completed in April 2018. Thank you to the University of Missouri's Kinder Institute on Constitutional Democracy for providing $\$ 3,075$ to conduct field research interviews in January 2017 . And thank you to the University of Missouri's Office of Graduate Studies from providing me with the Bies International Travel Grant $(\$ 1,500)$ to conduct further field research interviews in Mexico in May 2019. Without your support, my dissertation would not have been completed. 


\section{TABLE OF CONTENTS}

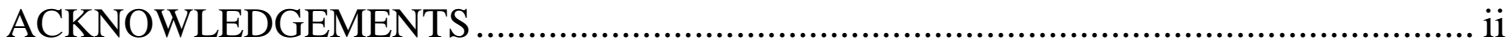

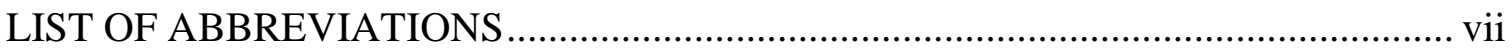

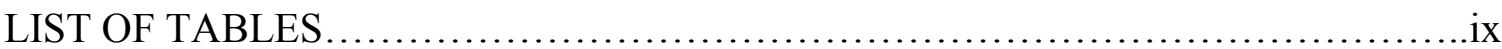

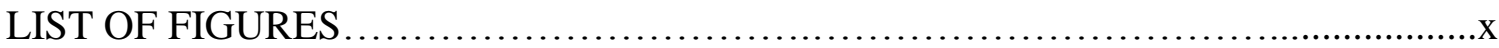

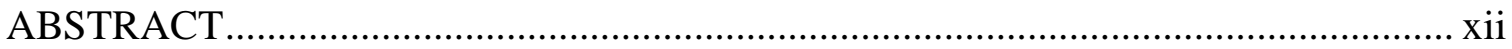

CHAPTER

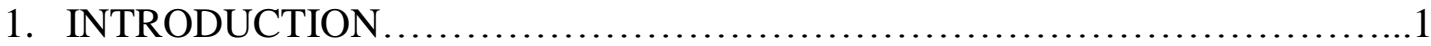

2. RESOURCE EXTRACTION AND PROTESTS. WHY NICARAGUA?............14

3. RESOURCE EXTRACTION, RESISTANCE, PROTESTS, AND SOCIAL MOVEMENTS: WHAT'S MISSING?

4. DEMANDS FOR RIGTHS AND SERVICES, SOCIAL ENGAGEMENT, AND RELIGION AS A CATALYST FOR SUCCESS ...............................72

5. RANCHO GRANDE'S ANTI-MINING RESISTANCE AGAINST

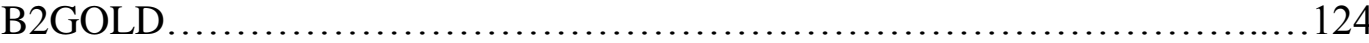

6. SANTO DOMINGO'S ANTI-MINING RESISTANCE AGAINST

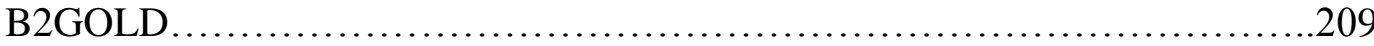

7. COMPARISONS AND CONCLUSION .....................................292

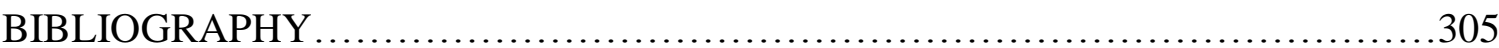

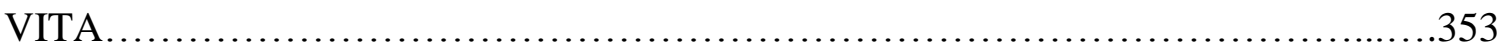




\section{LIST OF ABBREVIATIONS}

ADDAC Asociación para la Diversificación y Desarrollo Agrícola Comunal

ADIC Asociación para el Desarrollo Integral Comunitario

ARENA Alianza Republicana Nacionalista

BEC Basic Ecclesiastical Committees

BIT Bilateral Investment Treaties

CAMINIC Cámara Minera de Nicaragua

CELAM Consejo Episcopal Latinoamericano

CENIDH Centro Nicaragüense de los Derechos Humanos

CSR Corporate Social Responsibility

DESMINIC Desarollo Minero de Nicaragua

FMLN Frente Farabundo Martí de Liberación Nacional

FSLN Frente Sandinista de Liberación Nacional

FTA Free Trade Agreement

FUNIDES Fundación Nicaragüense para el Desarrollo Económico y Social

IEEPP Instituto de Estudios Estratégicos y Políticas Públicas

INMINE Corporación Nicaragüense de Minas

MACRU Rural Cultural Encouragement Movement

MARENA Ministry of Natural Resources and the Environment

MCN Movimiento Comunal Nicaragüense

MEM Ministry of Energy and Mines

MFIC Ministry of Forment, Industry, and Commerce

NRM New Religious Movements

NSM New Social Movements 
PROGRESA Program for Rural Business Management and Animal Health

RAAN Región Autónoma del Atlántico Norte

RAAS Región Autónoma del Atlántico Sur

UCA La Universidad Centroamericana

UNESCO United Nations Educational, Scientific, and Cultural Organization

UNO Unión Nacional Opositora

US United States

WTO World Trade Organization 


\section{LIST OF TABLES}

\section{Chapter 5}

- Table 5.1: Social Engagement's Relationship with Knowledge, Efficacy, and Community Worldview

- Table 5.2: Logistic Regression Results for Support of B2Gold's Mining Project

- Table 5.3: Disaggregated Social Engagement Components and Relationship with Protest Success

- Table 5.4: Logistic Regression Results for Successful Protest

- Table 5.1A: Survey Sample of Rancho Grande, Matagalpa

- Table 5.2A: Variable Coding, Frequency, and Percentages

- Table 5.3A: Variable Summary Statistics

- Table 5.4A: Survey Questions and Variable Explanations

\section{Chapter 6}

- Table 6.1: Social Engagement's Relationship with Knowledge, Efficacy, and Community Worldview

- Table 6.2: Logistic Regression Results for Support of B2Gold's Mining Project

- Table 6.3: Disaggregated Social Engagement Components and Relationship with Protest Success

- Table 6.4: Logistic Regression Results for Successful Protest

- Table 6.1A: Survey Sample of Santo Domingo, Chontales

- Table 6.2A: Variable Coding, Frequency, and Percentages

- Table 6.3A: Variable Summary Statistics

- Table 6.4A: Survey Questions and Variable Explanations

\section{Chapter 7}

- Table 7.1: Comparisons Between Rancho Grande and Santo Domingo 


\section{LIST OF FIGURES}

\section{Chapter 2}

- Figure 2.1: Extractive Protests in Latin America, 1972-2016

- Figure 2.2 Extractive Protests in Central America, 1972-2016

- Figure 2.3 The Increase in Nicaraguan Gold Production, 2008-2016

- Figure 2.4 Extractive Protests in Nicaragua, 1972-2016

- Figure 2.5: Locations of Rancho Grande and Santo Domingo

\section{Chapter 5}

- Figure 5.1: Rancho Grande's Location

- Figure 5.2: B2Gold's Exploration Concession in Rancho Grande

- Figure 5.3: Poverty Map of Rancho Grande

- Figure 5.4: Photos of Rancho Grande's Social Movement Activities

- Figure 5.5: Community Relationship with B2Gold

- Figure 5.6: Community Relationship with B2Gold 5 Years Ago

- Figure 5.7: Reasons Individuals in Rancho Grande Support B2Gold

- Figure 5.8: Reasons Individuals in Rancho Grande Oppose B2Gold

- Figure 5.9: Descriptive Statistics for Demands for Rights Variables

- Figure 5.10: Descriptive Statistics for Demands for Services Variables

- Figure 5.11: Social Engagement in Local Organizations

- Figure 5.12: Social Engagement and Support for Mining

- Figure 5.13: Average Marginal Effects with 95\% CIs for Model 1

- Figure 5.14: Average Marginal Effects with 95\% CIs for Model 2

- Figure 5.15: Respondent Beliefs About Successful Mining Protest Movement

- Figure 5.16: Respondent's Religion by Type

- Figure 5.17: Average Marginal Effects with 95\% CIs for Model 5

\section{Chapter 6}

- Figure 6.1: Santo Domingo's Location

- Figure 6.2: B2Gold's Mining Concession in Santo Domingo

- Figure 6.3: Deforestation in Santo Domingo

- Figure 6.4: Protesters in Santo Domingo

- Figure 6.5: Community Relationship with B2Gold

- Figure 6.6: Community Relationship with B2Gold 5 Years Ago

- Figure 6.7: Reasons Individuals in Santo Domingo Support B2Gold

- Figure 6.8: Reasons Individuals in Santo Domingo Support B2Gold

- Figure 6.9: Descriptive Statistics for Demands for Rights Variables

- Figure 6.10: Descriptive Statistics for Demands for Services Variables

- Figure 6.11: Social Engagement in Local Organizations

- Figure 6.12: Social Engagement and Support for Mining

- Figure 6.13: Average Marginal Effects with 95\% CIs for Model 1

- Figure 6.14: Average Marginal Effects with 95\% CIs for Model 2

- Figure 6.15: Respondent Beliefs About Successful Mining Protest Movement 
- Figure 6.16: Respondent's Religion by Type

- Figure 6.17: Average Marginal Effects with 95\% CIs for Model 5

- Figure 6.1A: Artisanal Mining Methods in Santo Domingo

- Figure 6.2A: Destruction of Homes by B2Gold's Explosives 


\title{
RESOURCE EXTRACTION, RESISTANCE, AND RELIGION IN NICARAGUA
}

\author{
Michael Hendricks
}

\author{
Moisés Arce, Dissertation Supervisor
}

\begin{abstract}
My dissertation examines the causes of protest over resource extraction in Nicaragua, and underlines the role of religion as a catalyst for sustained and successful challenges against resource extraction. With few exceptions, existing research has rarely explored individual-level attitudes related to resource extraction. Opposition and support towards mining are not mutually exclusive from protest success in overturning a mining concession. They build off each other. If a community strongly opposes mining, especially related to economic threats and grievances tied to environmental and agricultural concerns, it will likely continue its resistance movement until it sees policy changes that halt or overturn mining concessions in the community. However, if there is support for mining in the community over economic opportunities and benefits, mining activities will likely prevail because individuals in the community believe they will economically benefit from mining. I examine the causes of opposition and support over resource extraction in two Nicaraguan mining communities through qualitative interviews and public opinion surveys. I am particularly interested in why individuals either support or oppose resource extraction, and how these attitudes are shaped by social engagement (i.e., formed or reinforced) through participation in various types of local organizations. In doing so, scholars can begin to understand different individual responses to mining that underline the aggregate stories of homogenous community
\end{abstract}


resistance and better understand the individual mechanisms that lead citizens in extractive areas to either partake in mining resistance or abstain.

Additionally, existing literature has largely ignored the role of religion as a catalyst in fomenting successful resistance against resource extraction. In fact, there are thousands of protests against resource extraction in Latin America and hundreds throughout Nicaragua, but only a small fraction of them are effective in stopping mining concessions. Because there are clear power imbalances between communities and extractive companies, preventing a new mining project from being implemented or ending an existing project is a very difficult endeavor. Large-scale extractive companies often utilize "divide and rule" strategies that successfully break up local opposition to extraction. My dissertation examines how religion acts as a catalyzing agent in providing communities with the organizational tools and resources that assist individuals in effectively and sustainably to unite and organize against mining until the community achieves a successful national-level policy change reversing mining concessions. 
CHAPTER 1

"Introduction" 
Citizens of Rancho Grande, a municipality in the Department of Matagalpa ${ }^{1}$, Nicaragua, in solidarity, fought for nearly a decade utilizing protests, road blocks, boycotts, and other forms of resistance to protect their right to land, landscapes, water quantity and quality, and their environment from the Canadian gold mining company B2Gold's "El Pavón" open pit gold mining project (Cuffe 2015). On October 12, 2015, the mining project of B2Gold in the Cerro Pavón area of the municipality of Rancho Grande was declared not viable by the Nicaraguan national government (Sanchez Gonzalez 2016). Rosarillo Murillo, the wife of Nicaraguan President Daniel Ortega, whom at the time was the spokeswoman for the Nicaraguan government but is now the Vice President of Nicaragua, ${ }^{2}$ stated that the "conclusion of all the environmental experts is that the project is not viable due to the impacts it would have on the surroundings, on nature, on the environment, on people's way of life, [and] on water sources in general" (as quoted in Cuffe 2015).

The Nicaraguan national government's decision to overturn B2Gold's mining concession was the result of a decade of ongoing nonviolent resistance by the largely peasant population of Rancho Grande. The successful leadership and organization of Rancho Grande's social movement group against mining, Guardines de Yaoska, established a historic precedent. However, Guardines de Yaoksa and the citizens of Rancho Grande could not have successfully ended B2Gold's mining concession without the assistance of the Catholic Church, the Evangelical Church and other environmental

\footnotetext{
${ }^{1}$ Departments in Nicaragua are similar to what other countries call states, provinces, etc. There are 15 departments and 2 autonomous regions in Nicaragua.

${ }^{2}$ Rosarillo Murillo was elected Vice President in 2016 with her husband Daniel Ortega winning his thirdconsecutive 5-year term and fourth term overall.
} 
and agricultural organizations (Sanchez Gonzalez 2016). The community believes that the Churches' influence in the social movement against mining was paramount in the national government's decision to overturn B2Gold's mining concession. The Church leaders involved were key actors in organizing and unifying the community, which was so impactful for the community's success in overturning B2Gold's mining concession at the national level. The Church leaders garnered respect from the people in the community and united everyone to organize against mining. Additionally, the community believes its success is related to its strong religious conviction and its faith in God.

The municipality of Santo Domingo is home to another community in Nicaragua that largely opposes B2Gold's mining projects. Santo Domingo is located in the central region of Nicaragua in the Department of Chontales. Citizens in Santo Domingo have also largely opposed B2Gold's mining activities for nearly a decade for the same reasons that citizens in Rancho Grande do: to protect their right to land, landscapes, water quantity and quality, and their environment. B2Gold's mining activities have already heavily contaminated the land and the water in Santo Domingo, as well as forced citizens off their properties and destroyed people's homes. However, unlike Rancho Grande, citizens in Santo Domingo have not been able to successfully overturn B2Gold's mining concessions through policy changes at the national level, even after years of establishing a strong resistance movement against mining.

Salvemos Santo Domingo, the social movement group against mining in Santo Domingo, has practiced and continues to practice forms of resistances like protests, roadblocks, boycotts, and petitions. Their resistance is motivated by complaints "about the economic, environmental, and social effects" that industrial mining has on their 
community (Articulo 66 2018). The Nicaraguan government insists that "mining companies have executed projects in health, education, investments and, in the case of Santo Domingo, they opened a water purification plant" (Articulo 66 2018). Yet, the struggle between the citizens of Santo Domingo and B2Gold continues. In 2018, the citizens of Santo Domingo rejected a public consultation in regard to B2Gold's exploration project: Mina Jabalí. Citizens in Santo Domingo assured that if the Mina Jabalí project was to turn in to an exploitation project that it would solidify the environmental destruction of Santo Domingo. The Mina Jabalí project has led citizens to march through the streets while shouting "fuera, fuera, que se vayan" (get out, get out, make them leave) (Articulo 66 2018). Although, a large majority of the population continues to resist mining in Santo Domingo, B2Gold continues to extract gold in Santo Domingo. What is largely absent from Santo Domingo's social movement against B2Gold and mining is the role of religion as a catalyst for a successful resistance in achieving a national-level policy change that reverses the company's mining concession.

Beginning in the early 2000s, Nicaragua has been the scene of social mobilization around mining activity, as one can see with the communities of Rancho Grande and Santo Domingo. The majority of these conflicts have problematized the fulfillment of collective agreements, labor rights, and socio-environmental problems. Unfortunately, some of these cases escalated into violence to the point of claiming human lives from the parties involved: disputing actors as well as police forces. Despite these conflicting situations, in recent years, there have been social mobilizations in open opposition to the mining activity itself, as have been the cases of Rancho Grande and Santo Domingo who both face exposure to mining activity from Canadian mining 
company B2Gold. There are sectors in both of these Nicaraguan municipalities that have mobilized with a stance to curb the expansion and development of mining activity. However, a successful positive mobilization outcome (i.e., a national-level policy change reversing B2Gold's mining concession) has only been achieved in Rancho Grande, but not Santo Domingo. Therefore, I seek to understand the social, political, and economic factors for why citizens living in extractive areas, like Santo Domingo and Rancho Grande, either oppose or support resource extraction (i.e., gold mining), as well as understand the role that religion has in assisting local populations in successfully overturning mining concessions. Thus, I question, how are individuals' attitudes shaped by extractive activities? More specifically, what environmental concerns lead citizens to oppose extractive activities? What economic conditions are citizens likely to support extractive activities? How does social engagement shape individual attitudes toward resource extraction? And, does religion contribute to the success of extractive protests and/or social movements?

In order to understand what makes resistance against mining successful in terms of the reversal or gaining of mining concessions in communities, scholars need to understand what makes individuals oppose or support resource extraction. Current research on the politics of resource extraction focuses on successful campaigns against extraction and emphasizes the sources of opposition to mining. With few exceptions, existing research has rarely explored individual-level attitudes related to resource extraction. Opposition and support towards mining are not mutually exclusive from protest success in overturning a mining concession. They build off each other. If a community strongly opposes mining, especially related to economic threats and 
grievances tied to environmental and agricultural concerns, it will likely continue its resistance movement until it sees policy changes that halt or overturn mining concessions in the community. However, if there is support for mining in the community over economic opportunities and benefits, mining activities will likely prevail because individuals in the community believe they will benefit from mining activity.

I examine the causes of opposition and support over resource extraction in Rancho Grande and Santo Domingo. I am particularly interested in attitudes over economic threats and grievances related to the environment and agriculture that individuals hold towards mining, and how these attitudes are shaped by social engagement (i.e., formed or reinforced) through participation in various types of local organizations. In doing so, scholars can begin to understand the "variegated individual responses to mining" that underline the aggregate stories of homogenous community resistance (Dougherty 2018, 2). By understanding individual attitudes, beliefs, and characteristics towards mining, scholars of extractive protests and social movements will be able to better understand the individual mechanisms that lead citizens in extractive areas to either partake in mining resistance or abstain, as well as what individuals believe makes their protests and social movements more successful. For example, by understanding the reasons individuals in Rancho Grande and Santo Domingo, two communities that strongly resist mining, oppose or support mining, I can better understand the reasons why Rancho Grande successfully influenced policy changes at the national level and Santo Domingo did not.

I utilize qualitative empirical evidence from the mining communities of Rancho Grande and Santo Domingo from my own field work interviews from January 2017. I 
utilize interviews I conducted in Rancho Grande, Santo Domingo, and Managua with protest actors, social movement members, church leaders and members, community members, researchers and academics from universities and research centers, and environmental organization leaders. I also use existing academic literature and news articles related to protest activity in Rancho Grande and Santo Domingo. Additionally, I utilize survey research to ask citizens in Rancho Grande and Santo Domingo their views and perceptions to generalize from empirical data, rather than make inferred assumptions about individuals from aggregate community-level data in order to understand how the attitudes, beliefs, and characteristics of individuals living in these communities are shaped by the environments succumbed to the extractive frontier. I surveyed approximately 400 citizens in both Rancho Grande and Santo Domingo in April 2018. My survey data offers robust individual-level data that permits me to understand what prompts citizens to participate in protests by understanding what factors lead them to oppose or support mining, as well as what these individuals believe makes their protests successful.

In Chapter 2, I provide background information that examines investments in natural resources, like gold, silver, copper, etc. and protests related to the extraction of these natural resources in three contexts: (1) Latin America; (2) Central America; and (3) Nicaragua. The first context, the broader of the three, provides an overview of resource wealth and extractive protests throughout the entire region of Latin America to demonstrate that Latin America is one of the most resource wealthy regions in the world with thousands of extractive protests each year, which shows the region's importance for this dissertation. I also narrow the focus to specifically look at resource wealth and 
extractive protests throughout Central America to show that more and more scholars are focusing on the region due to the amount of extractive activities and protests in the region. Thus, Central America is an important region to study related to resource wealth, extractive investments, extractive activities, and protests.

In this dissertation, I specifically examine Nicaragua because, in recent years, the extraction of natural resources, in particular gold, has contributed to extraordinary economic development for Nicaragua. The country has become the top producer of gold in Central America, and currently houses large-scale gold mining companies, such as B2Gold and Condor Gold. However, with the extraction of gold, clashes with local communities over the use of land and water have significantly increased. There are thousands of protests against resource extraction in Latin America and hundreds throughout Nicaragua, but only a small fraction of them are effective in stopping mining concessions (i.e., Rancho Grande, Matagalpa).

Chapter 3 examines the current state of the resource extraction literature and its limitations. To date, existing research on the politics of resource extraction focuses on successful campaigns against extraction and tends to emphasize the sources of opposition to mining through the increased likelihood of a community's resistance towards mining with the majority of these studies characterizing extractive communities as homogenous actors. Essentially, the majority of the literature on mining resistance makes micro-level homogenous inferences at the aggregated community-level for why individuals resist mining without directly trying to understand why and how individuals either oppose or support mining. We currently do not understand the individual-level variation among 
those citizens living in mining areas as to whether they support or oppose mining and for what reasons.

Additionally, as Conde and Le Billon $(2017,682)$ suggest the majority of studies on mining resistance "consist of individual case studies, and more rarely comparative studies including large-N statistical analyses of conflicts and resistance to mining.” Much of this previous research makes micro-level inferences utilizing protest event data from communities cross-nationally or sub-nationally. Protest event data is often biased because it relies on large protest events and does not capture small protest events or smaller resistance campaigns. My dissertation seeks to address these limitations by directly asking citizens living in extractive areas (micro-level) why they support or oppose mining, as well as understand how social engagement in local organizations reinforces, shapes, and forms these attitudes.

In Chapter 3, I also examine the political process model literature and how religion's role intersects with this literature. While making important contributions, the existing literature, to date, has largely ignored the role of religion as a catalyst in fomenting successful resistance against resource extraction. In fact, there are thousands of protests against resource extraction in Latin America and hundreds throughout Nicaragua, but only a small fraction of them are effective in stopping mining concessions. Because there are clear power imbalances between communities and extractive companies, preventing a new mining project from being implemented or ending an existing project is a very difficult endeavor. Large-scale extractive companies often utilize "divide and rule" strategies that successfully break up local opposition to extraction. My dissertation examines how religion sustains and influences successful 
protests movements against extraction by assisting communities in overturning or gaining mining concessions.

Since, I am essentially addressing two dependent variables: Support for mining projects and Success in overturning mining concessions, as well as four main factors of theoretical interest, Chapter 4 is divided into three different theoretical sections to address my research questions. In part one, I address my first set of research questions: How are individuals' attitudes shaped by extractive activities? What environmental concerns lead citizens to oppose extractive activities? And, what economic conditions are citizens likely to support extractive activities? I utilize the "demands for rights" (economic threats) and "demands for services" (economic opportunities) framework put forth by Arce (2014b, 2015) and Arce and Hendricks (forthcoming) to address the environmental concerns and economic threats leading citizens to oppose extractive activities and the economic benefits and opportunities that lead citizens to support extractive activities. This section addresses my first dependent variable of interest: Support for mining projects.

In part two, I address my final research question associated with my first dependent variable: Support for mining projects. Again, I ask: How does social engagement shape individual attitudes toward resource extraction? I provide a theoretical framework on the micro-level politics that make individual citizens more likely to oppose mining. I argue that the more socially engaged individuals are in local organizations, the more likely they have: 1) access to critical organizational tools and information about mining; 2) a higher sense of self-efficacy and collective-efficacy empowering them and their communities; 3 ) and a stronger community worldview contributing to broad-based mobilization. 
Finally, in part three, I focus on my second dependent variable: Success in overturning mining concessions and how religion's role in extractive protest movements acts as the catalyzing factor for successfully achieving a national-level policy change that reverses mining concessions. This section addresses my final research question: Does religion contribute to the success of extractive protests and/or social movements? In this section, I emphasize the role of religion as a catalyst for sustained challenges and successful resistance against resource extraction by arguing that communities with more church involvement, in this case involvement tied to Catholicism and Evangelicalism, are better suited to sustain their opposition against resource extraction and assist communities to successfully achieve national-level policy changes that reverse mining concessions.

In Chapter 5, I discuss the community of Rancho Grande, B2Gold's influence on the community, and the organized and sustained protests and resistance that the community exerted against B2Gold and government officials for over a decade until B2Gold's concession to explore gold mining sites was overturned by the Nicaraguan national government in October 2015. I do this to demonstrate how Rancho Grande demonstrates all three theoretical components of my theory. I then use my individuallevel survey data from Rancho Grande to test these theoretical components and to confirm my theoretical expectations.

In Chapter 6, I discuss the community of Santo Domingo, B2Gold's influence on the community, and the organized and sustained protests and resistance that the community exerted and continues to exert against B2Gold and government officials for nearly a decade. Preventing a mining project from being implemented is difficult because 
there are clear power imbalances between extractive companies and governments with mining communities. Thus, I highlight the absence of religion's role in Santo Domingo, and how this absence did not assist in the successful overturn of B2Gold's mining concessions in the community. I then use my individual-level survey data from Santo Domingo to test my theoretical components and to confirm my theoretical expectations.

In Chapter 7, I analyze my final results and make final comparisons between Rancho Grande and Santo Domingo utilizing my individual-level results. The comparison demonstrates the similarities and differences between the two Nicaraguan cases impacted by B2Gold's mining activities. After making these comparisons, I conclude the chapter discussing the contributions from this dissertation and the implications that it has by stressing the utility of understanding individual-level opposition and support through economic opportunities, economic threats, and the micropolitics of social engagement, as well as stressing the rarely studied role of religion in resource extractive conflicts. The implications of my research are important for scholars because work on the attitudes, beliefs, and characteristics of people who oppose or support mineral extraction is relatively uncommon. Additionally, I systematically examine the role that religion has in mobilizations and show that it is an important catalyst for successful challenges against resource extraction and how it ultimately assists in correcting power imbalances between communities, mining companies, and governments.

Moving beyond the study of social movements through public opinion surveys, I expect to advance a broader understanding in regard to a range political science theories, as well as other social science theories. Given that extractive conflicts have occurred 
predominately in Latin America in recent years (Özkaynak, Rodríguez-Labajos, and Aydin 2015), addressing these issues in a Latin American context should enable scholars to inform policies aimed at conflict prevention and resolution. Therefore, using original data from Rancho Grande and Santo Domingo, studying discrete and well-defined arenas of conflict, and targeting where protests are against extractive companies and their activities; I expect to better understand the dynamics of anti-extraction mobilizationsconstituted by group dynamics and individual behaviors. I also highlight the role that religion plays in successful resistance campaigns, as compared to extractive areas that lack religious influence. 


\section{CHAPTER 2}

"Resource Extraction and Protests: Why Nicaragua?" 
Sanchez Gonzalez (2017) discusses how in modern Western culture and views, the West tends to separates culture from nature and focuses on exploiting nature and environment for commercial gain, which he describes as a central characteristic of extractive activities like mining. He further notes that mining "represents one of the most voracious forms of capitalist production with the greatest power for social and environmental destruction in the enclaves where it's ensconced" (Sanchez Gonzalez 2017). Conde and Le Billon (2017) note that prominent scholars like Bebbington and others ${ }^{3}$ have shown an increasing interest in mining conflicts and community resistance over the last decade. They suggest that the "growing interest reflects in part the rising number and prominence of cases of mining-related conflicts, with conflicts being considered here as a proxy for open expressions of resistance" (Conde and Le Billion 2017, 683). They further discuss how "more research remains needed [but] this rise in conflict seems to combine both an increase in the number of mining projects between 2005 and 2012, and possibly in the frequency of opposition to mining by affected communities" (Conde and Le Billon 2017, 683). The Environmental Justice Atlas reported 423 mining conflicts, which included 290 since 1999. Conde and Le Billon $(2017,683)$ believe that the "temporal distribution of these 290 conflicts suggests and upward trend in the cumulative number of mining conflicts between 2002 and 2013.",4

\footnotetext{
${ }^{3}$ See Bebbington (2012b); Kirsh, (2014); Arsel, Hogenboom, and Pellegrini (2016); Engels and Dietz (2017).

${ }^{4}$ Conde and Le Billon $(2017,683)$ also point out that the "ICMM's (2015) latest report on mining company-community conflicts identifies a smaller number of conflicts but relatively similar trend, with an increase in the number of reported incidents (from 10 to 90) between 2002 and 2012."
} 
A large portion of the existing research on mining related conflicts connects to socio-environmental conflicts, especially in Latin America in the later part of the 2000s (CIEL 2010; Defensoria Del Pueblo 2012; Firpo Porto, Pacheco, and Pierre Leroy 2013; OCMAL 2014; Perez Rincon 2015). Conde and Le Billon (2017) discuss the 2014 and 2015 reports from Global Witness. They note that the reports "show an increase in the number of environment and land defenders killed across the world, with 150 out of 908 killings committed between 2002 and 2014 relating to extractive conflicts." Similarly, Bond and Kirsh (2015) demonstrate, by examining 59 conflicts related to mining that involved physical injuries and casualties between 2005 and 2012, that there is a correlation between mining conflicts and commodity price booms. It appears that, "[o]verall, resistance to mining projects seems to have increased over the past two decades, and especially during the second phase of the last mining boom (2009-2012), along with an increase in repression against communities" (Conde and Le Billon 2017, 683). Although there appears to be a temporal upward trend in mining related community resistance across the world, I focus my dissertation on Nicaragua, a country in Latin America, because of Latin America's relevance to both the amount of resources it has and the amount of mining conflicts it has witnessed over the past decades.

\section{$\underline{\text { Extractivism and Mobilizations in Latin America }}$}

Despite these clashes, national governments in Latin America increasingly see extractivism as a vital source for national development and a strong source of revenue, even though the region has the highest number of extractive conflicts around the world (Özkaynak, Rodríguez-Labajos, and Aydin 2015). Resource wealthy Latin America has 
the largest source of minerals in the world (ECLAC 2013), and produces $15 \%$ of the world's gold, $45 \%$ of the world's silver, and $40 \%$ of the world's copper. According to the WTO (2013), 40\% of Latin America's exports were from minerals and oil. In 2013, the rents from extractive activities composed more than 15\% of Latin America's GDP (Walter 2016). Between 2000 and 2013, global investments in the extractive sector increased from US\$ 86 billion to US\$ 735 billion (ECLAC 2013), notably due to the record-high commodity prices around the world. By 2014, Latin America had received approximately $25 \%$ of global exploration investment flows and had more than $28 \%$ of the world's mineral investment portfolio. In 2012, the average mineral project investment throughout Latin America was US \$730 million, which twice superseded Asia’s average of US \$363 million (Walter 2016). While the extraction of mineral resources in Latin America has led to macroeconomic growth and development, the expansion of extractive activities throughout the region has led to clashes with local communities over a variety of issues (i.e., competition over the use of land and water; competition with an agricultural economy; forced relocations; unequal distribution of mineral rents and social programs). Figure 2.1 shows extractive conflicts in Latin America from 1972-2016. The points signify where extractive protests have occurred. 


\section{Figure 2.1: Extractive Protests in Latin America, 1972-2016}

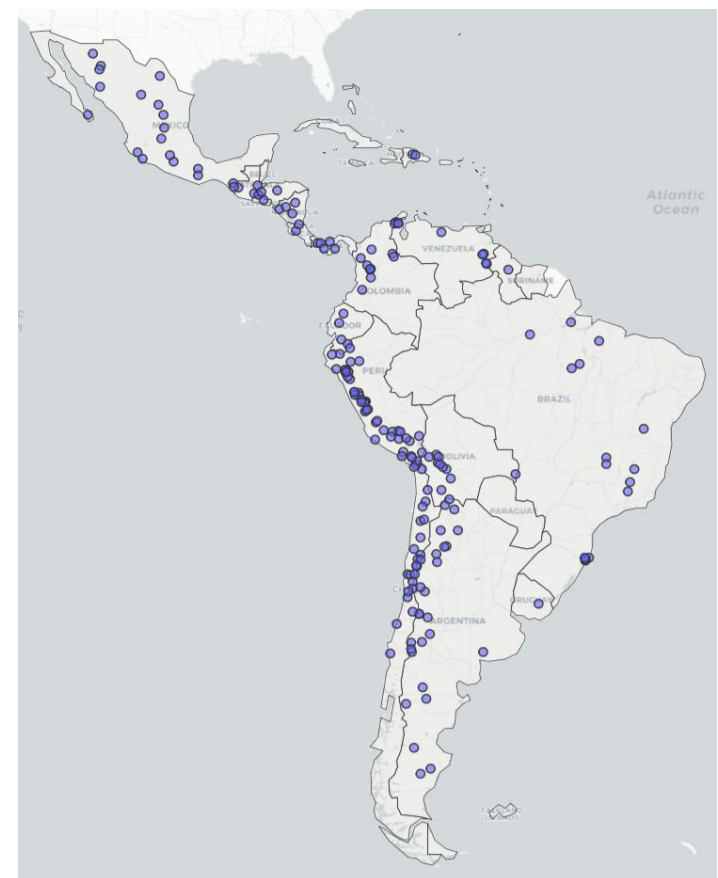

Source: Haslam and Tanimoune (2016).

Extractive activities in recent years have required less and less of unskilled labor due to technological conditions, which has led to less visible labor disputes between mining companies and workers (Bebbington 2009). However, with these technological advances that have led to mega-extractive projects, the need for water, energy, land, and landscape has drastically increased, especially related to open-pit mining. The implications from these technological advances, as well as the decrease of labor disputes among workers and mining companies, provides an alternative picture for those involved in extractive protests. Those involved are heavily concentrated in both rural and urban populations that are the most affected by extractive activities, and their claims against extraction include

\footnotetext{
${ }^{5}$ I would like to thank Bryce Reeder for creating this figure.
} 
the right to land, the right to water (both quantity and quality), landscape, and the protection of the environment and their livelihood. Based on these implications, extractivism permits one to understand a new set of aggrieved actors and their newly formed coalition types that do not conform to the urban and rural divide or environmental and nationalistic discourses. ${ }^{6}$

\section{$\underline{\text { Extractivism and Mobilization in Central America }}$}

Much of the work on extractive protests in Latin America focuses on events in countries in South America like Peru (i.e., Arce 2014b; Arce 2015; Arce and Hendricks forthcoming; De Echave et al. 2009; De Echave 2011; Arellano-Yanguas 2008, 2010, 2011, 2014; Aroca 2008; Bebbington 2012a; Bury 2005; Gil 2009; Li 2015; Ponce and McClintock 2015; Salas Carreno 2008), Colombia (Pérez Rincon 2015), Bolivia (Spronk and Webber 2007; Mähler and Pierskalla 2015), and Ecuador (Eisenstadt and West 2017) where mining and hydrocarbon extraction are the backbone for these economies.

However,_Sanchez Gonzalez (2017) discusses how Central America has grown as an area of interest for extractive activities with governments of Central America, no matter their political ideological backgrounds, adopting the "extractivist model as the fastest route for attracting foreign direct investment and increasing income” (Sanchez Gonzalez 2017). However, as Sanchez Gonzalez (2017) states, "[t]here has been no discussion of the

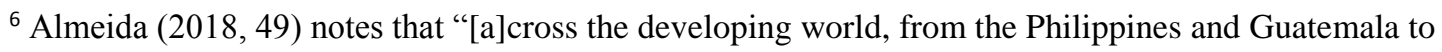
Nicaragua, Panama, and Peru, indigenous communities have launched fierce campaigns over the perceived threats of mining to the ecological health and sustainability of their ancestral lands (Arce 2014b; Camba 2016; Díaz Pinzón 2013; Sánchez González 2016; Yagenova 2015). Not just indigenous peoples, but rural populations throughout the Global South are joining in defensive struggles against the ecological threats associated with resource extraction industries and mega-development projects (Bebbington and Bury 2013; Cordero 2015)."
} 
intrinsic logic of this development model, and its socio-environmental impacts in the communities are routinely ignored."7

Thus, scholars have more recently started to focus their attention on extractive protests in Central America that are centered around gold mining extraction sites (Dougherty 2011; Dougherty and Olsen 2014; Dougherty 2018; Spalding 2011; Spalding 2016). Mining in Central America has been around since the colonial period, but the region was not as ripe for foreign investors until the market reforms in the region in the 1990s. The reforms led to a new wave of laws and international agreements that promoted foreign investment and open access to the region's minerals (Spalding 2016). For example, Spalding $(2016,6)$ states that " $[\mathrm{t}] \mathrm{hroughout} \mathrm{the} \mathrm{region,} \mathrm{permit} \mathrm{processes}$ were more clearly defined and investor guarantees strengthened through free trade agreements (FTAs) and bilateral investment treaties (BITs) that shifted international investment dispute settlement to international tribunals," allowing for a more investor friendly atmosphere. During the commodity price boom in the 2000s, the new mining laws coerced a significant number of small mining firms to invest in gold mining. ${ }^{8}$ Their investments increased and production grew modestly. However, these firms had limited records on best practices for social and environmental standards (Dougherty 2011), which is largely why one saw an increase in extractive protests in the region. Figure 2.2 depicts extractive protests in Central America from 1972-2016. The blue points signify where extractive protests occurred.

\footnotetext{
${ }^{7}$ Sanchez Gonzalez (2017) notes that "[s]ocial movements in both Central America and the rest of Latin America have been unable to find effective dialogue channels with governments to engage in a serious debate about the local, national and even regional development models that best meet human needs and aspirations."

${ }^{8}$ Spalding $(2016,6)$ discusses how during the 2000s "exploration identified gold concentrations available for extraction through diverse methods (subterranean tunnels, open pit chemical mining, and alluvial processes)."
} 


\section{Figure 2.2: Extractive Protests in Central America, 1972-2016 9}

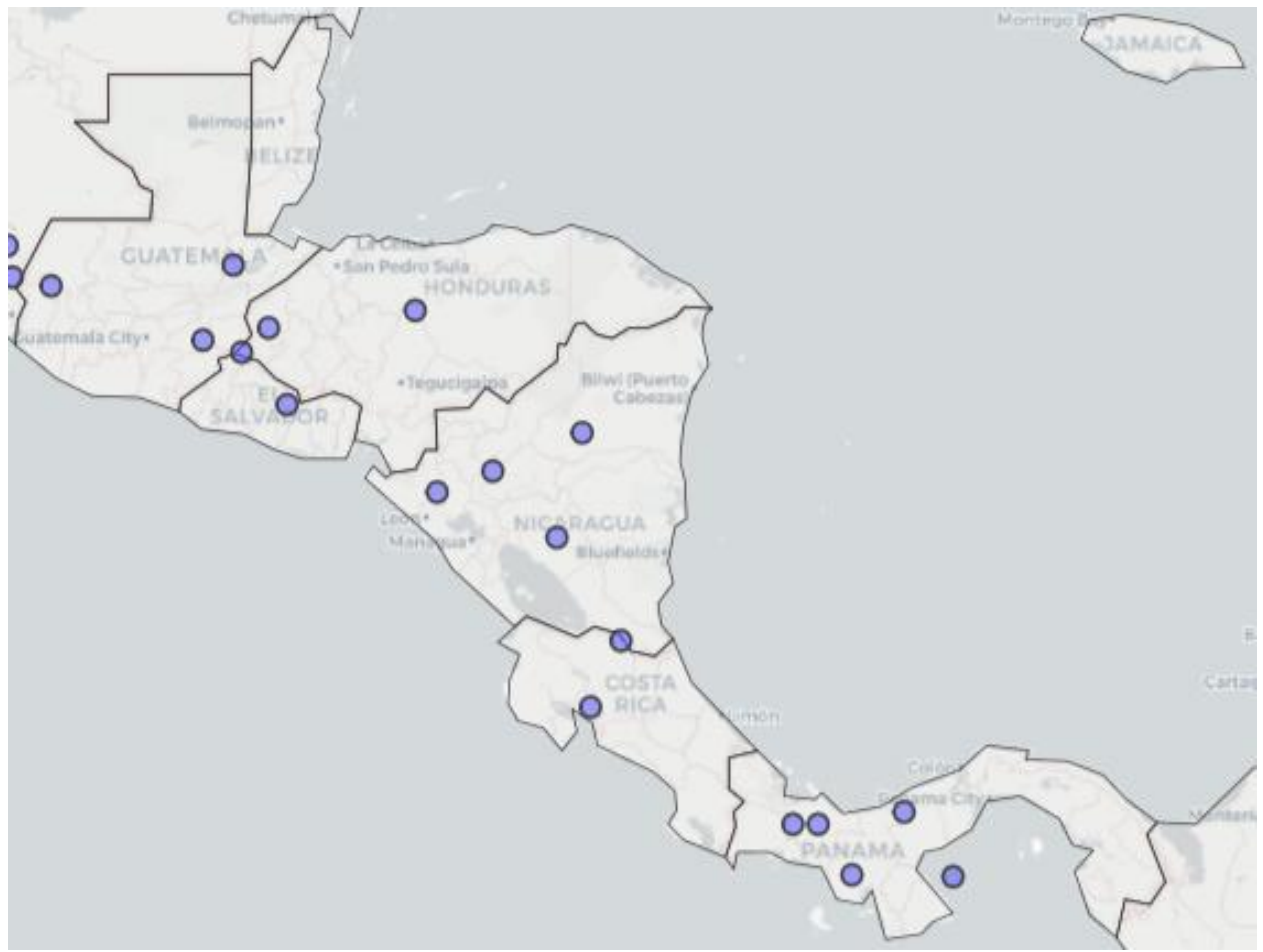

Source: Haslam and Tanimoune (2016).

Although Almeida's (2014) study does not study resource extractive protests, he documents a significant amount of protest activity throughout Central America with highway roadblocks being the most "crucial tactic." By using an extensive dataset with over 4,000 protest events from 1980-2013, Almeida (2014) geocoded protest events at the municipal level. He discovered that more protests occurred in municipalities with major road networks passing through them because protesters chose the road networks for ease of gathering, increased visibility, and potential impact (Almeida 2014). Almeida (2014) also finds that the presence of organizational infrastructure and local administration, as well as prior strategic experience with mobilizing were important in shaping the location of and the propensity of protests in Central America. Similarly, and related to resource

\footnotetext{
${ }^{9}$ I would like to thank Bryce Reeder for creating this figure.
} 
extractive protests, Spalding $(2016,7)$ notes that as "conflict over mining deepened in Central America, activists adopted four main strategies: protests, marches and roadblocks; community consultations; institutional engagement; and transnationalization."

Four Central American countries, in particular, have received the majority of the attention in the academic literature: Costa Rica, El Salvador, Guatemala, and Nicaragua; for a variety of reasons related to mining investment (i.e., friendly investment laws and complete bans on mining). Since the early 2000s, Guatemala and Nicaragua have mining laws in place that promote limited regulations, minimal taxes, and place a lot of faith in mining corporations to follow voluntary compliance mechanisms. Costa Rica and El Salvador have legally prohibited certain types of mining and have heavily regulated others (Spalding 2016). However, anti-mining type policies were not always the case for Costa Rica and El Salvador; extractive protests largely shaped mining policies in Costa Rica and El Salvador at the end of the Twentieth Century and the beginning of the Twenty First Century.

Costa Rica reformed and restructured its markets the earliest out of the four countries discussed with the goal to end its 1980 debt crisis (Edwards 1995; Spalding 2014a). In 1982, it also revised its mining code for the purposes of attracting more investments in its extractive sector. ${ }^{10}$ In 1990, investors prospected gold and discovered commercially viable deposits (Soto 2013). During this time, Costa Rica's government continued to strongly encourage foreign investment for extractive sector development (Spalding 2016). However, within this same timeframe, environmental protection

\footnotetext{
${ }^{10}$ Wo Ching (2014) shows that Costa Rica even allowed extractive investments in indigenous controlled areas that were historically protected.
} 
legislation was introduced (Evans 1999), which foreshadowed the extractive protests to come. By 2010, Costa Rica's judiciary banned permits from developing mines and its legislature banned any new open pit mines due to a sustained and continuous protest movement against open pit gold mining, as well as recurring judicial cases against open pit mining (Araya 2010; Soto 2013; Wo Ching 2014; Chacón and Merino 2014).

After the civil war in El Salvador (1980-1992), the country reformed its markets under the Alianza Republicana Nacionalista (ARENA) government in the 1990s, as well as its mining law in $1996^{11}$ that permitted an investor friendly environment with up to $3 \%{ }^{12}$ royalties (Spalding 2016). From 2000-2010, mining companies increased their interests in El Salvador, and the Dirección de Minas e Hidrocarburos of the Ministry of the Economy received 95 mining applications ${ }^{13}$ (González Oliva 2015). Like Costa Rica, an anti-mining sentiment grew throughout El Salvador, and by 2005, an anti-mining network arose, known as the Mesa Nacional Frente a la Minería Metálica (National Front Against Metal Mining). The anti-mining network connected a wide range of international and domestic groups with affiliations to the environment, agriculture, human rights, the Catholic Church, and communities affected by mining; which created a national challenge to mining throughout the country. This front against mining reacted quickly to the entrance of industrial mining companies into El Salvador, whose entry was without any prior consultation with local communities and threatened the autonomy and land rights of communities near proposed extraction locales. Prior consultation is the fundamental right given to communities, especially ethnic and indigenous communities,

\footnotetext{
${ }^{11}$ El Salvador's previous mining law dated back to 1922.

${ }^{12} \mathrm{El}$ Salvador lowered its mining royalty to $2 \%$ in 2001 to become more competitive in Central America.

${ }^{13}$ Out of the 95 applications, 92 were applications for exploration concessions and 3 were applications for exploitation concessions.
} 
to be a part of the decision-making process related to both legislative and administrative policies on projects that could affect or influence their territories (Agencia Nacional de Minería 2011). With ARENA (pro-mining) losing support to the revolutionary Frente Farabundo Martí de Liberación Nacional (FMLN) party, government officials abandoned the mining coalition with "an informal moratorium [going] into effect in 2008" (Spalding 2016, 2; see also: Spalding 2014b, 2015a; Broad and Cavanagh 2015).

The market reforms in El Salvador pressured Guatemala to adopt a new mining law in 1997 that lowered mining royalties from $6 \%$ to $1 \%$, as well as removed a former 100\% foreign ownership prohibition (Dougherty 2011). This created an investor friendly atmosphere for extraction in Guatemala, which made it the regional leader in gold extraction by 2006. However, a strong anti-mining sentiment grew in Guatemala at the community level. With repeated legal challenges and community-level protests against mining, a brief ban on new mining licenses occurred in 2010. The ban was short lived, and by 2012, even in the face of continued opposition, the Guatemalan government granted additional exploitation licenses that permitted extractive activities in new locations around the country (Spalding 2016).

Turning to Nicaragua, Sanchez Gonzalez (2017) discusses how metal mining started over two centuries ago in Nicaragua with its production focused on the international market and accumulating wealth for investment companies. He also discusses how mining in Nicaragua has a history of exploiting and plundering communities' natural assets and livelihoods, as well as creating conflicts between communities and mining companies and the government. Today, "Nicaragua is Latin America's fourth greatest country of destination for mining investment and the second 
most attractive for tax exemptions and other advantages it offers investors" (Sanchez Gonzalez 2017). Studies by Villafuerte (2015) and Spalding (2016) warn that the performance of the current government of Nicaragua is considered one of the most "promissory" administrations in Central America, together with Guatemala. Both Nicaragua and Guatemala contrast with El Salvador ${ }^{14}$ and Costa Rica ${ }^{15}$, two countries where laws have been enacted that prohibit open-pit metallic mining. This "prominent" pattern of the Nicaraguan government is evident in aggressive strategies to promote the country's "mining potential" for foreign investment. ${ }^{16}$ In legal and regulatory terms, the mining sector in Nicaragua has in its favor "11 laws and regulations that regulate the activity and establish the incentives on which the industry operates" (IEEPP and Centro Humboldt 2017, 8).

Sanchez Gonzalez (2017) describes joint research by Nicaragua’s Centro Humboldt and Institute for Strategic Studies and Public Policies that reveals "that mining companies have concessions for just short of 10,700 square miles of Nicaragua (23\% of its total land)." Nicaragua, since 2012, is the largest gold producer in Central America contributing 35.4\% to regional production (for years 2010-2014) (IEEPP and Centro Humboldt 2017). However, it is also clear that metal mining in Nicaragua causes environmental disasters in the countryside without creating many benefits for those being

\footnotetext{
${ }^{14}$ On March 29, 2017 the Prohibition of Metal Mining Law was approved, with the vote of all the political fractions of the Legislative Assembly. That same day, a delegation made up of communities and civil society organizations marched to the Legislative Assembly to deliver a list of 30,000 signatures supporting that law. The delegation was headed by the Archbishop of El Salvador, Monsignor José Luis Escobar Alas. 15 According to the publication of the Official Gazette, of February 10, 2011, Legislative Decree 8904 reforms Law No. 6787 of October 4, 1982, to declare Costa Rica a country free of open-pit metallic mining activity, according to Article 8.

16 The Ministry of Energy and Mines, the government agency for promoting investments (PRONicaragua) together with the Chamber of Mining, have promoted the holding of two International Mining Congresses in the country in 2014 and 2016 (see link: http: //www.congresointernacionaldemineria.com.ni/es/inicio/).
} 
directly impacted by the detriments of mining. For example, mining in Nicaragua only represents $1.14 \%$ of GDP, only employs $0.15 \%$ of the employable Nicaraguan population, and it has placed Nicaragua as the fourth most environmentally vulnerable on the 2017 Global Climate Risk Index (Sanchez Gonzalez 2017). Thus, Nicaragua is a prime example for extractivism in Latin America, yet relatively understudied compared to other countries in Latin America. In the next few paragraphs, I discuss briefly, but in some detail, Nicaragua's (historical) relationship with mining.

\section{$\underline{\text { Extractivism and Mobilization in Nicaragua }}$}

As previously discussed, Nicaragua has a long history of extractive activities, with mining activity dating back to the colonial period. ${ }^{17}$ Since colonial times, resource extraction has gone through different historical periods and has been characterized by excessive greed, dispossession, and exploitation of natural resources, to the detriment of the lives of local populations. For example, in 1583, there was a wave of indigenous rebellions near the current city of León that forced the closure of mining activities by the Spanish Crown (Newson 1987). In the early Twentieth Century (1920-1928), the guerrilla army led by Augusto C. Sandino carried out a series of sabotages and military actions in the mines of Nueva Segovia ${ }^{18}$ and the North Caribbean, which forced the cessation of the operations of the North American mining companies (Bengoechea 1966; Wünderich 1989, 2010) and the expulsion of the United States Marines (Walter 2004). More recently, in the 1990s, international financial organizations pressured the

\footnotetext{
17 Costa Rica, El Salvador, Guatemala, and Nicaragua had a gold mining legacy inherited from the colonial period (Bulmer-Thomas 1987, 8), but Nicaragua was distinctive in the extent to which gold mining activities persisted (Bulmer-Thomas 1987, Table A.7, 320-321).

${ }^{18}$ Nueva Segovia is a Nicaraguan department in the northern part of the country. It borders Honduras.
} 
government of Nicaragua, to readjust mining legislation, in order to deregulate and exempt mining activity from taxes (ERIC 2016) under the argument that foreign direct investment would contribute to greater economic growth and, therefore, to the development of the country.

The Nicaraguan government reformed its mining laws last out of the four Central American countries discussed. When Daniel Ortega and the Frente Sandinista de Liberación Nacional (FSLN) government were defeated in $1990{ }^{19}$ by Violeta Chamorro and the Unión Nacional Opositora (UNO) party, Chamorro ended the nationalization of Nicaragua's gold mines. ${ }^{20}$ With the end of Nicaragua's civil war and privatization, gold mining began to recover. In 1995, Cámara Minera de Nicaragua (CAMINIC) was founded, which is Nicaragua's mining business chamber. In 2001, the Nicaraguan government passed a new mining law (Law 387), which was intended to create more investment in the extractive sector. The law approved mining concessions that permitted investors to have up to a maximum of 50,000 hectares for 25 years and extendable for another 25 years. The law also permitted mining royalties at $3 \%$ (of the value of the extracted material), which is a deductible income tax expense (Spalding 2016) ${ }^{21}$.

\footnotetext{
${ }^{19}$ In 1989, Ortega met with the leaders of other Central American nations. The leaders of El Salvador, Costa Rica, Honduras, and Guatemala promised Ortega that they would close their Contra bases if Ortega allowed for free elections in Nicaragua within one year. Ortega agreed, and Nicaragua's first democratic election was held on February 26, 1990. Ortega and the FSLN Party were defeated in both the presidency and Nicaragua's National Assembly by Violeta Barrios de Chamorro and her opposition party: UNO. Ortega and the FSLN Party did transfer power peacefully to Chamorro and UNO for a more conservative democracy.

${ }^{20}$ During the Sandanista Revolution (1979-1990), the Sandanistas nationalized gold mines in Bonanza, RAAN, La Libertad, Chontales, and El Limón, León with Corporación Nicaragüense de Minas (INMINE) managing the mines, the state management agency. During the Nicaraguan civil war, the Contra military forces targeted these mines, which led to a drastic decline in production. The nationalization of the gold mines almost completely ceased any production by the end of the 1980s. For example, gold output in 1985 was only one-tenth of what it was in 1955 (FUNIDES 2014).

${ }^{21}$ Royalty payments in Nicaragua account for a significant amount of municipal budgets and determine availability of local services. Nicaragua has a $3 \%$ royalty tax that is divided using a formula that includes regional and municipal-level governments. The local governments, where mines are located, are allocated
} 
PRONicaragua (a public-private agency created in 2002) also attracted foreign investment by actively encouraging the mining sector to focus on Nicaragua's low labor costs, guarantees for foreign investors (Law 344), such as BITs, FTAs, and guaranteed access to international tribunals in case of investment disputes (PRONicaragua 2014). With a very investor friendly environment, Nicaragua became the top producer of gold in Central America by 2012 (Spalding 2016). With Nicaragua as the top gold producer of the region and the mining sector succumbing to both violent and non-violent protests against mining, it makes it an ideal country to study for the purposes of understanding individual-level attitudes related to resource extraction.

Beginning in the 2000s, extractivism in Nicaragua has been promoted both by governments of right-wing ideology and by self-proclaimed governments of the left, as has happened with the administration of Daniel Ortega, since his return to power in 2007. Ortega's return to power initially "raised concerns in some quarters, given the previous expropriations and regulatory controls adopted during the Sandinista Revolution and the prior record of hostile relations with the United States" (Spalding 2016, 11). However, Ortega began to embrace "populist capitalism” (Veltmeyer and Petras 2014, 225), which combined an anti-imperialism sentiment with modest social spending and pro-market policies that were negotiated with Nicaragua's business elites (Spalding forthcoming). Spalding (2016) discusses how Ortega extended pro-mining sentiments across all

$35 \%$ of the $3 \%$ royalty tax and $15 \%$ of the tax is designated for a national mine development fund. The additional $50 \%$ of the royalty tax goes to the national treasury (Spalding 2016). The only exception to this distribution is for the two ethnically distinct autonomous regions in the eastern part of Nicaragua: RAAN and RAAS. The distribution in these two autonomous regions are divided between regional (20\%) and national (30\%) governments (Dirección General de Energías y Minas 2014; Spalding 2016). 
political parties (right- and left-wing parties) by advocating for foreign investment, which led to no opposition against mining by parties on both sides of the ideological spectrum.

Nicaragua, to this day, remains the second poorest country in the Western Hemisphere and the poorest country in Latin America. ${ }^{22}$ For obvious reasons (i.e., Nicaragua's history with revolution, civil war, democratic instability, mining opposition, and extreme poverty), mining investors were hesitant to invest in the country. However, PRONicaragua coerced investors by pointing out Nicaragua's strong scores in the World Bank's "Doing Business" rankings. For example, Nicaragua provides mining investors with tax exemptions for inputs and machinery used in the mining process, no taxes on import and export on mining activity, and the growing availability of clean energy (Spalding 2016). Nicaragua, therefore, portrayed to mining investors that it was "open for business" (Carlos Zarruck, Nicaragua's General Director for Mining; as quoted by Lazenby 2014).

CAMINIC, the mining business chamber, enabled further collaboration between investors and the Nicaraguan government on contentious issues, such as territorial access for artisanal miners and community resistance to mining concessions. ${ }^{23}$ By 2013, CAMINIC's membership grew to 30 companies (PRONicaragua 2013, 15) with CAMINIC representing Nicaragua's three active gold mines. Desarollo Minero de Nicaragua (DESMINIC) operated La Libertad mine in the Department of Chontales and Triton Minera S.A. operated the El Limón mine in the Department of Leon. However,

\footnotetext{
${ }^{22}$ Haiti is the poorest country in the Western Hemisphere.

${ }^{23}$ Spalding $(2016,12$; as cited in PRONicaragua 2013, 15) notes that this includes "both metallic and nonmetallic mining sectors and both corporate and cooperative affiliates." Spalding $(2016,12)$ also notes that "[b]y 2014, $11.8 \%$ of national territory had been concessioned for metallic mining, with concessions solicited for another $4.1 \%$. Eager to attract more mine investment, the government advertised that an additional $45 \%$ of national territory remained available for concessioning in 2014."
} 
both were eventually acquired by Canadian mining company B2Gold in 2009. The third gold mine, HEMCO in Bonanza, was originally operated by Bunker Hunt (an investor from the United States) before Mineros S.A., a Colombian mining company bought it in 2013 (Spalding 2016).

With a very investor friendly environment, Nicaragua became the top producer of gold in Central America by 2012 (Spalding 2016). Mining investments grew exponentially in the 2000s and 2010s. From 2006 to 2017, the number of mining concessions increased by $310.84 \%$ (83 to 258) (Dirección General de Energías y Minas 2017). In nine years - from 2008 to 2016 - gold production increased by $288.46 \%$, as seen in Figure 2.3 (Banco Central de Nicaragua 2017). In Figure 2.3. the y-axis shows the amount of troy ounces (in thousands) of gold extracted in Nicaragua, and the x-axis shows the years. This indicates that the established mining companies expanded production, and new ventures began exploratory work.

Figure 2.3: The Increase in Nicaraguan Gold Production, 2008-2016

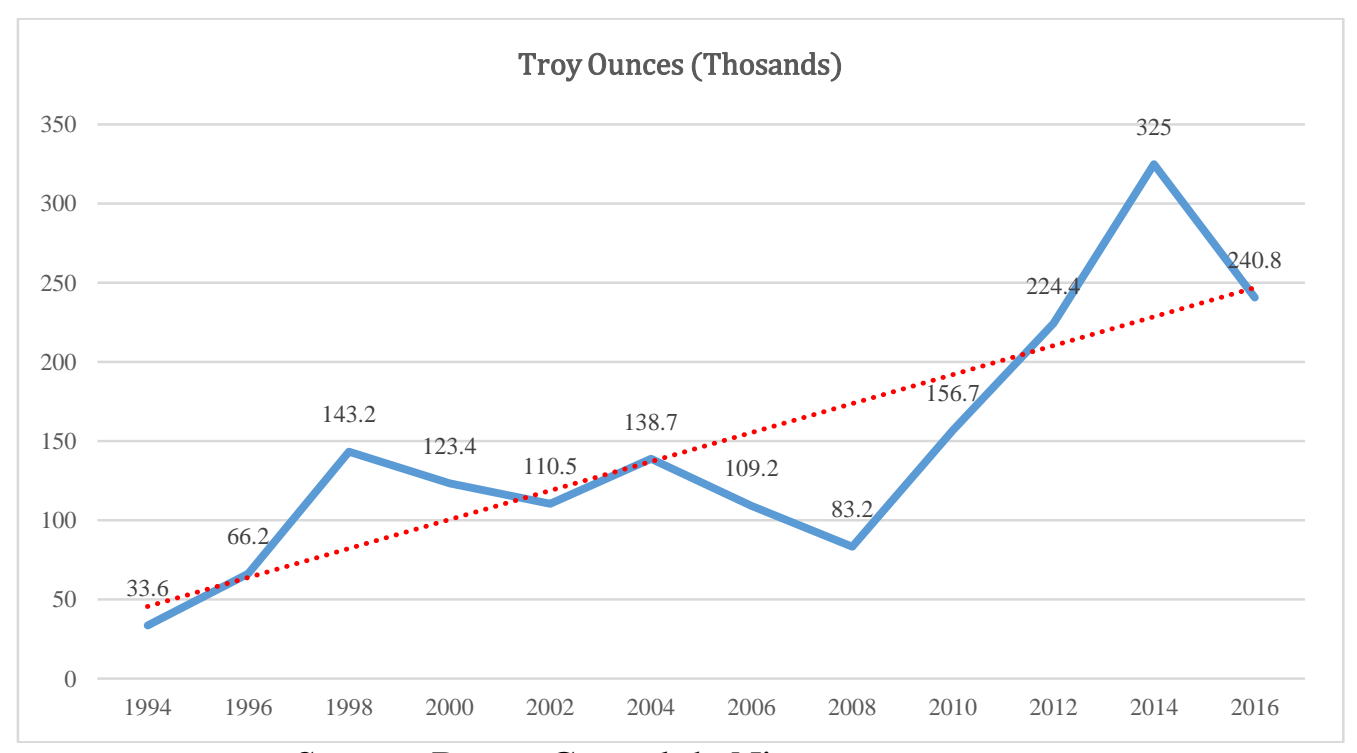

Source: Banco Central de Nicaragua. 
Consequently, this commitment to mining does not coincide with the perspective of local communities where concessions are granted and mining projects are developed, which, in general, are carried out without prior consultation or informed consent of the affected populations. As Svampa $(2017,62)$ warns, in Latin America, the equation of a greater extractivism minus democracy has been consolidated, as an expression that denounces the tendency to criminalize socio-environmental struggles and the disrespect and instrumentalization of the institutional mechanisms of prior consultation or public consultation (Constanza 2016). Alimonda $(2008,13)$ also points out the social relations of power that regulate access, availability, and use of natural resources are the same that feed power and divide societies according to that availability and their usufruct.

The scenario for Nicaragua is that the more intense and complex the mining is, there will be more violence that underlies the socio-environmental conflicts that it generates. Figure 2.4 depicts where extractive protests occurred in Nicaragua from 19722016. An alarming sign of this trend is the fact that the mining and oil sectors are still the most dangerous and lethal in the world for environmental defenders, according to Global Witness' (2015) records. This same report points to Nicaragua as the most dangerous country per capita in the world, in terms of environmental defenders, and in sixth place worldwide where 11 environmental defenders have been murdered. An increase in violence in socio-environmental conflicts, in large part, is provoked in several ways by the state: by its repressive response to the contenders; from the criminalization of protest; the use of force through security forces; by omission and failure to comply with administrative procedures within the framework of concessions; and due to inaction, in 
many cases deliberately. Thus, the due protection of leaders defending land and the environment from multiple threats by public and private actors has not been guaranteed.

Figure 2.4: Extractive Protests in Nicaragua, 1972-2016 ${ }^{24}$

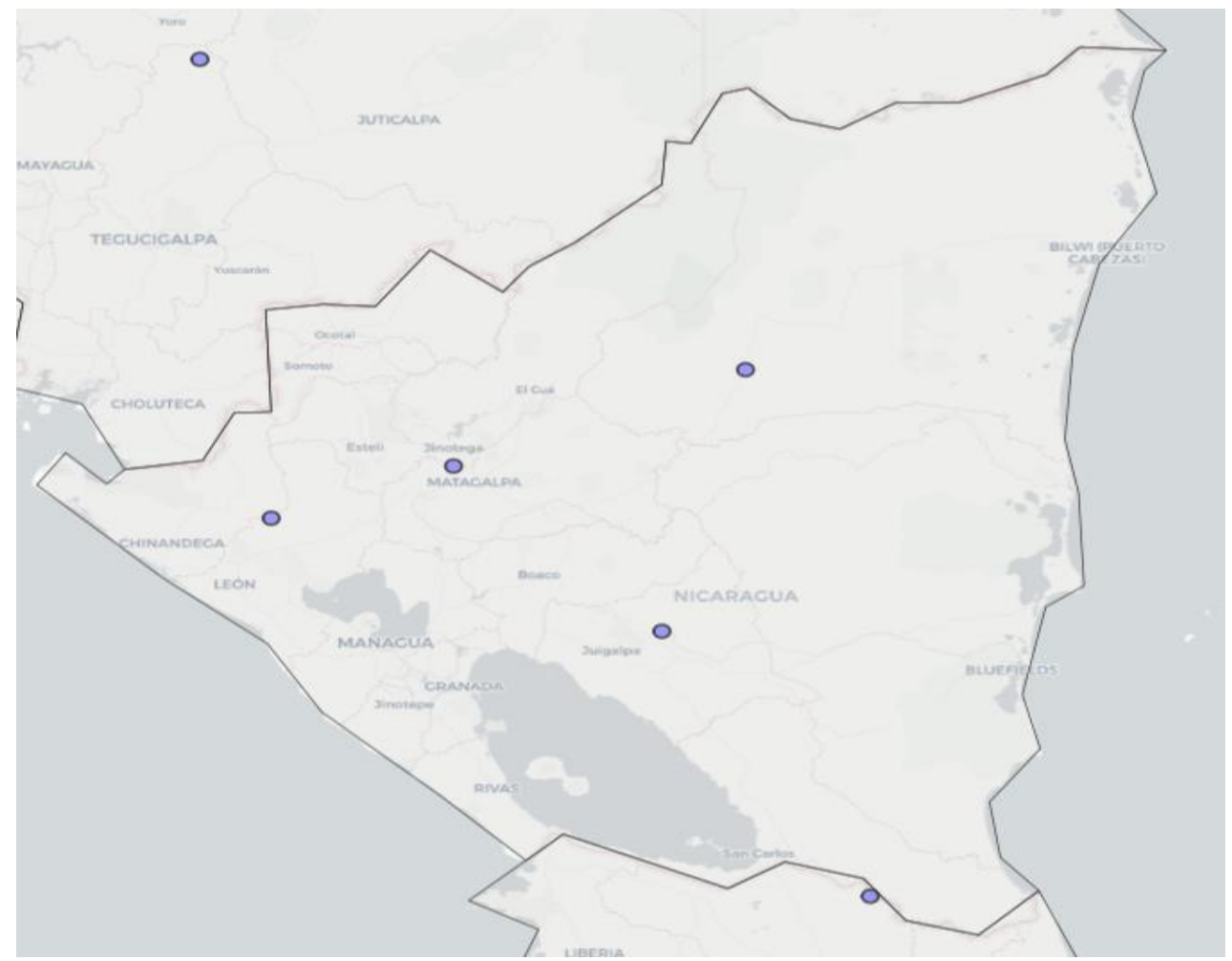

Source: Haslam and Tanimoune (2016).

By studying Nicaragua, one can understand the validity behind Montes' $(1988,274)$ historical reality of dispossession suffered by the peasantry in Central America, when he states: "the field has been [and continues being] the object of the social and political struggles to control the domain and use of the land." Gianotten, De Wit, and Montoya $(1987,49)$ point out that "historical facts show that peasants assume a cooperative attitude and position and unity when their vital interests are threatened." In addition, they have demonstrated not only their strength and creative resistance to fight in a sustained

\footnotetext{
${ }^{24}$ I would like to thank Bryce Reeder for creating this figure.
} 
manner, but they have confirmed other ways of exerting power from the community. The majority of mining conflicts in Nicaragua have problematized the fulfillment of collective agreements, labor rights, and socio-environmental problems. Unfortunately, some of these cases escalated into violence to the point of claiming human lives from both the disputing actors as well as police forces. Despite these disputes, it is assumed that in recent years, there have been social mobilizations in open opposition to the mining activity itself, as have been the cases of Rancho Grande, Matagalpa and Santo Domingo, Chontales who both face exposure to mining activity from Canadian mining company B2Gold. Rancho Grande is in the Department of Matagalpa and Santo Domingo is in the Department of Chontales. In Figure 2.5, I provide a map of Nicaragua with the locations of Rancho Grande (circled in red) and Santo Domingo (circled in blue).

\section{Figure 2.5: Locations of Rancho Grande and Santo Domingo}

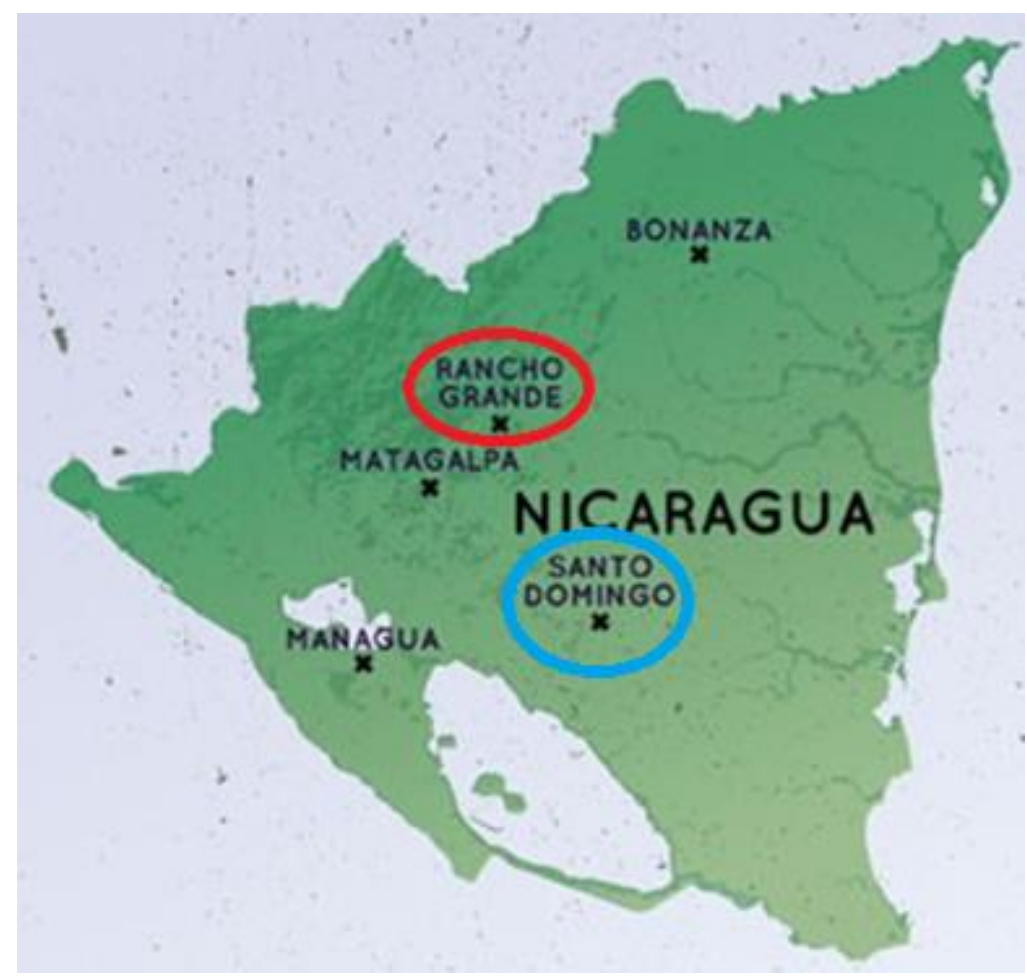

Source: Centro Humboldt (2015b). 
B2Gold has a strong presence in Nicaraguan gold production. B2Gold, headquartered in Vancouver, Canada, was founded in 2007 and is considered one of the fastest growing intermediate gold producers in the world. In fact, it was recently named "The World's New Senior Gold Producer." The company has five operating gold mines and various exploration and development projects in Nicaragua, the Philippines, Namibia, Mali, Burkina Faso, Colombia, and Finland. B2Gold strategically focuses on acquiring interests in mineral properties that have shown potential for gold deposits, as well as properties that are ripe for exploration and development for the construction of future gold mines (B2Gold 2018). B2Gold currently has production, exploitation, and exploration projects in La Libertad and Santo Domingo, Chontales and El Limon, Leon, while it only had an exploration projects in Rancho Grande, Matagalpa.

Because there are clear power imbalances between communities and extractive companies, preventing a new mining project from being implemented or ending an existing project is a very difficult endeavor. Large-scale extractive companies, like B2Gold, and local and national government agencies often utilize "divide and rule" strategies that try to break up local opposition to extraction. B2Gold and government agencies have used these tactics in both Rancho Grande and Santo Domingo. There are sectors in both Rancho Grande and Santo Domingo that have mobilized with a stance to curb the penetration and development of mining activity by B2Gold in their respective communities. However, in these resistance movements against mining, only the community of Rancho Grande, not Santo Domingo, witnessed a reversal in B2Gold's mining concession, a policy changed at the highest levels of Nicaragua's government. The community of Rancho Grande sees the government's reversal of B2Gold's 
concession as a success that they attest to their strong opposition and resistance against B2Gold and its activities. Santo Domingo continues, to this day, to oppose and resist B2Gold and its activities, but the community has not witnessed the same success as Rancho Grande.

In order to understand what makes resistance against mining successful in terms of the reversal of mining concessions in communities, scholars need to understand what makes individuals oppose or support resource extraction. Opposition and support towards mining are not mutually exclusive from protest success in overturning a mining concession. They build off each other. If a community strongly opposes mining, especially related to environmental threats, it will likely continue its resistance movement until it sees policy changes that halt or overturn mining concessions in the community. However, if there is support for mining in the community, mining activities will likely prevail because individuals in the community believe they will benefit from mining activity.

Therefore, I question, how are individuals' attitudes shaped by the extractive frontier? More specifically, what environmental concerns lead citizens to oppose extractive activities? What economic conditions are citizens likely to support extractive activities? And, how does social engagement shape individual attitudes toward resource extraction? I examine the causes of opposition and support over resource extraction in Rancho Grande and Santo Domingo. I am particularly interested in attitudes over grievances that individuals hold towards mining, and how these attitudes are shaped by social engagement (i.e., formed or reinforced) through participation in various types of local organizations. By understanding opposition and support in these communities that 
have both strongly resisted mining, I can better understand the reasons why Rancho Grande, through its resistance, influenced policy changes towards mining for its community, and Santo Domingo did not. 


\section{CHAPTER 3}

"Resource Extraction, Resistance, Protests, and Social Movements: What's Missing?" 
In order to understand what makes resistance against mining successful in terms of the reversal or gaining of mining concessions in communities, scholars need to understand what makes individuals oppose or support resource extraction. Current research on the politics of resource extraction focuses on successful campaigns against extraction and emphasizes the sources of opposition to mining. With few exceptions, existing research has rarely explored individual-level attitudes related to resource extraction. Opposition and support towards mining are not mutually exclusive from protest success in overturning a mining concession. They build off each other. If a community strongly opposes mining, especially related to environmental threats and grievances, it will likely continue its resistance movement until it sees policy changes that halt or overturn mining concessions in the community. However, if there is support for mining in the community, mining activities will likely prevail because individuals in the community believe they will benefit from mining activity.

Therefore, I question, how are individuals' attitudes shaped by the extractive frontier? More specifically, what environmental concerns lead citizens to oppose extractive activities? What economic conditions are citizens likely to support extractive activities? And, how does social engagement shape individual attitudes toward resource extraction? I examine the causes of opposition and support over resource extraction in Rancho Grande and Santo Domingo. I am particularly interested in attitudes over grievances that individuals hold towards mining, and how these attitudes are shaped by social engagement (i.e., formed or reinforced) through participation in various types of local organizations. By understanding opposition and support in these communities that have both strongly resisted mining, I can better understand the reasons why Rancho 
Grande, through its resistance, influenced policy changes towards mining for its community, and Santo Domingo did not. Since this dissertation essentially has two dependent variables: Support for B2Gold's mining projects and Success in overturning B2Gold's mining concession, I divide this chapter into two different sections related to the literature surrounding each dependent variable.

In the first half of the chapter, I examine the literature related to my first set of research questions and related to my dependent variable: Support for B2Gold's mining projects. To date, existing research on protests over resource extraction emphasizes the grievances that embolden social actors to mobilize, the coalitions that aggrieved groups forge in opposition to extraction, as well as the conditions facilitating the emergence of protest movements. While making important contributions, the existing literature has largely ignored examining the individual attitudes and characteristics that lead citizens living in the extractive frontier to either support or oppose resource extraction, which I argue will help scholars better understand the dynamics of anti-extraction mobilizations — constituted by group dynamics and individual behaviors.

In the second half of this chapter, I examine the political process model literature related to my last research question and my second dependent variable: Success in overturning B2Gold's mining concession and incorporate how religion's role intersects with this literature. While making important contributions, the existing literature, to date, has largely ignored the role of religion as a catalyst in fomenting successful resistance against resource extraction. In fact, there are thousands of protests against resource extraction in Latin America and hundreds throughout Nicaragua, but only a small fraction of them are effective in stopping mining concessions. Because there are clear power 
imbalances between communities and extractive companies, preventing a new mining project from being implemented or ending an existing project is a very difficult endeavor. Large-scale extractive companies often utilize "divide and rule" strategies that successfully break up local opposition to extraction. My dissertation examines how religion influences successful protests movements against extraction by assisting communities in overturning or gaining mining concessions from the mining company or the government. I argue that communities with more church involvement and stronger religious influence, in this case influence tied to Catholicism and Evangelicalism, are better suited to sustain their opposition against resource extraction and successfully end mining exploration or exploitation projects affecting their communities.

\section{$\underline{\text { Resource Extraction and Resistance }}$}

Resource extractive companies tend to go to locations that are socially and ecologically vulnerable (Conde and Le Billon 2017). Conde and Le Billon $(2017,682)$ explain that "[o]n many occasions these areas are inhabited by communities, many of them indigenous, who suffer the burdens of displacement and pollution due to resourcedependent livelihoods, unequal power distribution, and social inequalities associated with

ethnicities, castes, social classes and gender." 25 Scholars such as Franks et al. (2014) and Gamu, Le Billon, and Spiegel (2015) suggest that resistance by communities living in the extractive frontier play an important role for the political economy of mineral extraction, and Exner, Lauk, and Zittel (2015), Le Billon and Sommerville (2016), and Conde and

\footnotetext{
${ }^{25}$ See also Martinez-Alier et al. 2014.
} 
Kallis (2012) show how community resistance is particularly important for shaping the commodity frontier.

Conde and Le Billon (2017) provide a nice conceptual definition of what the literature ${ }^{26}$ refers to as community. ${ }^{27}$ They define community as a group "of lay people with links to the surrounding area of mining projects, but does not imply that these groups are immutable, geographically-confined, homogenous, and cohesive" (Conde and Le Billon 2017, 682). Conde and Le Billon $(2017,682)$ also provide a strong conceptual definition of resistance $e^{28}$ utilizing works from Rose (2002), Hollander and Einwohner (2004), Tarrow (1994), Anguelovski (2011) and Macintyre and Foale (2004). They state:

The concept of resistance can refer to different forms of opposition and mobilization. Generally representing a counter-hegemonic project or conduct...resistance includes two basic elements: opposition to existing power relations... and action, whether it be 'verbal, cognitive or physical.' Resistance can be visible and overt or invisible and covert, often then part of everyday socio-environmental resistance... Resistance can also be sporadic and anecdotal, or sustained over time and turned into social movements with organized collective actions backed by dense social networks... Resistance can be pursued for its stated goals, such as cancelling a mining project, or used by communities to increase their bargaining power in negotiations, such as blockading a mine construction site to increase compensation benefits.

Scholarly work on resource extraction and resistance is largely based on the grievances that communities face from extractive activities. The literature surrounding grievances often times uses the terms "grievances" and "threats" synonymously. ${ }^{29}$ Almeida $(2018,43)$ suggests that " $[\mathrm{g}]$ rievances involve the

\footnotetext{
${ }^{26}$ The "literature" meaning literature related to resource extraction and resistance.

${ }^{27}$ Italics added by the author.

${ }^{28}$ Italics added by the author.

${ }^{29}$ More recent scholarship distinctly differentiates between "grievances" and "threats" (Almeida 2018). However, for this dissertation, I will examine them as more synonymous terms.
} 
everyday problems subjectively experienced by communities and social groups." While Snow and Soule $(2010,23)$ define grievances as "troublesome matters or conditions, and the feelings associated with them—such as dissatisfaction, fear indignation, resentment, and moral shock." Almeida (2018) discusses that grievances can be held for long periods of times or over recent occurrences. Work by Gurney and Tierney (1982) and Gurr (1970) focus on the relationship between protest and inequality. These authors argue that grievances lead to more political participation through contentious activities. Feelings such as frustration, resentment, and anger about injustices likely lead individuals to protest (della Porta and Diani 2006), as well as influence protest participation discretely from rational cost-benefit calculations (Opp 2009; Stüurmer and Simon 2009). Scacco (2008) demonstrates that individuals are motivated to protest by the grievances they hold, even without resources and organization. Opp $(2009,1988)$ empirically shows that individual grievances directly affect individuals' participation in social movements. ${ }^{30}$

Reenock, Bernhard, and Sobek (2007) discuss how poverty delays economic development, which leads to "basic needs deprivation"—considered an especially salient grievance. In the Nicaraguan case, since I focus on two mining communities in Nicaragua, poverty is still widespread. Nicaragua is the second poorest country in the Western Hemisphere, and "approximately 30 percent of the population lives on less than $\$ 2$ per day. In rural areas, poverty rates are especially high, where $50 \%$ of households

\footnotetext{
${ }^{30}$ Critics of grievance theories (i.e., McCarthy and Zald 2002; Klandermans 1984), believe that individuals not only protest when they are frustrated and angry, but when they overcome the free-rider problem by coordinating collective action.
} 
live in extreme poverty." ${ }^{31}$ Reenock, Bernhard, and Sobek (2007) suggest that under extremely impoverished conditions and deprivation, individuals are more likely to have radical redistributive demands and preferences. Scholars including Martin, Brickman, and Murray (1983), have suggested that "moral outrage" from perceived economic deprivation or political oppression leads to individuals protesting. Gurr (1970) discusses how individual dissatisfaction with their economic situation is likely to relinquish the risks connected to violent collective action. Gurr (1970) attests this to gaps in individuals' perceptions between their expectations and the potential to fulfill them. Silva (2009) suggests that grievances are fundamental for the mobilization of social actors. Silva (2009) discusses how with the expansion and development of the extractive economy and extractive projects led to the greater need for water and land. This greater need led to individuals in extractive communities holding grievances, which exasperated protest against extraction.

However, a necessary prerequisite for the development of resistance is that the community or a social group collectively shares the grievances, and the grievances are simply not only experienced at the individual level (Snow 2013). For example, "[c]ommunities and social groups are more likely to collectively attempt to resolve such problems when opportunities or threats enter the political environment of the aggrieved population" (Almeida 2018, 43). Since resistance depends on collective action, it is necessary to define and discuss it. Collective action largely begins with Olson (1971). Olson (1971) emphasizes individual's incapacity to achieve both coordination and cooperation problems. The incapacity to coordinate is a key problem with collective

\footnotetext{
${ }^{31}$ See: https://opportunity.org/what-we-do/where-we-work/nicaragua-facts-about-poverty
} 
action because the lack of coordination signals a failure to achieve a desired objective or goal (Opp 2009). Problems related to cooperation are commonly known as the "free rider" problem. The "free rider" problem is when individuals in a group act rationally in their own interests in order to consume a public good without having to exert effort to obtain it. When individuals are members of a group and the group is larger in size, it is less likely that a public good will be provided. However, in the slight chance that the public good is provided, it is due to the existence of selective incentives (Olson 1971). The key assumption of Olson's (1971) theory is that rational and self-interested individuals do not contribute to attain common goals and objectives because rational individuals analyze the costs and benefits of their actions to provide the maximum utility for their actions. For instance, the cost of participating in a common goal (i.e., provision of public goods ${ }^{32}$ ) are usually higher than the benefits of the common goal.

The goal of scholarly work on collective action is to explain coordination and cooperation. Resistance against extraction is not an isolated individual event. In fact, they are joint events that involve many individuals in a community. However, for an extractive resistance to occur there has to be cooperation and coordination within the community. During my fieldwork in Rancho Grande, I witnessed collective action. I saw the same four words on almost every house, building, and public space, which were No a la Minería (No to Mining). The coordination and cooperation in Rancho Grande had a lot to do with leaders from the Guardines de Yaoska social movement group, local and national NGOs, and leaders from the Catholic and Evangelical Churches working

\footnotetext{
${ }^{32}$ Public goods are non-rival and non-excludable, and they represent a common interest. Non-excludable refers to the notion that individuals who did not provide or participate can still benefit and enjoy the public good (Olson 1971).
} 
together in coordination, which solved any coordination and cooperation issues and lowered the costs of collective action (Opp 2009). Thus, collective action through coordination and cooperation is necessary for resistance, protests, and social movements to occur.

Protests and social movements against resource extraction fit within this broader definition of resistance ${ }^{33}$ and rely on the collective action framework. There are various conceptual definitions of protests. Arce (2014b) suggests that protests are any action or claim that express dissatisfaction by a group of more than two people that are not connected to the structure of the state. Their actions or claims target economic and/or political elites and institutions within the state. Goodwin and Jasper $(2003,3)$ define protest as the act of challenging, resisting, or making demands upon authorities, powerholders, and/or cultural beliefs and practices by some individual or group.” Opp (2009) defines protests as the collective action of individuals aimed at achieving their goal(s) and objective(s) to influence the decisions of their target(s). This definition is unique because it focuses on two significant aspects: the collective action of the individuals and their goal(s) and objective(s). However, protests are different from other kinds of collective action because protesters are not capable of influencing specific outcomes on their own (i.e., providing a public good) due to their dependence on third parties (i.e., government agents or institutions) to alter the status quo (Opp 2009). Regarding social movements, McAdam, Tarrow, and Tilly's (2001) model allows one to recognize ways of conducting politics, beyond those conventionally established, especially when studying non-institutionalized groups or groups that have historically

\footnotetext{
${ }^{33}$ Italics added by the author.
} 
been marginalized. Although it is a model with a certain complexity, the political contest focuses on the sociohistorical analysis of collective actions from a relational and dynamic approach — between subjects, movement, and context. The subjects are the actors that are immersed in the political contest: 1) government agents-members of the political system who enjoy the usual access of the institutions and government resources; 2) challengers - constituted political actors who lack or are excluded from this type of access and resources; 3 ) people or groups that are not organized as political actors, but could be integrated into the mobilization process; and 4) external political actors at different national, regional, and international scales (McAdam, Tarrow, and Tilly 2001).

The movement refers to the social processes in which mechanisms and processes interact in the development of the political contest: 1) as the creation or appropriation of organizational structures ${ }^{34}$, which will serve as a vehicle of the struggle-mobilization structures; 2) the impact exerted by external actors in legitimizing or delegitimizing the contentious actions of the challenging subjects, that is, the certification/ decertification exercise; 3) the response that the government or the elites give to the demands of the contenders - whether facilitation or repression, whose effect modulates or radicalizes the repertoire of collective actions of the challengers; and 4) the framing process, which consists of the interactive construction of the disputes between the different actorschallengers, their opponents, the elements of the State, third parties, and the media. Through this exercise, the strategic objectives of a movement are formulated, to convert it into a broader set of interpretive processes, through which new threats and opportunities are identified by one or more of the parties to a conflict.

\footnotetext{
${ }^{34}$ According to McAdam, Tarrow, and Tilly (2001) mobilization structures can be pre-existing or created in the course of the contest.
} 
Regarding the context, it is necessary to recognize that although social movements are more related to incentives, the social, political, cultural, or economic structures of reality condition collective action in some way (Tarrow 1998). These three aspects — actors, movement, and context—are intrinsically related. They have been broken down in order to make visible the dimensions of a complex and dynamic reality of social transformation, such as social movements.

Directly related to resource extraction and resistance, scholars have studied the variation in the motivations and goals of local communities living within an extractive frontier (Arce 2014b, Bebbington and Bury 2013; Eisenstadt and West 2017; Spalding 2015b; Svampa and Antonelli 2009). These studies demonstrate that protesters mobilize in order to protect basic rights like water quantity and quality, land and landscapes, and a healthy livelihood (Arce 2014b; Bebbington, Bebbington, and Bury 2010; Bury 2005; DeEchave 2011; Gil 2009; Salas Carreno 2008; Aroca 2008; Li 2015). Building on the social movement literature (i.e., Tarrow 1998), scholars have stressed the grievances and complaints that encourage social actors to mobilize (Spronk and Webber 2007; ArellanoYanguas 2010,2011), such as the coalitions that aggrieved groups forge to oppose extractive activities, as well as the political conditions that facilitate the development of protest movements (Arce 2014b). These previous studies predominately focused on specific instances of resistance that opposed extractivism and emphasized the significance of broad coalitions with diverse sets of actors as key components to effective anti-mining movements (DeEchave et al. 2009).

Other scholars have sought to explain the difference in context and occurrence of extractive conflict in resource-rich countries cross-nationally (Arce and Miller 2016; 
Haslam and Tanimoune 2016) or sub-nationally (Arellano-Yanguas 2008,2010, 2011; Mähler and Pierskalla 2015; Ponce and McClintock 2014) concluding that mobilization and resource extraction correlate over time. Among many of these studies, some authors (Arce et al. 2018; Arce and Miller 2016; Arellano-Yanguas 2010, 2011) have depicted a relationship among protests and mineral wealth, while others (Haslam and Tanimoune 2016; Mähler and Pierskalla 2015) have shown a correlation between geo-referenced extractive areas and protests. Holistically, these previous studies confirm the connection between extractivism and resistance. In sum, current research on the politics of resource extraction focuses on successful campaigns against extraction and emphasizes the sources of opposition to mining. With few exceptions, existing research has rarely explored individual-level attitudes related to resource extraction.

For example, according to Dougherty $(2018,2)$ the current state of the literature "has a tendency to favor stories of resistance to mining on the community or municipal level." Dougherty $(2018,2)$ also notes that the current literature related to mining resistance "overlook[s] the variegated individual responses to mining underlying these aggregate stories." For instance, Dougherty $(2018,2)$ emphasizes that "scholars sometimes assume a convergence of perspectives among host-community residents regarding mining, which leads the literature to assign like decisions regarding whether to support mining to like motivations on the part of the individual. ${ }^{35}$ Dougherty (2018) suggests that this assumes individual beliefs about mining are unanimous and homogenous "vis-à-vis environmental decision making." He discusses how these previous studies have failed to study the variation of attitudes and beliefs of individuals

\footnotetext{
${ }^{35}$ For an example, see Haslam and Tanimoune (2016).
} 
living in extractive areas, which are "far from static, ebb, flow, overlap, and feed back on one another" (Dougherty 2018, 2). Similarly, as Conde and Le Billon (2017, 685-686) suggest community level resistance towards mining is rarely homogenous. Divisions and conflicts between community members over mining are common, especially between individuals that rely on their land and resources for their livelihoods and those that seek to economically benefit from mining through jobs and social programs.

Hence, scholars should not mischaracterize communities and assume all individuals in extractive communities have the same oppositional beliefs and attitudes towards mining. It is important to understand why "[n]ot all communities resist... [and] if they resist they do not resist with the same objectives, narratives, and intensity" (Conde and Le Billon 2017, 682). Thus, it is necessary to understand the attitudes, beliefs, and characteristics individuals hold towards mining, which will allow scholars of extractive protests and social movements to better understand the individual mechanisms that lead citizens in the extractive frontier to either partake in mining resistance or abstain.

Conde and Le Billon (2017) provide a valuable typography in their extensive review of the resource extractive conflict literature. They divided the literature into four thematic units for what it says about why communities have an increasing or decreasing likelihood to resist mining and mining projects. These four thematic units are: 1) mining project related factors; 2) community-related factors; 3) company-related factors; and 4) state related factors. Within these four thematic units, Conde and Le Billon (2017) added sub-categories that fit within the thematic units that explain what the literature suggests for why communities have an increasing or decreasing likelihood to resist mining and mining projects. In the next several paragraphs, I describe each thematic unit and the sub- 
categories that fit within each thematic unit, specifically noting the sub-categories that explain the likelihood of increasing resistance, decreasing resistance, or both.

The first thematic unit is "mining project related factors," which refers to the "geographic and resource characteristics of mining projects [that] determine their relative location, the type of mineral extraction and processing, and the associated impacts projects may cause” (Conde and Le Billon 2017, 684). For example, “[r]esource and geographic factors...influence the relative attractiveness of the mineral deposits to the mining industry and thus insistence even in the case of local resistance... the importance of local resources to community livelihoods and thus resistance likelihood" (Conde and Le Billon 2017, 684). This directly relates to the environmental impacts of mining projects, the impact that the mining project has on community infrastructure and agricultural economies, and the relative remoteness of projects. More specifically, certain mining project related factors lead to community resistance towards mining, while others factors are less likely to lead to resistance towards mining.

There are four specific mining project related factors that make communities more likely to resist mining. They are: 1) community displacement (Ahmad and LahiriDutt 2006; Downing 2002; Szablowski 2007; Owen and Kemp 2015; Lange 2015); 2) special removal and processing technology of large mining companies to remove lowgrade ore (Conde and Le Billon 2017, 3) open-pit mining (Haslam and Tanimoune 2016); and 4) the visibility of impacts (Haslam and Tanimoune 2016; Silva-Macher and Farrell 2014; Bebbington et al. 2008; Conde and Kallis 2012; Bury 2002; Kirsch 2001; Dougherty 2018). Mining project related factors that have shown communities to have 
both an increasing likelihood and decreasing likelihood of resistance towards mining are project remoteness $^{36}$ and project-driven participation ${ }^{37}$ (Conde and Le Billon 2017).

The second thematic unit is "community-related factors," which refers to how "[c]ommunities can respond in multiple forms to a proposed project in their lands" (Conde and Le Billon 2017, 685). Communities that are politically and socially marginalized $^{38}$ (Conde and Kallis 2012; Horowitz 2010) and dependent on external help ${ }^{39}$, such as previous mining projects (Cater and Keeling 2013; Harner 2001) and labor and corporate support through jobs or associated development projects (Scott and Bennett 2015; Conde and Kallis 2012) are less likely to resist mining and mining projects (Conde and Le Billon 2017). Several studies also note that communities that have a stronger trust in their institutions (i.e., government and mining corporations) are less likely to resist mining projects because they tend to believe these institutions have the best interest of the community in mind (Walter and Martinez-Alier 2010; Muradian, Martinez-Alier, and

\footnotetext{
${ }^{36}$ For evidence demonstrating the decreasing likelihood of mining resistance, see: Scheyvens and Lagisa (1998); Macintyre and Foale (2004); Coumans (2004); Kirsch (2007); Filer (1996); O’Fairecheallaigh (2013); Peterson St-Laurent and Le Billon (2015); Muradian, Martinez-Alier, and Correa (2003). For evidence demonstrating the increasing likelihood of mining resistance, see: Muradian, Martinez-Alier, and Correa (2003); Muradian, Folchi, and Martinez-Alier (2004); Guha and Martinez-Alier (1997); Conde and Kallis (2012); Ballard and Banks (2003); Scott (2014); De Echave et al. (2009); Bebbington et al. (2008); Haslam and Tanimoune (2016); Fox (2015).

${ }^{37}$ For evidence demonstrating the decreasing likelihood of mining resistance, see: Aubynn (2009). For evidence demonstrating the increasing likelihood of mining resistance, see: Hilson and Yakovleva (2007); Geenen (2014); Sánchez-Vázquez, Espinosa-Quezada, and Eguiguren-Riofrío (2016).

${ }^{38}$ Although research has shown that politically and socially marginalized communities decrease the likelihood of resistance towards mining and mining projects; other research has shown that economic marginalization has mixed evidence of both increasing (Haslam and Tanimoune 2016; Carstens and Hilson 2009 and decreasing (Conde and Kallis 2012) the likelihood of resistance towards mining and mining projects.

${ }^{39}$ Although research has shown that communities that are dependent on mining activity are less likely to resist mining projects; other research has shown that mining dependent communities with artisanal and small-scale mining have mixed evidence of both increasing (Andrews-Speed et al. 2005; Fisher 2007; Hilson and Yakovleva 2007; Yakovleva 2007; Escobar 1995; Martinez-Alier 2003; Liffman 1998; Rumsey and Weiner 2004) and decreasing (McNeish 2012; Horowitz 2012; Ali and Grewal 2006) the likelihood of resistance towards mining and mining projects.
} 
Correa 2003; Dougherty and Olson 2014; Barton 2005; Horowitz 2010; Labda 2011;

Zandvliet and Anderson 2009; Moffat and Zhang 2014; Hilson 2002; Dougherty 2018).

However, there are community-related factors associated with "strong cultural and spiritual place-based livelihood ties to land" (Conde and Le Billon 2017, 685) that make communities more likely to resist mining projects (Peterson 2015; Bebbington et al. 2008; De la Cadena 2015; Clammer Poirer, and Schwimmer 2004; Stoler 2008; Gordillo 2014; Larsen 2004; Li 2000; Acuña 2015; Temper and Martinez-Alier 2013; Avci and Fernández-Salvador 2016; Özen and Özen 2017; Penman 2016; Wayland and Kuniholm 2016; Erb 2016; Urkidi 2010, 2011; Parajuli 1996; Escobar 2001; Kirsch 2001;

Dougherty 2018). In contrast to a community's trust in its institutions, Dougherty and Olson (2014) show in Guatemala that communities with strong relational trust among community members are more likely to resist mining projects.

The final community-related factor that makes mining resistance more likely is community-driven participation (Escobar 2001; Martinez-Alier 2003; Helwege 2015; Urkidi 2011; Fraser 1998; Scholosberg 2007; Urkidi and Walter 2011; Bullard 1990; Cole and Foster 2001; Walter and Urkidi 2015; Laplante and Nolin 2014; Haarstad and Fløysand 2007; Bebbington 2012a; Duthie 2012; McGee 2009). The literature also shows that community alliances can increase ${ }^{40}$ and decrease ${ }^{41}$ the likelihood of mining resistance due to the nature of the community alliance and who the alliance is between (Conde and Le Billon 2017).

\footnotetext{
${ }^{40}$ For evidence on increasing the likelihood of mining resistance, see: Keck and Sikkink (1998); Urkidi (2010); Swyngedouw (1997); Walter and Martinez-Alier (2010); Conde and Kallis (2012); Bond (2008); Martinez-Alier et al. (2014); Conde (2016); Özen and Özen (2011, 2017); Walter and Urkidi (2015); Svampa and Antonelli (2009).

${ }^{41}$ For evidence on decreasing the likelihood of mining resistance, see: Barton (2005); DeEchave (2005); McDonald and Young (2012); Moroz, Kayseas, and Anderson (2014); Richards (2013).
} 
The third thematic unit is "company-related factors," which suggest that "[c]ompanies have a major influence with regard to community resistance as they initiate and manage projects and related activities, often working within a hybrid governance system involving host country regulations and their own corporate guidelines" (Conde and Le Billon 2017, 691). The size of the company matters and the findings in the literature show that there is variation related to the size of the company in relation to increasing or decreasing the likelihood of resistance. For example, the literature shows that medium size extractive companies are more likely to increase resistance within mining communities (Dougherty 2011; Bebbington 2012b; Haslam and Tanimoune 2016). However, findings in the literature show that both junior extractive firms (Dougherty 2011; Bebbington 2012b) and large scale extractive companies increase and decrease the likelihood of resistance against mining (Haslam and Tanimoune 2016). Other company-related factors that have shown both the likelihood to increase and decrease mining resistance from communities are corporate social responsibility (CSR) programs and compensation packages. Companies tend to utilize CSR programs and compensation packages within communities in order to avoid community resistance to mining ${ }^{42}$. However, both CSR programs ${ }^{43}$ and compensation packages ${ }^{44}$ can "backfire

\footnotetext{
${ }^{42}$ For evidence of CSR programs and compensation packages working to effectively decrease the likelihood of mining resistance, see: O'Faircheallaigh and Ali (2008); Himley (2013); Jenkins (2004); Yakovleva (2005); Barton (2005); Horowitz (2010); Labda (2011); Mofiat and Zhang (2014); Zandvliet and Anderson (2009); Boelens, Getches, and Gil (2010); DeEchave et al., (2009); O'Faircheallaigh (2013); Schilling-Vacaflor (2012); Vieyra and Masson (2014); Rogge (1996); Herbertson et al. (2009).

${ }^{43}$ For evidence of CSR programs increasing the likelihood of mining resistance, see: Fulmer, Godoy, and Neff (2008); Jenkins and Yakovleva (2006); Newell (2005); Sosa and Keenan (2001); Dougherty and Olson (2014); Warnaars (2012); Hilson and Yakovleva (2007); Abuya (2016); Gilberthorpe and Banks (2012); Bebbington et al. (2008); Emel, Makene, and Wangari (2012); Anguelovski (2011); Kemp et al. (2011); Kemp and Owen (2013).

${ }^{44}$ For evidence on compensation packages increasing the likelihood of mining resistance, see: ArellanoYanguas (2011); Barrantes (2005); Kirsch (2007); Ali and Grewal (2006); Avci, Adaman, and Özkaynak (2010); Temper and Martinez-Alier (2013).
} 
when poorly designed and implemented" (Conde and Le Billon 2017, 691). Finally, community driven participation is another factor that shows to be both likely to increase $\mathrm{s}^{45}$ and decrease ${ }^{46}$ the likelihood of resistance towards mining. Conde and Le Billon (2017, 691) suggest that "[c]orporate driven community participation can also fail to address the communities' motivations and incentives for resistance; especially if companies mostly see such participation as an 'education' exercise for communities, or as a way to 'negotiate' a rapid implementation of the project."

The final thematic unit is "state related factors," which demonstrates how "[s]tates have a critical role with regard to community resistance, but this role is often articulated around the relative absence of state as a representative of affected communities and as environmental stewards, and its selective presence as the 'sovereign' authority over resources and public enforcer of corporate entitlements..." (Conde and Le Billon 2017, 691). Community resistance to mining often exists because of the extractivist development models and pro-mining industry policies, ${ }^{47}$ which often are associated with state repression and the criminalization of dissent and protests, ${ }^{48}$ corruption and rentseeking behaviors ${ }^{49}$, and the inadequate planning and implementation of mining

\footnotetext{
${ }^{45}$ For evidence of increasing the likelihood of mining resistance, see: Baker and McLelland (2003); O'Faircheallaigh and Corbett (2005); O'Fairchellaigh (2008); Szablowski (2007).

${ }^{46}$ For evidence of decreasing the likelihood of resistance, see: Owen and Kemp (2013); Banks (2013); Caballero-Anthony (2013); Sawyer and Gomez (2008).

${ }^{47}$ For evidence of pro-mining industry policies increasing the likelihood of mining resistance, see: Bridge (2004); Martin and Pierce (2013); Engels and Dietz (2017); Kohl and Farthing (2012); Burchardt and Dietz (2014); Villalba-Eguiluz and Etxano (2017); Arsel, Hogenboom, and Pellegrini (2016); Vélez-Torres (2014); Arce (2014b); Arellano-Yanguas (2010, 2011).

${ }^{48}$ For evidence of state repression and criminalization increasing the likelihood of mining resistance, see: Bebbington and Bebbington (2011); Martinez-Alier et al. (2014); Middeodorp, Morales, van der Haar (2016); Andreucci and Radhuber (2015).

${ }^{49}$ For evidence of corruption and rent seeking behaviors increasing the likelihood of mining resistance, see: Kolstad and Soreide (2009); Le Billon (2011, 2014); Le Billon, Gamu, and Conde (2016); Cheng and Zaum (2013).
} 
projects. ${ }^{50}$ Finally, "[s]tate-driven community participation that is not based on Free Prior and Informed Consent principles can increase community distrust and give further ground for resistance" (Conde and Le Billon 2017, 691). ${ }^{51}$ However, when state driven community participation utilizes Free Prior and Informed Consent principles community resistance towards mining is more likely to decrease (Schilling-Vacaflor and Flemmer 2013; Rodhouse and Vanclay 2016).

To summarize this literature, research on the politics of resource extraction focuses on successful campaigns against extraction and tends to emphasize the sources of opposition $^{52}$ to mining through the increased likelihood of a community's resistance towards mining with the majority of these studies characterizing extractive communities as homogenous actors. Essentially, the majority of the literature on mining resistance makes micro-level homogenous inferences at the aggregated community-level for why individuals resist mining without directly trying to understand if individuals oppose or support mining. We currently do not understand the individual-level variation among those citizens living in mining areas as to whether they support or oppose mining and for what reasons.

Additionally, as Conde and Le Billon (2017, 682) suggest the majority of studies on mining resistance "consist of individual case studies, and more rarely comparative studies including large-N statistical analyses of conflicts and resistance to mining." Much

\footnotetext{
${ }^{50}$ For evidence of the inadequate planning and implementation of mining projects increasing the likelihood of mining resistance, see: Lay, Thiele, and Wiebelt (2008); Robinson, Torvik, and Verdier (2006); Kohl and Farthing (2012); Arellano-Yanguas (2011); Hilson and Potter (2005); Fisher (2007); Teschner (2012); Hilson and McQuilken (2015); Vélez-Torres (2014).

${ }^{51}$ For evidence of state driven community participation (absent of Free Prior and Informed Consent principles) increasing the likelihood of community resistance to mining, see: Owen and Kemp (2014); Goodland (2004); Jahncke Benavente and Meza (2010) Rodriguez Garavito et al. (2010).

${ }^{52}$ In the literature, there is a far less focus on reasons for why communities support mining activities.
} 
of this previous research makes micro-level inferences utilizing protest event data from communities cross-nationally or sub-nationally. Protest event data is often biased because it relies on large protest events and does not capture small protest events or smaller resistance campaigns. Again, these studies have "a tendency to favor stories of resistance to mining on the community or municipal level and therefore to overlook the variegated individual responses to mining underlying these aggregate stories" (Dougherty 2018, 2). My dissertation seeks to address these limitations by directly asking citizens living in extractive areas (micro-level) why they support or oppose mining, as well as understand the micro-level politics (i.e., social engagement in local organizations) that shape individual attitudes towards extraction.

Some scholars have begun to pave the way for utilizing individual-survey data to explore the reasons why individuals living in extractive areas either support or oppose extraction. For example, Eisenstadt and West (2017) use individual-level survey data to find that individuals in Ecuador express environmental concern when they are objectively vulnerable to environmental damage and when they live in areas where extraction has occurred or is debated. Dougherty and Olsen $(2014,183)$ also utilize individual-survey data and interviews in gold mining communities in Guatemala to study "individual decision-making around mineral conflicts in an effort to bring the microsocial into focus." They particularly focus on trust and self-efficacy. They suggest trust is a largely ignored dimension. In their study, they provide two types of trust, institutional and relational trust, which help show how citizens living in extractive areas form oppositional or supportive attitudes towards mining. Those that have strong relational trust are more likely to oppose mining, while those that have strong institutional trust are more likely to 
support mining. They “argue that individuals' sense of self-efficacy underlies their decisions about whom to trust or distrust" (Dougherty and Olsen 2014, 183). Using the same individual-level survey from Guatemala, Dougherty $(2018,1)$ shows that citizens who believe they will benefit economically from mining support mining projects, while individuals that face health and environmental threats oppose mining. Finally, Moffat and Zhang $(2014,68)$ also utilize two online surveys in mining communities in Australia to study individual-level attitudes. Their analysis demonstrates that citizens in Australian mining communities tend to support mining when they "reported feeling heard, listened to, and that the company would act on their concerns, their trust in the company was enhanced."

My dissertation aims to build on these studies and contribute to the literature by systematically studying the attitudes of individuals in highly visible extractive protest cases by directly asking them what makes them oppose or support resource extraction, as well as understand the micro-level politics (i.e., social engagement in local organizations) that shape individual attitudes towards extraction. These questions have been relatively uncommon in scholarly work. ${ }^{53}$ There is growing divide between those who oppose extraction and those who support it, which is why it is essential that scholars begin to study the rarely explored individual-level attitudes, beliefs, and characteristics related to resource extraction. Therefore, utilizing survey research, I ask citizens their views and perceptions to generalize from empirical data, rather than make inferred assumptions about individuals from aggregate community-level data.

\footnotetext{
${ }^{53}$ Cederman, Gleditsch, and Buhaug $(2013,208-213)$ believe one should reconsider group grievances as well as national and subnational causes of conflict.
} 
I seek to understand how individuals' attitudes are shaped by the environments succumbed to the extractive frontier by balancing the current bias in the literature with more systematic information related to individual attitudes, beliefs, and characteristics of those in extractive protest areas to more fully understand the reasons why individuals oppose or support mining activities. As Dougherty $(2018,2)$ states, “[f]ocusing on individual attitudes and logics draws attention to nuance and aims to parse the link between motive and decision to demonstrate that individual decisions stem from a dynamic cluster of motives and rationales." By understanding the reasons why and how individuals either support or oppose resource extraction, scholars will better understand what causes some citizens to mobilize and others to abstain.

Moving beyond the study of social movements through public opinion surveys, I expect to advance a broader understanding in regard to a range political science theories, as well as other social science theories. Given that extractive conflicts have occurred predominately in Latin America in recent years (Özkaynak, Rodríguez-Labajos, and Aydin 2015), addressing these issues in a Latin American context should enable scholars to inform policies aimed at conflict prevention and resolution. Therefore, using original data from public opinion surveys from Rancho Grande, Matagalpa, Nicaragua and Santo Domingo, Chontales, Nicaragua (April 2018), studying discrete and well-defined arenas of conflict, and targeting where protests are against extractive companies and their activities; I expect to better understand the dynamics of anti-extraction mobilizationsconstituted by group dynamics and individual behaviors.

\section{Religion and the Political Process Model}


Many scholars eventually moved past grievances/threats and the claims movements made and began to focus on the political process model (i.e., political opportunity structures, resource mobilization theory, and frame alignment) by examining the context in which protests and social movements operated for understanding protest and social movement dynamics (Meyer 2004). Political opportunity structure and resource mobilization theory emerged first (i.e., Eisinger 1973; Tilly 1978; McCarthy and Zald 1977; McAdam 1983), with frame alignment (Snow et al. 1986) quickly to follow in their footsteps. Today, political opportunity structure, resource mobilization theory, and frame alignment are all understood to be components of the political process model. However, it has become largely accepted among social science scholars that in order for extractive resistance and protest movements to be successful there needs to be some form of an interaction between grievance theory and the political process model (Arce 2014b). While making important contributions, the current literature, to date, has largely ignored the role of religion as a catalyst in fomenting successful resistance against resource extraction. Therefore, in this section, I examine the political process model literature and how religion's influence fits within this model.

Although largely ignored in the extractive protest literature, Kirmani (2008) discusses how religion has played an influential role in the development of mobilizing tactics for secular and non-secular social movements throughout the world. Kirmani $(2008,26)$ further notes that "religious groups and institutions are frequently active participants in secular social movements and religious ideologies often support the goals of movements for social change." Thus, according to Kirmani $(2008,26)$ it is essential that we understand the interactive mechanisms in which religion has in shaping and 
influencing contemporary social movements, and the impacts that these mechanisms have on the processes of social movements.

According to Smith (1996), one of the main reasons that social scientists have neglected to incorporate religion in social movement theorizing is due to the fact that social movement scholars tend to focus on secularization theory, which is the idea that religion's significance in society is diminishing due to modernization. Thus, Smith (1996) discusses how religion was not considered a significant enough social factor during the formative years of social movement theories. Both Smith (1996) and Hannigan (1991) also discuss how during the formative years of social movement theory were heavily influenced by structural-functionalism. Under this perspective, religion was viewed as “part of society's need of integration and social cohesion, rather than a possible basis for social changes that challenge the status quo" (Kirmani 2008, 26).

It is also worth mentioning that Beckford (1985b) discusses how social science scholars have fragmented social inquiry by insulating the sociology of religion from the rest of social science studies. Beckford (1985b) believes that this insulation has hindered any collaboration or interaction between religion and social movement theories. Finally, Smith (1996) notes that many of the social movements in the world that influenced the formation of social movement theories were not influenced significantly by religion and even hindered the process of these particular social movements, which Smith suggests accounts for a larger disconnect and absence of religion from social movement theories. However, as Kirmani $(2008,27)$ notes, the "tide... is turning, with an increasing recognition of religion's role in the success or failure of secular social movements, as well as a growing body of literature on the increasing numbers of new religious 
movements (NRMs) that have emerged in various parts of the world." Therefore, I believe my dissertation adds to the absence in the literature on studying the connections between religion and social movements and the impacts and influences religion has on the successes and failures of social movements and protests, especially related to antiextraction protest movements.

Beginning with political opportunity structures, Tarrow (1998, 49-50) identifies certain situations in which the opportunity structures emerge as a process of appropriation and empowerment of the contestants: 1) when some processes increase access to stakeholder participation; 2) moments of alteration or destabilization of the alignments in power; 3) when the influence of the allies can be articulated in a grand coalition against a common opponent; and 4) finally when the division among the elites is taken advantage of by the challengers to obtain concessions. Thus, political opportunity structure refers to the political environment that corresponds to the "context within which politics take place" (Eisinger 1973, 11).

Under political opportunity structure there are several perspectives that can be

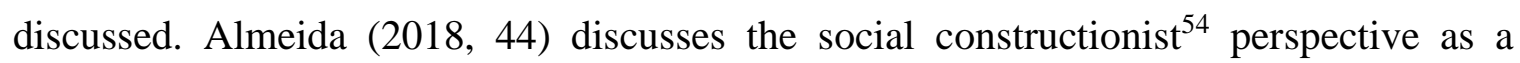
perspective that "assist[s] in linking specific opportunities and threats to encouraging individual level participation in collective action." For instance, researchers believe that protesters would find it useful to analyze specific threats "in terms of defining the harms they create and attributing culpability in convincing fashion before mobilizing can take place" (Almeida 2018, 44-45; see also: Jasper 1997; Snow and Benford 1988; Snow and

\footnotetext{
${ }^{54}$ McAdam (1983) suggested that actions of insubordination and rebellion against forms of domination, depend on the production of a framework of injustice. In other words, not only is a material situation enough, but a social construction of a framework of injustice in an ideological plane is needed, since they play an important role in the process prior to social mobilization.
} 
Corrigal-Brown 2005). Auyero (2006) and Scott (1976) follow a "moral economy" theoretical perspective that "connect cultural processes to the likelihood of opportunities and threats converting grievances into sustained campaigns of protest by contextualizing the particular hardship within the moral belief systems of the community or society in question" (Almeida 2018, 45; See also: Simmons 2016).

For example, with the simultaneous advance of neoliberal reform and democratization in Latin America, Ortiz (2013) and Bellinger and Arce (2011) show how the growing public expression of demands often gives rise to protests and demonstrations. Arce (2010) demonstrates another example by showing how residual power concentrations and legislative fragmentation likely frustrate individuals who try to create change through electoral turnover, which leads them to street level protests (as a preferable mean) to exert pressure. In Spalding's $(2016,7)$ study on mining related protests, she notes that "[w]ith increased investment came increased public attention to the associated costs. Concerns about mining intersected with unresolved, pre-existing or simultaneous conflicts, making the context ripe for new forms of social mobilization." These examples provide some scenarios of the political environment that corresponds to the "context within which politics take place" in Latin America related to why individuals protest.

The introduction of mining into communities can act as the political opportunity that leads to mobilization. Related to mining protests and social movement activity, political opportunities "provide occasions to address long-standing grievances via social movement-type actions. Political opportunities signal to communities experiencing adversity that if they mobilize in the present, they are more likely to alleviate existing wrongs and 'collective bads"' (Almeida 2018, 43) associated with mining and mining 
activities. The existing empirical and theoretical research highlights the motivating factors for why individuals engage and participate in collective action with increases in political opportunities or threats (Almeida 2018, 45) For example, Goldstone and Tilly (2001) suggest that opportunities provide the chance of acquiring new benefits by participating in social movement activity. And Almeida $(2018,45)$ notes that " $[t]$ hreats drive individuals into collective mobilization by making current conditions worse if defensive action is not undertaken." In relation to mining, individuals likely collectively mobilize in order to not make the current threats from mining worse. Essentially, they take defensive action in order to protect their community from the ills of mining.

Scholarly work on religion's role in extractive protests and social movements is largely absent as well, save the work by Arellano-Yanguas (2014) and Spalding (2011). Arellano-Yanguas (2014) analyzes the Catholic Church's participation in extractive mobilizations in Peru by assuming a different approach than "the perspectives of the role played by institutional actors and the influence of progressive ideologies, especially liberation theology" (Arellano-Yanguas 2014, 77). ${ }^{55}$ He does not negate the significance of the institutional and ideological factors, but shifts the focus to how social actors at the grassroots level shape the church's response. He suggests that the Church is not the main actor at the local level, and he believes that the church interacts with local populations in a more nuanced manner. The church's role especially depends on the local context and the type of conflict (Arellano-Yanguas 2014, 66 and 77). Thus, Arellano-Yanguas (2014,

\footnotetext{
${ }^{55}$ For detailed discussion of this literature, please see Arellano-Yanguas $(2014,69)$. Briefly though, previous research has shown the importance of the agency of bishops, priests, nuns and other religious figures (Levine and Mainwaring 1989; Adriance 1991); progressive theologians and Catholic intellectuals (Peña 1994); and the role of ideas (i.e., liberation theology) (Holden and Jacobson 2009).
} 
66) provides an analysis as to how and why the church chooses to involve itself in specific conflicts focusing on the internal processes that shape its participation because this "sheds light on some novelties emerging in the relationship between religion and contentious political processes in contemporary Latin America.” Arellano-Yanguas' (2014) study demonstrates how religion fits within Tarrow's (1998) conceptualization of political opportunity structure. He shows that mining increased religion's role in empowering citizens and stakeholders to increase their participation in mining resistance through its formation of a coalition alliance with mining communities in Peru that formed a unified opposition towards mining and destabilized those in power to the point of offering concessions.

Additionally, religion has been viewed by social science scholars as an antisystemic force in the context of collective behavior theory. Under this viewpoint, scholars focused on cults and fringe religious movements to portray deviant and irrational belief systems that result from material deprivation (McGlaughlin 1969). Focusing on rationality and rational politics, Williams (2006) discusses how the influence of resource mobilization theory shifted scholars' focus to rational politics more so than the "irrational" factors such as culture. Williams (2006) believes that this focus has led scholars to neglect studying religion's impact and influence among social movements. However, religion and religious organizations do provide communities, especially mining communities, the resources they need to collectively resist. Thus, religion's role in resource mobilization theory should not be ignored.

Since I am interested in how religion fits within the resource mobilization theory framework, it is necessary to examine previous research related to resource mobilization. 
Resource mobilization theorists moved past theories of collective action based on grievances and deprivation because they believe that grievances always exist. Based on this assumption, resource mobilization theorists believe that an alternative approach is needed to explain the variation in protest cycles. Thus, scholars focus on the opportunity rather than the desire to protest (Corning and Myers 2002). For example, McCarthy and Zald $(2002,1977)$ suggest that resource mobilization is contingent on "scope conditions." Scholars, such as McCarthy and Zald (2002, 1977, 1973), Klandermans (1984), Corning and Myers (2002); Jenkins (1983), and Tilly (1978) argue that individuals protest because they coordinate collective action and move past the "free-rider" problem. These individuals focus on the procedures of resource accumulation, "beyond membership consciousness and manpower, that may become available to potential movements to produce action and achieve their goals... These resources support the growth and vitality of movements and movement organizations" (Aguad 2017, 23).

Aguad $(2017,23)$ suggests that resource mobilization theory stresses the capacity of a social movement to attain resources and mobilize movement participants in achieving the movement's goals and objectives. However, Opp $(2009,139)$ points out that resources is not a very defined term, and is largely understood as the goods and materials that individuals are able to control. Jenkins $(1983,532)$ discusses the term mobilization, which is the process by which individuals and groups secure collective control over the resources needed for collective action. The resource mobilization approach focuses on societal support and constraint of social movement phenomena (Aguad 2017). McCarthy and Zald (1977) suggest that resource mobilization theory examines different resources that must be mobilized, the linkages of social movements to other groups, the dependence of 
movements upon external support for success, and the tactics used by authorities to control or incorporate movements (Aguad 2017). According to McCarthy and Zald (1977), there is unclear evidence to judge whether grievances and deprivation are important variables in explaining protest behavior. Thus, they believe that one should not disregard the previous theoretical approaches, but rather focus and emphasize the role of structural conditions that lead to protests. ${ }^{56}$

For Tilly (1978), the degree of mobilization of a group is defined by two factors: 1) the amount of resources that are under the control of the group; and 2) the probability that these resources may trigger a collective action. He points out that there are different types of mobilization: 1) when a group experiences an external threat to their well-being and responds accordingly (i.e., mining activity); 2) a grouping of resources in response to a foundational opportunity; and 3) a long-term vision in the face of a future threat or an opportunity to harvest enough resources for impending battles in the future (Tilly 1978). Thus, "[i]n order to fend off threats, communities require some level of resource infrastructure. This infrastructure includes the human, organizational, material, technical, and experimental stockpiles of capital available to populations under various form of threat" (Almeida 2018, 45).

Religion, or more specifically, the Catholic and Evangelical churches are the mechanisms that "allow organizational deficits to be overcome by oppressed or resource poor populations" (McAdam, Tarrow and Tilly 2001, 48). Agreeably, Tarrow (1998)

\footnotetext{
${ }^{56}$ Almeida $(2018,46)$ discusses how "[a]t the structural level, scholars have elaborated more objective measures of opportunities and threats...The core dimensions of elite conflict, institutional access, changing electoral alignments, external allies, and declining repression are highlighted in this literature as the facilitating macro conditions encouraging attempts at collective mobilization. In more recent elaborations of the perspective, a new dimension of the "multiplicity of independent centers of power within the regime" has been introduced as an additional opportunity."
} 
emphasizes the importance of the preexisting organizations (i.e., Catholic and Evangelical Churches) within the possible groups of social movements, and also identifies central elements that affect said organizations: 1) the importance of pre-existing forms of formal and informal organization; 2) the solidarity incentives ${ }^{57}$ that many groups provide through certain resources, help the recruitment of new members and strengthen the cohesion of the groups; and 3) communication networks that can mean the difference between a successful mobilization and the loss of opportunities. It is important to highlight that the mobilization structure allows the recognition of what Almeida (2016) calls the community infrastructure and Arce (2014b) defines as associative power. These pre-existing organizational scaffolds are reconfigured and adapted to the challenges of the conjuncture, according to the collective objectives of the contenders.

In addition to Arellano-Yanguas' (2014) study, Rose Spalding has a working paper that explores the "case of the anti-mining movement in El Salvador...[and] analyzes the ways in which a national level network adapted and deployed resources mobilized through transnational alliances in order to build a domestic resistance movement" (Spalding 2011, 2). Spalding (2011, 2) utilizes Putnam's (2000) bridging and bonding techniques to explore the local community groups (i.e., environmental rights organizations, epistemic allies, and the Catholic Church leadership) that had their own set of allies connected transnationally. These groups worked together to form a "reform coalition" that created a national policy change towards mining. Her research "suggests the significance of several sets of actors, particularly a local resistance network with strong ties to affected communities; a group of tenacious advocacy organizations focused

\footnotetext{
${ }^{57}$ These are pre-established or identified interpersonal rewards or incentive structures that derive from group solidarity, in such a way that they can help overcome many obstacles.
} 
on environmental and social rights; an emerging network of activist-oriented researchers and specialists; [and] a religious network, ultimately led by Catholic Church bishops" (Spalding 2011, 7). These Catholic Church bishops following a doctrinally-based policy worked together with these other organizations, groups, and activists through alliances to intervene and prevent mining advancements in El Salvador (Spalding 2011, 7).

Finally, the third leg to the political process model is frame alignment. Frame alignment developed with Snow et al. (1986) when they argued that for a social movement to resonate with individuals and generate movement participants and mobilization support, individuals must recognize the movement's frames through the mechanisms that they recognize the world. Essentially, the way in which individuals view the world must align with the goals, objectives, and/or activities of the social movement.

Ten years later, McAdam, McCarthy, and Zald (1996) provided a more succinct definition of frame alignment in reference to social movements. They suggested that "the conscious strategic efforts by groups of people to fashion shared understandings of the world and of themselves that legitimate and motivate collective action" (McAdam, McCarthy, and Zald 1996, 6). Mueller (1992) suggests that frame alignment tends to forget that the language, symbols, and historical memory of movement participants and movement leaders are rooted in the same setting. Thus, Mueller (1992) believes that the movement-framing processes are nonexistent outside of the context in which the social movement takes place, and frames are a product of their context. Therefore, under this perspective studying frames as a motivating tool for political protests should only be understood when one analyzes the meanings of frames in the context and setting in which they are used. 
Simmons $(2019,30)$ suggests that "movements may emerge or grow because leaders frame or reframe messages in ways that can attract a new or broader constituency. Or, potential participants may shift their own beliefs or expectations as a result of a movement's repackaging, bringing an audience into closer alignment with a movement's objectives." In relation to Rancho Grande, Nicaragua, Spalding $(2016,18)$ notes that "[r]eligious leaders provided moral framing; Father Teodoro Custer, a Maryknoll priest who had become pastor of Rancho Grande's Catholic parish in 1999, forcefully challenged the project, broadening the network of oppositional voices." For example, and as I previously discussed, the same four words were painted on almost every house, building, and public space, which were No a la Minería (No to Mining). This had a lot to do with leaders from the Guardines de Yaoska social movement group, leaders from the Catholic and Evangelical Churches, and local NGOs working together in coordination to provide the moral framing that aligned with the goals, objectives, and/or activities of the social movement against mining. These four words resonated with me while visiting Rancho Grande because I understood that the citizens of Rancho Grande, through their attention to this particular framing process around these four words, produced a culture (Simmons 2019, 30). These four words were significant for the Rancho Grande community because they had a sympathetic or positive response that "evoked emotions, images, or memories" towards mining, mining activities, government responses to mining, and B2Gold and their influences in the community (Simmons 2019, 30).

Finally, Dougherty (2018) utilized individual surveys in four mining communities in Guatemala. His results demonstrate that citizens living in these communities "who associated religion with development frequently invoked the notion of 'life' by 
associating mining with death... [and the absence] of mining with life" (Dougherty 2018, 15). Dougherty argues that the "association stemmed from the centrality of the notion of the dignity of human life to Catholic moral vision and social teaching” $(2018,15)$. For example, he quotes a religious leader in Guatemala from his field research interviews, as well as a lay representative of the Catholic Church. The religious leader stated that "I believe that as agents of the Church, we must accompany the people in their resistance to these [mining] projects, which instead of bringing development, just bring death" (Dougherty 2018, 15).

The lay representative of the Catholic Church, whom Dougherty describes as active in the social wing of the diocese suggested in an interview that "We must pray that mining doesn't start. People say that mining is practical. Everything is becoming more practical, but life is less and less. I have a nice house and everything, but if I die faster, we have less life" (Dougherty 2018, 15). Hence, based on Dougherty’s findings, individuals that are religious or associated with religion are more likely to oppose mining because it threatens their life and existence on Earth. Although, his findings are not directly tied to protests or social movement activity, they are still important because they help us understand the role that religion and religious association have on oppositional attitude formation against mining, which could eventually lead to protests and social movement activity against mining.

It appears that the connection between social movement activity and religion has been neglected in the formation of social movement theorizing, but it is starting to gain traction among social science scholars. However, a very limited amount of studies have examined how religion impacts protest movements related to resource extraction 
(Arellano-Yanguas 2014; Spalding 2011) and an even fewer utilize individual responses to examine how religion shapes attitudes towards mining (Dougherty 2018). Thus, I plan to build off these studies and directly ask individuals living in the extractive frontier (based off of their own experiences in extractive protests): Does religion contribute to the success (i.e., overturning a mining concession) of extractive protests and/or social movements? Essentially, I want to understand and show whether individuals that partake in or influenced by extractive protests see religion as a mechanism for catalyzing successful protest movements against extraction.

In the next chapter and in the last part of my theoretical framework, "Religion as a Catalyst for Success," I address my final research question by emphasizing the role of religion as a catalyst for sustained challenges and successful resistance against resource extraction. I argue that communities with more church involvement and stronger religious influence, in this case influence tied to Catholicism and Evangelicalism, are better suited to sustain their opposition against resource extraction and successfully end mining exploration or exploitation projects affecting their communities. I demonstrate how religion influences successful protests movements against extraction by assisting communities in overturning or gaining mining concessions from the mining company or the government. I utilize and build off of literature related to social movements and religion and religion and ecology to develop this portion of my theoretical framework. 


\section{CHAPTER 4}

"Demands for Rights and Services, Social Engagement, and Catalyzing Religion" 
In order to understand what makes resistance against mining successful in terms of the reversal or gaining of mining concessions in communities, scholars need to understand what makes individuals oppose or support resource extraction. Current research on the politics of resource extraction focuses on successful campaigns against extraction and emphasizes the sources of opposition to mining. With few exceptions, existing research has rarely explored individual-level attitudes related to resource extraction. Opposition and support towards mining are not mutually exclusive from protest success in overturning a mining concession. They build off each other. If a community strongly opposes mining, especially related to environmental threats and grievances, it will likely continue its resistance movement until it sees policy changes that halt or overturn mining concessions in the community. However, if there is support for mining in the community, mining activities will likely prevail because individuals in the community believe they will benefit from mining activity.

Therefore, I question, how are individuals' attitudes shaped by the extractive frontier? More specifically, what environmental concerns lead citizens to oppose extractive activities? What economic conditions are citizens likely to support extractive activities? And, how does social engagement shape individual attitudes toward resource extraction? I examine the causes of opposition and support over resource extraction in Rancho Grande and Santo Domingo. I am particularly interested in attitudes over grievances that individuals hold towards mining, and how these attitudes are shaped by social engagement (i.e., formed or reinforced) through participation in various types of local organizations. In doing so, scholars can begin to understand the "variegated individual responses to mining" that underline the aggregate stories of homogenous 
community resistance (Dougherty 2018, 2). By understanding individual attitudes, beliefs, and characteristics towards mining, scholars of extractive protests and social movements will be able to better understand the individual mechanisms that lead citizens in the extractive frontier to either partake in mining resistance or abstain, as well as what individuals believe makes their protests and social movements more successful. For example, by understanding the reasons individuals in Rancho Grande and Santo Domingo, two communities that strongly resist mining, oppose or support mining, I can better understand the reasons why Rancho Grande successfully influenced policy changes at the national level and Santo Domingo did not.

Since this dissertation essentially has two dependent variables: Support for B2Gold's mining projects and Success in overturning B2Gold's mining concession, as well as four main factors of theoretical interest: Demands for Services, Demands for Rights, Social Engagement, and Religion as a catalyst for successful protest movements. I divide this chapter into three different theoretical sections to address my research questions. In part one, "Understanding Opposition for and Support of Resource Extraction," I address my first set of research questions: How are individuals' attitudes shaped by the extractive frontier? What environmental concerns lead citizens to oppose extractive activities? And, what economic conditions are citizens likely to support extractive activities? I utilize the "demands for rights" and "demands for services" framework put forth by Arce (2014b, 2015) and Arce and Hendricks (forthcoming) to address the environmental concerns leading citizens to oppose extractive activities and the economic conditions that lead citizens to support extractive activities. This section addresses my first dependent variable of interest: Support for B2Gold's mining projects. 
In part two, "The "Social Engagement and the Micro-politics of Resource Extraction," I address my final research question associated with my first dependent variable: Support for B2Gold's mining projects. Again, I ask: How does social engagement shape individual attitudes toward resource extraction? I provide a theoretical framework on the micro-level politics that make individual citizens more likely to oppose mining. I argue that the more socially engaged individuals are in local organizations, the more likely they have: 1) access to critical organizational tools and information about mining; 2) a higher sense of self-efficacy and collective-efficacy empowering them and their communities; 3 ) and a stronger community worldview contributing to broad-based mobilization.

Finally, in part three, I focus on my second dependent variable: Success in overturning B2Gold's mining concession and Religion as the catalyzing factor for successful protest movements against mining. This section addresses my final research question: Does religion contribute to the success of extractive protests and/or social movements? In this section, I emphasize the role of religion as a catalyst for sustained challenges and successful resistance against resource extraction by arguing that communities with more church involvement, in this case involvement tied to Catholicism and Evangelicalism, are better suited to sustain their opposition against resource extraction and assist communities to be successful against mining in terms of the reversal of mining concessions in communities.

My theoretical framework permits me to systematically study the attitudes, beliefs, and characteristics of individuals in highly visible extractive protest cases by directly asking them what makes them oppose or support resource extraction, as well as 
understand the micro-level politics (i.e., social engagement in local organizations) that shape individual attitudes towards extraction. This theoretical framework, especially part three, also permits me to understand what attitudes, beliefs, and characteristics individuals have in highly visible protest cases for successfully overturning mining concessions through sustained protests and social movement resistance. Thus, I seek to understand how individuals' attitudes, beliefs, and characteristics are shaped by the environments succumbed to the extractive frontier. By focusing on individual attitudes, beliefs, and characteristics of those that live directly in mining areas, scholars will have a more nuanced perspective to understand the links between individual motives and decisions involved in extraction mobilizations that are constituted by group dynamics and individual behaviors.

\section{Understanding Opposition and Support for Resource Extraction}

As previously discussed in Chapter 3, scholars have studied the variation in the motivations and goals of local populations living within an extractive frontier (Arce 2014b, Bebbington and Bury 2013; Eisenstadt and West 2017; Spalding 2015b; Svampa and Antonelli 2009). These studies demonstrate that protesters mobilize in order to protect basic rights like water quantity and quality, land and landscapes, and a healthy livelihood (Arce 2014b; Bebbington, Bebbington, and Bury 2010; Bury 2005; DeEchave 2011; Gil 2009; Salas Carreno 2008; Aroca 2008; Li 2015). In other words, they mobilize and protest because they feel threatened. Almeida $(2018,43)$ discusses how at the turn of the Twentieth Century scholars such as Jasper (1997), Snow et al. (1998), and Goldstone and Tilly (2001) provided empirical research that focused on worsening conditions that 
threatened communities, which provided the means for collective mobilization (Almeida 2003; Andrews and Seguin 2015; Dodson 2016; Einwohner and Maher 2011; Inclán 2009; Johnson and Frickel 2011; Maher 2010; Martin 2013; Martin and Dixon 2010; Mora et al. 2017; Shriver et al. 2015; Simmons 2014; Van Dyke and Soule 2002; ZepedaMillán 2017). As Pinard (2011) suggests, when increased threats and hardships accompany existing hardships, grievances increase in turn.

Therefore, my dissertation, particularly the first part of this theoretical chapter, aims to utilize this "threat structure" outlined and analyzed by Almeida (2018), by building on Arce's (2014b, 2015) and Arce and Hendricks' (forthcoming) work. In this section, I question: What environmental concerns lead citizens to oppose extractive activities? And, what economic conditions are citizens likely to support extractive activities? By utilizing the theoretical framework of these authors I can systematically understand the attitudes of individuals in highly visible protest cases. Although, these authors studied extractive protests utilizing media reports and protests events (Arce 2014a) and made micro-level inferences at the community level, which I criticized in Chapter 3 for being inherently biased and flawed; they provide a theoretical framework that is useful and valuable to ask individuals why they oppose or support resource extraction.

Protests against natural resource extraction have similarities in their claims (i.e., environmental conflicts and redistribution conflicts). The networks of actors in opposition (i.e., local communities affected by extraction, environmental NGOs, etc.) and support (i.e., extractive companies, national governments, etc.) of extraction are similar as well. However, the dynamics of the protests against natural resource extraction are 
different. I differentiate the diversity of mobilizations surrounding resource extraction. I argue that some of these mobilizations are driven by "demands for rights," which are encouraged by the adverse impact of mining on livelihoods and the environment; and other mobilizations are driven by "demands for services," which arise as a consequence of disputes over the distribution and use of revenues generated from resource extraction. ${ }^{58}$ Both types of mobilizations suggest how the extraction of natural resources makes contentious activity likely, albeit for different reasons. This perspective focuses on the importance of economic conditions, either threats or opportunities, that could be used to encourage protests but for different reasons (Arce, 2014b, 2015; Arce and Hendricks forthcoming).

This framework can be utilized to describe mining conflicts in Nicaragua. Similar to other mining locales where mining has encompassed the economic life of the community, there are several Nicaraguan communities (i.e., El Limon, León, Nicaragua) where the local economies survive on mining activities and the continuation of mining activities. Within these communities, the elites nor the community members tend to seek the total abolition of mining, and if conflicts do emerge in these communities they tend to be distributive struggles that focus on the distribution of mining profits, economic benefits, and social programs from mining companies (Spalding 2016). However, in Nicaraguan communities where mining companies have not had a prior influence (Rancho Grande, Matagalpa, Nicaragua), "where the social and environmental costs of mining had not been normalized, and where livelihoods based on agriculture clashed directly with the resource demands of industrial and chemical mining, opposition often

\footnotetext{
${ }^{58}$ The distinction between "demands for rights" and "demands for services" follows Arce (2014b, 2015) and Arce and Hendricks (forthcoming).
} 
became fundamental" (Spalding 2016, 14). When mining companies explore these communities, they often create threats to the local populations in the forms of residence and production, which often times leads to a forceful response by community members to halt mining projects from starting. Mining conflicts such as these, are definitional struggles where the stakes are high for those that live in the affected communities (Spalding 2016). In the next sections, I elaborate on service-based claims and protests and rights-based claims and protests.

\section{Service-Based Protests Against Resource Extraction}

The "good news" of resource extraction refers to the "demand for services", which relates to how wealth related to extraction is distributed to the public and for public goods. Individuals under this type of protest are not automatically against mining and typically do not directly involve extractive companies. However, extractive companies can still be involved due to the companies' community development promises tied to its corporate social responsibility (De Echave et al. 2009; Dougherty and Olsen 2013). These protests tend to involve local communities, political officials, and mining officials that represent the different levels of community, government, and private corporations where the extraction occurs. This category of protests is common in areas where extraction is the only economic viable activity in the locale and does not compete with other economic sectors, like agriculture. Thus, regional and local governments and some extractive companies pursue the integration of existing extractive activities with the development of communities in which the extraction occurs. Dougherty's $(2018,16)$ individual-level study of four mining communities in Guatemala demonstrates that individuals supported 
mining and mining activity for economic development purposes. Additionally, his interviews with some individuals living in the extractive frontier in Guatemala also demonstrate the support for mining due to economic development and educational attainment that mining brings to their communities (Dougherty 2018). ${ }^{59}$

Based on the "good news" of resource extraction and when individuals" perceptions are high related to the economic benefits that mining will bring to them, their families, and their communities, the more likely I expect individuals living in the extractive frontier to support mining and mining related activities. Therefore, I theoretically expect the following:

Hypothesis 1: The higher the perception of economic benefits from mining, the more likely individuals are to support extractive activities.

However, when services, resources, and/or benefits (i.e., economic development, jobs, education, healthcare programs) are not provided as promised by local governments or the mining company, communities tend to protest until the promised services, resources, or benefits are provided. These protests have to do with the efficient use of resource incomes, meaning both the proper use of the resource incomes and the capacity of local governments and mining companies to bring development to where resource extraction occurs, such as the delivery of social services or infrastructure projects (i.e., roads,

\footnotetext{
${ }^{59}$ Dougherty's (2018) study quotes two individuals from Guatemala that show their support for mining. For example, in an interview Dougherty had with a peasant man from Ascunción Mita, Guatemala, whose son worked for the mining company (GoldCorp) stated that "Mining is development, it's change, it's progress, it's moving out of backwardness" (as quoted in Dougherty 2018, 16). In another interview in Dougherty's study with an individual that did not have any direct connection with the mine, the individual stated that "Now the children get to seventh grade, eight grade. But before they just finished first or second grade. Now we're seeing our development that we wanted" (as quoted in Dougherty 2018, 16). This individual connected educational attainment with mining benefits.
} 
schools, and health facilities) (Arce 2014, 2015; Arce and Hendricks forthcoming). ${ }^{60}$

Protesters under the "good news" of resource extraction have very specific claims that are negotiable, and they typically protest in a non-stop pattern over a short period of time, which garners small concessions until their next specific grievance. The same short, nonstop pattern continues as their demands are fulfilled and new grievances or threats come to the surface. Mobilizations under this category are seen as an economic opportunity because individuals mobilize to enhance their situation. Therefore, protests, under this category, are used as a bargaining tool to accomplish political goals or policy demands by local populations in resource wealthy regions to enhance their situation (Arce 2014b, 2015; Arce and Hendricks forthcoming).

In Nicaragua, the "good news" of resource extraction often involves "[c]ompetition between mine operators and community activists over economic resources [that] can revolve around issues of employment, collective bargaining, wages and working conditions, as in classic labor disputes, or around the distribution of taxes and royalty payments" (Spalding 2016, 14). For example, in 2015, the mining community of El Limón in the Department of León faced a labor conflict with Canadian mining company B2Gold (Centro Humboldt 2015c). B2Gold gained 95\% of El Limón’s mine in 2009. The other $5 \%$ of the mine was controlled by unionized mine workers. With the acquisition of $95 \%$ of the mine, B2Gold enhanced their production of gold. With B2Gold's expansion in El Limón, community members began to complain about building damage, sink holes, water stoppages, and power outages due to the increases in extractive

\footnotetext{
${ }^{60}$ Almeida (2018, 47; see also: Caren Gaby, and Herrold 2017; Enríquez 2010; Hall et al. 2015; Schock 2015; and Snow et al. 1998) discusses how threats related to economic conditions are one of the driving factors for collective action throughout history and how there are numerous ways for economic circumstances and material circumstances lead to defensive mobilization.
} 
activities (Spalding 2016). In 2015, there were strikes and aggressive disturbances, which were heavily related to the community's free electricity supply from B2Gold (i.e., economic service) (Spalding 2016). Prior to these community conflicts, B2Gold went under new management, and under the new management the community's free electricity was cut. Three members of El Limón's mining union were also fired without an explanation. These events led community members of El Limón and activists to setup road blocks that directly blocked access to the mine and halted all mine production. ${ }^{61}$ The road blocks occurred from September $28^{\text {th }}$ until October $18^{\text {th }}, 2015$. The roadblock was eventually broken by police forces and B2Gold's operations continued, but not after both protesters and police faced several injuries and one police officer died (Spalding 2016).

The events that unfolded in El Limón in 2015 over electricity being cut by B2Gold is an example of a service-based claim that created heated conflicts with community members and activists against B2Gold and police forces for a short period of time. Protests and conflicts, as seen in the El Limón mining community and following the pattern of service-based claims and protests, were contained at the local level. Spalding $(2016,15)$ notes that the "FSLN government was often able to limit labor and community activism through strategic tripartite bargaining in which municipal officials, sometimes accompanied by police or military officers, secured modest material concession for protesters and got production quickly back on track." However, when their "efforts failed, forcible measures, including the arrest and imprisonment of leaders, served as a last resort" (Spalding 2016, 15). The punishment of protesters and criminalization of protest is a common method used in Nicaragua, as it is elsewhere, by pro-mining officials

\footnotetext{
${ }^{61}$ Almeida (2016) explains that the use of roadblocks is one of the most common types of resistance in protests throughout Central America.
} 
when protests disrupt and hinder mining production (MiningWatch Canada and International Civil Liberties Monitoring Group 2015).

\section{Rights-Based Protests Against Resource Extraction}

Vulnerability, or "the susceptibility to be harmed" can help one understand the reasons why those who live near the extractive frontier oppose extractive activities related to exploration and exploitation of minerals like gold (Adger 2006, 286). Adger (2006, 268269) defines vulnerability, in opposition to resilience, as "the magnitude of disturbance that can be absorbed before a system changes to a radically different state as well as the capacity to self-organize and the capacity for adaptation to emerging circumstances." Adger's goal is to understand the human factors that affect vulnerability, such as "the common property resource tradition, for example, stresses the importance of social, political, and economic organizations in social ecological systems, with institutions as mediating factors that govern the relationship between social systems and the ecosystems on which they depend" (269). Vulnerability can be shown as it relates to the environment and resource extraction because it is likely that those that live within the extractive frontier and who perceive themselves at risk due to ecosystem fluctuations (e.g., drought, disappearance of habitats) or because of competing interests over local agriculture economy (e.g., the increase scarcity of fresh water and arable land) are more likely to oppose mining (Eisenstadt and West 2017; Haslam and Tanimoune 2016).

Furthermore, Johnson and Frickel $(2011,305)$ define an "ecological threat" as the "costs associated with environmental degradation as it disrupts (or is perceived to disrupt) ecosystems, human health, and societal well-being." There are many resource related 
conflicts that arise when mining exploration and exploitation clash with the local agriculture economy over things such as, the increasing scarcity of fresh water and arable land, which can have serious implications on the livelihoods of those living in the extractive frontier. Others like Bury (2002), Martinez-Alier (2003), Kirsch (2001), Perreault (2013), and Urkidi (2010) highlight the impacts and effects that mining can have on peasant communities via their livelihoods, cultural traditions, and internal relations. Conde and Billon (2017) also suggest that when mining competes with an agricultural economy it is linked to economic marginalization within these communities and leads to resistance among the community. Additionally, Haslam and Tanimoune's (2016) study of communities resisting mining in the mid-level altitudes in the Andes demonstrates the economic threats from mining related to the communities' agricultural dependence. For example, these communities in the Andes are agricultural dependent and mining threatens their water supply and access to arable land, which leads them to compete with the mining industry for resources (Silva-Macher and Farrell 2014; Bebbington et al. 2008). Hence, when mining activity competes with the livelihoods of communities via agriculture, the environment, water quality and quantity, etc. (i.e., economic threats), the community tends to oppose and resist mining.

Additionally, mining projects can lead to community displacement to a completely new location, which poses high risks for the livelihoods, health, and social ties of the community members (Conde and Le Billon 2017). Scholars such as Ahmad and Lahiri-Dutt (2006) and Downing (2002) note that mining related displacement and uneven compensation for relocation causes stress and feelings of inequality with communities directly affected, but also communities in the broader impacted area. 
Mining companies are supposed to follow the World Bank Group's social safeguards for involuntary resettlement. Szablowski (2007) and Owen and Kemp (2015) discuss how these social safeguards stress that relocated communities due to mining related activities should be compensated and as well off as they were before they were relocated. However, mining companies tend to not follow these social safeguards because they are voluntary (Lange 2011), and conflicts tend to emerge because the mining companies do not follow a generic framework and they ignore specific contexts and do not incorporate community participation and feedback into design and implementation of relocation plans, which often marginalizes local people (Szablowski 2007; Owen and Kemp 2015). Also, the state and local governments delegate representation and assistance to the mining company, which includes design and enforcement of relocation. This leaves the companies to have to deal with "complex issues relating to legacy, traditional forms of land ownership, multiple resettlements, and changed ownership" (Owen and Kemp 2015, 486). Finally, Downing (2002) discusses that under-financing is a significant failure of relocating communities and community displacements. ${ }^{62}$

These resource related conflicts have become known as the "bad news" of resource extraction or rights-based protests (Arce 2014b, 2015; Arce and Hendricks forthcoming). ${ }^{63}$ The "bad news" of resource extraction refers to the "demand for rights",

${ }^{62}$ Conde and Le Billon $(2017,685)$ note that often times artisanal miners are displaced to make way for large-scale extractive projects, which directly impacts source of income and livelihoods for these artisanal miners.

${ }^{63}$ Almeida $(2018,48)$ suggests that mining's direct threats to public health and the environment provide strong reasons for communities to collectively oppose and resist mining in order to gain relief or compensation from the negative externalities associated with mining. The threat is to people's actual physical well-being and long-term health (Szasz 2007). At times, this form of threat creates 'a suddenly imposed grievance' (Walsh et al. 1997); interruptions to daily patterns (Snow et al. 1998); or a 'moral shock' (Jasper 1997). 
which are protests related to environmental concerns that deal with the defense of local water supplies or the protection of agricultural land. Protesters under this category largely oppose mining because they feel marginalized or excluded from the decision-making process related to natural resource extraction. Compared to protests over demands for services, these mobilizations raise broader claims that are more difficult to accommodate, and therefore, more likely to produce organized and sustained challenges against extraction. The mobilizations over demands for rights approximate the sort of economic threats (or grievances) that typically encourage people to participate in protest activity (Arce 2014b, 2015; Arce and Hendricks forthcoming). For example, Dougherty $(2018,1)$ finds in his individual-level study of four mining communities in Guatemala that individuals living in the extractive frontier who oppose mining tend to oppose mining due to the negative externalities that mining causes to public health and the local environment.

Thus, rights-based protests aim to provide a citizen-centered explanation on how extraction affects local communities. In several mining conflicts, some groups continue to oppose extraction due the adverse impact of mining on the environment. These movements seek to defend basic rights, such as water access and quality, the integrity of land and landscapes, and/or cultural survival of indigenous or other minorities. Rightsoriented protesters frame their claims in terms of environmental risks and damages, and their collective resistance aims to block the granting of permits for new extractive sites or to halt the expansion of existing extractive activities. These zero-sum protests raise broad claims about basic rights that are more difficult to accommodate, but, consequently, are 
more likely to produce organized and sustained challenges against extraction (Arce 2014, 2015b; Arce and Hendricks forthcoming).

Based on the previous paragraphs related to "demands for rights", I expect when economic threats, tied to the environment, agriculture, displacement, land quality and quantity, and water quality and quantity, are tied to mining communities that individuals living in these communities will likely oppose mining and its activities. Therefore, I theoretically expect the following:

Hypothesis 2: The higher the perception of economic threats tied to mining, the more likely individuals are to oppose extractive activities.

Rights- and service-based mobilizations are not mutually exclusive categories, rather they aim to provide a citizen-centered explanation on how extraction affects local communities. In several mining conflicts, some groups continue to oppose extraction due the adverse impact of mining on the environment (rights-based mobilizations), but other people who are benefiting from mining operations are more likely to raise claims about financial improvement (service-based mobilizations). Thus, theoretically, when I discuss opposition, I emphasize the defense of basic rights or economic threats (i.e., demands for rights). When I discuss support I emphasize the distribution of benefits or economic opportunities (i.e., demands for services). However, I need to move past the perceptions of economic threats and economic opportunities about mining (which could be fluid) and examine sets of factors that make individuals different from one another. My argument, discussed in depth in the next section, is that social engagement differentiates these actors. Socially engaged individuals in local community organizations are more likely to oppose extractive activities than individuals who are less socially engaged. 


\section{Social Engagement \& the Micro-politics of Resource Extraction}

Part one of my theoretical framework provides a useful typology for understanding the motivating factors (i.e., demands for rights and demands for services) that lead citizens living in the extractive frontier to either oppose or support resource extraction. However, what this existing typology does not provide is how these citizens come to form or solidify their attitudes towards resource extraction. Thus, I question: How does social engagement shape individual attitudes toward resource extraction? This section of my theory provides a framework on the micro-level politics that make individual citizens more likely to oppose mining. I argue that the more socially engaged individuals are in local organizations (i.e., church organizations, environmental organizations, community organizations, and agricultural organizations), the more likely they have: 1) access to critical organizational tools and information about mining; 2) a higher sense of selfefficacy and collective-efficacy empowering them and their communities to resist mining; 3) and a stronger community worldview (i.e., community identity and values) contributing to broad-based mobilization and resistance.

\section{Knowledge: A Source for Organizational Tools and Information About Mining}

Although, Latin Americans receive the majority of their news from television (Weyland 2003), Baker, Ames, and Renno (2006, 382) observe the importance of potentially biased media - perhaps stemming from authoritarian days — and argue that "interpersonal influence produces short-term preference volatility among voters and shapes election outcomes." Although, I do not specifically emphasize voting and voting behavior for this 
dissertation, I believe that the theoretical framework provided by Baker, Ames, and Renno (2006) informs scholars on how citizens living in the extractive frontier can form their attitudes towards mining. They inform themselves through social engagement with others in community groups and organizations. For example, the authors show that in the Brazilian context, during electoral campaigns, citizens collected information and get informed about candidates through discussions within personal social networks. In weak party systems, often found in countries throughout Latin America, the neighborhood offers an opportunity for people to freely express their views, as well as to be influenced by the political preferences of others

I argue that opposing attitudes towards resource extraction in Latin America, and particularly Nicaragua, a region and a country with predominately weakly institutionalized party systems (Levitsky et al. 2016) could be directly obtained or transmitted among people through peer-to-peer contact in their personal networks within their communities. Citizens disagree on central issues related to politics and depend on one another to inform themselves and persuade others about political, economic, and social-related issues (Huckfeldt, Johnson, and Sprague 2004). Unlike media theories that suggest those engaged with political information are likely to change preferences (i.e., Boas, 2005; Lawson and McCann, 2004), here those with little access to other information are more susceptible via these social interactions to change their preference. Media can still matter by exposing a few well-informed individuals who then pass the message on, meaning social interaction can magnify the effect of media coverage. ${ }^{64}$

\footnotetext{
${ }^{64}$ The use of the radio by the Catholic Church and Guardines de Yaoska in Rancho Grande, to spread antimining sentiment and rhetoric did help Rancho Grande successfully organize and protest, but I believe it is the peer-to-peer interaction that individuals have with each other at local organizational meetings that shape their attitude formation towards resource extraction.
} 
Building on Moseley (2015), Arce, Polizzi, and Reeder (N.D.) suggest that social engagement is a significant determinant for individuals to participate in collective action. As Jenkins (1983) and McCarthy and Zald (1973, 1977) have shown participation networks provide the opportunities and the organizational resources needed for individuals to partake in successful collective action. Grounded in the resource mobilization literature, socially engaged individuals have access to networks of participation that are unavailable to those not socially engaged or disconnected. Thus, when citizens believe that social engagement is a valuable tool for political participation, they are more likely to have an interest in politics, be politically sophisticated, join groups and organizations that act collectively, and are more likely to partake in collective action. On the contrary, citizens that are not socially engaged or view social engagement as a useful tool for political participation are less likely to be politically active and act collectively (Arce, Polizzi, and Reeder N.D.).

Similarly, Moseley (2015) suggests that socially engaged citizens are more likely to protest for two reasons. First, when citizens are socially engaged in their communities, they are more likely to have access to crucial organizational tools essential for communication and mobilization. Second, by being a member of political and nonpolitical organizations and groups, socially engaged citizens face more exposure to the relative strengths and weaknesses of formal institutional structures. This exposure offers these individuals the necessary information to make sound decisions about the necessity and/or effectiveness of protest participation. Finally, Arce, Polizzi, and Reeder (N.D.) also conclude socially engaged citizens are more likely to protest resource extractive activities because their participation in organizations and groups permits them 
to be more aware of the relative strengths and weaknesses of their government environment. This participation offers these individuals the necessary information to make sound decisions about whether to collectively resist mining.

As such, I utilize a social engagement approach to understand how citizens form or reinforce their attitudes towards resource extraction through participation in community groups and/or organizations, and in turn, these groups and organizations provide the tools and information needed to organize collectively and mobilize against mining. Agreeably, Tarrow (1998) emphasizes the importance of the preexisting organizations within the possible groups of social movements, and also identifies central elements that affect said organizations: 1) the importance of pre-existing forms of formal and informal organization; 2) the solidarity incentives ${ }^{65}$ that many groups provide through certain resources, help the recruitment of new members and strengthen the cohesion of the groups; and 3) communication networks that can mean the difference between a successful mobilization and the loss of opportunities. Although the previous research just discussed offers mechanisms for how being socially engaged in community organizations offers individuals organizational tools and information about mining, it does not offer any details on how being socially engaged leads directly to proenvironmental behaviors or opposition towards mining due to the environmental damages that mining causes.

Borrowing from the environmental psychology literature, Estrada et al (2017) suggests that previous experimental findings show that when individuals receive

\footnotetext{
65 These are pre-established or identified interpersonal rewards or incentive structures that derive from group solidarity, in such a way that they can help overcome many obstacles.
} 
information it does not necessarily change their behaviors, ${ }^{66}$ even though individuals often suggest that the information they received changed their behavior. ${ }^{67}$ Estrada et al. (2017) discusses how the acquisition of knowledge and engagement in pro-environmental behavior relates to the type of information provided. ${ }^{68}$ These authors suggest that knowledge is a necessary precondition for individual action in pro-environmental behavior, but it is necessary to recognize that science knowledge must be provided to individuals in order for them to engage in pro-environmental behavior. ${ }^{69}$ Additionally, and as Göckertiz et al. (2010) describe, there is a significant amount of evidence that indicates that social influence research is important for increasing engagement in proenvironmental behaviors.

Estrada et al.'s (2017) study is based on climate change education and engagement in pro-environmental behavior. Although, I am not discussing climate change knowledge and education in this dissertation; I do believe that Estrada et al.'s (2017) study is transferable to mining knowledge and education and engagement in proenvironmental behavior among individuals living in the extractive frontier. As Estrada et al. $(2017,171)$ suggest, climate change education is "not an objective imparting of facts upon a passive individual but a socializing process. Climate change education potentially shifts not only knowledge about scientific facts and processes but also provides information that can impact the efficacy, identity, and value system of those being educated." Therefore, acquiring this knowledge is seen as an accumulation for an individual to feel more engaged in their community and in promoting pro-environmental

\footnotetext{
${ }^{66}$ See also: Schultz (1999) and Schultz and Tabanico (2007).

${ }^{67}$ See also: Nolan et al. (2008).

${ }^{68}$ See also: Kaiser, Roczen, and Bogner (2008).

${ }^{69}$ See also: Kaiser and Fuhrer (2003).
} 
behavior (Estrada et al. 2017). Thus, individuals living in the extractive frontier learn from being actively involved and engaged in local groups and organizations within their communities. Their pro-environmental behavior leads to negative and opposing attitudes towards mining because the negative externalities that mining causes to the environment and agriculture.

The components of Estrada et al.'s (2017) model are derived from Kelman's classic social influence work, which suggests there is an influencing agent and a target influence (Kelman 1956, 1958, 2006). In the context of mining knowledge, the influencing agents are representatives or members of the community concerned about mining, such as community leaders, educators, scientists, farmers, environmentalists, church leaders, etc. (Estrada et al. 2017). These influencers are individuals who desire to inform and educate their fellow community members about mining, its activities, and the detrimental impact it causes to the environment, agriculture, and the community. Estrada et al. (2017, 171-172) defines the community as opinion-based, which means that members of the community "see themselves as collectively defined and adhere to the norms of that group usually related to positive social change. The targets of influence are potential and current persons of the larger community."

Estrada et al.'s $(2017,172)$ study, demonstrates that knowledge is the catalyst that integrates individuals into a community of citizens that care about the environment and practice pro-environmental behavior. Estrada et al. $(2017,172)$ suggests that "individuals integrate to the extent that they gain... knowledge in a way that increases efficacy, identity, and values.” Knowledge does not necessarily increase an individual's efficacy, identity, or values, but likely accompany knowledge in assisting an individual's 
integration into the community (Estrada et al. 2017). Thus, efficacy, identity, and values mediate the relationship between mining knowledge and engagement, which provides a stronger connection to the community and the feeling of empowerment to oppose mining through broad-based mobilization and resistance. Therefore, individual integration can affect both short- and long-term community engagement in terms of normative behaviors in which individuals feel integrated. Individuals integrated into their community and concerned about the negative externalities of mining on the environment are more likely to participate in the behavioral norms of the community, which likely include proenvironmental behaviors and opposition to mining.

\section{Feeling Empowered: The Role of Self- and Collective-Efficacy}

Borrowing from the social psychology literature, Bandura (1997) offers one of the strongest predictors of individual engagement, which is self-efficacy. Bandura $(1997,3)$ defines self-efficacy as “the belief in one's capabilities to organize and execute courses of action required to produce given attainments.” In 2010, Bandura offered an alternative definition related to one's environment, which is defined as an individual's belief "in their capability to exercise control over their own functioning and over environmental events" (Bandura 2010, 860). Bandura and Locke (2003) suggest that when an individual believes in his or her ability to act, that the individual is more likely to take action. Additionally, Dougherty and Olsen (2014) refer to agency as an individual's capacity to act and self-efficacy as the individual's belief in that capacity. These authors suggest that when individuals feel empowered is when they are able to transform their choices into actions and outcomes (Dougherty and Olsen 2014). Thus, when individuals believe they 
can act or fulfill community requests (i.e., efficacy), individuals are more likely to feel integrated into their community (Estrada et al. 2017). ${ }^{70}$ Bandura suggests that there are four interconnected ways that self-efficacy impacts individuals: 1) shapes individuals interpretations of experiences; 2) encourages individuals to set high goals and be dedicated to achieving those goals; 3 ) reduces an individual's stress and helps individuals cope; and 4) influences individuals' environments and activities they wish to pursue. Hence, self-efficacy is both socially and contextually dependent (Dougherty and Olsen 2014).

Moving away from the social psychology literature's discussion on self-efficacy, the environmental psychology literature often discusses efficacy as an individual's perceived competency. Meinhold and Malkus (2005) have examined efficacy directly and in relation to knowledge. They discovered efficacy and knowledge are positively correlated, which suggests that when individuals understand the detriments that mining causes to the environment, these individuals believe they have a greater ability and capacity to act, mitigate, or adapt to the detrimental influences from mining affecting their communities. Additionally, scholars like Hines, Hungerford, and Tomera (1987) and Spence et al. (2011) have discovered that efficacy and engagement in pro-environmental behaviors are positively correlated and persist through time (Milfont 2012). Estrada et al. (2017) also note that efficacy acts as a mediator between engagement and knowledge. Dougherty and Olsen (2014) connect trust to self-efficacy in important ways by suggesting that self-efficacy and self-trust/self-confidence are partially a function of each other. Dougherty and Olsen (2014) build upon Kuttschreuter's (2006) risk management

\footnotetext{
${ }^{70}$ See also: Estrada et al. (2011).
} 
theory that connects low self-efficacy, institutional trust, and low risk perception and how institutional trust and risk perception are negatively associated (Trumbo and McComas 2003). Dougherty and Olsen (2014) also note that the opposite is true. For example, Rimal (2001) shows that there is a positive correlation between high self-efficacy and high risk perception. Dougherty and Olsen (2014) also demonstrate that some communities have low levels of collective-efficacy and low levels of relational trust, they are more likely to have higher levels of institutional trust. Thus, when self- and collective- efficacy are low, individuals utilize institutional trust to cope (Sztompka 1999). These types of communities are more vulnerable to outside interests, which likely means that when individuals living in mining communities have low levels of self- and collective-efficacy they are more likely to support mining because they have trust in their local government institutions and the mining company.

Dougherty and Olsen's (2014) study of individuals living in four Guatemala mining communities also demonstrates that individuals' sense of self-efficacy underlies their decisions about whom to trust or distrust and plays a central role in forming individual attitudes towards mining. For example, individuals in some mining communities may feel more interconnected and bonded to the community and its members. This bond and interconnectedness, according to Dougherty and Olsen (2014), leads to higher levels of self-efficacy and collective-efficacy among individuals in these communities, which likely makes them more resistant and oppositional towards mining. Further, the authors show that highly bonded communities usually mistrust authorities when their expectations are unmet. Additionally, Dougherty and Olsen (2014) demonstrate that the most well-positioned communities have both relational and 
institutional trust, and they suggest that those organizing against mining need to build self-efficacy among residents.

\section{A Strong Community World View: Resistance and Opposition to Mining}

The third micro-political component of social engagement relates to individuals' community worldview. I examine "community worldview" through the identities and values that individuals share with their communities and community members. Kelman (2006) suggests identities occur when individuals accept the influences of other individuals or a group for the purposes of establishing and/or maintaining a satisfying and self-defining relationship. Turner and Oakes (1986) believe that a person is more likely to accept influences from another person or a group when that individual shares a social identity or self-concept with the other individual or group. Essentially, identity, according to Cook, Kerr, and Moore (2002), is the way in which people socially define themselves. Although environmental psychology research exists in abundance, the definition for identity is inconsistent throughout the literature. However, for purposes here, I borrow the definition for environmental self-identity, which is defined "as the extent to which a person self-defines or labels themselves as being the type of person who engages in proenvironmental behaviors" (Estrada et al. 2017, 173; see also: Van der Werff, Steg, and Keizer 2013). ${ }^{71}$ Estrada et al. $(2017,173)$ note that environmental self-identity includes an individual's involvement in an opinion-based community instead of an organized group. In order to uphold a strong group consensus and status, individuals need to obey the norms of the group or organization as long as their group or organization's identity is

\footnotetext{
${ }^{71}$ Estrada et al. $(2017,173)$ note that "environmental self-identity differs from the study of environmental identity, which has been conceptualized as a level of connection a person has to the environment."
} 
relevant to the situation (Kelman and Hamilton 1989). Essentially, individuals that identify strongly with their community and its members are more likely to engage in proenvironmental behaviors and opposition to mining (Estrada et al. 2017).

There is an abundance of research that incorporates values as a strong predictor of engagement in pro-environmental behavior (Stern 2000; Clark, Kotchen, and Moore 2003; Steg and De Groot 2012). However, unlike the previous discussion on identity ${ }^{72}$, values can operate uniquely and independently within a person (Estrada et al. 2017). Schwartz et al. $(2001,521)$ describes values as "a guiding principle in life." Kelman $(2006,4)$ defines values as a process of internalization, which occurs when "an individual accepts influence from another in order to maintain the congruency of actions and beliefs with his or her own value system." Essentially, individuals that are integrated into their community comply with behavioral norms of the community because they encompass the individual's internalized value system, which the individual shares with the broader community (Estrada et al. 2017). As Estrada et al. (2017) indicate, given an individual's value system with the community, one should expect that the individual's values predict engagement in the behavioral norms of the community he or she is a part of.

As I previously mentioned, an abundance of research evidence exists that strongly connects values with pro-environmental behavior, there also exists research related to how values and engagement are linked. For example, Schultz and Zelezny (1998) demonstrated that values were pertinent in predicting engagement in pro-environmental behavior. De Groot and Steg (2010) offer an empirical example that shows how different value alignments linked to motivations lead to engagement in pro-environmental

\footnotetext{
${ }^{72}$ Identity delineates an association with a particular entity (Estrada et al. 2017).
} 
behaviors. Thus, when individuals know and understand more about mining and its negative externalities to the environment, individuals are more likely to reinforce their values that they share with the community and its members that are worried about mining impacts. Theoretically, they are more likely to participate in the behavioral norms that the community promotes (Estrada et al. 2017). The connections between community identity, the internalization of values within a community concerned about mining, and knowledge about mining to integration and engagement in pro-environmental behavior and opposition towards mining have yet to be studied under an extractive resources framework.

Related to community identities and values, I argue that when individuals are socially engaged in their communities they develop stronger identities that leads them to engage in pro-environmental behavior, which tends to be opposition to mining activities. Also, the internalization of values within a community concerned about mining and its impacts connects to knowledge about mining and engagement in pro-environmental behavior or opposition towards mining. Although not directly related to mining resistance, Simmons' (2016) study of Bolivia's Water Wars in Cochabamba highlight some of the key components of how community identities and values can create a community worldview that assists in creating a broad-based mobilization. Her research examines the way that things like water can create a conception of community. For example, in Cochabamba, Bolivia, water symbolized community for all community members independent of their social and economic statuses. She demonstrates how the privatization of water did not just threaten the small neighborhoods and communities in Cochabamba, but threatened the entire nation of Bolivia. For instance, Simmons (2016, 
41) describes how "water symbolized region, nation, and Andean heritage... When whatever is marketized it symbolizes imagined and/or quotidian communities that reach beyond particular occupational, sectoral, or class categories, perceived threats to community can cross cleavages and create the conditions of possibility for broad-based mobilization" (Simmons 2016, 41).

Many Cochabambans and Bolivians shared their beliefs that water symbolized something more than its "biophysical characteristics" (Simmons 2016, 43). Cochabambans believed that water connected them to their local and regional identities via the community's irrigation practices, its agricultural past, and their continued struggles with resource scarcity. Simmons $(2016,43)$ stresses how the "conceptions of indigenous heritage, national belonging, communal reciprocity, collective imaginings around region, nation, and ethnicity were critical to the Cochabamba movement, and they were available to movement organizers because of the ways in which water indexed community to Cochabambans across class, ethnic, and regional divides." Therefore, when individuals know and understand the treats to their material wellbeing and their shared community relationships, commitments, and connectedness; an increased sense of group belonging can contribute to broad based mobilization (Simmons 2016, 37). I believe, like Simmons $(2016,42)$, that individuals find belonging and security in community-level relationships that provide daily material and social needs, as well as pride in community identity and values. When a community's collective identification through its identity and values is threatened by an outside source (i.e., mining), resistance and opposition is likely more powerful (Simmons 2016). 
In this section, I provided a framework on the micro-level politics that make individual citizens more likely to oppose mining. I argued that the more socially engaged individuals are in local organizations (i.e., church organizations, environmental organizations, community organizations, and agricultural organizations), the more likely they have: 1) knowledge and access to critical organizational tools and information about mining; 2) a higher sense of self-efficacy and collective-efficacy empowering them and their communities to resist mining; 3 ) and a stronger community worldview (i.e., community identity and values) contributing to broad-based mobilization and resistance. Therefore, I theoretically expect the following:

Hypothesis 3: Socially engaged individuals are more likely to oppose extractive activities than those individuals who are less involved in social organizations.

\section{$\underline{\text { Religion as a Catalyst for Success }}$}

Following Arce's (2014b, 2015) and Arce and Hendricks; (forthcoming) typology of protests over resource extraction (i.e., demands for rights and demands for services) outlined in part one of this theoretical chapter, the authors also argue that successful campaigns against mineral extraction are more likely to encompass rights-based claims. Although individuals living in Rancho Grande and Santo Domingo mining communities are influenced by both service-based claims and rights-based claims against B2Gold, I argue that the organized and sustained challenges against extractive activities seen in Rancho Grande and Santo Domingo fit more within the theoretical framework and typology of rights-based claims because individuals' livelihoods, related to agriculture and environment, have been or continue to be vulnerable and/or threatened by B2Gold's 
mining activities. Rights-based protests are characterized by organized and sustained challenges against resource extraction as compared to service-based protests that typically follow a non-stop pattern over a short period of time, which garners small concessions until their next specific grievance. The resistance campaigns seen in Rancho Grande and Santo Domingo represent emblematic cases, generated a great deal of publicity from local and even international media outlets, and evoked calls for social justice in home and host countries. However, unlike Rancho Grande's successful overturn of B2Gold's concession, Santo Domingo's organized and sustained rights-based protests against B2Gold have not been successful in overturning B2Gold's operations within the community.

The different outcomes witnessed in Rancho Grande and Santo Domingo lead me to believe that the theoretical framework and typology of Arce (2014b, 2015) and Arce and Hendricks (forthcoming) successfully explain the motivating factors that lead individuals to organized and sustained protest movements. However, these authors also suggest that rights-based claims and protests, which both Rancho Grande and Santo Domingo exemplify, make successful campaigns against mineral extraction more likely. Since, one does not see a successful overturn of B2Gold's concessions in Santo Domingo, I argue that this theoretical framework does not offer a concrete explanation for why organized and sustained protests can successfully overturn a mining concession.

In part three of my theoretical framework, "Religion as a Catalyst for Success," I address my final research question: Does religion contribute to the success of extractive protests and/or social movements? Conde and Le Billon (2017) discuss the importance of everyday informal networks, such as church groups, NGOs, and student organizations, 
for catalyzing resistance and overcoming political marginalization. Bebbington (2007) coins these groups or informal networks as social movement organizations. Holden and Jacobson (2009) and Bebbington et al. (2008) have demonstrated how the church, as a social movement organization, has been an important ally for social movements and resistance throughout Latin America. Thus, I emphasize the role of religion as a catalyst for sustained challenges and successful resistance against resource extraction. I argue that communities with more church involvement and stronger religious influence, in this case involvement tied to Catholicism and Evangelicalism, are better suited to sustain their opposition against resource extraction and successfully end mining exploration or exploitation projects affecting their communities. I utilize and build off of literature related to religion and social movements, religion and ecology, and religion and extractivism to demonstrate, theoretically, how and why religion plays a pertinent and decisive role in successful protest movements against mining.

\section{Religion's Role in and Connection to Social Movements}

Before discussing religion's role(s) in social movement activities, I think it is important to provide a strong definition of what religion is, since itself is a contested term (Kirmani 2008). Beckford $(2001,244)$ defines religion as "broadly encompassing... constellations of immensely variable beliefs and practices by means of which human beings attribute the highest significance to all manner of objects, events, ideas, values, sentiments, and ways of living. The boundaries of the religious are constantly being negotiated, contested, and renegotiated." Beckford (1990) was one of the first scholars and theorists to study the links between religion and social movement theories. Beckford (1990) links the "new 
spirituality" present in new social movement ideologies that are otherwise secular. Beckford argues that this "new spirituality...favors synoptic, holistic and global perspectives on issues transcending the privatized self and the individual state" $(1990,9)$. Beckford (2001,235) further argues that there is an abundance of similarities among the operation of institutionalized religious groups and social movements related to the promotion of values, collective identity, and communal solidarity. Additionally, and as Kirmani $(2008,27)$ nicely puts it, religious groups and their ideologies have an important role in social movements by assisting communities to mobilize around their shared identities and values in order to emphasize a feeling of collective solidarity.

Additionally, Beckford (2000) links the processes of globalization with the growth of new religious movements (NRMs) around the world. Beckford argues that the strengthening of global forces has contributed and benefited to NRMs. He shows how NRMs transverse nation-state boundaries in their activities and their identification through operating at global levels and promoting a universal vision. Beckford acknowledges that NRMs rarely affect the exercise of power at the global level, but he believes that they do affect wider and largely secular social movements that seek to promote peace, environmental sustainability, or human rights (Beckford 2000, 177). Therefore, as Kirmani $(2008,28)$ suggests, there exists a strong connection between the processes of globalization and the development of NRMs.

Kirmani $(2008,28)$ suggests that there exists an abundance of literature that examines various types of religious mobilizations. She discusses that much of this work examines how both formal religious institutions and informal religious groups, acting outside traditional institutional channels, are affiliated in some way with social 
movements and mobilizations. For instance, Haynes (1995) uses institutional and noninstitutional forms of current religious mobilizations to identify four broad categories of religious movements: culturalist, syncretistic, fundamentalist, and community-oriented. Haynes (1995) classifies these four categories on whether or not they serve as a mechanism for opposition or as a mechanism for community development. There are two points of commonality between Haynes's four categories. For example, in all four categories, social movement leaders and religious leaders utilize religious ideologies, teachings, and beliefs to promote a message of home and a program of action to individuals. These messages make a political impact and tend to be oppositional in character (Kirmani 2008).

Haynes (1995) suggests that culturalist movements erupt when groups of people that share religious and ethnic backgrounds feel vulnerable, threatened, and/or repressed by outsiders. In relation, to extractive protest movements in Latin America, and particularly Nicaragua, the majority of the citizens in extractive sites share the same ethnic and religious backgrounds and are threatened and vulnerable to mining activities brought on by community outsiders like mining companies and national government officials and organizations. Haynes describes syncretistic movements as movements that combine aspects of different religious practices in order to forge a collective identity and to create group cohesion and solidarity in the face of threats from outside sources. In relation to mining conflicts in Latin America, again particularly in Nicaragua, and more specifically in Rancho Grande, both Catholics and Evangelicals worked together against B2Gold to forge a collective identity and build group solidarity and cohesion to ward off the threats from B2Gold's mining activities and influence. Although not directly tied to 
the social movements I witnessed against mining in Nicaragua, Haynes's fundamentalist movements seek to change society along the tenets of the Abrahamic religions (Judaism, Christianity, and Islam). ${ }^{73}$

Community-oriented religious movements use fundamentals of religious faith to improve the well-being of a community, often in the face of government repression (Haynes 1990). Again, this fourth category of religious movements can be applied to extractive protest movements because the majority of the time, when religion is involved in these movements; religious leaders, churches, and religious organizations utilize spiritual social teachings to improve the well-being of a community that is often repressed ${ }^{74}$ by local and national government forces for speaking out and protesting against mining. Although, Haynes (1990) distinguishes these four types of religious social movements, he does not believe that they are mutually exclusive because they often overlap and display different characteristics at different points in time. One can even see the shared characteristics in the brief connections I made between these movement types and extractive protest movements. As Kirmani (2008) puts it nicely, Haynes's four categories offer a valuable path for understanding the importance of religion, religious ideologies, and religious groups and organizations in mobilizing political and social movements across the globe.

Kirmani (2008) additionally discusses how there is literature, although rare, on the connections between institutions and religion, religious ideologies, and religious groups and organization and broader movements of social change. This literature

\footnotetext{
${ }^{73}$ Haynes (1990) does acknowledge that fundamentalist movements can follow tenets of Buddhism and Hinduism as well.

${ }^{74}$ Government repression against mining opposition in Latin America has become a widely used tactic against social movement activists and protesters speaking out against mining.
} 
highlights the crucial role of religious groups and institutions on democratization, suggesting that religion offered the spaces for the creation and growth of an active civil society. For example, Casanova (2001) examines the importance of religious institutions taking on state power in the Solidarity Movement in Poland, as well as countries like Brazil, Spain, South Korea, South Africa, and the Philippines. Casanova's study shows how the Catholic Church acted in the forefront on the movement towards democratization in the countries mentioned. During these movements, the physical dwellings of churches acted as autonomous public spaces where activists could effectively organize and mobilize support to strengthen and sustain the resistance to keep the movement progressing. As one will see in a few pages, an example from two mining communities threatened by mining in Veracruz, Mexico used the church in their town as a public meeting place to gather, organize, and mobilize against mining in their community.

One cannot discuss religion and social movements without at least briefly mentioning liberation theology. Liberation theology is '[p]erhaps one of the most prominent example[s] of the use of religion as a driver for... social change [that was] ... seen in the various movements...that emerged across Latin America in the latter half of the [T]wentieth [C]entury" (Kirmani 2008, 31). Through the utilization of Christian social teachings as a tool for inspiring movements, liberation theology sparked mobilizations for democracy, human rights, and social justice. Liberation theology's popularity sparked in Latin America in the second half of the Twentieth Century due to its majority Catholic and impoverished population. Liberation theology is often characterized to have a radical take on Christianity and its mission to help impoverished populations from oppressive and exploitive economic and political forces as we see with 
the contemporary practices of extractive mining companies and governments in many communities in Latin America and throughout the world (Kirmani 2008, 31). Many communities, especially Indigenous communities, utilize liberation theology and Christian social teachings as an inspiration and a source of collective identity in the face of oppression. Essentially, liberation theology shifted the focus of the Catholic Church away from eternal salvation to the more pressing need of the impoverished, suffering, and oppressed: earthly liberation (Singer 2013). ${ }^{75}$

Finally, related to religion's role in social movements and social movement activities, scholars have suggested that religion, religious ideologies, and religious groups and organizations provide the resources for mobilization (Kirmani 2008). For example, Beckford $(2001,238)$ focuses on the contribution of religious social networks providing the resources needed for success in both historical and contemporary social movements. Beckford (2001) examines movements like the antislavery movement, the Civil Rights movement, and the temperance and peace movements in his study to show how existing religious social networks aided in connecting members of religious groups, which ultimately assisted in the successes of these movements. The observations made by Beckford (2001) builds off of resource mobilization theory because it highlights the importance of preexisting social networks providing the resources and structure for the emergence of a social movement.

\footnotetext{
${ }^{75}$ Research on Latin American social movements that were inspired by liberation theology and Christian social teachings focused on historical, social, political, and religious dimensions of these movements and analyzed their "emergence in relation to historical colonial legacies as well as the contemporary forces of globalization and neo-liberalism" (Kirmani 2008, 31; see also: Clearly and Steigenga 2004; Levine 1988; Dodson 1979; Yoder 1990). It is beyond the scope and capacity of this dissertation to provide any further depth and detail about these movements. However, "it is worth noting their significance as examples of ways in which religious teachings have been used as a source of inspiration in mobilizations for social change" (Kirmani 2008, 31).
} 
Additionally, Smith $(1996,13)$ demonstrates how religious groups contribute to social movements by offering trained leaders and leadership that are capable of motivating and attracting movement participants. For example, religion plays "a legitimating role in social movements, providing a moral justification for activism and sustaining movements by referring to a higher truth in the face of challenges from outside forces" (Kirmani 2008, 32). Lastly, Tarrow's (1998) influential study discusses the importance of the emotional resources that religion provides in mobilizing resistance, protests, and social movements related to providing sources of "ready-made symbols, rituals, and solidarities that can be accessed and appropriated by movement leaders" $(1998,112)$. Therefore, religion is a powerful source that can inspire and motivate individuals to participate in social movements and social movement activities, as well as provide the spaces, organization, and resources for social movements (Kirmani 2008), especially social movements and protest movements related to mining and the extractive industry.

\section{Religion's Call for Environmental Activism}

Although still heavily connected to religion's role in social movements, this section shifts gears to religion's call for environmental activism and how church leaders, groups, organizations, etc. have begun to call for environmental protection from greed and exploitative activities that often affect the world's impoverished; often times through social movements and protest movements against governments and extractive companies. Concern about the moral and ethical meaning of environmental destruction has long roots in various religious traditions, Catholicism among them (Jenkins 2008), especially with 
the Catholic Church's last two Pontiffs and its current one. In recent years with these three Popes, the Catholic Church and other religions have taken strides towards environmental activism and protecting "Mother Earth" because they understand the importance of the negative implications that environmental destruction has on earth, but also vulnerable and impoverished populations around the world. In the 1980s, Pope John Paul II encouraged Catholics all over the world to consider environmental problems a necessity. Church leaders in North America followed the Pope's directive. For example, in 1991, the United States Conference of Catholic Bishops "released the pastoral letter, Renewing the Earth, naming the environmental crisis as a significant "moral challenge" (Witt 2017, 29-30). Additionally, Spalding $(2011,20)$ discusses how Pope Benedict XVI, often times called the "Green Pope" among some media outlets, promoted the protection of nature and ecological health as a central tenant in several of his pronouncements. He specifically focused on this theme when speaking with young people (Koenig-Bricker 2009; Benedict XVI 2010) to try and encourage attention to the disconnect between environmental sustainability and globalization and global economic processes within the Catholic Church's networks (Spalding 2011).

In the mid-2000s, the environmental activism of the Catholic Church really took root in Latin America. At the fifth Consejo Episcopal Latinoamericano (CELAM) or the Council of Latin American Bishops conference, 160 Latin American bishops met in Aparecida, Brazil (CELAM 2007). Spalding $(2011,20)$ quotes the declaration that the "Care for the Environment" section at the CELAM conference put forward ${ }^{76}$ :

Today the natural wealth of Latin America and the Caribbean is being subjected to an irrational exploitation that is leaving ruin and

\footnotetext{
${ }^{76}$ See also: CELAM (2007).
} 
even death in its wake, throughout our region. A great deal [of] responsibility in this entire process must be attributed to the current economic model which prizes unfettered pursuit of riches over the life of individual persons and peoples and rational respect for nature. A similar warning must be made about resource-extraction industries which, when they fail to control and offset their harmful effects on the surrounding environment, destroy forests and contaminate water, and turn the areas exploited into vast deserts.

It is clear from this statement, that these bishops understood that the current economic model practiced around the world created greed and exploitation of vulnerable societies and their environments. It is interesting that the statement directly calls out the resourceextractive industry as one of the main sectors in the current economic model that creates harmful effects for the environment and for citizens living within these environments. It seems apparent, based on this declaration, that these bishops understood that they needed to become more active agents (perhaps in assisting in protests and social movements against mining) in helping communities in Latin America protect their environments and livelihoods that have been negatively influenced by mining, mining activities, and extractive companies.

Witt $(2017,30)$ discusses how the relationship between Catholic social teachings and environmental issues became even more clear and apparent in 2015 with Pope Francis' encyclical publication titled, Laudato Si': On Care for our Common Home. Pope Francis declared that "This sister [the earth] now cries out to us because of the harm we have inflicted on her by our irresponsible use and abuse of the good with which God has endowed her" (Francis I 2015, 1). In the same declaration, Pope Francis blamed human greed, hubris, and exploitative economic systems and technologies as the causes of current environmental injustices. He also discussed how the environmental degradation caused by exploitative economic practices tend to harm vulnerable and impoverished 
populations around the world, arguing that responses to environmental injustices "must integrate questions of justice in debates on the environment, so as to hear both the cry of the earth and the cry of the poor" (Francis 12015,23$)$.

Witt $(2017,30)$ suggests that Pope Francis', the leader of the world's largest church, publication offered an authoritative push for the world's Catholics by highlighting current environmental issues within purview of Catholic social teaching. Thus, Catholics around the world, especially in Latin America where mining and extractive industries are exploiting the environment and vulnerable and impoverished populations have become emboldened and empowered by Pope Francis' message "to engage in religious anti-extraction environmentalism" (Witt 2017, 30). For example, a Catholic nun named Ann Scholz ${ }^{77}$ described the motivating values of the Sisters of Loretto by stating that "No Christian can live the gospel fully unless they attend the needs of their brothers and sisters, including Mother Earth" (Witt 2017, 27; see also: Diener 2016).

It seems like this growing call for environmental activism and protecting the world's vulnerable and impoverished have led many Catholic leaders, churches, and organizations to have a more pivotal role in creating resistance and social movements. For example, Spalding (2011) discusses how the Catholic Church and its officials have actively challenged the exclusionary consequences of inadequately regulated market systems (i.e., the extractive industry) throughout Latin America. Furthermore, the Catholic Church is a domestically rooted transnational actor that uses its position to translate and spread global messages, like environmental activism, to local communities

${ }^{77}$ Ann Scholz is the associate director at the Leadership Conference of Women Religious. 
and to connect these communities across divisions of gender, ethnicity, race, and class. Additionally, Witt (2016) discovers an assortment of religious views that intertwined with activists' feeling of place and connection with nature at the height of an antiextraction movement against surface mining between 2005 and 2015. These activists' decisions to organize and resist mining were informed and inspired by Catholic, Protestant, and Evangelical teachings and traditions. During their social movement, these activists utilized religious frameworks to create organizational strategies and provide responses to regional residents in support of mining (Turman 2018; Witt 2016). In this capacity, religion has become a powerful actor and contributor to anti-extraction protest movements against mining (Spalding 2011).

Until the last paragraph, I have predominately focused on the Catholic Church and its social teachings related to environmental activism and calls for environmental justice and protecting the vulnerable and impoverished populations. Focusing on Catholicism seems relevant for this dissertation because the majority of religious influence stems from the Catholic Church, its ideology, its leaders, and its religious organizations. However, a growing number of the Latin American population are becoming Evangelical Protestants. ${ }^{78}$ Thus, it is important to examine the role that Evangelical Protestantism has on communities negatively impacted by the environmental destruction and degradation caused by extractive activities like mining. Gooren (2002, 40) in his study on why Guatemalans chose to join Evangelical Protestant churches instead of continuing to be Catholics, notes that "the preference of many among the poor

\footnotetext{
${ }^{78}$ The Pew Research Center (2014) identified that $84 \%$ of Latin Americans were raised Catholic and 69\% were currently Catholic, while 9\% of Latin Americans were raised Evangelical Protestant and 19\% were currently Evangelical Protestant.
} 
for membership in non-Catholic churches was part of both a spiritual quest for a new morality and of a strategy for self-improvement. The self-improvement not only had a clear moral element, but also many practical ones." Gooren (2002) discusses how membership into Evangelical churches gave many of the impoverished immediate advantages, which was ever more popular in a situation where unfettered capitalism (i.e., small scale free enterprise) was the inescapable way of things and for many Guatemalans the only path out of poverty. Understanding the capitalism was the new way of things and their likelihood of escaping poverty was unlikely, Guatemalans created their own form of liberation theology. This transition to Evangelical churches and creating selfimprovement through their own liberation theology helped many people deal with poverty, exploitation, and environmental problems caused by mining and capitalist mining companies.

\section{Religion's Role in Extractive Protests in Latin America}

I have already stressed the important role religion has played in extractive protests in Nicaragua, especially in Rancho Grande throughout this dissertation and will do so more in Chapters 5 and $6 .^{79}$ In the context of mining and extraction, others have studied religion's role in extractive protests, especially in Latin America (i.e., Arellano-Yanguas 2014; Spalding 2011; Dougherty 2018). In the next few paragraphs, I discuss these studies in more detail and how these studies contribute to my overall theoretical framework: religion serves as a catalyzing factor in successfully organizing extractive

\footnotetext{
${ }^{79}$ I explore the role that religion played in Chapter 5 when exploring Rancho Grande's successful protest movement in overturning B2Gold's mining concession. I also explore the absence of religion in Chapter 6 when exploring why Santo Domingo did not share the same success as Rancho Grande in overturning B2Gold's mining concession affecting the community.
} 
communities in protest movements against mining and successfully overturning mining concessions. Overall, these studies on religion's role in extractive protests relate to the church's spiritual teachings and their call to protect "Mother Earth" and environmental activism because the church understands the detrimental impacts that mining causes to the environment, the Earth, and the livelihoods of local communities for the sake of greed.

In Arellano-Yanguas' $(2014,61)$ study of extractive communities in Peru, he theorizes that the "importance conventionally given to the role of particular religious figures, their adherence to progressive ideologies, and the defense of the Church's strategic interests do not fully encompass the complexity of local processes." In fact, he analyzes the Church's involvement in three extractive conflicts in Peru and he demonstrates the internal components and contextual factors that distinctively interact. Through this purely qualitative study, Arellano-Yanguas (2014) demonstrates how the institutional embeddedness of the Catholic Church in local networks, groups, and organizations was the most influential factor for the Catholic Church's involvement in the anti-mining resistance movements in these Peruvian communities. He suggests that this embeddedness overlaps with the spirituality that prioritizes the agency of local community members, whereby the Catholic Church and its local priests followed and accompanied the goals, objectives, and initiatives of local community leaders instead of taking a lead role. To be clear, this does not mean the church assumed a submissive role in these conflicts.

Arellano-Yanguas (2014) believes that one can better understand church involvement through the four different ways the church embeds itself in local 
communities. First, he emphasizes the participatory role or religious teachers in local organizations. Second, he highlights a "spirituality of accompaniment" approach that stresses the importance of a local population's opinions. Third, he discusses the responsibility of "social interpreters," whose main responsibility is to support local church officials in understanding local level situations. And finally, he stresses the importance of how pastoral agents can involve environmental and human rights dialogues into a religious context. Arellano-Yanguas (2014) believes, and I agree, that these four embeddedness factors provide an alternative bottom-up approach to understand religion's role in extractive protest activity and how they assist local communities in organizing against mining and provide the resources necessary to help these communities successfully overturn mining concessions and halt the environmental destruction that mining causes.

Spalding (2011) in her study on extractive protest movements in El Salvador, also briefly discusses how anti-mining forces in Honduras received strong support from the Catholic Church and its leaders. Cardinal Oscar Andrés Rodríguez, in response to continuous community complaints about the contamination of local water sources due to mining activities, led a protest march against mining in March 2002. Additionally, a cyanide spill at the San Andrés mine killed fish in the Lara River and contaminated the water, which led to more marches and demonstrations that were coordinated by church officials in coordination with local government officials and community activists. This coordinated effort between local communities, local organizations, local governments, and church officials led to conflict escalation, which led the Honduran national government to suspend new mining permits in July 2004. (Spalding 2011). 
In the same study, Spalding (2011) discusses how El Salvador's anti-mining coalition was strongly supported by the "upper echelons" of the Catholic Church's leadership. This coalition and the Catholic Church both opposed metal mining, and their coordinated efforts in opposition to mining allowed them to expand the anti-mining movement to recruit more participants. ${ }^{80}$ For example, the Catholic Church's official international relief, development, and social service agency, Cáritas, promoted advocacy on a number of environmental issues, including mining with many of Cáritas' leaders becoming active participants in El Salvador's anti-mining coalition. The leaders of Cáritas also brought Salvadoran bishops into the mining conversation by providing them with peer consultation about the dangers of mining for Salvadoran communities (Spalding 2011). Cáritas' leaders brought in Catholic bishops from Honduras and Guatemala, two neighboring countries with church leadership paving the way for antimining coalitions. The bishops eventually acknowledged that the type of metal mining in El Salvador creates irreversible damage to the environment and affected communities, which lead to health problems, water and soil contamination, and harmful effects to all types of agricultural production. The bishops concluded that metal mining needed to be stopped throughout El Salvador. This call to activism by "Salvadoran bishops for greater environmental protection, in keeping with pronouncements from other church authorities in Central America and beyond, presented the mining industry with a serious challenge" (Spalding 2011, 21).

\footnotetext{
${ }^{80}$ Spalding $(2011,21)$ discusses how "the Catholic Church's reach in El Salvador had tended to decline over time, as elsewhere in Latin America, Catholicism remained the dominant religion in the country." Additionally, "the Catholic Church consistently received the highest institutional trust scores, with $41 \%$ of Salvadoran respondents indicating "much' confidence in this institution in 2008...a figure that rose to $47 \%$ in the 2009 survey" (Spalding 2011, 21).
} 
This serious challenge for the mining industry continues in Mexico, as well. The communities of Actopan and Alto Lucero in the eastern State of Veracruz, Mexico are the proposed destination for Candelaria Mining's Caballo Blanco gold mine: La Paila. The company plans to have an open-pit mining operation that can produce approximately 100,000 ounces of gold a year (Ruiz Leotaud 2018). ${ }^{81}$ In May 2018, environmentalist organizations, religious organizations, and Indigenous groups protested together against the development of La Paila mine. The groups involved issued a press release, organized a conference at one of the Catholic Churches in the community, and marched in solidarity towards City Hall. Together they marched with signs that read "Open-pit mines in Actopan and Alto Lucero use poisonous cyanide" and "We are against the privatization of our water" (Ruiz Leotaud 2018).

The Veracruzan Assembly of Environmental Initiatives and Defense released a statement during the protests that read "We demand that they respect our human rights and put a halt, cancel or stop issuing mining permits in the region. These mining concessions affect residents' individual and collective rights” (Ruiz Leotaud 2018). Those opposing mining activities, including the religious organizations, are concerned with the environmental impacts that the mine will cause to their livelihoods and way of life. The mining project is currently in limbo with the Canadian company waiting for the Mexican Environmental Authority to conduct an updated review and assessment of the environmental impact (Ruiz Leotaud 2018). What is clear from these two Mexican communities is that individuals in these communities are concerned over the environmental degradation that this mining project will cause. Additionally, their

\footnotetext{
${ }^{81}$ This is not an academic study, but it still points out the role religion played in this extractive protest movement.
} 
organization, resistance, and protests against the mine were in conjunction with the church and religious organizations, which again shows the relevance of religion's role in extractive protest movements.

Finally, Dougherty (2018) in his individual-level survey study of four Guatemalan communities, demonstrates that individuals who associate development and religion are more likely to oppose mining because they have a tendency to invoke the notion of "life" with absence of mining, and the notion of "death" with the development of mining. Dougherty (2018) suggests that individuals shared this association because of the Catholic Church's moral vision and social teachings. In his study, he quotes a religious leader from one of the communities he studied. The religious leader states, "I believe that, as agents of the Church, we must accompany the people in their resistance to these [mining] projects, which, instead of bringing development, just bring death" (as quoted in Dougherty 2018, 15). Additionally, a lay representative for the Catholic Church in Guatemala also suggested, "We must pray that mining doesn't start. People say that mining is practical. Everything is becoming more practical, but life is less and less. I have a nice house and everything, but if I die faster, we have less life" (as quoted in Dougherty 2018, 15). Thus, we learn from Dougherty's study that individuals who are religious tend to oppose mining because it threatens their existence.

Although studies are rare on religion's role in extractive protests, it appears that a trend is growing, not just in the literature, but in application of the church, church leadership, and religious organizations assisting communities with anti-mining movements across Latin America based on environmental activism and protection against 
the harms mining causes. Just briefly, I have discussed religion's role in anti-mining movements in Peru, El Salvador, Honduras, Guatemala, and Mexico. In the next two chapters, I switch the focus to discuss the role religion played in Rancho Grande and Santo Domingo, Nicaragua. I wish to highlight religion's role (and its absence) in assisting communities in (un)successfully resisting mining and mining activities on the basis of environmental destruction. Therefore, based on the third theoretical component of this chapter, I theoretically expect the following:

Hypothesis 4: Strong involvement between religion (i.e., churches, church leaders, and religious organizations) and communities in extractive areas are more likely to have successful extractive protest movements than those communities with less involvement between religion and the community.

Based on this third theoretical component, I have shown that religion is a key component in the creation and mobilization of social movements and protests, including extractive protests against mining. However, it is still worth noting that religion's involvement in social movements is often only one of the influential factors that interact with a host of factors to create and propel groups towards mobilizing. Hence, as Kirmani (2008, 32) suggests "it is crucial that any analysis of the role of religion in social movements must take into account the interaction of various social and contextual factors alongside

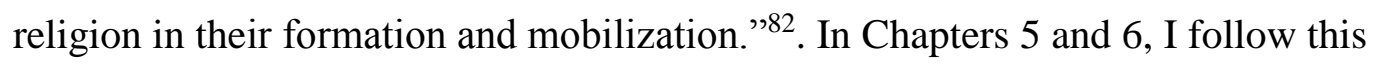
directive, but I also highlight how two very similar communities have protested against the mining activities and influences of Canadian mining company B2Gold with very different outcomes (i.e., a successful overturn of a mining concession vs. an unsuccessful

\footnotetext{
${ }^{82}$ Kirmani $(2008,32-33)$ also notes that "[w]hile the religious factor may be important in improving understanding of many contemporary social movements, analyses of religion should avoid an essentialist approach and should instead aim to contextualize religion as one amongst many potential mobilizing forces that determine the emergence, operation and impact of social movements."
} 
overturn of a mining concession). I also highlight how religion was actively involved in Rancho Grande, Nicaragua where the community, local organizations, religious organizations, the church, and church leadership worked in conjunction with each other to stage a successful resistance against mining in their community on the basis of protecting their environment, their water, their agriculture, their livestock, and their livelihoods. Similar claims of environmental destruction have been made in Santo Domingo's social movement against mining, but a successful overturn of B2Gold's mining concession has not been achieved. I argue this is because of the lack of religious involvement in Santo Domingo's social movement to end mining in its community.

\section{$\underline{\text { Conclusion }}$}

My theoretical framework permits me to systematically study the attitudes, beliefs, and characteristics of individuals in highly visible extractive protest cases by directly asking them what makes them oppose or support resource extraction, as well as understand the micro-level politics (i.e., social engagement in local organizations) that shape individual attitudes towards extraction. This theoretical framework, especially part three, also permits me to understand what attitudes, beliefs, and characteristics individuals have in highly visible protest cases for successfully overturning mining concessions through sustained protests and social movement resistance. Thus, I seek to understand how individuals' attitudes, beliefs, and characteristics are shaped by the environments succumbed to the extractive frontier. This project is unique because it helps us understand why some citizens mobilize and some do not at the individual level, and what makes these mobilizations successful. 
In both Chapters 5 (Rancho Grande) and 6 (Santo Domingo), I use a mixedmethod approach that utilizes qualitative and quantitative data from field research in Nicaragua. I utilize qualitative data from my own field work interviews in Rancho Grande, Santo Domingo, and in Managua with researchers and academics from universities and research centers, members of environmental organizations, agricultural organizations, religious organizations, social movement organizations, and community organizations. I also utilize quantitative data from public opinion surveys that I designed to measure individuals' perceptions of mining in these two municipalities. I surveyed approximately 400 citizens in Rancho Grande and 400 citizens in Santo Domingo.

Moving beyond the study of social movements through public opinion surveys, I expect to advance a broader understanding in regard to a range of political science theories, as well as other social science theories. Given that extractive conflicts have occurred predominately in Latin America in recent years (Özkaynak, Rodríguez-Labajos, and Aydin 2015), addressing these issues in a Latin American context should enable scholars to inform policies aimed at conflict prevention and resolution. Scholarly work on the attitudes of people who oppose or support mineral extraction is relatively uncommon. Thus, study offers robust individual-level data that will permit me to understand what prompts citizens to participate in protests by understanding whether they either oppose or support extraction. By conducting surveys with clustering respondents around the extractive protest sites of Rancho Grande and Santo Domingo, I will test both rightsbased claims and service-based claims to better understand what causes some citizens to oppose or support resource extraction. I will also test the social engagement component to incorporate how citizens living in the extractive frontier form or solidify their attitudes 
that lead them to environmentally oppose resource extraction. I also test if individuals believe that religion acts as a catalyst for success against resource extraction by ending mining exploration or exploitation projects in affected communities. 


\section{CHAPTER 5}

"Rancho Grande's Anti-Mining Resistance Movement Against B2Gold" 
My theoretical framework discussed in Chapter 4 permits me to systematically study the attitudes, beliefs, and characteristics of individuals in highly visible extractive protest cases, like Rancho Grande, by directly asking them what makes them oppose or support resource extraction, as well as understand the micro-level politics that shape individual attitudes towards extraction. The third part of my theoretical framework also permits me to understand what attitudes, beliefs, and characteristics individuals have in highly visible protest cases for successfully overturning mining concessions through sustained protests and social movement resistance. By understanding individual attitudes, beliefs, and characteristics towards mining, scholars of extractive protests and social movements will be able to better understand the individual mechanisms that lead citizens in the extractive frontier to either partake in mining resistance or abstain, as well as what individuals believe makes their protests and social movements more successful. For example, by understanding the reasons individuals in Rancho Grande, a community that strongly resisted mining, oppose or support mining, I can better understand the reasons why citizens in Rancho Grande believe they successfully influenced policy changes at the national level.

In this chapter, I utilize qualitative empirical evidence from the mining community of Rancho Grande from my own field work interviews from January 2017. I utilize interviews I conducted in Rancho Grande and Managua with protest actors, social movement members, church leaders and members, community members, researchers and academics from universities and research centers, and environmental organization leaders. I also use existing academic literature and news articles related to protest activity in Rancho Grande. Additionally, I use survey research to ask citizens in Rancho Grande 
their views and perceptions to generalize from empirical data, rather than make inferred assumptions about individuals from aggregate community-level data in order to understand how the attitudes, beliefs, and characteristics of individuals living in Rancho Grande are shaped by the environments succumbed to the extractive frontier. I surveyed approximately 400 citizens in Rancho Grande in April 2018. My survey data offers robust individual-level data that permits me to understand what prompts citizens to participate in protests by understanding what factors lead them to oppose or support mining, as well as what these individuals believe makes their protests successful. I test my theoretical framework and confirm my theoretical and empirical expectations using my survey data.

\section{$\underline{\text { Rancho Grande's Resistance to B2Gold's Mining Concession }}$}

In the municipality of Rancho Grande, Matagalpa, Nicaragua, resides a working population that is proud of its land and aware of the need to protect it for its own sustainable future (Centro Humboldt 2015b). Rancho Grande has an estimated population of 49,730 inhabitants, $90 \%$ of which are located in rural areas (INIDE 2005). This community has always subsisted economically and socially on the production and commercialization of agriculture — mainly coffee and cocoa, as well as other fruits and vegetables native to Nicaragua. In the production of coffee and cocoa, agroforestry systems have been established as a means to guarantee environmental protection, diversification of crops, and therefore greater profitability for producing families. The climate and soil conditions found in Rancho Grande, as well as the sustainable practices applied by its agricultural producers have generated positive conditions (Centro 
Humboldt 2015b). The crop production just from Rancho Grande alone fills the entire market in Matagalpa's departmental capital on a daily basis. It also fills a large portion of Managua's markets, and some of it is even sent north to Honduras, El Salvador, and Guatemala. $^{83}$

Despite agricultural production being the most significant economic driver for Rancho Grande, livestock production is the second most important economic commodity for the community. In Rancho Grande, many inhabitants rely on livestock production, which requires a healthy and vital landscape for the animals. In fact, the Nicaraguan Program for Rural Business Management and Animal Health (PROGRESA) recently managed to serve some 21 communities with 2,781 heads of livestock (943 cows, 730 heifers, 727 calves, and 381 steers), obtaining 6,000 liters of milk production per day (Centro Humboldt 2015b).

Ecotourism is the third economic driver for Rancho Grande. Rancho Grande is home to Macizo de Penas Blancas Nature Reserve, named for its rocky outcrops, and is considered one of the six protected areas that are part of the Bosawás Biosphere Reserve. Bosawás was declared a Biosphere Reserve by United Nations Educational, Scientific, and Cultural Organization (UNESCO) in 1997 and is known internationally as the "Heart of the Biological Corridor", the largest forestry reserve in Nicaragua and Central America (Centro Humboldt 2015b). There are several natural reserves in Rancho Grande that protect some of Nicaragua's most prized flaura and fauna, which could be used for tourism purposes. The area is ripe for tourism, but the country has not developed it yet. ${ }^{84}$

\footnotetext{
${ }^{83}$ Author's personal interview with a leader of Guardines de Yaoska social movement group: January 2017.
} ${ }^{84}$ Author's personal interview with a leader of Guardines de Yaoska social movement group: January 2017. 
In Rancho Grande, the Yaoska River is the main river that sustains the way of life. The other main rivers according to their importance for the life of the population and the biodiversity of the area are Manceras, Kiwaska, and Babaska, which travel throughout the length and breadth of the municipality (Centro Humboldt 2015b). In April 2014, Centro Humboldt, a Nicaraguan national environmental NGO stationed in Managua, measured the water flows of these main rivers, which found a great potential of water for Rancho Grande's inhabitants, agricultural production, and environmental sustainability. In October 2014, Centro Humboldt conducted a study to confirm that the waters of the main rivers of Rancho Grande were suitable for human consumption and were free from dangerous levels of harmful metals and pesticides. This made their protection a significant priority by the population, local authorities, and national authorities in order to avoid them becoming one more negative statistic of the rivers contaminated and extinguished by mining in Nicaragua, as was the case of the Mico River, in the Department of Chontales (Centro Humboldt 2015b). Figure 5.1 displays Rancho Grande's location in relation to the northern Department of Matagalpa and Nicaragua as a whole. 


\section{Figure 5.1: Rancho Grande's Location}

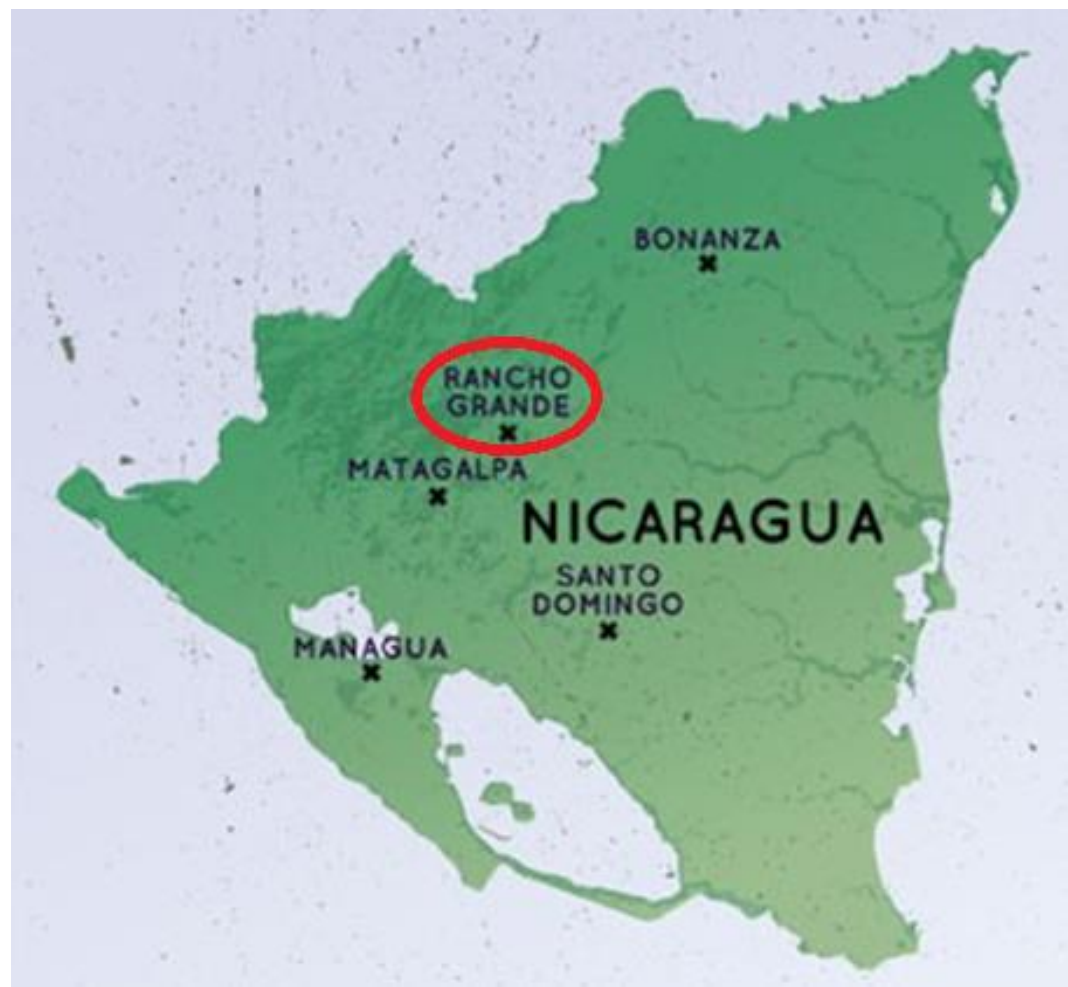

Source: Centro Humboldt (2015b).

Despite all the potential that Rancho Grande has to offer; its environment, its agricultural production, its livestock, its water sources, and its inhabitants' livelihoods have all been threatened for over a decade by B2Gold's exploration activity. B2Gold, headquartered in Vancouver, Canada, was founded in 2007 and is considered one of the fastest growing intermediate gold producers in the world. In fact, it was recently named "The World's New Senior Gold Producer.” The company has five operating gold mines and various exploration and development projects in Nicaragua, the Philippines, Namibia, Mali, Burkina Faso, Colombia, and Finland. B2Gold has a strong presence in Nicaraguan gold production. B2Gold strategically focuses on acquiring interests in mineral properties that have shown potential for gold deposits, as well as properties that are ripe for exploration and development for the construction of future gold mines (B2Gold 2018). B2Gold 
currently has production, exploitation, and exploration projects in La Libertad and Santo Domingo, Chontales and El Limon, Leon, while it only had an exploration projects in Rancho Grande, Matagalpa.

B2Gold's influence in Rancho Grande occurred through a series of steps. In 2003, Nicaragua's National Government through the Ministry of Forment, Industry, and Commerce (MIFIC) ${ }^{85}$ granted a concession in Rancho Grande to the Canadian mining company MINESA for 49,000 hectares. In 2007, after an initial phase of exploration, the concession was reduced to an area of 1,301.1 hectares after MINESA sold its concession rights to another Canadian mining company-Minerals Nueva Esperanza S.A., a subsidiary of B2Gold (Ministerio de Energías y Minas 2014). Since 2007, Minerals Nueva Esperanza S.A. has received other concessions in Rancho Grande from Nicaragua's Ministry of Energy and Mines (MEM). Below in Figure 5.2 is a map of B2Gold's exploration concessions in Rancho Grande.

${ }^{85}$ A regulatory body prior to the Ministry of Energy and Mines (MEM), which was created in 2007. 


\section{Figure 5.2: B2Gold's Exploration Concession in Rancho Grande}

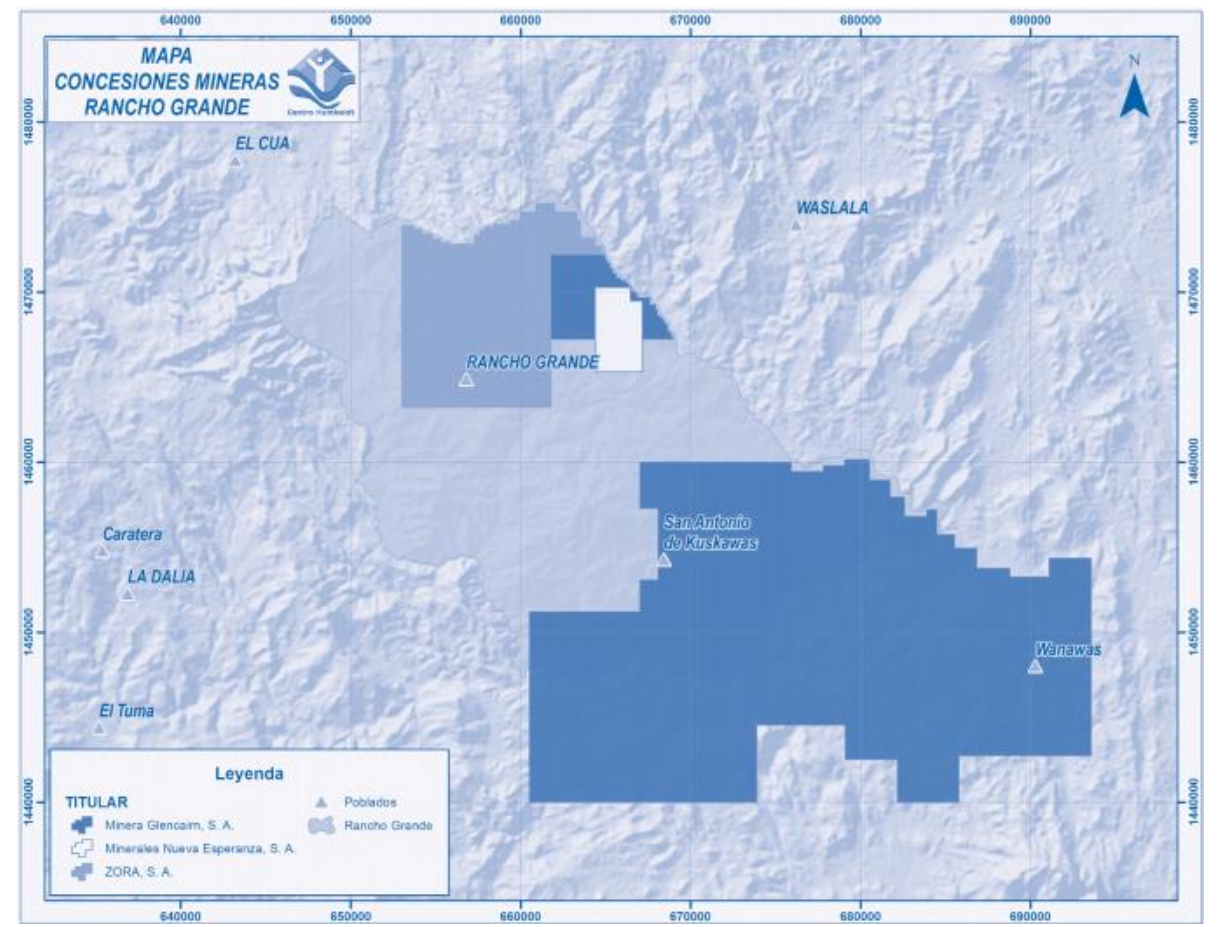

Source: Centro Humboldt (2015b).

In Chapter 2, I discussed Nicaragua's history with mining and how it has grown to become the top producer of gold in Central America, surpassing Guatemala in 2012. Spalding (2016) notes that as international gold prices rose and Nicaragua became an investment friendly country for extractive companies, more and more companies began to invest in Nicaragua and explore previously unexplored parts of the country in search for commercially feasible gold deposits located near water sources that are required for present day gold mining. Rancho Grande was one of these previously unexplored locations and was deemed prosperous by the extractive sector. Spalding (2016) suggests that B2Gold has become Nicaragua's lead corporate investor and part of this is due to its acquisition of mining concessions around Nicaragua, but particularly in Rancho Grande.

Beginning in 2010, B2Gold, became more committed to its social campaign in convincing the local authorities and the population to approve and endorse open-pit 
exploitation projects, especially on the hill known as "El Pavón" in the community of Yaoska. The company attempted to create support and ease the concerns of citizens living in Rancho Grande by cultivating social infrastructure and microfinance programs (Spalding 2016). Additionally, B2Gold also developed propaganda like strategies to create a positive image of itself among citizens living in Rancho Grande. For example, public school teachers and health staff distributed baseball caps with the B2Gold logo and T-shirts with messages about corporate social responsibility (Sanchez Gonzalez 2017). B2Gold officials offered gifts to the children during Christmas, it gave the police new equipment, and it gave the local health clinics new equipment and medicine. The company promoted these types of activities in order to gain the support of the local government, the local government agencies, and the local organizations by offering them gifts and monetary benefits. Initially, the Mayor's office (the Mayor is part of the FSLN party), the police, the local government, and a variety of local agencies were originally for the mine because they knew that they would receive monetary benefits from B2Gold. ${ }^{86}$

Company officials also propagandized a forestry nursery it had financed (Sanchez Gonzalez 2017). B2Gold also used the local radio stations to spread propaganda about the benefits of "green mining" and its capacity to create jobs and economic development for the community and Nicaragua (Sanchez Gonzalez 2017). For example, B2Gold promised local business owners in Rancho Grande that they would indirectly prosper from mining activity in the community through things like an increase of B2Gold employees using local business services. B2Gold even offered monetary support to local business owners

\footnotetext{
${ }^{86}$ Author's personal interview with the leader of Guardines de Yaoska social movement group: January 2017.
} 
to improve their facilities and businesses in preparation for the eventual increase in services. Some of these owners, an unorganized minority, came out in favor of the mining project. B2Gold said that it would offer job perks to local citizens and even pay them nicely for their land.

Additionally, the company created a state-mining company alliance, an alliance with Nicaragua's national government (Spalding 2016). For example, Sanchez Gonzalez (2017) notes that according to a leader in Matagalpa's Communal Movement:

The government was complicit in everything the mining company did there, because it allowed the company to manipulate the government's own projects: if the government was donating sheets of zinc roofing, it wasn't the political secretary who gave them out; it was a representative of $B 2$ Gold. About two years ago a brigade of Army doctors came to the area but it wasn't the military who presented them; it was B2Gold, as propaganda for what it was doing.

For a poor municipality like Rancho Grande, neglected by the State, the offer of new economic opportunities became an important issue (Sanchez Gonzalez 2017). Over 58\% of Nicaraguans live in poverty, $29 \%$ of the population lives in extreme poverty, and $67 \%$ barely survive on more than $\$ 1.00 /$ day. In Nicaragua, poverty tends to persist in rural areas. For example, of those that live in extreme poverty, $78 \%$ live in rural areas. Within Nicaragua, there are five departments that are the most rural: Jinotega, Matagalpa, Boaco, Madriz, and Nueva Segovia. Rancho Grande is a very rural area located in the Department of Matagalpa (Agros International, N.D.) Rancho Grande suffers from extreme poverty and underdevelopment. For example, people live in homes made of plastic tarps with dirt floors, no running water, no electricity, etc. There are not many places to eat or shop. There are no banks. The school is rundown, and there is only one 
road that is unpaved or poorly paved. The rest of the roads are rocky, wet, and muddy making it difficult to navigate. ${ }^{87}$

The offer of jobs, employment opportunities, and economic development by B2Gold seems like a benefit to the Rancho Grande community and its inhabitants. Below, in Figure 5.3, is an illustration of poverty affecting different parts of Rancho Grande. Purple represents severe rates of poverty, orange represents high rates of poverty, green represents a mid-level rate of poverty, and yellow represents a low-level rate of poverty. Given the promise of jobs, employment opportunities, and economic development, media reports began to show that the community of Rancho Grande approved of B2Gold and the company advancing its activities to begin exploiting gold from the area (Spalding 2016). Essentially, B2Gold tried to buy the "hearts and minds" of the citizens to gain their support (Sanchez Gonzalez 2017).

${ }^{87}$ Author's personal observations in Rancho Grande: January 2017. 


\section{Figure 5.3: Poverty Map of Rancho Grande}

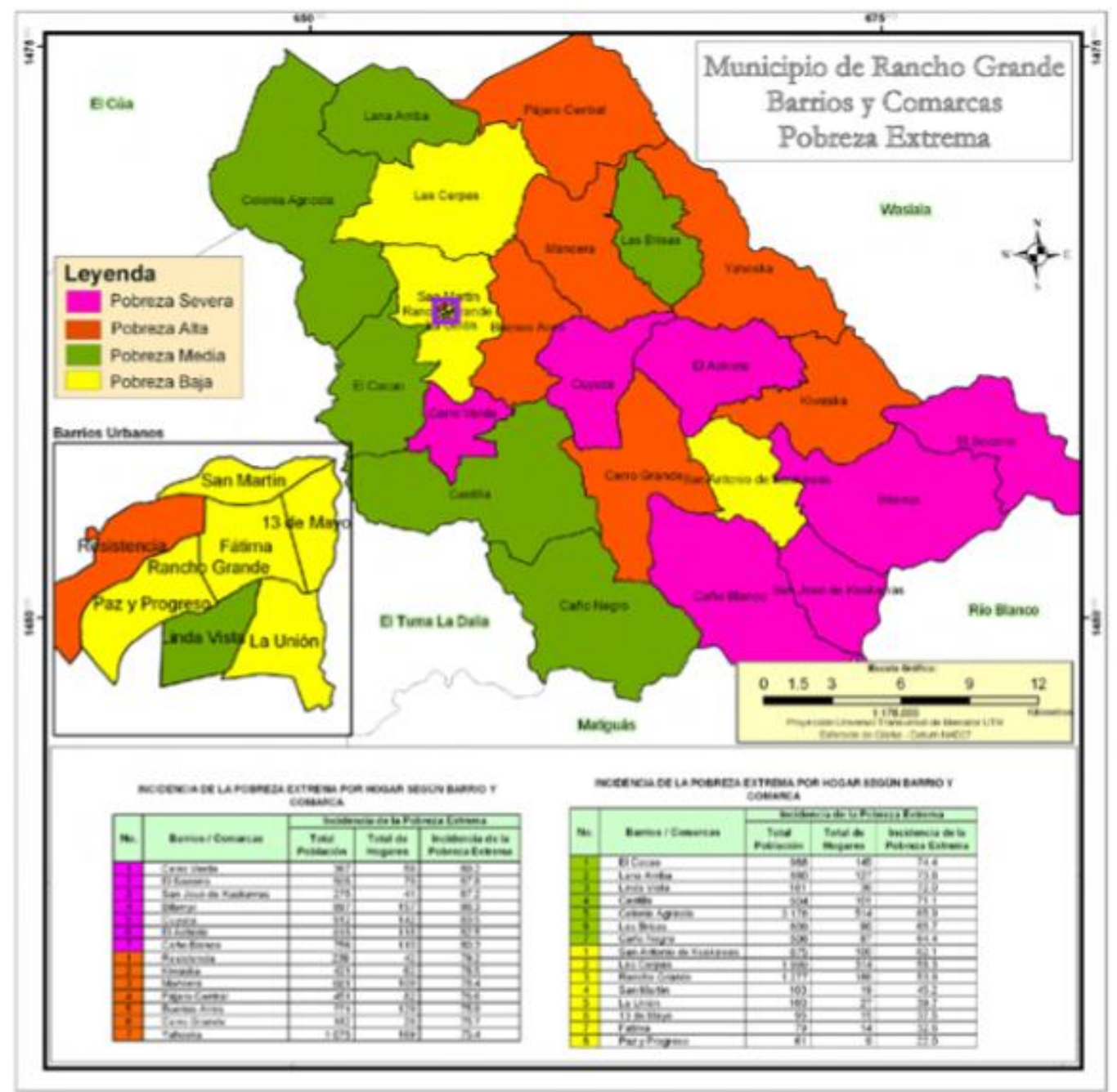

Ilustración 5 Mapa de Pobreza de Rancho Grande.

Fuente INIDE 2011

Source: Centro Humboldt (2015b).

In the beginning stages of B2Gold's presence in the community, citizens appreciated the gifts and the social programs B2Gold offered. Some people, although few, supported the mine, the mining company, and the mining concession because they believed that it would bring the community economic growth and development and employment opportunities. However, the job creation that B2Gold promised or said it brought to Rancho Grande was fake. The company only provided some citizens with work for a 
month, then another person would take his or her place. ${ }^{88}$ In total, B2Gold only employed 80 people in Rancho Grande, but the company said it had between 200-300 employees working in Rancho Grande (Sanchez Gonzalez 2017). The citizens of Rancho Grande seemed to recognize B2Gold's tactics. For example, when the company tried to buy land from Rancho Grande residents, the citizens saw this as a deceitful tactic. The company was known for sending representatives in disguise to small farms in the Yaoska district to purchase land. These representatives would try to convince and persuade the farm owner into selling the property to them, and in turn, the representatives would sell the property to B2Gold (Sanchez Gonzalez 2017).

Even with the potential benefits that B2Gold promised to the citizens of Rancho Grande, beginning in 2005, the population became aware of the socio-environmental impacts generated by mining projects leading them to publicly and categorically oppose any mining activity in their municipality. For example, in my personal interview with a member from the Rancho Grande community, this individual suggested to me that "It would be a disaster if the mining concession went through. Look how beautiful Rancho Grande is. Rancho Grande is surrounded by rivers and mountains that are covered by jungles and forests." ${ }^{89}$ In an additional interview I held with an individual from Rancho Grande, the individual stated: "I can only imagine if the mining concession went through for B2Gold. Rancho Grande's environment would be negatively affected like it is being affected in Santo Domingo." 90 When B2Gold, in 2010, began increasing its commitment to persuade the community of Rancho Grande to accept mining so it could begin

\footnotetext{
${ }^{88}$ Author's personal interview with the leader of Guardines de Yaoska social movement group: January 2017.

${ }^{89}$ Author's personal interview with a citizen from Rancho Grande: January 2017.

${ }^{90}$ Author's personal interview with a citizen from Rancho Grande: January 2017.
} 
exploiting gold in the area, a round of opposition marches started (Spalding 2016; López and Dávila 2014). As I discussed, Rancho Grande is a community that depends on its agriculture, its livestock, its environment, and its water sources to sustain its ways of life. Before B2Gold even entered the community, Rancho Grande had practiced sustainable agriculture production and pro-environmental behavior with the help of local agricultural and environmental NGOs.

NGOs in Matagalpa, such as the Asociación para la Diversificación y Desarrollo Agrícola Comunal (ADDAC) ${ }^{91}$ and the Rural Cultural Encouragement Movement (MACRU), had assisted the citizens of Rancho Grande in promoting sustainable agricultural development since the 1990s (Sanchez Gonzalez 2017). Additionally, ADDAC encouraged the development of skills in local cooperatives that helped improve the production quality of cacao and coffee. ADDAC also created a network of affiliates that eventually became important actors in Rancho Grande's anti-mining resistance movement (Spalding 2016). For instance, Rios de Agua Viva (Rivers of Life Water) is one of the many cooperatives that was created and strengthened with the support of ADDAC. It currently comprises 39 communities with more than 1,311 participants, which promotes the development of organic agriculture, the protection of the environment, peasant organizations, gender organizations, and support for agricultural marketing and alternative credit (Centro Humboldt 2015b). Additionally, Centro Humboldt, a Nicaraguan national environmental NGO, started outreach initiatives in

\footnotetext{
${ }^{91}$ The Association for the Diversification and Development of Community Agriculture of Matagalpa is a Nicaraguan non-profit organization established in 1991 with headquarters in Matagalpa. It initially arose to improve health conditions incorporating new themes and social groups to achieve true community development. It has consolidated its position as one of the main supporters for agricultural production and commercialization in Rancho Grande and its neighboring municipalities.
} 
Rancho Grande in the early 2000s to promote environmental awareness and forest preservation (Spalding 2016). Thus, before mining even entered the picture, citizens in Rancho Grande were already connected by a network tied to community organizations, especially environmental and agricultural organizations, that taught citizens in Rancho Grande sustainable agricultural practices and environmental protection.

This promotion of sustainable agriculture and environmental protection caused a large majority of citizens to already have pro-environmental attitudes. Environmentalism and sustainable agriculture were instilled into and throughout the community and "the idea was sown that agricultural sustainability and life strategies in the countryside substantially depend on using, conserving and recovering the resources that nourish them" (Sanchez Gonzalez 2017). According to Sanchez Gonzalez (2017), the ideas of environmentalism and sustainable agriculture injected energy into many peasants in their mobilization in defense of their territory. For example, Sanchez Gonzalez (2017) provides a passage that highlights this influence and impact from organizations, like ADDAC, promoting sustainable agriculture and pro-environmental behavior in Rancho Grande from an interview he held with an individual from Rancho Grande. This individual stated:

I've been looking after the forest on my property for many years. I've had training and guidance from an organization called $A D D A C$, which taught us a long time ago to take care of the environment, the water, forests and land-not to burn it. I started to care for the forests thanks to an exchange of experiences...I would gladly give my life for the environment. That's why the teaching about caring for and conserving this forest appealed to me. This forest won't be cut down as long as I live. 
In an additional interview Sanchez Gonzalez (2017) held with an

individual from Rancho Grande, the individual suggested that B2Gold and the Nicaraguan government:

...tell us we were ignorant and that we needed civilization. That remark was drilled into us daily. But we don't need a lot of civilization to love the land and to know that it's the land that provides us with food, water and all other resources.

Both passages demonstrate the love and dedication that individuals in Rancho Grande have for their land and their environment. The second passage also demonstrates the strong connection that individuals have towards their community identity and community values through the use of "us" and "we" in the passage. The passage gives one a sense that this individual has a strong commitment to the land and resources in Rancho Grande, but also to his community as a whole. As Sanchez Gonzalez (2017) suggests "the organizations supporting the social movement also recognized that Rancho Grande had... territorial identity and roots..." Bishop Álvarez, the bishop for Matagalpa, Matagalpa, suggested that Rancho Grande's struggle to protect their territorial and community identity and roots to their land, their agriculture, their environment, their water, and to each other, began from acknowledging the people of Rancho Grande and their dignity. He discusses how Rancho Grande has a tradition and a history of community struggle, which helped consolidate the community beyond politics, ideologies, and religion. The threats from mining united the community and strengthened their cohesion and solidarity (Sanchez Gonzalez 2017).

When B2Gold first started to take interest in Rancho Grande, ADDAC was asked by the community to come and listen to their concerns about B2Gold and mining. These communities reached out to ADDAC because of their long and continuous relationship it 
had with the people in these communities, as well as their concern about the damages that the mining company would cause to their environment, their water sources, and their agricultural production that is key to their livelihoods. The citizens in these communities did not understand why B2Gold would be granted access to the destruction of the environment and the forests if their community had been practicing sustainable production methods for so many years. ADDAC entered the communities and listened to citizens' complaints and concerns and gathered information. Citizens from these communities felt comfortable with ADDAC to listen and gather information because they had relational trust with the organization. Once ADDAC collected information, details, and data; it used its connections with Centro Humboldt. ADDAC invited Centro Humboldt to Rancho Grande to listen, speak, and gather information from the community and its members. Essentially, ADDAC acted as the intermediary between the communities and Centro Humboldt. The connection and trust that ADDAC had with the community and its connection that it had with Centro Humboldt allowed Centro Humboldt to start conducting scientific studies in the area to inform citizens about why mining would be destructive for Rancho Grande. This was one of the first steps in the organizational capacity that helped Rancho Grande become united and become informed so they could act together against B2Gold and its activities. $^{92}$

One of the key factors for the emergence of Guardines de Yaoska ${ }^{93}$ (Guardians of Yaoska) social movement group against mining was the access to more information, especially from other mining communities throughout Nicaragua and Central America,

\footnotetext{
${ }^{92}$ Author's personal interview with a representative from ADDAC: January 2017.

${ }^{93}$ Guardines de Yaoska (Guardians of Yaoska) adopted this name because of the group's prerogative to protect the Yaoska river and the district of Yaoska that would directly be impacted by B2Gold's mining activity.
} 
about the socio-environmental harms mining causes. Citizens were exposed to the harmful impacts that metal mining causes from other communities through Nicaragua, as well as communities in El Salvador, Honduras, and Guatemala through environmental and agricultural NGOs and religious leaders (Sanchez Gonzalez 2017). For example, a Delegate of the Word in San Antonio de Kuskawás community said, 'We're witnesses to the fact that where there's mining there's a lot of destruction and regret. This is what we're basing our struggle on"” (Sanchez Gonzalez 2017). Sanchez Gonzalez (2017) describes the learning process from the information that was provided to Rancho Grande citizens from other mining communities as "shock therapy." 94 Sanchez Gonzalez (2017) quotes one of the founders of Guardines de Yaoska to demonstrate the effect this information or shock therapy had on citizens in Rancho Grande and the emergence of Guardines de Yaoska. The founder stated:

I was motivated by seeing the El Limón and Santa Pancha mines. I also know the mines in Chontales. It pained me a lot and made me think it isn't right for them to come here to Rancho Grande, such a beautiful municipality with lovely scenery, and do the same nastiness they've done in other places. Since then I've thrown myself into the struggle, and I haven't stopped; I haven 't even paused.

Throughout Rancho Grande's resistance against B2Gold and its mining projects, the Catholic Church also played a crucial role. Father Pablo Espinoza of Nuestra Señora de Fátima Church in Rancho Grande began work with Teodoro Custer, a local Catholic priest and one of the main motivators of Rancho Grande's anti-mining movement whom was at the forefront in Rancho Grande in realizing the danger and damages that mining

\footnotetext{
${ }^{94}$ Spalding $(2016,18)$ also suggests that Rancho Grande citizens were "[a]rmed with information about the harmful impact mining can have on water quality and their own observations of mine damage from the Bonanza region."
} 
would cause. Father Teodoro Custer learned about the harmful effects that mining causes to the environment from the Maryknoll Sisters' experiences in Guatemala, which shaped his actions and willingness to share information and knowledge with citizens in Rancho Grande to create a sustained organizational resistance within Rancho Grande (Sanchez Gonzalez 2017). Without the assistance from these two priests, Rancho Grande would have remained unorganized and received less crucial information about the harms mining causes to the environment. Through the guidance of these priests, other religious leaders would visit with citizens throughout all of Rancho Grande's communities to provide information and assist them in unifying against mining. Their organizational efforts and their efforts to unite the people and communities in Rancho Grande started very early, early enough so Rancho Grande could get a hold on the situation and resist B2Gold and mining from the company's initial involvement and influence in the community. ${ }^{95}$ These priests were eventually able to gain the support of Catholic Church leadership in the departmental capital of Matagalpa. For example, Sanchez Gonzalez (2017) quotes the Bishop of Matagalpa, Rolando José Álvarez Lagos, who stated:

Biblical considerations have motivated and encouraged us to be aware that we are the custodians of creation... Then Pope Francis' encyclical 'Laudato Si' consolidated our struggle and our efforts for the common good of Rancho Grande's population. It consolidated our mystique and widened our horizons even further and, of course, it gave us greater hope in the possibility of struggle and achieving what we proposed, what we're convinced was and still is right and just.

The Catholic Church's choice to support Rancho Grande on environmental grounds did not solely include environmental action into its pastoral plan or forming operational

\footnotetext{
${ }^{95}$ Author's personal interview with the leader from the Guardines de Yaoska social movement group: January 2017.
} 
agencies like the Diocesan Commission for Ecology and Life. The Church committed itself to Rancho Grande and its opposition to mining (Sanchez Gonzalez 2017). For example, Sanchez Gonzalez (2017) quotes the vicar general for the Diocese of Matagalpa, Monsignor Edgar Sacasa Sierra, of the San Isidro-Sébaco parish, who stated:

For the past three years there's been a new pastoral option: the environmental option. It started very gently with reforestation, building plant nurseries, founding environmental clubs. It started with positive environmentalism. But when it came to mining it was no longer positive environmentalism but environmentalism in rebellion, in protest, environmentalism that shocks, denounces, confronts the powerful.

The community of Rancho Grande's faith in God and reasons related to its own survival are key factors for why its social movement, "an expression of the environmentalism of the poor, took its stance against extractivism" (Sanchez Gonzalez 2017). As a woman from Rancho Grande stated, "I could never support mining because I'm against destroying the environment. What motivates me is that I have to love Mother Earth because she's the treasure God left for us" (as quoted in Sanchez Gonzalez 2017). It is apparent that the Catholic Church, its leaders, and the members of Rancho Grande's community understood that halting B2Gold's mining projects were essential to the community's survival. For example, in an interview with Sanchez Gonzalez (2017), Monsignor Sacasa of Matagalpa stated:

The Church is pro-environment and so are our flocks. We came to realize that the case of Rancho Grande was a matter of life or death. We also felt it as an institutional deception; a supposed development project that was trying to sell the people a siren song, a mirage. The people drew us in and we can't fail them. If we weren't with the people, we'd have nothing to do in Rancho Grande. We couldn't' stand back. It was the people who committed us. 
Additionally, Sanchez Gonzalez (2017) discusses how many women in Rancho Grande express themselves through the spiritual relationship they share with their land and their surrounding environment that they believe is God's sacred gift to them. For example, in an interview with Sanchez Gonzalez (2017), a woman and a Delegate of the Word from a local community in Rancho Grande, San Antonio de Kuskawás stated that in "Studying the Bible, I see how we should value, care for and defend Mother Earth because it says there that she's like a mother's womb." The Catholic Church, its leaders, and its followers were always anti-mining in Rancho Grande from the moment that B2Gold became interested in the area. Although the Evangelical Church in Rancho Grande was not fully against mining at the beginning of B2Gold's influence in the community, once it learned the information that Centro Humboldt and ADDAC provided, it eventually joined forces with the Catholic Church and played an important role in assisting the community in its anti-extraction movement. ${ }^{96}$

The unity between the Catholic Church and the Evangelical Churches was essential for uniting the whole community. For example, the Catholic Church and the Evangelical Church came together despite their different religious beliefs in order to work together to organize and unite the community. The Catholic priests and the Evangelical ministers were very respected and trusted throughout Rancho Grande and community members listened to them because of this. This allowed organizations like Guardines de Yaosoka, ADDAC, and Centro Humboldt to work with both churches to help broaden their social networks and organize and unite the people of Rancho Grande. ${ }^{97}$

\footnotetext{
${ }^{96}$ Author's personal interviews with the leader from the Guardines de Yaoska social movement group and a representative from ADDAC: January 2017.

${ }^{97}$ Author's personal interviews with the leader from the Guardines de Yaoska social movement group and a representative from ADDAC: January 2017.
} 
With the imminent threats of mining from B2Gold, the Rancho Grande community united on all fronts and Guardines de Yaoska created a five-member directorate that had a network of supporters in 39 communities that ADDAC helped originally organize. Guardines de Yaoska, with the help of the Churches and NGOs, continued to spread knowledge and information throughout Rancho Grande's communities that B2Gold's mining projects would directly compete with Rancho Grande's agricultural economy and would "offer only short term resources at the expense of long term development; opponents deployed the movement slogan, 'bread today, hunger tomorrow"' (Spalding 2016, 18). The Strategic Group Against Mining was also formed, which is a network of anti-mining activists in the departmental capital, Matagalpa. The group includes ADDAC, Asociación para el Desarrollo Integral Comunitario (ADIC), Radio Comunal Católica, the Movimiento de Mujeres de Matagalpa, the local Movimiento Comunal Nicaragüense (MCN), and the Rios de Agua Viva Cooperative (Spalding 2016). Centro Humboldt, the national environmental organization and Centro Nicaragüense de los Derechos Humanos (CENIDH), the national human rights organization continuously provided information and support while documenting Rancho Grande's anti-extraction efforts (Spalding 2016; Sanchez Gonzalez 2017).

Throughout their social movement efforts against B2Gold and mining, one of the ways in which this anti-mining alliance or coalition against mining spread information about mining's harmful impacts was "[c]ommunicating ideas via alternative communication media" (Sanchez Gonzalez 2017). For example, the Catholic Church on its a daily radio show at 1:00 pm provided the people and the communities of Rancho 
Grande with information about what would happen if B2Gold did begin to extract gold in Rancho Grande. Guardines de Yaosoka also utilized the radio on its daily radio show that gave similar information. Essentially, both radio shows provided talks, workshops, and provided key information from places like Centro Humboldt, ADDAC, and CENIDH to inform the people of the harms that mining can cause to communities like those of Rancho Grande. ${ }^{98}$ Media, like the Catholic Church's and Guardines de Yaoska's radio shows, matter by exposing a few well-informed individuals who then pass the message on, meaning social interaction can magnify the effect of media coverage (Estrada et al. 2017).

Guardines de Yaoska, the Catholic Church, the Evangelical Church, ADDAC, and organizations a part of the Strategic Group Against Mining provided the "information, training, awareness-building, organizational strengthening and mobilizations around the mining threat" (Sanchez Gonzalez 2017). These organizations and groups provided access to critical organizational tools and information about mining and "enriched the social movement's resistance capacity and empowerment" (Sanchez Gonzalez 2017). By putting their individual interests and ideological differences aside, these groups were able to collectively organize and unite the community of Rancho Grande in solidarity among their shared values and identities to form a cohesive social movement against B2Gold and its mining projects. Throughout its resistance movement against mining, Rancho Grande faced resource inefficiencies for carrying out their social movement and marches against mining. It was difficult for people to afford to take off work, to travel to the marches, and to feed themselves during the marches. Additionally, citizens lost their jobs,

\footnotetext{
${ }^{98}$ Author's personal interviews with a leader from the Guardines de Yaoska social movement group and a representative from ADDAC: January 2017.
} 
were unemployed for long periods, and did not have money to pay for food or transportation. Rancho Grande's social movement brought on even more severe economic hardships for the people involved, which was almost everyone in the community. However, the community's unity prevailed through their hearts and love of Rancho Grande and their hearts and love for their rights that were at risk. The citizens assisted each other when they could. When another community member was facing a difficult time due to participation in social movement activities, other community members were there to help. If they needed a ride, they would get a ride. If they needed to eat, they would eat. They helped each other, which helped their unity, their social movement, and their success. ${ }^{99}$

The citizens of Rancho Grande created a dialogue, No a la Mineria (No to Mining) that the people in the community could support. The message was painted on the majority of homes and buildings throughout Rancho Grande. This statement became the message for the social movement against mining that persisted in the peoples' hearts, minds, and souls, and served as a unifying factor for the dissemination of an ideology that permitted the recognition of a situation as unjust (McAdam, Tarrow, and Tilly 2005). This saying is of course backed by the harms that the mining company and the mining project would bring to Rancho Grande. It would harm their livelihoods, their water access, and their habitable environment. This saying strongly represented the feelings and passions behind what would happen if B2Gold began to exploit gold. ${ }^{100}$ Throughout Rancho Grande's social movement, the citizens understood that nobody other than

\footnotetext{
${ }^{99}$ Author's personal interview with a leader from the Guardines de Yaoska social movement group and a representative of ADDAC: January 2017.

${ }^{100}$ Author's personal interview with a representative from ADDAC: January 2017.
} 
themselves and their supporters could be relied on to defend and support their socioenvironmental rights (Sanchez Gonzalez 2017), which influenced the inhabitants of Rancho Grande to collectively organize and form various protests and mobilizations against mining in their community in order to protect their environment, their agriculture, their water quantity and quality, and their livelihoods. For example, over Rancho Grande's decade long resistance against mining in their community, its citizens:

- had more than 15 peaceful marches, at municipal and departmental level (20102015);

- participated in awareness workshops;

- compiled and delivered to the National Assembly and the Presidency more than 6,000 signatures of the population that is against mining (2014);

- filed appeals with Courts in Matagalpa and the Supreme Court of Justice in Managua ${ }^{101}$; and;

- performed other actions in which the population of Rancho Grande had publicly denounced mining and claim that it does not want or need mining (Centro Humboldt 2015b, 2015c).

As previously discussed in this chapter, a state-mining company alliance was created, which eventually tried to control local media outlets and promote pro-mining public opinion, while also denying access to media outlets for those that opposed mining and to cover any actions and demands by Rancho Grande's social movement against mining (Sanchez Gonzalez 2017). Additionally, they tried to stop any anti-mining activities promoted by Rancho Grande's social movement. For example, the community created a petition against B2Gold's mining projects. Local government agencies attempted to stop the petition by denying social movement participants access to certain neighborhoods and districts in Rancho Grande, as well as requiring a fee of 200 Cordobas $^{102}$ (roughly $\$ 10$ ),

\footnotetext{
${ }^{101}$ Spalding $(2016,20)$ notes that in "January 2015 Guardianes de Yaoska leaders filed for an injunction with the Tribunal de Apelaciones in Matagalpa on behalf of 57 affiliates, calling on the court to halt the issuance of the mining permit."

102 The Cordoba is Nicaragua's national currency.
} 
which is a significant amount of money for a very impoverished municipality like Rancho Grande. However, community members were able to overcome this harassment and assist each other financially through their unity and organization to ensure that citizens signed the petition. ${ }^{103}$

Additionally, the state-mining company alliance permitted B2Gold to enter health centers, partake in government activities, and conduct pro-mining workshops in the community's public schools. B2Gold's pro-mining workshops in the public schools, as well as offering the students and the teachers schools supplies stemmed from a deal that the company made with the Ministry of Education (MINED). In order to receive school type benefits, MINED granted B2Gold access to school classrooms to give presentations to the students about how beneficial a mine in their community would be to their future. The company promised jobs, economic growth, and economic development for Rancho Grande. B2Gold also told the students that no harm would be done to the water, the environment, or their livelihoods around agriculture. The parents of the students were not allowed access to the classrooms to tell their side of the story and why mining would be harmful to the community. ${ }^{104}$ However, this did not stop Rancho Grande's social movement from developing its own resistance mechanisms that promoted opposition to B2Gold and its projects (Sanchez Gonzalez 2017). ${ }^{105}$

Given B2Gold's activities in Rancho Grande's local schools in promoting mining and the denial of social movement actors in these schools to spread information about the

\footnotetext{
103 Author's personal interview with a leader from Guardines de Yaoska social movement group: January 2017.

104 Author's personal interview with the leader of Guardines de Yaoska social movement group: January 2017.

${ }^{105}$ Sanchez Gonzalez (2017) notes that the "most significant actions took place throughout 2015, when the social penetration strategies of the state-mining company alliance became more evident."
} 
harms of mining; on July 13, 2014, school officials and parents decided to establish a "School Stoppage." This meant that the children and teachers of Rancho Grande stopped attending school until the municipal authorities and the national government expelled B2Gold from spreading pro-mining sentiments within the schools. The "School Stoppage" was an evident rejection to mining activity. Although they were heavily criticized for violating the right to education, they advocated for higher rights, such as: the right to life, the right to water, and the right to a healthy environment (Centro Humboldt 2015b). One of Guardines de Yaoska's leaders reported to Sanchez Gonzalez (2017) that:

There are communities where the schools were closed for three months; 90\% of the municipality closed its schools because the children didn't go; their parents didn't send them. We know the company has money and it's easy to deceive a child, so it would go to a school supposedly to provide training. It would give the children a snack and then start asking them, 'Sonny, who's your daddy? Who's your mummy? How many people live in your house?' Then they would go to the house. That's why the school strike started and it was quite successful, because even the education minister herself had to come out and resolve it.

The "School Stoppage" attracted the attention of high-ranking government officials at the national and municipal levels, such as Rancho Grande's Mayor María Isabel González, Deputy Minister of Energy and Mines Lorena Lanzas; Minister of the Environment and Natural Resources Juanita Argeñal, Minister of Education Miriam Ráudez, and Matagalpa Mayor Zadrach Zeledón (Sanchez Gonzalez 2017). The intent of these leaders and public officials was to persuade the leaders of Guardines de Yaoska to halt the "School Stoppage" and support B2Gold's activities in the community. However, their efforts failed because these officials, prior to the "School Stoppage", had never even visited Rancho Grande to conduct a public consultation exercise to socially legitimize 
B2Gold's mining concession in Cerro Pavón. (Sanchez Gonzalez 2017). Sanchez Gonzalez (2017) further notes that "the words of Deputy Minister Lanzas raised even greater concerns when she informed people that the Nicaraguan government wanted to guarantee that all foreign investment in mining exploration would recover their investment and make a profit in the country." As one of the coordinators of the Guardines de Yaoska said to Sanchez Gonzalez (2017), "We showed the government and the world that you can fight and win. How did we do it? By uniting, setting aside parties, everyone together, Liberals and Sandinistas, Evangelicals and Catholics, through a single cause and with nonviolence." Essentially, as a founder of the Guardines de Yaoska put it to Sanchez Gonzalez (2017):

The social movement is us. We're a social movement that arose to protect Rancho Grande, to protect our environment, to fight so they listen to us, because here in Rancho Grande we don't have anyone inside the government or municipal government who is looking out for what's happening in the communities.

The majority of these public officials that visited Rancho Grande associated with the FSLN political party. Sanchez Gonzalez (2017) discusses how the integration of sympathizers from different political parties in Rancho Grande did not happen spontaneously. He mentions how it "responded to a politically mature process of standing back from certain structures and refuting the challenges and exclusions of the statemining company alliance." In some cases, some citizens of Rancho Grande even left their political parties. For example, Sanchez Gonzalez quotes a leader from Guardines de Yaoska on his abandonment of the FSLN political party. The leader stated:

I belong to the FSLN. I've been active in this party since I could think for myself, just like all my family. But from the moment all this 
began here, I haven't attended a single meeting of the party or the municipal government. They used to meet here in my house but I told them, 'I don't want you to come back here until this is fixed.'

The citizens of Rancho Grande moved beyond the role of political parties and took action into their own hands in order to defend their rights and their existence to life. For example, Sanchez Gonzalez (2017) quotes Monsignor Edgar Sacasa, who stated, "We believe the people of Rancho Grande are now capable of doing what the political parties can't do and that we're wrong in saying the people are afraid. I don't know if they are or not, but they're capable of mobilizing and when they do they can move the nation." Rancho Grande is the type of community that possesses strong intra-community bonds via its relationship with community organizations and via its collective capacity to successfully organize (i.e., the "School Stoppage"). Strongly bonded communities, like Rancho Grande, have higher self-efficacy and collective-efficacy and may, therefore, be more resistant to the designs of multinational extractive companies. Also, highly bonded communities, like Rancho Grande, usually mistrust authorities when their expectations are unmet, which the previous paragraphs demonstrated via the community's interactions with public officials, and the community's interaction with political parties like FSLN.

Rancho Grande's opposition did not end with the "School Stoppage." Its opposition to B2Gold in the community came to a head on August 13, 2014 when more than 500 people from different communities began marching peacefully to Managua in a movement they called "For the Defense of the Common Good, Protect Mother Earth!" The participants of the march were arrested in the municipality of La Dalia, Matagalpa by riot police who took away the participants' identification cards and driver licenses to prevent the peaceful mobilization from continuing on to Managua. Two days later, 
representatives from national government ministries and local government organizations called for an alleged "open dialogue" on the topic of mining in Rancho Grande. Three thousand inhabitants of Rancho Grande filled the local sports center and together, in one voice, openly opposed mining in their communities. However, before starting the open dialogue, a group of B2Gold supporters wearing B2Gold's logo and the caption "If Responsible Mining," incited violence against the multitude of people concentrated in the sports center leading to several injuries. The violence against these inhabitants did not deter them. By October, a cultural festival and march were held against mining, which was organized by representatives of the Basic Ecclesiastical Committees (CEB) with representatives from the social movement group Guardines de Yaoska and organizations and associations from the Strategic Group of Matagalpa Against Mining (ADDAC, $\mathrm{MCN}^{106}$, and others) (Centro Humboldt 2015c).

Additionally, in March 2013, forty-three priests from the Diocese of Matagalpa, led by Bishop Monseñor Rolando José Alvarez Lagos, signed a statement that concluded "No existe en este proyecto un punto de equilibrio entre las ganancias de unos pocos y el perjuicio de las mayorías." This translates to "There is not balance point in this project between the profits of a few and the damage of the majority" (Spalding 2016, 19). Additionally, in March 2013, Father Pablo Espinoza lead a march with approximately 6,000 participants who mobilized against mining in Rancho Grande (Spalding 2016). The Catholic Church's influence in Rancho Grande eventually transcended the Diocese of Matagalpa and reached the national level when the Episcopal Conference took interest in Rancho Grande's anti-extraction movement in May 2014, and in solidarity, the Catholic

\footnotetext{
${ }^{106}$ The Movimiento Comunal Nicaraguense (Community Movement Nicaragua) is a library program for rural communities that aid primary and secondary students with reading and school activities.
} 
Church leadership in Nicaragua delivered a letter to President Ortega against mining in Rancho Grande (Sanchez Gonzalez 2017). In Sanchez Gonzalez's interview with Monsignor Sacasa, the Monsignor told Sanchez Gonzalez, "It reached the highest levels an appeal can reach and all the bishops contributed to it and supported it."

Furthermore, Bishop Rolando José Álvarez Lagos also called for a community referendum on mining and sent a leader from Guardines de Yaoska to El Salvador to observe a local mining referendum. After months of planning arranged by Bishop Rolando José Álvarez Lagos, both the Catholic and Evangelical Churches in conjunction with the Rancho Grande community organized a massive march against mining in the first week of October 2015. They strategically called the march the "Pilgrimage for Life" (Sanchez Gonzalez 2017). Although there is no record that fully captures the amount of participants that marched in the "Pilgrimage for Life" on October 3, 2015; organizers and participants estimate that over 10,000 people marched in solidarity against metal mining in Rancho Grande and promoted the protection of Rancho Grande's environment and the communities right to existence (Sanchez Gonzalez 2017). As Monsignor Edgar Sacasa suggested to Sanchez Gonzalez (2017), the "Pilgrimage for Life" was a "political referendum.” The Monsignor further stated to Sanchez Gonzalez (2017) that:

If the government decided to support the mine, the people decided to reject it. The images of the massive pilgrimage and the voices of the social movement were heard in Managua through many national media outlets. Interpreting them as a threat to other important interests, the government declared mining activity in Rancho Grande "unfeasible" only a week later, on October 12.

The Nicaraguan national media was always invited to Rancho Grande's previous marches and mobilizations, however, they never chose to attend. The sheer size of this movement 
attracted national media attention for the first time. Such media coverage and the massive presence of protesters against the "El Pavón" project that demanded a true public, transparent, and inclusive consultation aroused the attention of international media sources and international organizations that never previously focused on this particular anti-extraction case in Nicaragua. With this coverage and newly formed awareness, the Nicaraguan national government on October 12, 2015-Day of Indigenous Resistancedeclared the "El Pavón" project unfeasible and ended this particular concession. However, many believe that the government's declaration stemmed from almost 10 years of social pressure against mining from the inhabitants of Rancho Grande, which was largely supported by the Catholic Church and Evangelical Church (Centro Humboldt 2015c). As Monsignor Edgar Sacasa contends to Sanchez Gonzalez:

Rancho Grande has become a beacon for many people...Rancho Grande and what we did is now illuminating many other communities. I think they will have to think hard about another project like this... It's now part of grassroots awareness that one cannot go against the Earth, against Nature, against God's Creation. And that awareness has a lot of heft.

Citizens of Rancho Grande, in solidarity, fought for nearly a decade utilizing protests, road blocks, boycotts, and other forms of resistance to protect their right to land, landscapes, water quantity and quality, and their environment from B2Gold's "El Pavón" open pit gold mining project (Cuffe 2015). In Figure 5.4, below, I provide some photographs of some of Rancho Grande's social movement activities. On October 12, 2015, the mining project of B2Gold in the Cerro Pavón area of the municipality of Rancho Grande was declared "unviable" by the Nicaraguan national government (Sanchez Gonzalez 2016). Rosarillo Murillo, the wife of Nicaraguan President Daniel 
Ortega, whom at the time was the spokeswoman for the Nicaraguan government but is now the Vice President of Nicaragua, ${ }^{107}$ stated that the "conclusion of all the environmental experts is that the project is not viable due to the impacts it would have on the surroundings, on nature, on the environment, on people's way of life, [and] on water sources in general" (as quoted in Cuffe 2015).

\section{Figure 5.4: Photos of Rancho Grande's Social Movement Activities}

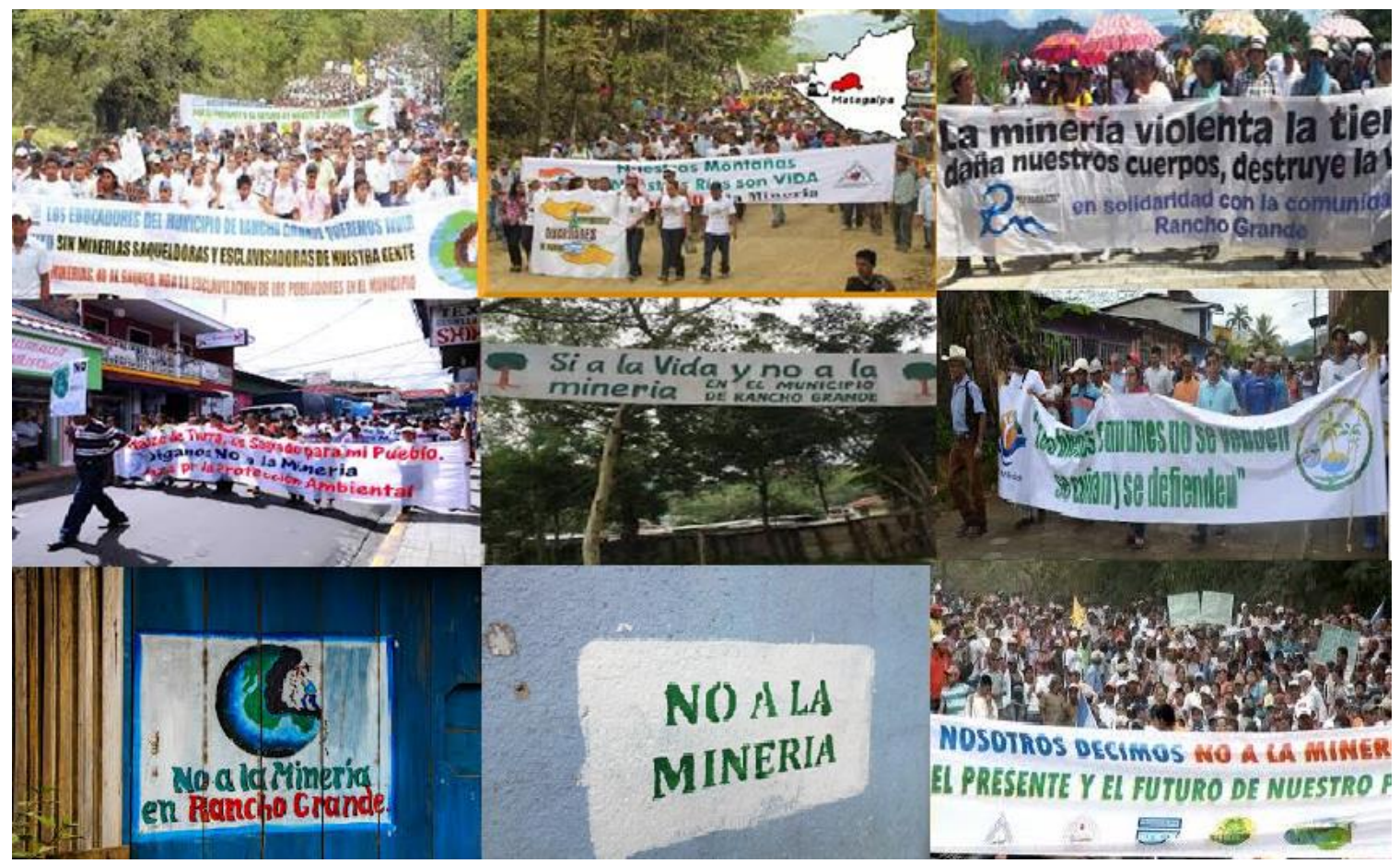

Sources: Author's photos and Google images.

The Nicaraguan national government's decision to overturn B2Gold's mining concession was the result of a decade of ongoing nonviolent resistance by the largely peasant population of Rancho Grande. ${ }^{108}$ The successful leadership of Guardines de Yaoska's

\footnotetext{
${ }^{107}$ Rosarillo Murillo was elected Vice President in 2016 with her husband Daniel Ortega winning his thirdconsecutive 5-year term and fourth term overall.

${ }^{108}$ Cuffe (2015) notes that "[m]ore than 90 percent of the municipality's...inhabitants oppose mining." My own survey data suggests the same. Out of the 408 and citizens I surveyed in Rancho Grande in April of 2018,90 percent of the respondents oppose mining.
} 
struggle against mining and mining activities established a historic precedent. However, Guardines de Yaoksa and the citizens of Rancho Grande could not have successfully ended B2Gold's mining concession without the assistance of the Catholic Church and the Evangelical Church and other environmental and agricultural organizations (Sanchez Gonzalez 2016). The community believes that the Churches' influence in the social movement against mining was paramount in the national government's decision to overturn B2Gold's mining concession. The Church leaders involved were key actors in organizing and unifying the community, which was so impactful for the community's success in overturning B2Gold's mining concession. The Church leaders garnered respect from the people in the community and united everyone to organize against mining. Additionally, the community believes its success is related to its strong religious conviction and its faith in God. The Department of Matagalpa and the community of Rancho Grande is believed to be an area in Nicaragua where one can find the most religious Nicaraguans. Their strong religious conviction allowed them to stay united and to persist through the difficulties they faced during their anti-extraction movement, and continue their resistance until they were successful. ${ }^{109}$

\section{$\underline{\text { Research Design and Empirical Analysis }}$}

\section{Survey Sampling}

In collaboration with the Socio-Cultural Analysis Center at La Universidad Centroamericana in Managua, Nicaragua; I completed public opinion surveys in April

\footnotetext{
109 Author's personal interviews with a community member in Rancho Grande and a representative from ADDAC: January 2017.
} 
2018 to fulfill a comprehensive database with just under 200 variable indicators related to: the environment, water resources, agricultural activity, security of the land, public services, politics and political beliefs, protest beliefs, economic dynamics, social capital, public institutions, mining activity, and a battery of controls. The data was collected through an application of approximately 400 surveys through personal interviews with residents of Rancho Grande. The surveys were facilitated and supervised by members of the Socio-Cultural Analysis Center. Table 5.1A in the Appendix outlines the survey sample design for Rancho Grande. The municipality of Rancho Grande is composed of 7 neighborhoods and 22 districts. With an estimated population of 49,730 inhabitants, $90 \%$ of which are located in rural areas (INIDE 2005), the survey randomly chose roughly (+/) $10 \%$ of individuals living in the 7 neighborhoods and 22 districts that could be surveyed. Out of those individuals randomly chosen, the survey randomly chose approximately (+/-) $10 \%$ of individuals living in the 7 neighborhoods and 22 districts. Approximately 400 surveys were distributed in the districts and neighborhoods in a proportional and randomized manner. These samples are based on data from the 2005 Nicaragua census (INIDE 2005).

With the data from the public opinion surveys, I can understand and study what makes individuals oppose or support resource extraction, as well as understand the microlevel politics (i.e., social engagement in local organizations) that shape individual attitudes, beliefs, and characteristics towards mining. Again, the survey data offers robust individual-level data that permits me to understand what prompts citizens to participate in protests by understanding the factors that lead them to oppose mining. By conducting these surveys with clustering respondents around extractive protest sites like Rancho 
Grande, I understand what causes some citizens to mobilize and others to abstain against resource extraction; uniquely at the individual level. This survey data also permits me to understand what attitudes, beliefs, and characteristics individuals have in highly visible protest cases for successfully overturning mining concessions through sustained protests and social movement resistance. Therefore, I utilize the data to ask citizens in Rancho Grande their views and perceptions to generalize from empirical data, rather than make inferred assumptions about individuals from aggregate community-level data.

In Figure 5.5 and Figure $5.6^{110}$, based on my survey responses from Rancho Grande, one sees a negative community relationship between residents of Rancho Grande and B2Gold. Figure 5.5 depicts this relationship when the survey was taken in April 2018, which is after Rancho Grande's successful resistance movement. The majority of the community members still have negative feelings towards B2Gold, which likely stems from the company's divisive and deceitful actions and the mistrust that community members feel towards the company and its actions. Nearly 200 of the roughly 400 respondents in my survey suggest that the community's relationship with B2Gold is bad. This negative sentiment was even higher five years earlier in 2013, which can be seen in Figure 5.6. Just over 200 of the roughly 400 respondents in my survey suggest that community's relationship with B2Gold was bad. This makes sense since in 2013 Rancho Grande and its citizens were at the height of their resistance movement against B2Gold's El Pavón project.

\footnotetext{
${ }^{110}$ The survey question for Figure 5.5 that I asked respondents is "How would you classify the relationship between the local population and B2Gold?" The answers were very good, good, average, and very bad. The survey question for Figure 5.6 that I asked respondents is "Five years ago, how would you classify the relationship between the local population and B2Gold?" The answers were very good, good, average, and very bad.
} 
Figure 5.5: Community Relationship with B2Gold

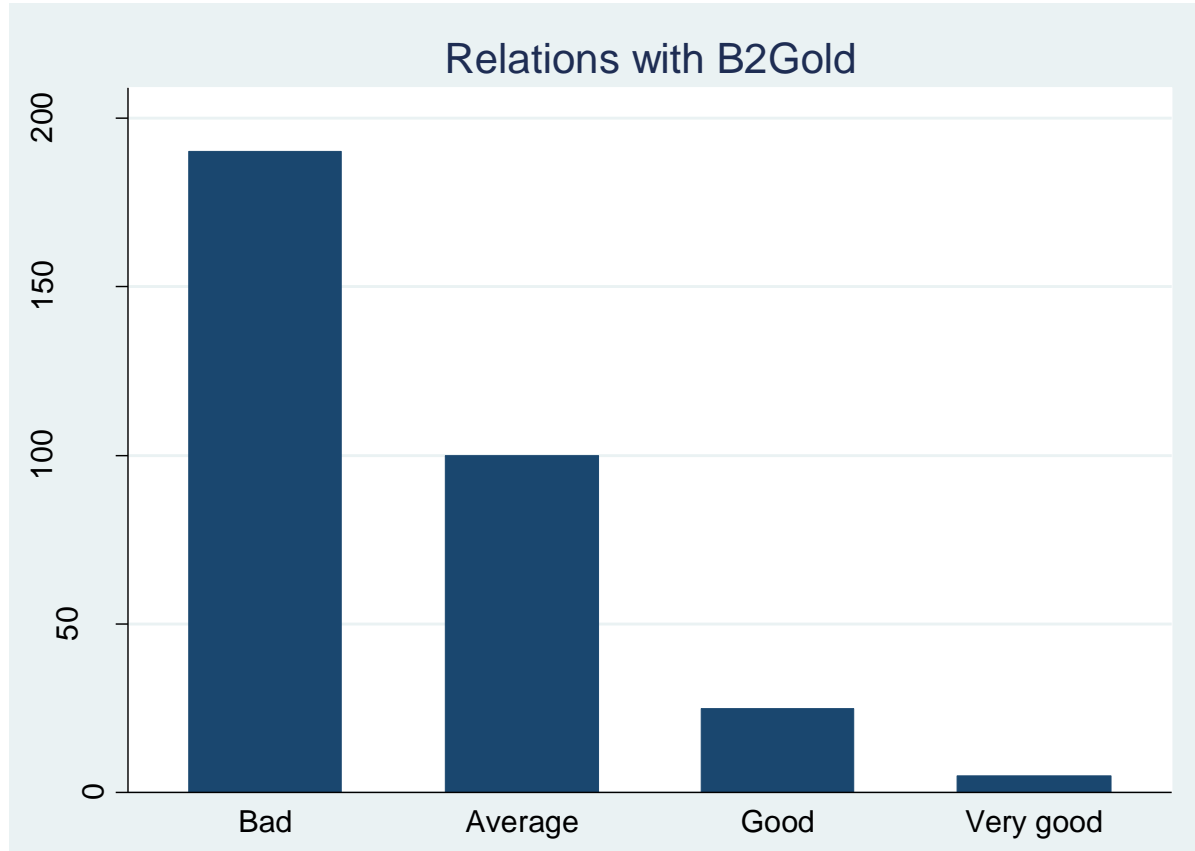

Source: Author's data.

Figure 5.6: Community Relationship with B2Gold 5 Years Ago

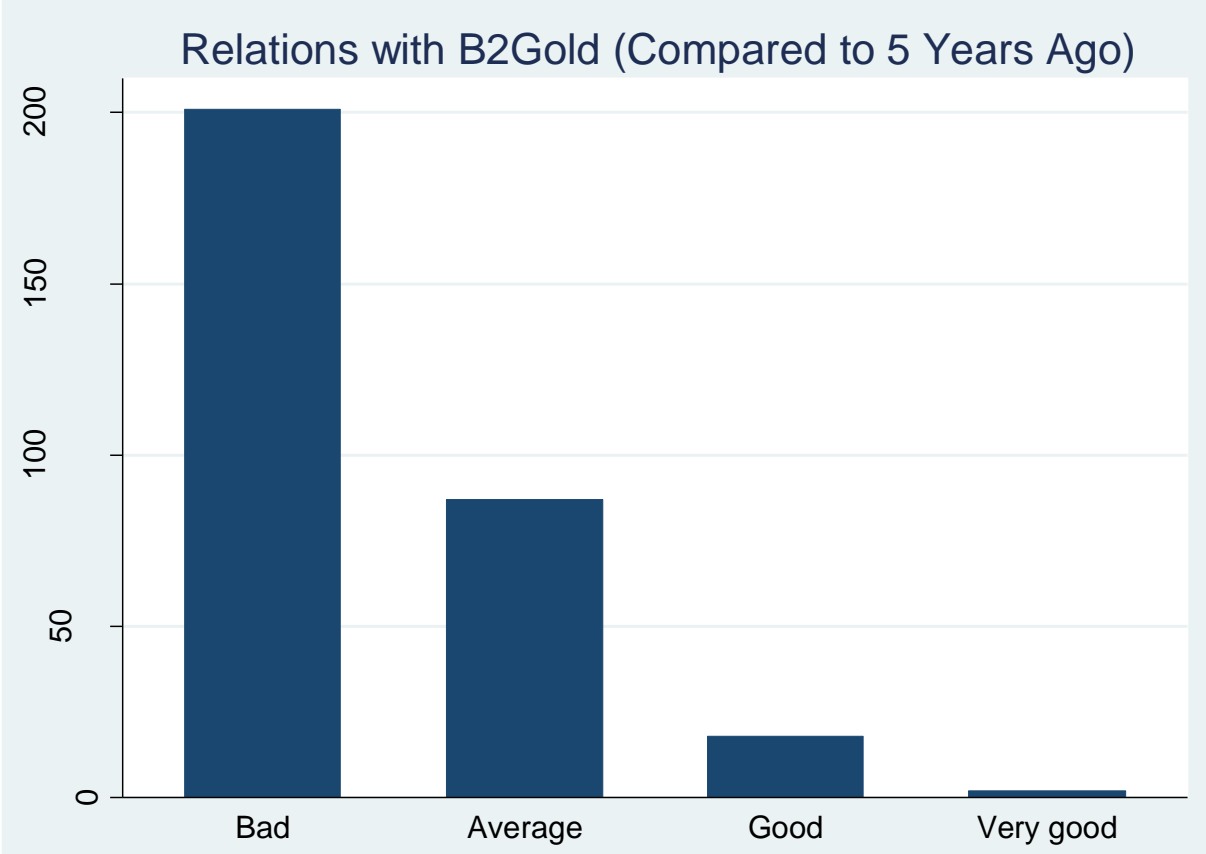

Source: Author's data. 


\section{Dependent Variable and Statistical Model—Support for B2Gold's Mining Activities}

In the first part of my analysis, my first dependent variable—Support for B2Gold's mining activities - is a dichotomous variable that asks an individual if she supports or opposes B2Gold's mining exploration projects. ${ }^{111}$ In my survey, $9.44 \%$ of respondents in Rancho Grande supported the project, while $90.56 \%$ of respondents opposed it. Given the dichotomous nature of the dependent variable, I use a logistic regression model. Below, Figure 5.7 demonstrates the reasons individuals in Rancho Grande support B2Gold's influence in their community. I asked individuals in Rancho Grande, "What is the main reason that you support the projects of B2Gold?” Although only 9.44\% of respondents from my survey in Rancho Grande support B2Gold and its activities, the top three reasons for support are employment opportunities, economic benefits, and social programs. The other reasons that respondents support B2Gold and its activities are because the company and its activities do not hurt the environment, there is strong state oversight, and B2Gold is a respectful company. However, the top three rated reasons by respondents represent demands for services characteristics.

${ }^{111}$ In the Appendix for this chapter, one can find more information about my dependent variable in Table 5.2A ("Variable Coding, Frequency, and Percentages"), Table 5.3A ("Variable Summary Statistics"), and Table 5.4A ("Survey Questions and Variable Explanations"). 


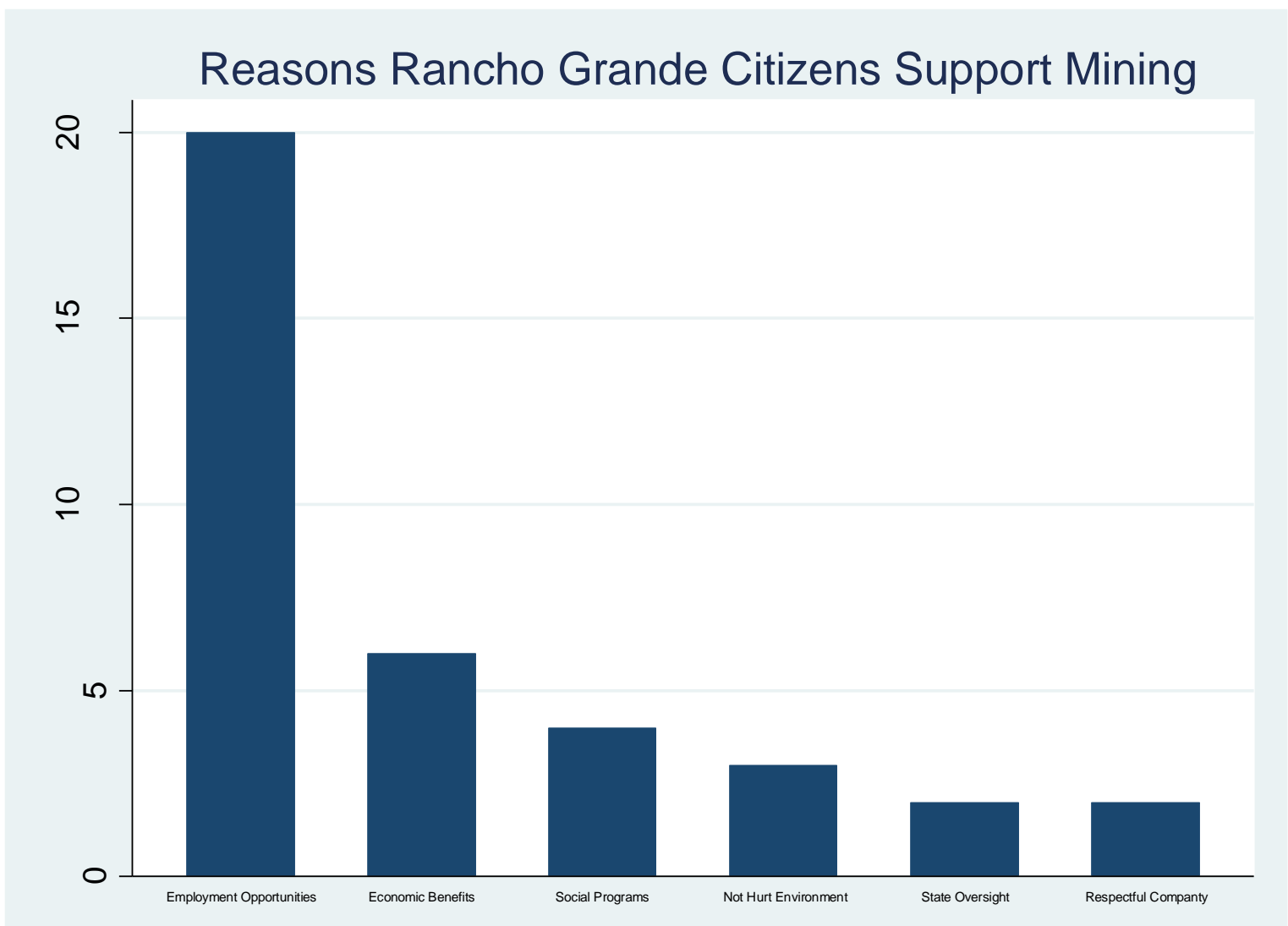

Source: Author's data.

Below, Figure 5.8 demonstrates the reasons individuals in Rancho Grande oppose B2Gold's influence in their community. I asked individuals in Rancho Grande, "What is the main reason that you oppose the projects of B2Gold?" Of the $90.56 \%$ of respondents who oppose B2Gold and its activities, the overwhelming reason is because they believe it hurts the environment. Over $175(\sim 43 \%)$ respondents in my survey oppose mining for environmental reasons. The second reason individuals in Rancho Grande oppose mining relates to water contamination. They are fearful that mining and its activities will contaminate its rivers and water sources. Just over $75(\sim 18 \%)$ respondents from my survey oppose mining because of water contamination. Two other reasons individuals from my survey oppose mining are linked to land expropriation and harmful impacts to 
agricultural production. Both are just under $30(\sim 7 \%)$ respondents each in my survey. It is significant to point out that four main reasons respondents in my survey oppose mining have to do with environmental reasons, agricultural reasons, water reasons (related to both environmental and agricultural reasons), and land expropriation (taking them away from their cultural heritage and their home), which represent demands for rights characteristics. ${ }^{112}$

Figure 5.8: Reasons Individuals in Rancho Grande Oppose B2Gold

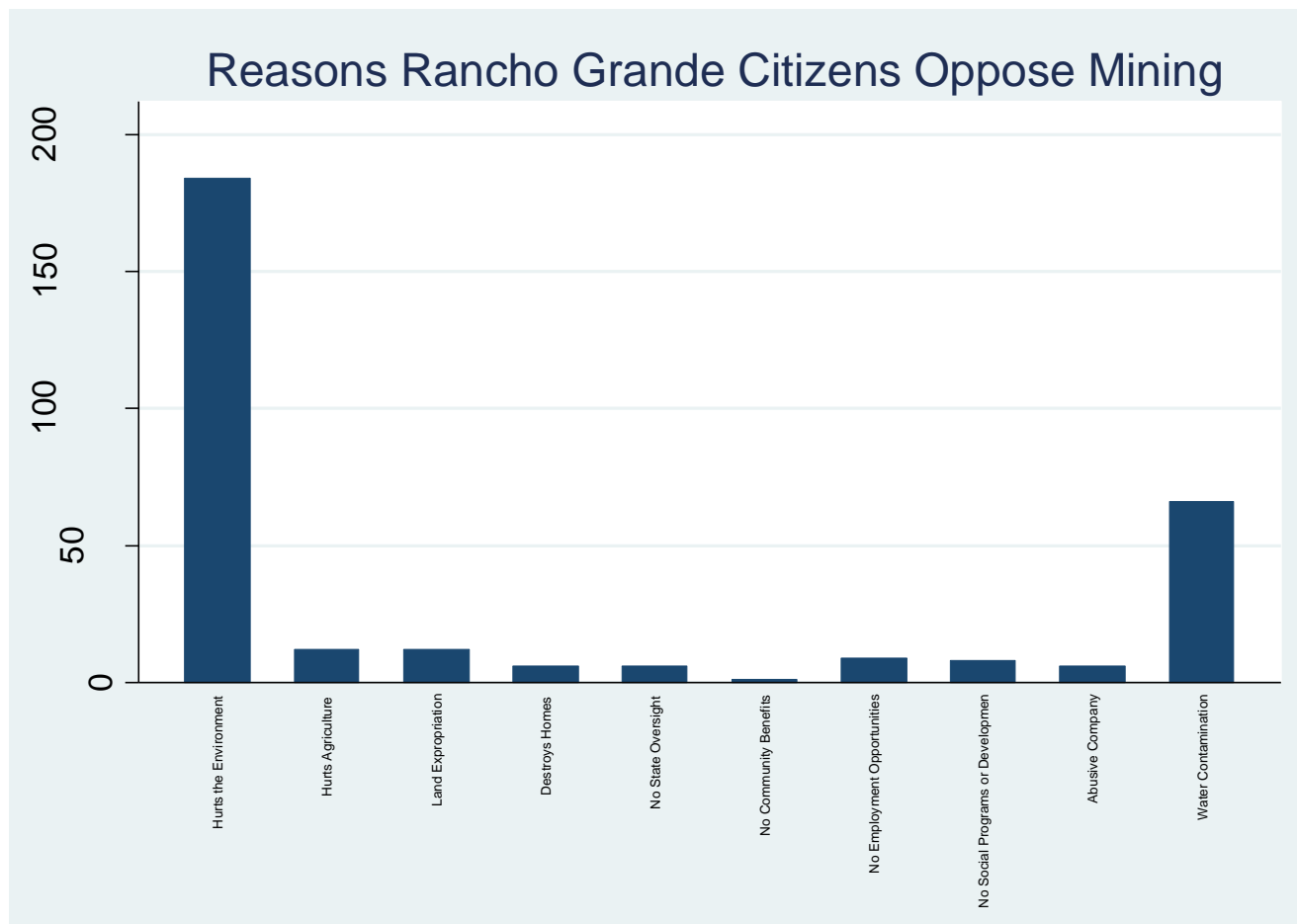

Source: Author's data.

\footnotetext{
${ }^{112}$ The other reasons respondents oppose B2Gold and its activities are related to the destruction of homes, lack of state oversight, lack of community input, lack of provisions related to social programs and economic development, and B2Gold is an abusive company. However, the top four related reasons are linked to demands for rights.
} 


\section{Independent Variables-Demands for Rights, Demands for Services, and Social}

\section{Engagement}

My independent variables of interest include two variables measuring demands for rights, two variables gauging demands for services, and a variable measuring individuals' social engagement in community organizations. ${ }^{113}$ I explain each of these variables in turn. My main independent variables of interest seek to capture the relative importance of rightsand service-based claims, which conceptually can be seen as sources of opposition and support, respectively. With regards to rights-based claims, I asked respondents, "What impact will B2Gold's activity have on the environment? This variable, Environmental Impact is dichotomous ( $1=$ negative; $0=$ positive $)$. I also asked respondents if they agreed or disagreed with the following statement: "The drilling of the land done for mining activity damages the environment and agriculture." This variable, Agricultural Impact, is dichotomous ( 1 =agree; $0=$ disagree $)$. Turning to service-based claims, I asked respondents, "What impact will B2Gold's activity have on employment opportunities?" This variable, Employment Opportunities, is a dichotomous variable (1=(very) positive; $0=($ very $)$ negative). I also asked respondents, "Has the mining company helped improved education services in your community?" This variable, Educational Opportunities, is dichotomous $(1=y e s ; 0=$ no $)$.

Below are Figure 5.9 and Figure 5.10. Figure 5.9 illustrates my two demands for rights variables: Environmental Impact and Agricultural Impact. Over 300 respondents in Rancho Grande believe that mining damages the environment and agriculture, while less

\footnotetext{
${ }^{113}$ In the Appendix for this chapter, one can find more information about my independent variables in Table 5.2A ("Variable Coding, Frequency, and Percentages"), Table 5.3A ("Variable Summary Statistics"), and Table 5.4A ("Survey Questions and Variable Explanations").
} 
than 100 respondents believe that mining does not damage the environment and agriculture. Figure 5.10 illustrates my two demands for services variables: Employment Opportunities and Educational Opportunities. Approximately 300 respondents in Rancho Grande believe that mining does not create employment opportunities, while approximately 400 respondents in Rancho Grande do not think mining creates educational opportunities. While just over 100 respondents in Rancho Grande believe that mining creates employment opportunities and just under 100 respondents believe mining creates educational opportunities. Based on these descriptive statistics it is clear that Rancho Grande is more of a "demands for rights" community than it is a "demands for services" communities.

\section{Figure 5.9: Descriptive Statistics for Demands for Rights Variables}

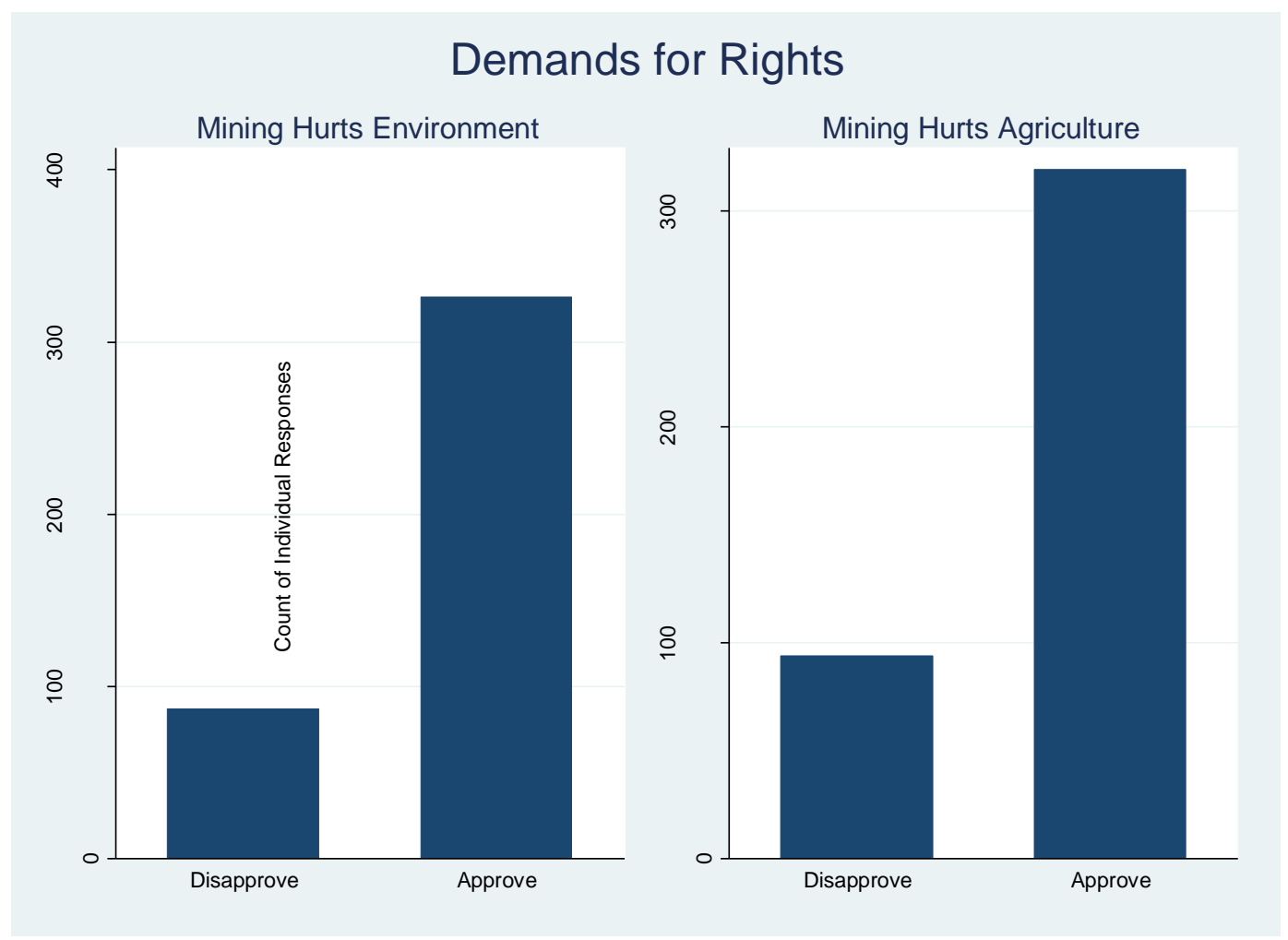

Source: Author's data. 


\section{Figure 5.10: Descriptive Statistics for Demands for Services Variables}

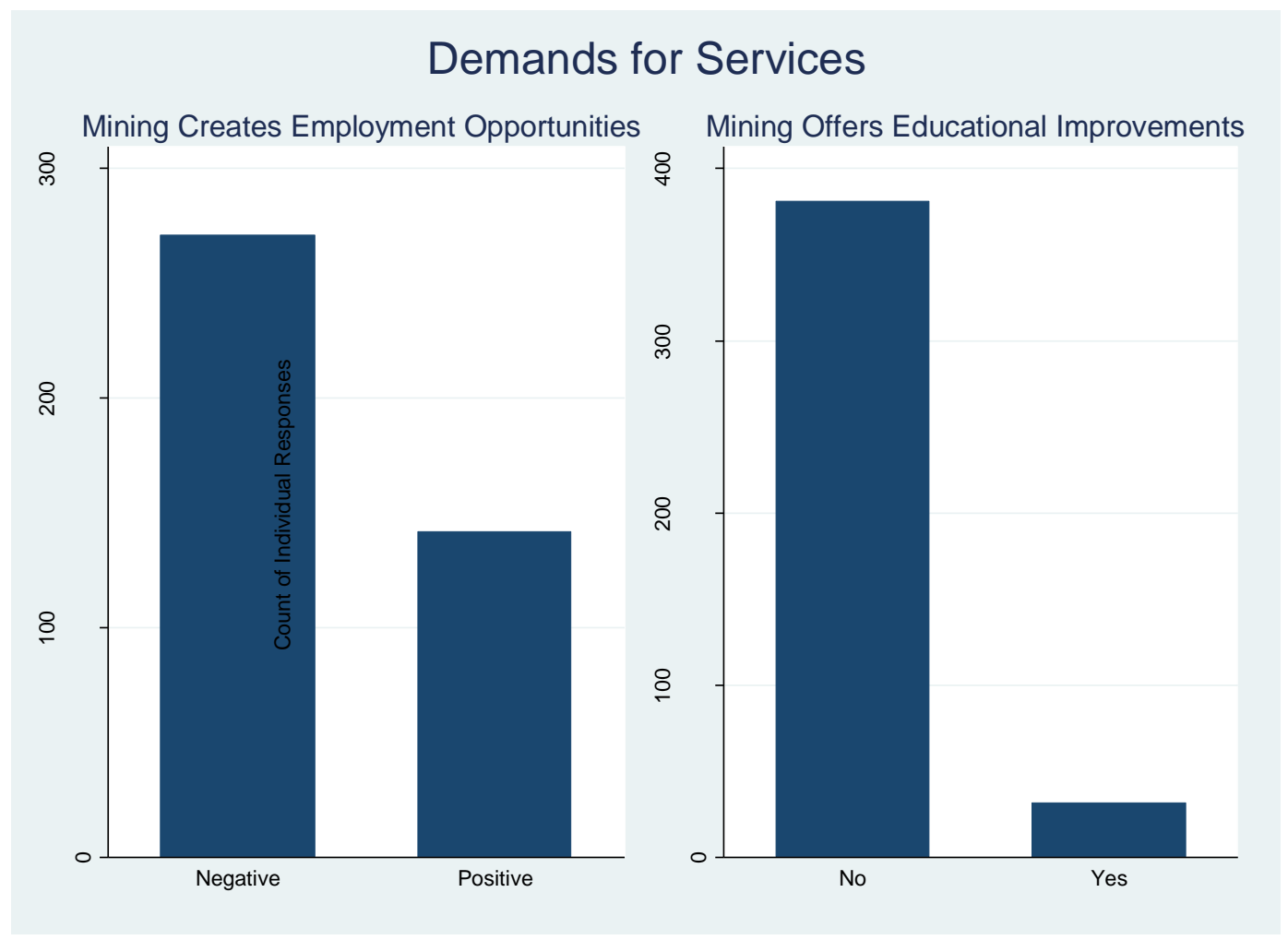

Source: Author's data.

I am also interested in the effects that Social Engagement has on attitudes towards mining. The question from my survey that I utilized is, "How frequently do you attend an organization meeting?" Although, my survey asked individuals about their participation in various community organizations, I used the following four organizations based on my expectations: 1) general community organizations; 2) environmental organizations; 3 ) agricultural organizations; and 4) religious organizations. A respondent received a 0 if he or she never engaged or participated in a community, environmental, agricultural, or religious organization. A respondent received a 1 if he or she participated or engaged in a community, environmental, agricultural, or religious organization once a week, twice a month, or once a month. The Social Engagement variable is an additive index based on a 
respondent's participation in a community, environmental, agricultural, and/or religious organizations. For example, if a respondent participates at least once a month in: all four organizations, the respondent receives a 4 ; in three of the four organizations, the respondent receives a 3; in two of the four organizations, the respondent receives a 2; in one of the four organizations, the respondent receives a 1 ; and in none of the organizations, the respondent receives a 0 . Thus, this variable ranges from $0-4$ and is used to measure individuals' social engagement in community organizations. I find congruence between my measure of social engagement and Moseley's (2015) indicator of community engagement - an indicator that gauges the frequency with which citizens participate in local organizations and can effectively measure the dense organizational networks that are pivotal to shape and form individual attitudes and beliefs towards mining.

Figure 5.11 and Figure 5.12 below provide some basic descriptive statistics for my Social Engagement variable based on survey respondents from Rancho Grande. Figure 5.11 displays a bar graph that shows respondents that participate in local community organizations in Rancho Grande. There are 93 respondents that do not participate, there are 134 respondents that participate in at least 1 organization, there are 80 respondents that participate in 2 organizations, there are 56 respondents that participate in 3 organizations, and there are 50 respondents that participate in 4 organizations. Remember that the four organizations are general community organizations, environmental organizations, agricultural organizations, and religious organizations. Out of the approximate 400 respondents in my survey from Rancho Grande, 320 individuals are socially engaged, at some level, in local organizations. 
Figure 5.12 shows the relationship between my Social Engagement variable and Support for B2Gold's mining activities. There are only 14 out of the 134 respondents that participate in 1 organization that support B2Gold's mining activities. There are only 7 out of the 80 respondents that participate in 2 organizations that support B2Gold's mining activities. There are only 6 out of the 56 respondents that participate in 3 organizations that support B2Gold's mining activities. And, there are just 4 out of the 50 respondents that participate in 4 organizations that support B2Gold's mining activities. Although not causation, one sees a strong correlation for those that are socially engaged in local community organizations, at some level, are less likely to support mining and mining activities.

\section{Figure 5.11: Social Engagement in Local Organizations}

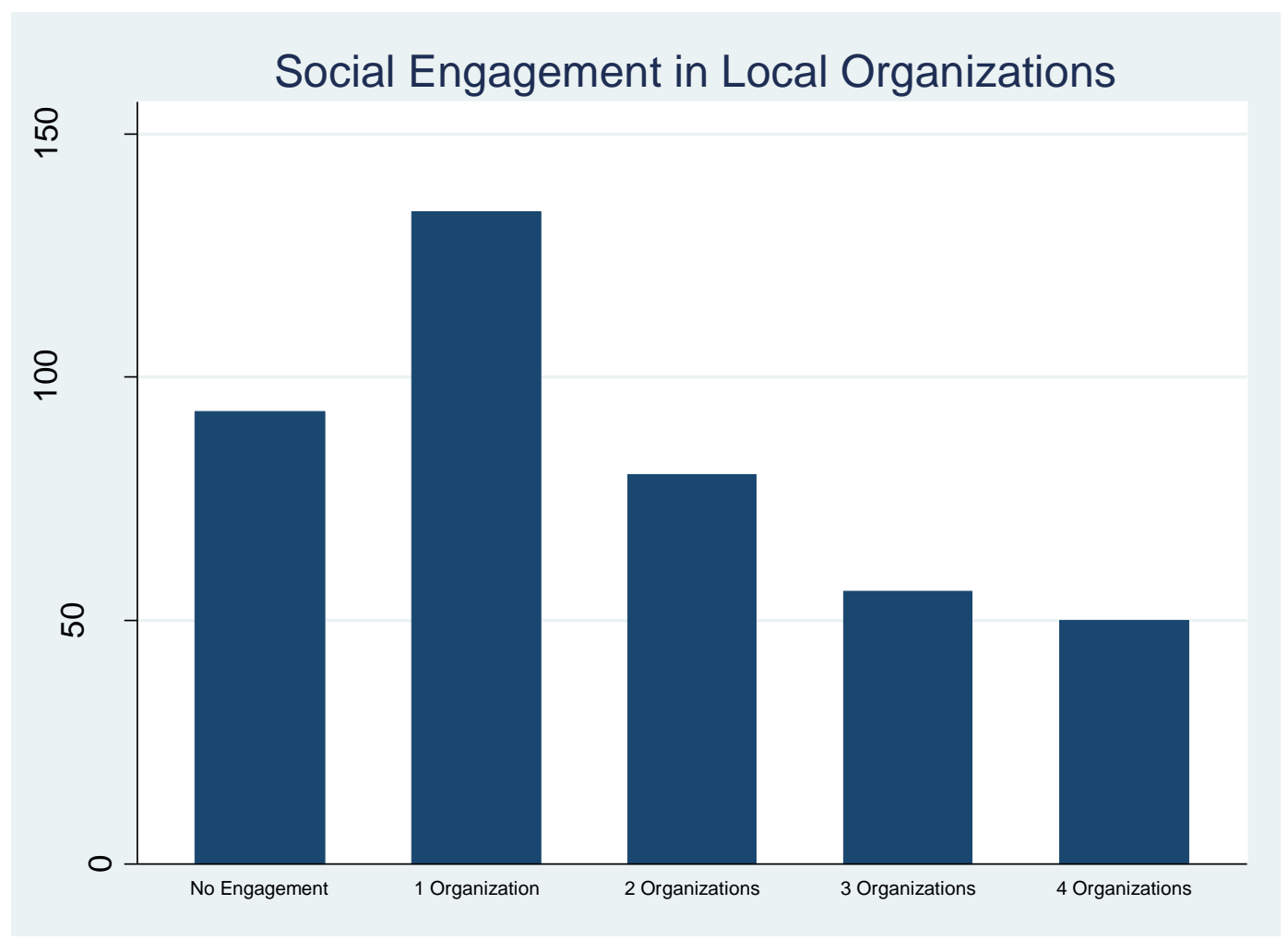

Source: Author's data. 


\section{Figure 5.12: Social Engagement and Support for Mining}

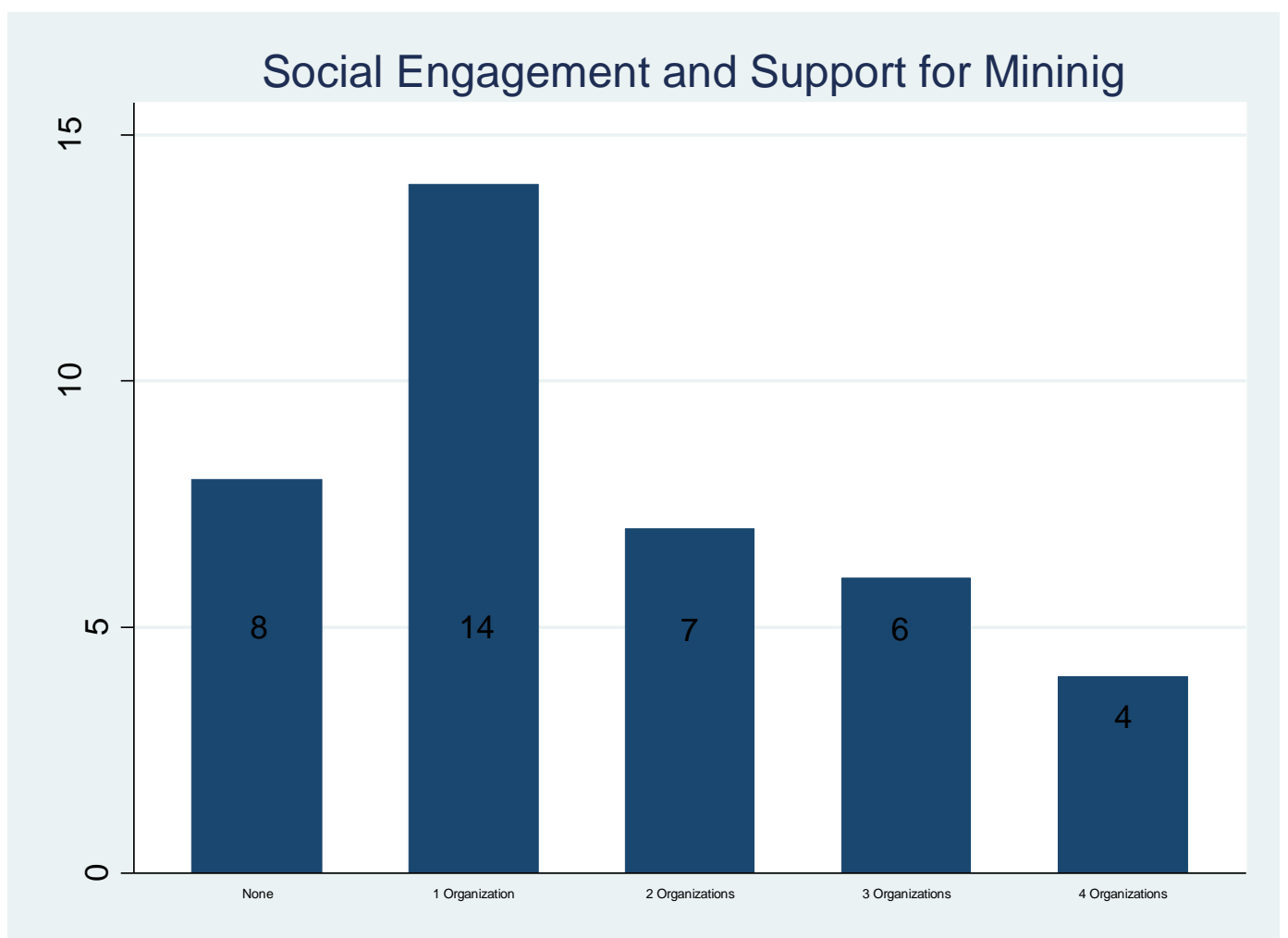

Source: Author's data.

Table 5.1 below provides correlations between individuals who are engaged in local organizations with the components that I argue make socially engaged individuals more likely to oppose mining projects because they more likely have: 1) access to critical organizational tools and information about mining; 2) a higher sense of self-efficacy and collective-efficacy empowering them and their communities to resist mining; 3 ) and a stronger community worldview contributing to broad-based mobilization. In these crosstab correlation tables, individuals that participated in one, two, three, and/or four organizations at some level received a 1 ; otherwise individuals received a 0 . I utilized my Social Engagement variable specified earlier, and made it dichotomous instead of 
continuous for ease of comparison purposes. This variable is used in all four of the crosstab tables.

Organizational Tools and Information About Mining is also dichotomous. If survey respondents answered that they know: 1) where B2Gold's headquarters are; 2) who Guardines de Yaoska are; 3) who B2Gold's subsidiary company is; and/or 4) B2Gold's mining project; the respondents received a $1(0=$ respondents did not know any of the four categories). Out of the respondents, it appears that the majority of them, 234 (56.7\%), participate in local organizations and have the organizational tools and information about mining, which is what I expected. Self-efficacy is based on a survey question that asked respondents the following question: "Should communities protect their land from mining companies entering them?" The variable is dichotomous (1=yes; $0=$ no). Out of the 397 respondents, it appears that the majority of them, $297(74.8 \%)$ have a higher sense of self-efficacy and believe that they can resist mining, which is what I expected.

Finally, the last two crosstab tables look at two different variables related to community to gauge respondents' community worldview. The first, Community Divided, is based on a survey question that asked individuals if they believed their community was divided. Respondents received a 1 if they believed Rancho Grande was divided; a 0 otherwise. Although not a majority, 47.4\% (190/401) of respondents that participate in community organizations do not think Rancho Grande is divided, which is a stronger relationship than the other options presented in the table and lends support to my expectations. The second, Community Development, which is based on a survey question that asks respondents the following: "Do you believe that people are ready to contribute 
to the development of your community?" It is a dichotomous variable ( $1=\mathrm{yes} ; 0=\mathrm{no})$. It appears that socially engaged individuals are more likely to say yes, $73 \%$ (284/389), to the belief that their fellow community members are ready to help with the development of Rancho Grande, which is what I expected because they have a stronger community worldview. All four relationships do not represent causation, but do show strong correlations between social engagement and the reasons I theorized on how socially engaged individuals form or shape their oppositional attitudes against mining.

Table 5.1: Social Engagement's Relationship with Knowledge, Efficacy, and Community Worldview

\begin{tabular}{|c|c|c|c|}
\hline & \multicolumn{3}{|c|}{ Socially Engaged Individuals } \\
\hline Organizational & \multicolumn{3}{|c|}{ Participation in Community Organizations } \\
\hline & $\begin{array}{c}\text { Does Not } \\
\text { Participate }\end{array}$ & Particpates & Total \\
\hline Yes & 61 & 234 & 295 \\
\hline No & 32 & 86 & 118 \\
\hline \multirow[t]{2}{*}{ Total } & 93 & 320 & 413 \\
\hline & \multicolumn{3}{|c|}{ Socially Engaged Individuals } \\
\hline \multirow[t]{2}{*}{ Self-Efficacy } & \multicolumn{3}{|c|}{ Participation in Community Organizations } \\
\hline & $\begin{array}{c}\text { Does Not } \\
\text { Participate }\end{array}$ & Particpates & Total \\
\hline Yes & 89 & 297 & 386 \\
\hline No & 2 & 9 & 11 \\
\hline \multirow[t]{2}{*}{ Total } & 91 & 306 & 397 \\
\hline & \multicolumn{3}{|c|}{ Socially Engaged Individuals } \\
\hline \multirow[t]{2}{*}{$\begin{array}{c}\text { Community } \\
\text { Divided }\end{array}$} & \multicolumn{3}{|c|}{ Participation in Community Organizations } \\
\hline & $\begin{array}{c}\text { Does Not } \\
\text { Participate }\end{array}$ & Particpates & Total \\
\hline Not Divided & 41 & 190 & 231 \\
\hline Divided & 48 & 122 & 170 \\
\hline \multirow[t]{2}{*}{ Total } & 89 & 312 & 401 \\
\hline & \multicolumn{3}{|c|}{ Socially Engaged Individuals } \\
\hline $\begin{array}{c}\text { Community } \\
\text { Development }\end{array}$ & \multicolumn{3}{|c|}{ Participation in Community Organizations } \\
\hline
\end{tabular}




\begin{tabular}{|c|c|c|c|}
\hline & $\begin{array}{c}\text { Does Not } \\
\text { Participate }\end{array}$ & Particpates & Total \\
\hline Yes & 79 & 284 & 363 \\
\hline No & 6 & 25 & 31 \\
\hline Total & 85 & 309 & 394 \\
\hline
\end{tabular}

Source: Author's data.

\section{Control Variables}

The predominance of the previous literature, one way or another, has utilized both political, economic, and demographic control variables for their impact and influence on mining related resistance. I include a number of these indicators from my survey as control variables. I divided my control variables into four sections. Under the first section, "Mining Variables," I include the following variables Importance of Mining for Nicaragua, Knowledge of the Project, and Proximity to Extraction. I created Importance of Mining using the question, "How important are the mining companies for the economic development of Nicaragua?" The variable is continuous ( $1=$ very important; 2=some importance; $3=$ little importance). Respondents were also asked to gauge their level of mining by measuring their Knowledge of the Project based on survey questions related to B2Gold and mining. This variable is an additive index. I also created a variable, Proximity to Extraction, that captures a respondent's proximity to B2Gold's proposed El Pavón mining project. Those that live in the direct vicinity of the proposed extraction site were coded as 1 ; otherwise they were coded as 0 .

The second set of control variables are my "Political Variables." Respondents were asked to gauge their Approval of the Local Mayor and their level of Political Interest. My third set of control variables are my "Economic Variables." I control for the evaluations of One's Personal Economic Situation as well as evaluations of the National 
Economic Situation. Finally, I control for "Socio-demographic Variables." I control for the respondent's Level of Income, Level of Education, gender (Female), and Age; since I am concerned with local-level attitudes towards mining. In the Appendix for this chapter, one can find more information about my control variables in Table 5.2A ("Variable Coding, Frequency, and Percentages"), Table 5.3A ("Variable Summary Statistics"), and Table 5.4A (“Survey Questions and Variable Explanations”).

\section{First Empirical Findings}

In Table 5.2, I present two different models. In Model 1, I present the results of a logistic regression for only the rights-based claims (Environmental Impact and Agricultural Impact) and service-based claims (Employment Opportunities and Educational Opportunities). Model 2 adds the variable Social Engagement. Both models include the same set of mining variables, political variables, economic variables, and sociodemographic variables.

Table 5.2: Logistic Regression Results for Support of B2Gold's Mining Project

\begin{tabular}{lcc} 
VARIABLES & $\underline{\text { Model 1 }}$ & Model 2 \\
\hline $\begin{array}{lcc}\text { Social } \\
\text { Engagement }\end{array}$ & & \\
\hline Social & & $-0.8790^{* *}$ \\
Engagement & & $(0.409)$ \\
Demands for & & \\
Rights & & \\
Environmental & $-1.5769^{*}$ & $-1.4305^{*}$ \\
Impact & $(0.808)$ & $(0.850)$ \\
Agricultural & $-2.2438^{* * *}$ & $-2.6196^{* * *}$ \\
Impact & $(0.670)$ & $(0.833)$ \\
Demands for & & \\
Services & & \\
Employment & $2.5841^{* *}$ & $2.4995^{* * *}$ \\
Opportunities & $(1.032)$ & $(0.861)$
\end{tabular}




$\begin{array}{lcc}\text { Educational } & 1.6556 & 2.0656 \\ \text { Opportunities } & (1.206) & (1.422) \\ \text { Mining Variables } & & \\ \text { Importance of } & 2.2553 * * * & 2.5607 * * * \\ \text { Mining } & (0.452) & (0.648) \\ \text { Knowledge of } & -0.3817 & -0.1755 \\ \text { Project } & (0.527) & (0.712) \\ \text { Proximity to } & 0.4459 & 1.2409 \\ \text { Extraction } & (0.719) & (0.913) \\ \text { Political } & & \\ \text { Variables } & & \\ \text { Approval of } & 0.2600 & 0.2166 \\ \text { Mayor } & (0.659) & (0.647) \\ \text { Political Interest } & -0.2482 & -0.2539 \\ & (0.411) & (0.429) \\ \text { Economic } & & \\ \text { Variables } & & \\ \text { Personal } & -0.3380 & 0.0695 \\ \text { Economic } & (0.745) & (0.699) \\ \text { Situation } & & \\ \text { National } & -0.5592 & -0.7997 \\ \text { Economic } & (0.681) & (0.645) \\ \text { Situation } & & \end{array}$

Situation

\begin{tabular}{lcc}
$\begin{array}{l}\text { Socio- } \\
\text { demographic } \\
\text { Variables }\end{array}$ & \\
Income & 0.0911 & 0.0729 \\
& $(0.092)$ & $(0.084)$ \\
Education & 0.0838 & 0.2314 \\
Female & $(0.205)$ & $(0.293)$ \\
& 0.1929 & 0.0236 \\
Age & $(0.671)$ & $(0.772)$ \\
& $-1.2810^{* * *}$ & $-1.4685 * * *$ \\
Constant & $(0.453)$ & $(0.569)$ \\
& -1.6656 & -1.2349 \\
& $(2.135)$ & $(2.371)$ \\
Observations & 254 & 254 \\
\hline \multicolumn{4}{r}{ Robust standard errors in parentheses } \\
$* * * \mathrm{p}<0.01, * * \mathrm{p}<0.05, * \mathrm{p}<0.1$
\end{tabular}

My results show that rights-based claims significantly decrease one's likelihood of supporting B2Gold's mining project (Model 1), which is what I expected. I am 99\% 
confident that Agricultural Impacts and 90\% confident that Environmental Impacts decrease one's likelihood of supporting B2Gold's mining project. Conversely, servicebased claims positively and significantly influence one's likelihood of supporting B2Gold's mining project (Model 1), which is what I expected. However, only Employment Opportunities is statistically significant at any conventional level (95\%).

My results hold when I include Social Engagement in Model 2. ${ }^{114}$ As I predicted, Social Engagement is negative and statistically significant at 95\% confidence. This indicates that individuals that engage in local-level organizations (i.e., community organizations, environmental organizations, agricultural organizations, and/or religious organizations) are more likely to oppose mining projects because they more likely have: 1) access to critical organizational tools and information about mining; 2) a higher sense of self-efficacy and collective-efficacy empowering them and their communities; 3) and a stronger community worldview contributing to broad-based mobilization. For my control variables, only Age and Importance of Mining are statistically significant at any conventional level. Age is negative and statistically significant at $99 \%$ confidence in Models 1 and 2. Importance of Mining is positive and statistically significant at 99\% confidence in Models 1 and 2.

The coefficients in a logistic regression do not provide the capability of interpreting substantive effects of my variables of interest. Thus, in Figure 5.13 (Model 1) and Figure 5.14 (Model 2), I display the average marginal effects (with 95\% confidence intervals). I estimate marginal effects or changes in mean predicted probabilities taking into account the observed values of control variables. Notice that my approach for

\footnotetext{
${ }^{114}$ Employment Opportunities level of statistical significance increases to 99\% confidence in Model 2.
} 
estimating marginal effects in mean predicted probabilities does not hold constant control variables at their means or other values, but rather takes into account the full variation of the data. I use the margins command in Stata with the default specification. For more information on the margins command (Mitchell 2012). In Figure 5.13, the likelihood of an individual opposing B2Gold's mining project for environmental reasons and agricultural reasons are approximately 5\% and $8 \%$, respectively. The likelihood of an individual supporting B2Gold's mining project for employment opportunities is approximately $8 \%$. Turning to Figure 5.14 (Model 2), the likelihood of an individual opposing B2Gold's mining project for environmental and agricultural reasons are approximately $5 \%$ and $9 \%$, respectively. The likelihood of an individual supporting B2Gold's mining project for employment opportunities is approximately $8 \%$. An individual that is socially engaged in local community organizations, is approximately $4 \%$ more likely to oppose B2Gold's mining project.

Figure 5.13: Average Marginal Effects with 95\% CIs for Model 1

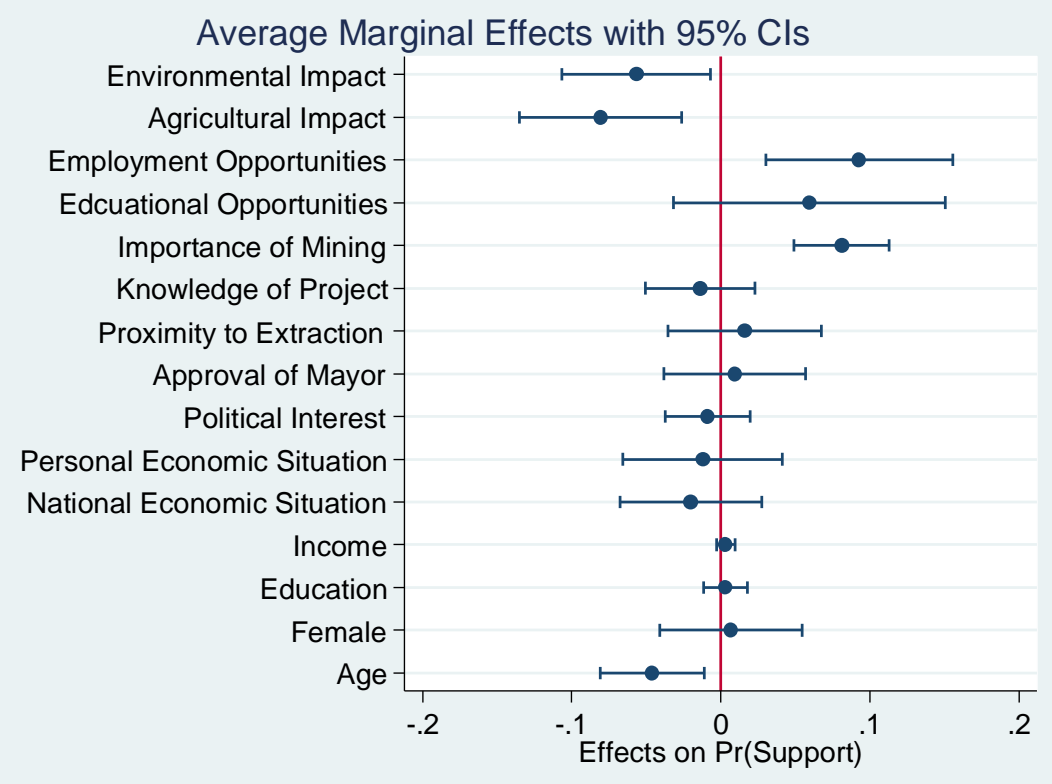




\section{Figure 5.14: Average Marginal Effects with 95\% CIs for Model 2}

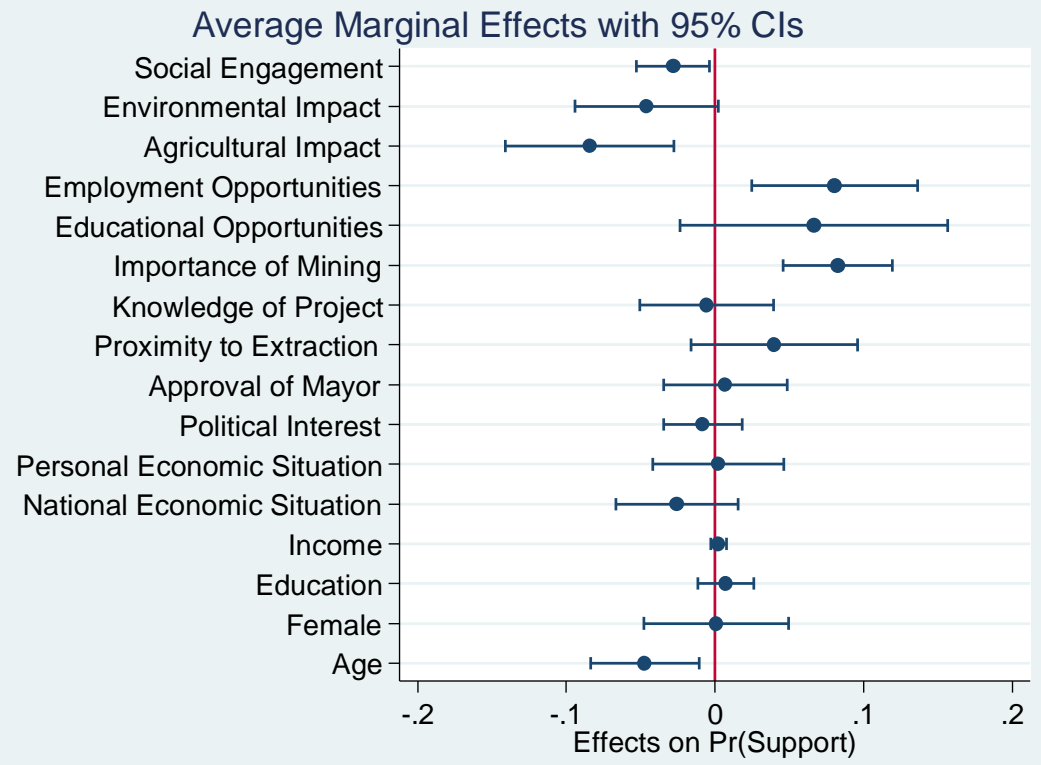

\section{Discussion}

Beyond economic threats (i.e., environmental and agricultural impacts) and social engagement creating oppositional attitudes towards mining in Rancho Grande, there are possible other reasons that can help explain the opposition to B2Gold's El Pavón project. For example, mining companies, like B2Gold, tend to be allies with governments, like Nicaragua's, to develop "fraudulent mechanisms and increasingly sophisticated technologies of socio-cultural penetration to ensure the social license needed to operate in the new territories. It's what mining transnationals and their partners do, even knowing that when they enter a territory they always cause damage to the ways of life, cultures and policies that ensure the social reproduction of the populations living there" (Sanchez Gonzalez 2017). For example, in 2014, after a violent outbreak against protesters in Rancho Grande by supporters of B2Gold, the Vice Minister of the Ministry of Energy 
and Mines (MEM) stated:

No one is going to come to a country to invest a large amount of money, more than 10 to 15 million dollars in an exploration for the search of a resource, and suddenly it will not have the right to produce it ... in a certain sense we have to guarantee that if they find gold, they can produce it, to recover their investment that they have made in the country...

The Vice Minister's statements raise two clear reflections. First, they ignore what is regulated by Nicaragua's Environmental Law 217 and Decree 76-2006 of the

Environmental Assessment System, which refers to environmental assessment procedures for mining projects such as the preparation of studies, holding public consultations, and an authorization or denial by the competent national, regional, or territorial authority. Thus, just because B2Gold has a mining concession to explore the areas around Rancho Grande, does not grant it the environmental permits to exploit gold. The company still needs to go through an environmental assessment that could conclude, as Law 217 suggests, with the authorization or the denial by the competent authority (Centro Humboldt 20145).

The second reflection from the statements of the former Vice Minister of the MEM, is that the words denote a clear "deviation of power" to pretend to disguise an act for which the national government has jurisdiction. In fact, in Nicaragua, there exists no national laws that give MEM the absolute power to decide unilaterally on whether or not to execute a mining exploitation or exploration concession. There are controls linked to municipal autonomy to the environmental authority, and above all, to the constitutional rights of the population such as life, health, healthy environment, education, and the right to be consulted (Centro Humboldt 20145). 
Inhabitants of Rancho Grande are not only battling their government's neglect and inaction, but also the mining company B2Gold's divisiveness. For example, in October 2014, local authorities began collecting signatures for activities that never before had required such information, such as: medical appointments, visits to the police, matriculation of students, etc. They delivered the signatures to B2Gold, who in an illicit manner and lack of procedural logic, intended to use them to obtain a supposed "Social Guarantee" for the project "El Pavón." Essentially, B2Gold wanted to use the signatures to falsely demonstrate that citizens of Rancho Grande supported mining (Centro Humboldt 2015b).

Sanchez Gonzalez (2017) notes that mining companies also resort to violence and governments criminalize protesters. Both mining companies and governments manipulate those in resistance through fear tactics and mechanisms of domination. In Rancho Grande, community members, members of Guardines de Yaoska, members of churches, and other local organizations were subjected to different forms of violence. Sanchez Gonzalez (2017) discusses some violent actions taken by officials of B2Gold against community members in Rancho Grande, especially farming families. The follow passage is a citizen from Rancho Grande, as quoted in Sanchez Gonzalez (2017):

There was a lot of intimidation. People told me about it. People disguised with hoods came to their houses and asked them if they had guns, or if they had drugs. One was detained for a month after they found a gun he had, but he had bought it legally and hadn't committed any crime. They stole C\$10,000 (US\$300) from this man's house and fondled his wife and forced her to get undressed saying she was hiding guns and drugs.... Others were taken to B2Gold premises rather than the police station for interrogation. They sent people to convince local inhabitants not to go against mining, saying that if they did they would suffer reprisals. 
Sanchez Gonzalez (2017) also discusses how Father Pablo Espinoza, the Rancho Grande parish priest, told him:

Rumors are always circulating about what they're planning, but they don't scare me. Death threats just give us priests more courage. Many Delegates of the Word have been detained by the police at the crossroads when they leave their communities to see if they have their documents with them and they're in order...

Sanchez Gonzalez (2017) also demonstrates how B2Gold tried coercive tactics on José Rolando Álvarez Lagos, the bishop of Matagalpa who told him that:

At first they wanted to convince us of the feasibility and importance of mining. The second time they tried to approach us with ignoble intentions, disrespecting our criteria and our positions. On the third occasion I would call it coercion, because they wanted to pressure us from different angles, using upper-level personalities from the ecclesiastic, political and economic world to lobby us.

Based on these passages, it is necessary to emphasize that the technical, environmental, economic, and social implications of B2Gold's El Pavón mining project were and are completely unknown. Citizens of Rancho Grande "called for implementation of the consultation provisions in the 2003 Citizen Participation Law (\#475), which were designed to facilitate local level involvement in municipal development policy discussions" (Spalding 2016, 18). However, to date, it has never been publicly consulted or presented to any sector of the population of Rancho Grande by either B2Gold or representatives from Nicaraguan government agencies (Centro Humboldt 2015b). In most instances in Rancho Grande, B2Gold has not followed their commitments to environmental stewardship and social responsibility, while the Nicaraguan government has failed to follow their own mining laws or support the local population of Rancho Grande. Both the negligence of B2Gold and Nicaragua's government, as well as the 
negative impacts associated with mining have also influenced opposition in Rancho Grande.

Finally, mining never previously existed in Rancho Grande like it did in other locations throughout Nicaragua (i.e., departments of Nueva Segovia, Chontales, and RAAN). For example, artisanal mining never even existed in Rancho Grande or the surrounding areas, let alone large scale mining. This could perhaps have made citizens of Rancho Grande more oppositional towards mining because they never had any preexisting experiences, positive or negative. Essentially, there was more on the line for the citizens of Rancho Grande than other locations throughout Nicaragua. Citizens understood that mining would destroy their water sources, their environment, and their agricultural livelihoods, which led to approximately $90 \%$ of the community opposing B2Gold and its activities. ${ }^{115}$

\section{Dependent Variable and Statistical Model—Religion as a Catalyst for Success}

In the second part of my analysis, my second dependent variable-Successful Protest against B2Gold's mining activities — is a dichotomous variable that asks respondents the following: "Have the protests organized by your community been successful against the mining company?" 116 In the survey, $15.12 \%$ of respondents in Rancho Grande believed their protest movement against B2Gold's mining activities was unsuccessful, while $84.88 \%$ of the respondents believed that their protest movement was successful. Figure

\footnotetext{
115 Author's personal interview with a community member in Rancho Grande: January 2017.

116 In the Appendix for this chapter, one can find more information about my dependent variable in Table 5.2A ("Variable Coding, Frequency, and Percentages"), Table 5.3A ("Variable Summary Statistics"), and Table 5.4A ("Survey Questions and Variable Explanations").
} 
5.15 displays a bar graph that shows 275 out of 324 of my survey respondents that believed Rancho Grande's protest movement was successful in overturning B2Gold's mining concession via a policy change by the national government. Given the dichotomous nature of the dependent variable, I use a logistic regression model.

\section{Figure 5.15: Respondent Beliefs About Successful Mining Protest Movement}

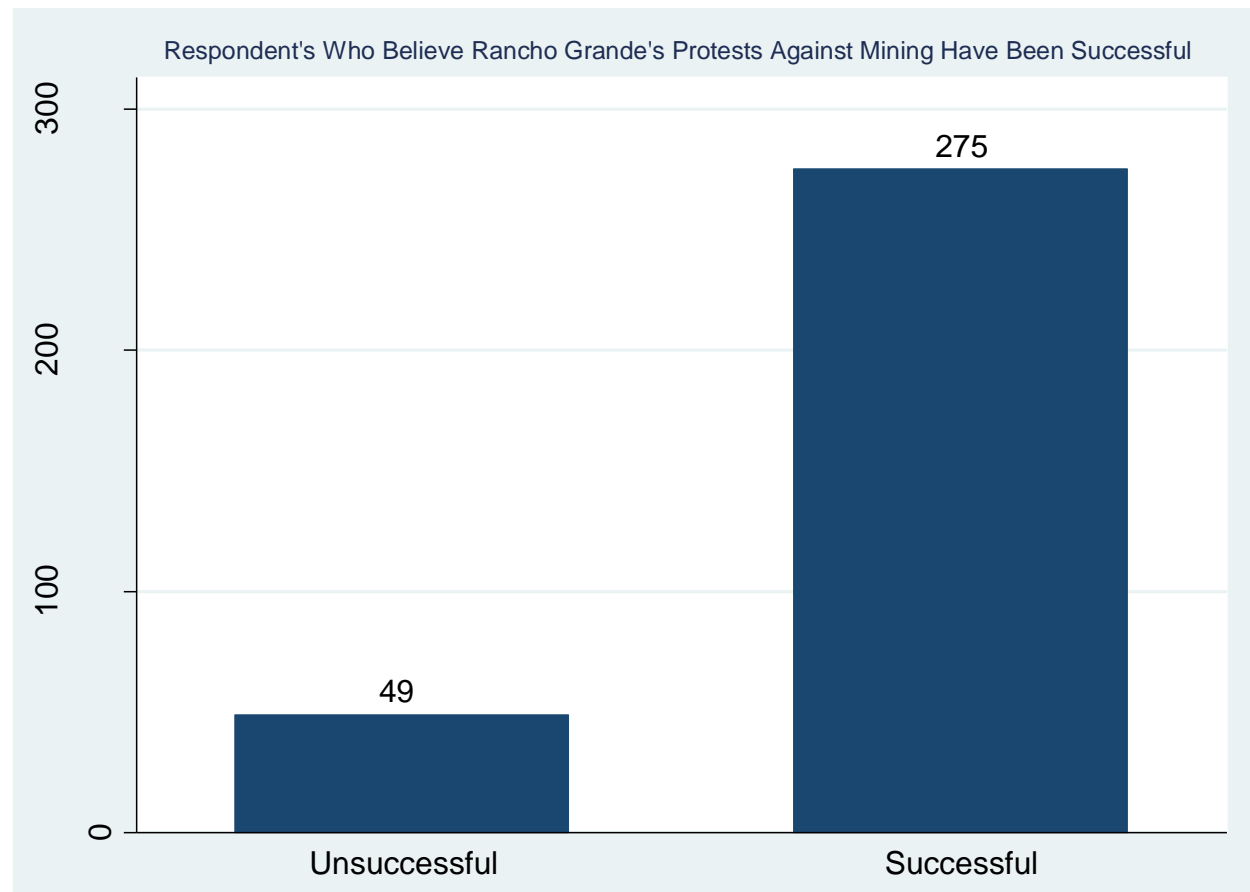

Source: Author's data.

\section{Independent Variables—Demands for Rights, Demands for Services, Social}

\section{Engagement, and Religion as a Catalyst}

I am broadly interested in why Rancho Grande was able to halt B2Gold's mining concession in their community and Santo Domingo cannot. As previously discussed, Arce (2014b, 2015) and Arce and Hendricks (forthcoming) claim that successful campaigns against mineral extraction are more likely to encompass rights-based claims 
than service-based claims. Therefore, like in the previous analytical section of this chapter, I use the rights- and service-based variables. Thus, four of my independent variables include the same two variables measuring demands for rights; Environmental Impacts and Agricultural Impacts and the same two variables gauging demands for services: Employment Opportunities and Educational Opportunities. Additionally, since I show support in my previous analytical section for how Social Engagement provides individuals with: 1) access to critical organizational tools and information about mining; 2) a higher sense of self-efficacy and collective-efficacy empowering them and their communities to resist mining; 3 ) and a stronger community worldview contributing to broad-based mobilization; I include Social Engagement in my models in this analytical section as well. One should recall that Social Engagement is an additive index that measures the frequency of participation by individuals in community organizations, agricultural organizations, environmental organizations, and religious organizations.

In Table $5.3^{117}$, I disaggregated the components that make up my Social Engagement variable (i.e., participation and engagement in community organizations, environmental organizations, agricultural organizations, and religious organizations) with my dependent variable—Successful Protest. Table 5.3 specifically examines crosstabs between religious social engagement and protest success, environmental social engagement and protest success, agricultural social engagement and protest success, and community social engagement and protest success. The relationship between religious social engagement with protest success is much stronger than the other three social engagement components (participation and engagement in environmental organizations,

${ }^{117}$ Data for Table 5.3 are from the author's survey data. 
agricultural organizations, and community organizations). In fact, the other three social engagement components actually have a stronger correlation with not attending an organizational meeting and protest success. Therefore, respondents that participate in religious organizations appear to more likely believe that Rancho Grande was successful in overturning B2Gold's mining concession than respondents that participated in other community organizations, environmental organizations, and agricultural organizations. This demonstrates the importance community members hold for the role that religion played in assisting them become united against mining, and successfully ending B2Gold's influence in the community.

Table 5.3: Disaggregated Social Engagement Components and Relationship with Protest Success

\begin{tabular}{|c|c|c|c|}
\hline \multirow{2}{*}{$\begin{array}{l}\text { Protest } \\
\text { Successful }\end{array}$} & \multicolumn{3}{|c|}{ Religious Social Engagement } \\
\hline & $\begin{array}{l}\text { Attends a Religious } \\
\text { Organization Regularly }\end{array}$ & $\begin{array}{l}\text { Does Not Attend a } \\
\text { Religious Organization } \\
\text { Regularly }\end{array}$ & Total \\
\hline Yes & 195 & 80 & 275 \\
\hline No & 29 & 20 & 49 \\
\hline Total & 224 & 100 & 324 \\
\hline $\begin{array}{l}\text { Protest } \\
\text { Successful }\end{array}$ & \multicolumn{3}{|c|}{ Environmental Social Engagement } \\
\hline & $\begin{array}{l}\text { Attends an Environmental } \\
\text { Organization Regularly }\end{array}$ & $\begin{array}{l}\text { Does Not Attend an } \\
\text { Environmental } \\
\text { Organization Regularly }\end{array}$ & Total \\
\hline Yes & 90 & 185 & 275 \\
\hline No & 13 & 36 & 49 \\
\hline Total & 103 & 221 & 324 \\
\hline $\begin{array}{l}\text { Protest } \\
\text { Successful }\end{array}$ & \multicolumn{3}{|c|}{ Agricultural Social Engagement } \\
\hline & $\begin{array}{l}\text { Attends an Agricultural } \\
\text { Organization Regularly }\end{array}$ & $\begin{array}{l}\text { Does Not Attend an } \\
\text { Agricultural Organization } \\
\text { Regularly }\end{array}$ & Total \\
\hline Yes & 72 & 203 & 275 \\
\hline No & 12 & 37 & 49 \\
\hline Total & 84 & 240 & 324 \\
\hline
\end{tabular}




\begin{tabular}{|l|c|c|c|}
\hline $\begin{array}{l}\text { Protest } \\
\text { Successful }\end{array}$ & \multicolumn{3}{|c|}{ Community Social Engagement } \\
\hline & $\begin{array}{l}\text { Attends a Community } \\
\text { Organization Regularly }\end{array}$ & $\begin{array}{l}\text { Does Not Attend a } \\
\text { Community Organization } \\
\text { Regularly }\end{array}$ & Total \\
\hline Yes & 131 & 144 & 275 \\
\hline No & 19 & 30 & 49 \\
\hline Total & 150 & 174 & 324 \\
\hline
\end{tabular}

Source: Author's data.

My main independent variable of interest for this analytical section is Religion, since I theorize that religion is the catalyzing agent that leads to successful protest movements against mining activities. Below, Figure 5.16 displays a bar graph that depicts survey respondents' religion by type. As previously mentioned and consistent with the two most popular religions in Nicaragua, the respondents' in Rancho Grande are overwhelmingly Catholic (170/403) and Evangelical (192/403). Religion is a dichotomous variable that asks respondents the following: "In solution of mining conflicts between the community population and the mining company, how would you rate the work of the Churches?" The variable is coded as 1 if respondents rated Churches as (very) positive; and 0 otherwise. In the survey, $93.02 \%$ of respondents in Rancho Grande rated the Churches positively in response to assisting the community solve its mining conflict. Only $6.98 \%$ did not think positively of the Churches. In the Appendix for this chapter, one can find more information about Religion in Table 5.2A ("Variable Coding, Frequency, and Percentages"), Table 5.3A ("Variable Summary Statistics"), and Table 5.4A ("Survey Questions and Variable Explanations"). 


\section{Figure 5.16: Respondent's Religion by Type}

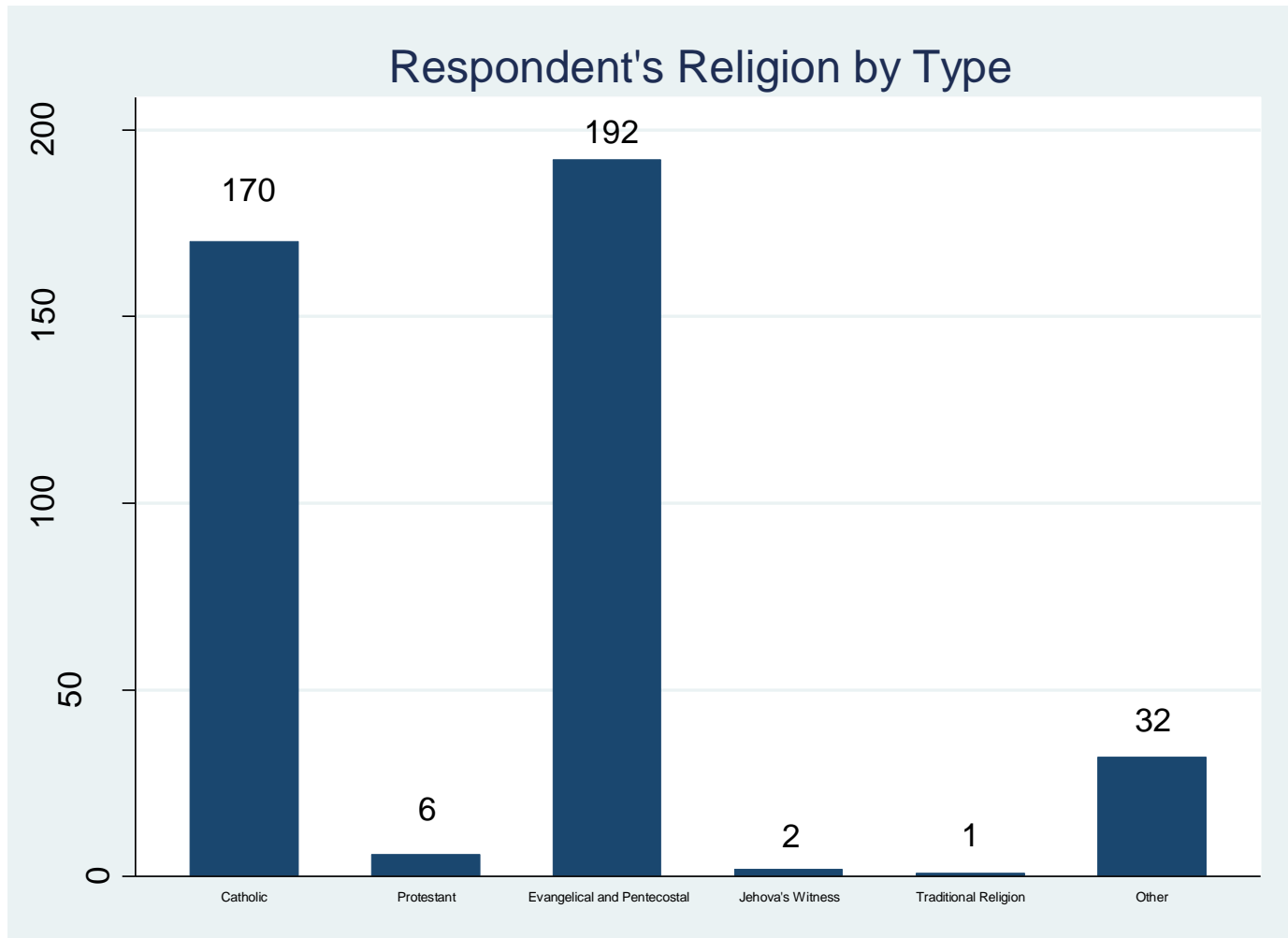

Source: Author's data.

\section{Control Variables}

Similar to the previous analytical section I include indicators from my survey as control variables. Like before, I divided my control variables into sections. I have added a section, "Community Variables." Under the first section, "Mining Variables," I again include the variables Knowledge of the Project and Proximity to Extraction. I exclude Importance of Mining for Nicaragua in this analysis. My "Community Variables" are Interpersonal Trust and Community Divided. Interpersonal Trust is a variable created from the following survey question: "Would you say the people in your community are trustworthy?" The variable is coded as dichotomous $(1=$ (very) trustworthy and $0=($ very $)$ untrustworthy). Community Divided is a variable that is based on the following survey 
question: "For you, is your community divided?" The variable is dichotomous $(1=$ yes and $0=$ no).

For my "Political Variables" I continue using Approval of the Local Mayor and level of Political Interest. I also incorporate Public Corruption and Political Ideology. Public Corruption asks respondents the following question: "Have you ever seen a public official accept a bribe?" The variable is dichotomous ( $1=$ yes; $0=$ no). Political Ideology is a continuous variable that asked respondents to rate their political ideology on a left (1) to right (10) scale. For my "Economic Variables", I continue to control for are the evaluations of One's Personal Economic Situation as well as evaluations of the National Economic Situation. Finally, I control for "Socio-demographic Variables." I continue to control for the respondent's Level of Income, Level of Education, gender (Female), and Age. In the Appendix for this chapter, one can find more information about my control variables in Table 5.2A ("Variable Coding, Frequency, and Percentages"), Table 5.3A ("Variable Summary Statistics"), and Table 5.4A ("Survey Questions and Variable Explanations").

\section{Second Empirical Findings}

In Table 5.4, I present three different models. In Model 3, I present the results of a logistic regression for only Religion and my socio-demographic variables. Model 4 adds my rights-based variables (Environmental Impact and Agricultural Impact), my servicebased variables (Employment Opportunities and Educational Opportunities), and Social Engagement. Model 5 adds the rest of my control variables. 
Table 5.4: Logistic Regression Results for Successful Protest

\begin{tabular}{|c|c|c|c|}
\hline VARIABLES & Model 3 & Model 4 & Model 5 \\
\hline \multicolumn{4}{|l|}{$\overline{\text { Religion }}$} \\
\hline Religion & $\begin{array}{c}1.3367 * * \\
(0.552)\end{array}$ & $\begin{array}{c}1.2573 * * \\
(0.553)\end{array}$ & $\begin{array}{c}2.1408 * * \\
(1.056)\end{array}$ \\
\hline \multicolumn{4}{|l|}{$\begin{array}{l}\text { Social } \\
\text { Engagement }\end{array}$} \\
\hline Social & & 0.0796 & 0.0594 \\
\hline Engagement & & $(0.161)$ & $(0.257)$ \\
\hline \multicolumn{4}{|l|}{$\begin{array}{l}\text { Demands for } \\
\text { Rights }\end{array}$} \\
\hline Environmental & & -1.1710 & Omitted $^{118}$ \\
\hline Agricultural & & 0.5073 & 0.8383 \\
\hline Impact & & $(0.446)$ & $(0.573)$ \\
\hline \multicolumn{4}{|l|}{$\begin{array}{l}\text { Demands for } \\
\text { Services }\end{array}$} \\
\hline Employment & & 0.0250 & -0.0952 \\
\hline Opportunities & & $(0.421)$ & $(0.612)$ \\
\hline Educational & & -0.5918 & $-1.8870 * *$ \\
\hline Opportunities & & $(0.712)$ & $(0.914)$ \\
\hline \multicolumn{4}{|l|}{ Mining Variables } \\
\hline Knowledge of & & & 0.0460 \\
\hline Project & & & $(0.501)$ \\
\hline Proximity to & & & $-1.2484 *$ \\
\hline Extraction & & & $(0.668)$ \\
\hline \multicolumn{4}{|l|}{ Community } \\
\hline Interpersonal & & & 1.0670 \\
\hline Trust & & & $(0.651)$ \\
\hline Community & & & -0.1541 \\
\hline Divided & & & $(0.602)$ \\
\hline \multicolumn{4}{|l|}{$\begin{array}{l}\text { Political } \\
\text { Variables }\end{array}$} \\
\hline Approval of & & & -0.2870 \\
\hline Mayor & & & $(0.684)$ \\
\hline Public Corruption & & & $\begin{array}{l}-0.5700 \\
(0.910)\end{array}$ \\
\hline Political Interest & & & $\begin{array}{l}0.1550 \\
(0.447)\end{array}$ \\
\hline Political Ideology & & & $\begin{array}{l}-0.1242 \\
(0.091)\end{array}$ \\
\hline $\begin{array}{l}\text { Economic } \\
\text { Variables }\end{array}$ & & & \\
\hline
\end{tabular}

${ }^{118}$ Environmental Impact was omitted because it was a perfect predictor of Successful Protest. 


\begin{tabular}{llll}
$\begin{array}{l}\text { Personal } \\
\text { Economic } \\
\text { Situation } \\
\text { National }\end{array}$ & & & 0.2568 \\
Economic & & & $(0.512)$ \\
Situation & & & -0.1889 \\
Socio- & & $(0.413)$ \\
demographic & & & \\
Variables & & & \\
Income & 0.0147 & 0.0174 & -0.0595 \\
& $(0.040)$ & $(0.040)$ & $(0.064)$ \\
Education & -0.0158 & -0.0211 & 0.1884 \\
& $(0.163)$ & $(0.167)$ & $(0.270)$ \\
Female & 0.3957 & 0.4963 & -0.1733 \\
& $(0.378)$ & $(0.375)$ & $(0.553)$ \\
Age & 0.0335 & 0.0738 & 0.5585 \\
& $(0.314)$ & $(0.305)$ & $(0.464)$ \\
Constant & & & \\
& 0.2631 & 0.7536 & -1.9457 \\
& $(1.173)$ & $(1.439)$ & $(2.645)$ \\
Observations & & & \\
\hline & 242 & 242 & 133 \\
\hline
\end{tabular}

Robust standard errors in parentheses
$* * * \mathrm{p}<0.01, * * \mathrm{p}<0.05, * \mathrm{p}<0.1$

In Model 3, my results show that Religion significantly increases (95\% confident) one's likelihood of believing that the protest movement against B2Gold and mining was successful in leading to a national-level policy change that overturned B2Gold's mining concession, which is what I expected. In Model 3, none of my socio-demographic control variables are at conventional levels for statistical significance. In Model 4, I add my rights- and service-based variables and Social Engagement. My results continue to show that Religion significantly increases (95\% confident) one's likelihood of believing that the protest movement against B2Gold and mining was successful in leading to a nationallevel policy change that overturned B2Gold's mining concession, which is what I expected. My rights-based variables, service-based variables, Social Engagement, and my 
socio-demographic control variables are not statistically significant at any conventional level. I believe this indicates that Religion is likely the driving force behind successful protest movements against the extractive industry.

In Model 5, I add the rest of my control variables. My results hold and continue to show that Religion increases (95\% confident) one's likelihood of believing that the protest movement against B2Gold and mining was successful in leading to a nationallevel policy change that overturned B2Gold's mining concession, which is what I expected. My rights-based variables and my socio-demographic control variables are not statistically significant at any conventional level. Again, Social Engagement is not statistically significant at any conventional level in Model 5. I expected that socially engaged individuals would be more effective and successful in their resistance against mining, but perhaps this gives credence to the power behind religion's role in Rancho Grande's successful resistance. In Model 5, Educational Opportunities is negative and statistically significant at the 95\% confidence level and Proximity to Extraction is negative and statistically significant at the $90 \%$ confidence level. Environmental Impact was omitted because it was a perfect predictor of Successful Protest. None of my control variables were significant at any conventional level.

As I previously discussed, the coefficients in a logistic regression do not provide the capability of interpreting substantive effects of my variables of interest. Thus, in Figure 5.17 (Model 5), I display the average marginal effects (with 95\% confidence intervals). Again, I estimate marginal effects or changes in mean predicted probabilities taking into account the observed values of control variables. Notice that my approach for estimating marginal effects in mean predicted probabilities does not hold constant control 
variables at their means or other values, but rather takes into account the full variation of the data. Like before, I use the margins command in Stata with the default specification (Mitchell 2012). In Figure 5.17, the likelihood of an individual believing that the protest movement against B2Gold and mining was successful due to religion and the Church's role in Rancho Grande is approximately 30\%. This demonstrates the crucial role that Catholic Church, the Evangelical Church, religious leaders, and the community's faith and conviction in God had in assisting the community of Rancho Grande resist mining and successfully halt mining from impacting the community.

Figure 5.17: Average Marginal Effects with 95\% CIs for Model 6

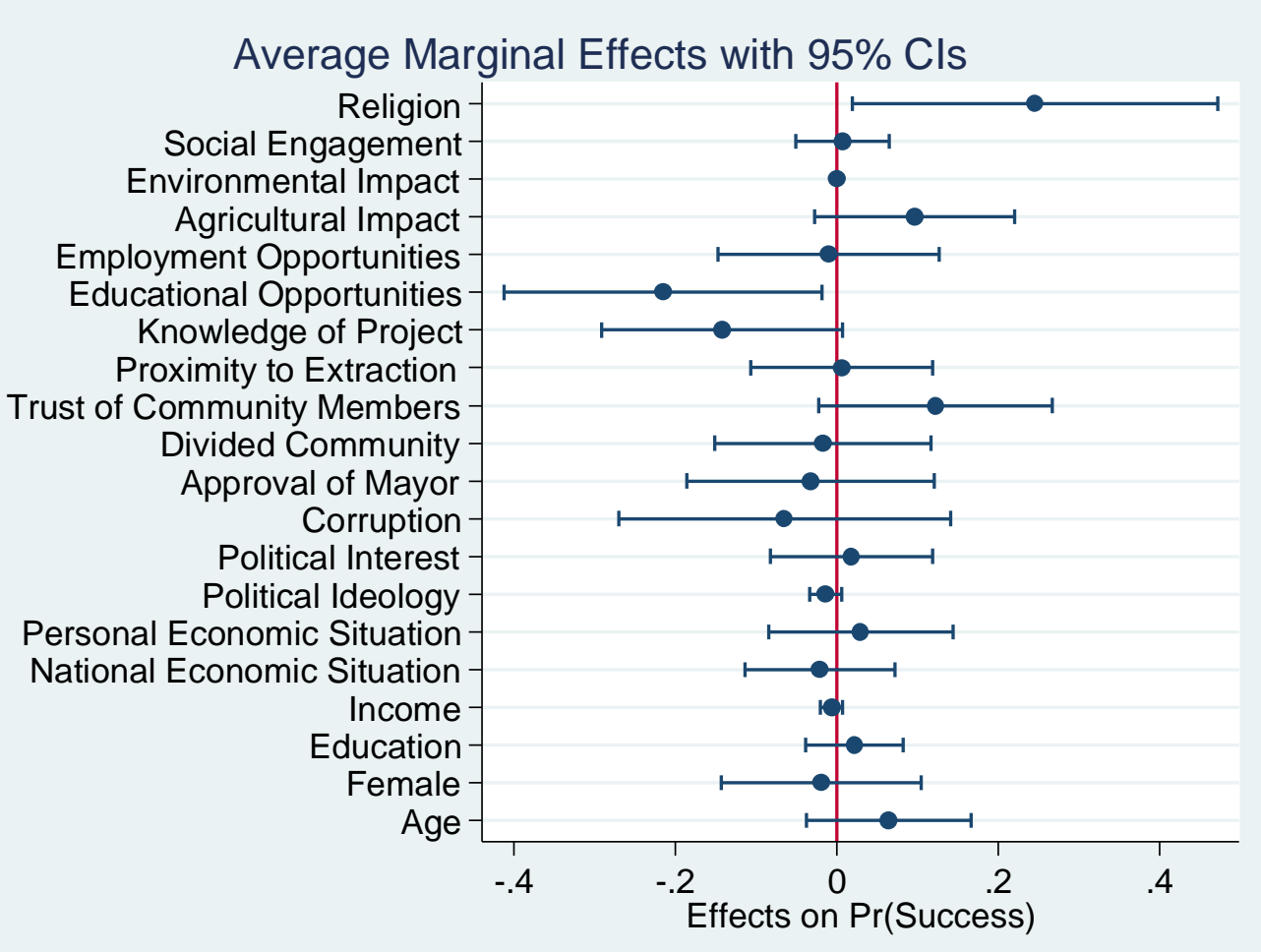




\section{Discussion}

Beyond religion's role as a catalyst for success in overturning B2Gold's mining concession in Rancho Grande, there are possible other reasons that can help explain Rancho Grande's success against mining. Rancho Grande's use of nonviolent strategies throughout its social movement were very helpful in helping the community overturn B2Gold's mining concession. The community peacefully marched on the streets and highways through different communities in Rancho Grande spreading their antiextraction and pro-environmental message, as well as setting up roadblocks preventing B2Gold from entering communities. The use of nonviolent strategies was important for their success because they did not want to be viewed as criminals, which would have hurt their cause. Some communities in Nicaragua have become militant against mining and used violent means. These communities were criminalized and punished, which ultimately hurt their chances at successfully stopping mining's influences. ${ }^{119}$

In addition to using nonviolent means, Rancho Grande’s social movement against mining remained nonpolitical, which the community also attests to its success in halting B2Gold's mining concession. When news about Rancho Grande started to receive national and international attention, different Nicaraguan political party bosses visited Rancho Grande to see if they could offer any services. The community expressed its gratitude to the party bosses, but the party bosses were always asked to politely leave. The community did not want the social movement to become a political game because then it would be left in the hands of politicians, which citizens knew would not lead to the community's success against mining.

\footnotetext{
${ }^{119}$ Author's personal interview with a leader from Guardines de Yaoska social movement group and a representative from ADDAC: January 2017.
} 
Additionally, the Churches always made sure that Rancho Grande remained nonpolitical, particularly in national politics, because they wanted to ensure that the issues facing the communities of Rancho Grande were at the forefront of the social movement and not in the hands of politicians. Additionally, towards the final years of Rancho Grande's anti-extraction movement, the community started to be covered by national and international media outlets. Media used cameras and video cameras to capture Rancho Grande's efforts, which helped the community gain local, national, and international attention. Media attention put pressure on President Daniel Ortega and his dominantly controlled FSLN government for the 2016 Nicaraguan elections, which could have been a factor for Rosario Murillo's decision to reverse B2Gold's mining concession. ${ }^{120}$

\section{Conclusion}

To date, research on the politics of resource extraction focuses on successful campaigns against extraction and emphasizes the sources of opposition to mining. With few exceptions, existing research has also rarely explored individual-level attitudes related to resource extraction. Departing from previous scholarship, and based on original data from a 2018 survey in Rancho Grande, Matagalpa, Nicaragua, I trace the sources of opposition and support for resource extraction at the individual level in a context where there is both resistance to and backing for mining in order to understand the attitudes, beliefs, and characteristics of individuals in the context of successful resistance movements against mining.

\footnotetext{
${ }^{120}$ Author's personal interview with a leader from Guardines de Yaoska social movement group, a community member from Rancho Grande, and a representative from ADDAC: January 2017.
} 
My results reveal that individuals who perceive the impact of mining as an environmental threat that is detrimental to agriculture and the environment are more likely to oppose B2Gold and its mining activities. Additionally, individuals that are more socially engaged in community organizations are more likely to oppose B2Gold and its mining activities. My only control variable that indicates opposition towards mining is a respondent's age, which suggests that the older the respondent the more likely he or she opposes mining. This makes sense since typically younger individuals are probably more likely to support mining if it generates employment opportunities. In fact, results show that individuals who perceive the impact of mining for economic opportunities like the generation of employment opportunities are more likely to support the mining project. Additionally, mining appears to matter for the importance of Nicaragua's economic development. Individuals are more likely to support mining if it assists the country's economic growth and development. This likely speaks to the impact of Nicaragua's mining boom discussed in Chapter 2. These results remain robust across several models as well as with the inclusion of a host of theoretical and control variables. Ultimately, the future of resource extraction in Nicaragua faces the paradox of individual support and collective resistance.

There is growing divide between those who oppose extraction and those who support it, which is why it is essential that scholars begin to study the rarely explored individual-level attitudes, beliefs, and characteristics related to resource extraction. In doing so, social scientists can start to understand the "variegated individual responses to mining" that underline the aggregate stories of homogenous community resistance (Dougherty 2018, 2). My study demonstrates reasons why and how individuals living in 
the extractive frontier either support or oppose mining and mining projects. By understanding individual attitudes, beliefs, and characteristics towards mining, scholars of extractive protests and social movements will be able to better understand the individual mechanisms that lead citizens in the extractive frontier to either partake in mining resistance or abstain.

In order to understand what makes protests successful or unsuccessful, scholars need to understand what makes individuals oppose or support resource extraction. Opposition and support towards mining are not mutually exclusive from protest success in overturning a mining concession. They build off each other. My study of Rancho Grande shows what individuals believe makes their protests and social movements more successful after fully understanding what makes them either oppose or support resource extraction.

Although studies are rare on the church's role in extractive protests, it appears that a trend is growing, not just in the literature, but in application of the church, church leadership, and religious organizations assisting communities with anti-mining movements across Latin America based on environmental activism and protection against the harmful impacts from mining. I have shown, qualitatively and quantitatively, that religion is a key component in the creation and mobilization of social movements and protests, including extractive protests against mining. Citizens in Rancho Grande believe that religion (i.e., churches, church leaders, religious organizations, and faith and conviction in God) is likely to lead to a successful extractive protest movement. 


\section{Appendix}

Table 5.1A: Survey Sample of Rancho Grande, Matagalpa

\begin{tabular}{|l|l|l|}
\hline Neighborhoods & Individuals & \# of Surveys \\
\hline Resistencia & 59 & 5 \\
\hline San Martín & 45 & 4 \\
\hline 13 de Mayo & 44 & 3 \\
\hline Fátima & 46 & 4 \\
\hline Paz y Progreso & 51 & 4 \\
\hline Linda Vista & 57 & 5 \\
\hline La Unión & 74 & 6 \\
\hline & & \\
\hline Districts & Individuals & of Surveys \\
\hline Colonia Agrícola & 839 & 70 \\
\hline Lana Arriba & 181 & 14 \\
\hline Pájaro Central & 108 & 9 \\
\hline Yahoska & 238 & 20 \\
\hline Las Brisas & 145 & 12 \\
\hline Mancera & 160 & 13 \\
\hline Las Carpas & 585 & 49 \\
\hline Rancho Grande & 358 & 30 \\
\hline Buenos Aires & 176 & 15 \\
\hline Cuyuca & 167 & 14 \\
\hline El Achiote & 149 & 12 \\
\hline Kiwaska & 84 & 7 \\
\hline San Antonio de Kuskawas & 176 & 15 \\
\hline Cerro Grande & 36 & 3 \\
\hline Castilla & 150 & 12 \\
\hline Cerro Verde & 72 & 6 \\
\hline El Cacao & 202 & 17 \\
\hline Caño Negro & 113 & 9 \\
\hline Caño Blanco & 159 & 13 \\
\hline San José de Kuskawas & 54 & 4 \\
\hline Bilampi & 204 & 8 \\
\hline El Socorro & 96 & $\mathbf{4 0 0}$ \\
\hline & & \\
\hline Total & $\mathbf{4 8 2 8}$ & \\
\hline & & \\
\hline
\end{tabular}


Table 5.2A: Variable Coding, Frequency, and Percentages

\begin{tabular}{|c|c|c|c|c|c|}
\hline Variable & $N$ & Mode & Coding & Frequency & Percentage \\
\hline \multicolumn{6}{|c|}{ DEPENDENT VARIABLES } \\
\hline \multicolumn{6}{|c|}{ Support for Mining } \\
\hline \multirow{2}{*}{$\begin{array}{l}\text { Support for } \\
\text { Mining }\end{array}$} & \multirow{3}{*}{$\begin{array}{c}41 \\
3\end{array}$} & \multirow[t]{2}{*}{0} & 0 & 374 & 90.56 \\
\hline & & & $1=$ Support & 39 & 9.44 \\
\hline \multicolumn{5}{|c|}{ Successful Protest } & \\
\hline \multirow{2}{*}{$\begin{array}{c}\text { Successful } \\
\text { Protest }\end{array}$} & \multirow[t]{2}{*}{324} & \multirow[t]{2}{*}{1} & 0 & 49 & 15.12 \\
\hline & & & $1=$ Success & 275 & 84.88 \\
\hline \multicolumn{6}{|c|}{ INDEPENDENT VARIABLES } \\
\hline \multicolumn{6}{|c|}{ Engagement } \\
\hline \multirow{5}{*}{$\begin{array}{c}\text { Social } \\
\text { Engagement }\end{array}$} & \multirow{5}{*}{$\begin{array}{c}41 \\
3\end{array}$} & \multirow[t]{5}{*}{1} & $0=$ No engagement & 93 & 22.52 \\
\hline & & & $\begin{array}{c}1=\text { Engaged in } 1 \\
\text { organization }\end{array}$ & 134 & 32.45 \\
\hline & & & $\begin{array}{l}2=\text { Engaged in } 2 \\
\text { organizations }\end{array}$ & 80 & 19.37 \\
\hline & & & $\begin{array}{c}3=\text { Engaged in } 3 \\
\text { organizations }\end{array}$ & 56 & 13.56 \\
\hline & & & $\begin{array}{c}4=\text { Engaged in } 4 \\
\text { organizations }\end{array}$ & 50 & 12.11 \\
\hline \multirow[t]{2}{*}{ Religion } & \multirow[t]{2}{*}{358} & \multirow[t]{2}{*}{1} & $0=($ Very) negative & 25 & 6.98 \\
\hline & & & $1=$ (Very) positive & 333 & 93.02 \\
\hline \multicolumn{6}{|c|}{ Demands for Rights } \\
\hline \multirow{2}{*}{$\begin{array}{c}\text { Environmenta } \\
1 \text { Impact }\end{array}$} & \multirow[t]{2}{*}{413} & \multirow[t]{2}{*}{1} & 0 & 87 & 21.07 \\
\hline & & & 1=Negative impact & 326 & 78.93 \\
\hline \multirow{2}{*}{$\begin{array}{l}\text { Agricultural } \\
\text { Impact }\end{array}$} & \multirow[t]{2}{*}{413} & \multirow[t]{2}{*}{1} & 0 & 94 & 22.76 \\
\hline & & & $\begin{array}{c}1=\text { Agree that mining } \\
\text { damages }\end{array}$ & 319 & 77.24 \\
\hline \multicolumn{6}{|c|}{ Demands for Services } \\
\hline \multirow{2}{*}{$\begin{array}{l}\text { Employment } \\
\text { Opportunities }\end{array}$} & \multirow[t]{2}{*}{413} & \multirow[t]{2}{*}{0} & 0 & 271 & 65.62 \\
\hline & & & 1=Positive impact & 142 & 34.38 \\
\hline \multirow{2}{*}{$\begin{array}{c}\text { Educational } \\
\text { Opportunities }\end{array}$} & 413 & 0 & 0 & 381 & 92.25 \\
\hline & & & $1=$ Positive impact & 32 & 7.75 \\
\hline & & & ONTROL VARIABL & & \\
\hline & & & Mining Variables & & \\
\hline Knowledge of & 413 & 1 & $0=$ No knowledge & 145 & 35.11 \\
\hline Project & & & $\begin{array}{c}1=\text { Knowledge of one } \\
\text { indicator }\end{array}$ & 226 & 54.72 \\
\hline & & & $\begin{array}{c}2=\text { Knowledge of two } \\
\text { indicators }\end{array}$ & 42 & 10.17 \\
\hline Proximity to & 413 & 0 & 0 & 322 & 77.97 \\
\hline Extraction & & & $\begin{array}{c}1=\text { Lives in mine } \\
\text { proximity }\end{array}$ & 91 & 22.03 \\
\hline
\end{tabular}




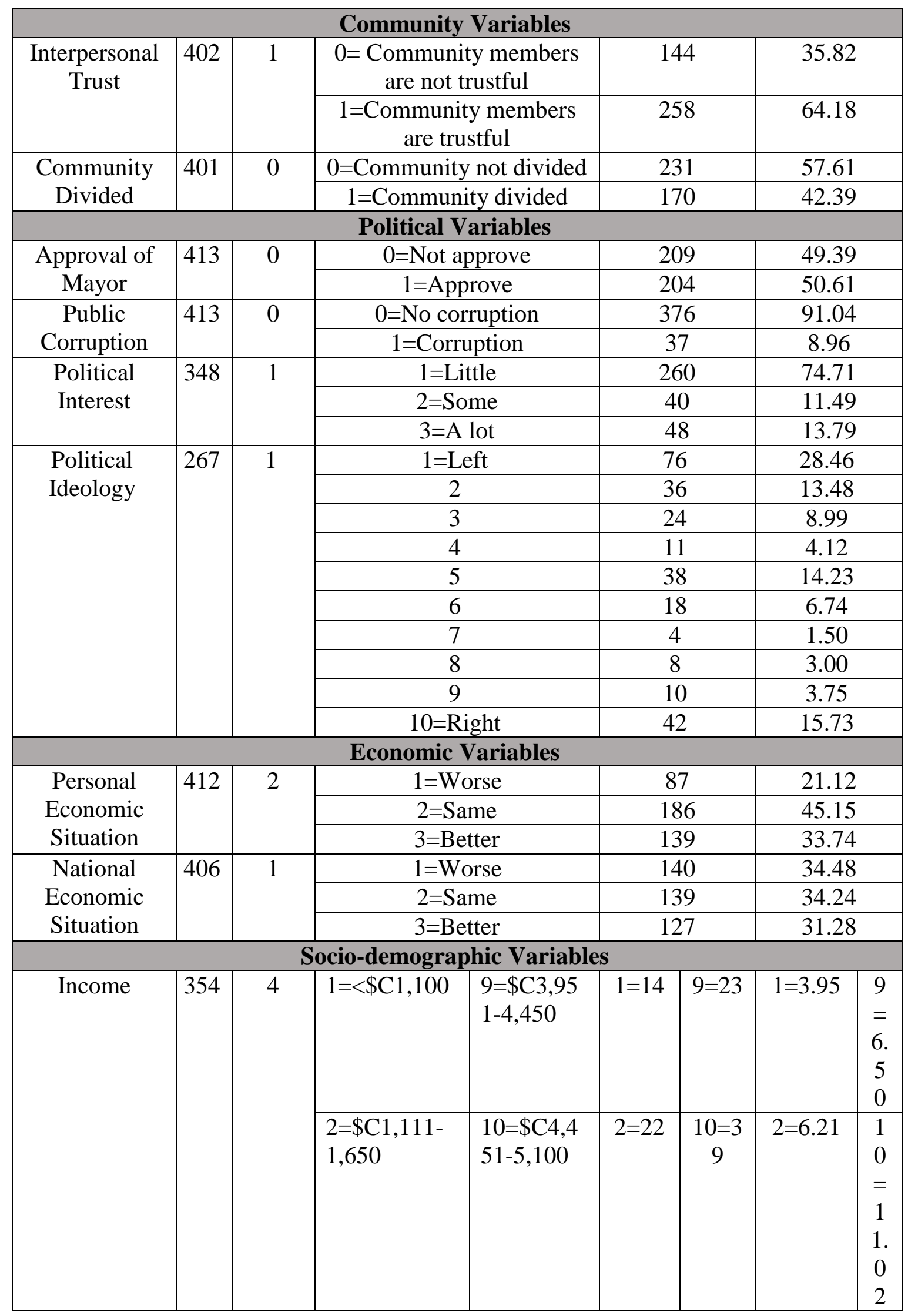




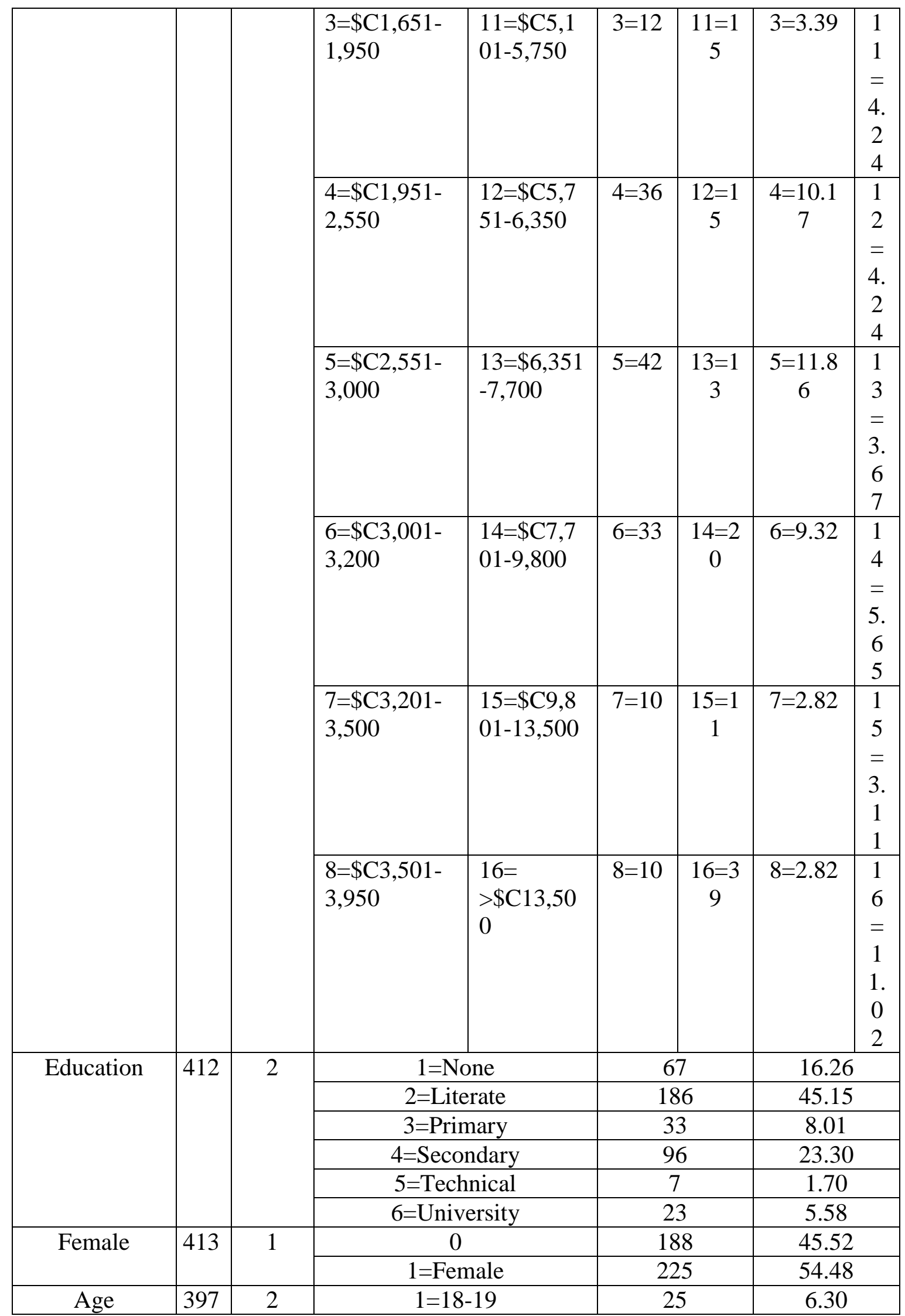




\begin{tabular}{|c|c|c|c|c|}
\hline \multirow{3}{*}{} & \multirow{4}{*}{} & $2=20-39$ & 200 & 50.38 \\
\cline { 3 - 5 } & & $3=40-69$ & 154 & 38.79 \\
\hline & & $4=70+$ & 18 & 4.53 \\
\hline
\end{tabular}


Table 5.3A: Variable Summary Statistics

\begin{tabular}{|c|c|c|c|c|c|}
\hline Variable & $N$ & Mean & $\begin{array}{l}\text { Stan. } \\
\text { Dev. }\end{array}$ & Min. & Max. \\
\hline \multicolumn{6}{|c|}{ DEPENDENT VARIABLES } \\
\hline \multicolumn{6}{|c|}{ Support for Mining } \\
\hline $\begin{array}{l}\text { Support for } \\
\text { Mining }\end{array}$ & 413 & .094431 & .2927821 & 0 & 1 \\
\hline \multicolumn{6}{|c|}{ Successful Protest } \\
\hline $\begin{array}{l}\text { Successful } \\
\text { Protest }\end{array}$ & 324 & .8487654 & .3588315 & 0 & 1 \\
\hline \multicolumn{6}{|c|}{ INDEPENDENT VARIABLES } \\
\hline \multicolumn{6}{|c|}{ Engagement } \\
\hline $\begin{array}{c}\text { Social } \\
\text { Engagement } \\
\text { Index }\end{array}$ & 413 & 1.602906 & 1.300557 & 0 & 4 \\
\hline Religion & 358 & .9301676 & .2552211 & 0 & 1 \\
\hline \multicolumn{6}{|c|}{ Demands for Rights } \\
\hline $\begin{array}{l}\text { Environmental } \\
\text { Impact }\end{array}$ & 413 & .7893462 & .4082675 & 0 & 1 \\
\hline $\begin{array}{l}\text { Agricultural } \\
\text { Impact }\end{array}$ & 413 & .7723971 & .4197934 & 0 & 1 \\
\hline \multicolumn{6}{|c|}{ Demands for Services } \\
\hline $\begin{array}{l}\text { Employment } \\
\text { Opportunities }\end{array}$ & 413 & .3438257 & .4755599 & 0 & 1 \\
\hline $\begin{array}{l}\text { Educational } \\
\text { Opportunities }\end{array}$ & 413 & .0774818 & .2676787 & 0 & 1 \\
\hline \multicolumn{6}{|c|}{ CONTROL VARIABLES } \\
\hline & & ining Vari & bles & & \\
\hline $\begin{array}{c}\text { Knowledge of } \\
\text { Project }\end{array}$ & 413 & .7506053 & .6257274 & 0 & 2 \\
\hline $\begin{array}{l}\text { Proximity to } \\
\text { Extraction }\end{array}$ & 413 & .220339 & .4149779 & 0 & 1 \\
\hline \multicolumn{6}{|c|}{ Community Variables } \\
\hline $\begin{array}{c}\text { Interpersonal } \\
\text { Trust }\end{array}$ & 402 & .641791 & .4800715 & 0 & 1 \\
\hline $\begin{array}{l}\text { Community } \\
\text { Divided }\end{array}$ & 401 & .4239401 & .4947984 & 0 & 1 \\
\hline \multicolumn{6}{|c|}{ Political Variables } \\
\hline $\begin{array}{l}\text { Approval of } \\
\text { Mayor }\end{array}$ & 413 & .4939467 & .5005697 & 0 & 1 \\
\hline $\begin{array}{c}\text { Public } \\
\text { Corruption }\end{array}$ & 413 & .0895884 & .2859375 & 0 & 1 \\
\hline Political Interest & 348 & 1.390805 & .7179272 & 1 & 3 \\
\hline Political & 267 & 4.359551 & 3.275268 & 1 & 10 \\
\hline
\end{tabular}




\begin{tabular}{|c|c|c|c|c|c|}
\hline \multicolumn{7}{|c|}{ Economic Variables } & \\
\hline Ideology & 412 & 2.126214 & .7306913 & 1 & 3 \\
\hline $\begin{array}{c}\text { Personal } \\
\text { Economic } \\
\text { Situation }\end{array}$ & & & & & \\
\hline $\begin{array}{c}\text { National } \\
\text { Economic } \\
\text { Situation }\end{array}$ & 406 & 1.96798 & .8113147 & 1 & 3 \\
\hline \multicolumn{7}{|c|}{ Socio-demographic Variables } \\
\hline Income & 354 & 8.40678 & 4.59382 & 1 & 16 \\
\hline Education & 412 & 2.657767 & 1.338868 & 1 & 6 \\
\hline Female & 413 & .5447942 & .4985934 & 0 & 1 \\
\hline Age & 397 & 2.415617 & .6787228 & 1 & 4 \\
\hline
\end{tabular}


Table 5.4A: Survey Questions and Variable Explanations

\begin{tabular}{|c|c|c|c|}
\hline Variable Name & Survey Question & $\begin{array}{l}\text { Variable } \\
\text { Type }\end{array}$ & $\begin{array}{l}\text { Variable } \\
\text { Coding }\end{array}$ \\
\hline \multicolumn{4}{|c|}{ DEPENDENT VARIABLES } \\
\hline \multicolumn{4}{|c|}{ Support for Mining } \\
\hline Support for Mining & $\begin{array}{l}\text { Are you for or against the } \\
\text { development of B2Gold's } \\
\text { mining projects? }\end{array}$ & Dichotomous & $\begin{array}{l}0=\text { Not } \\
\text { supportive; } \\
\text { 1=Supportive }\end{array}$ \\
\hline \multicolumn{4}{|c|}{ Successful Protest } \\
\hline Successful Protest & $\begin{array}{l}\text { Have the protests organized } \\
\text { by your community been } \\
\text { successful against the mining } \\
\text { company? }\end{array}$ & Dichotomous & $\begin{array}{l}0=\text { Not } \\
\text { successful; } \\
1=\text { Successful }\end{array}$ \\
\hline \multicolumn{4}{|c|}{ INDEPENDENT VARIABLES } \\
\hline \multicolumn{4}{|c|}{ Engagement } \\
\hline Social Engagement & $\begin{array}{l}\text { How frequently do you } \\
\text { attend a: } \\
\text { 1) Community } \\
\text { Organization; } \\
\text { 2) Environmental } \\
\text { Organization; } \\
\text { 3) Agricultural } \\
\text { Organization; } \\
\text { 4) Religious } \\
\text { Organization? }\end{array}$ & $\begin{array}{l}\text { Dichotomous } \\
\text { Additive } \\
\text { Index }\end{array}$ & $\begin{array}{l}0=\text { Not engaged } \\
\text { (If respondents } \\
\text { never } \\
\text { participate); } \\
1=\text { Engaged (If } \\
\text { respondents said } \\
\text { they } \\
\text { participated } \\
\text { once a week, } \\
\text { twice a month, } \\
\text { or once a } \\
\text { month). } \\
\text { Index means if a } \\
\text { respondent } \\
\text { participates at } \\
\text { least once a } \\
\text { month in: all } \\
\text { four } \\
\text { organizations, } \\
\text { the respondent } \\
\text { receives a } 4 ; \text { in } \\
\text { three of the four } \\
\text { organizations, } \\
\text { the respondent } \\
\text { receives a } 3 ; \text { in } \\
\text { two of the four } \\
\text { organizations, } \\
\text { the respondent } \\
\text { receives a } 2 ; \text { in }\end{array}$ \\
\hline
\end{tabular}




\begin{tabular}{|c|c|c|c|}
\hline & & & $\begin{array}{l}\text { one of the four } \\
\text { organizations, } \\
\text { the respondent } \\
\text { receives a } 1 ; \\
\text { and in none of } \\
\text { the } \\
\text { organizations, } \\
\text { the respondent } \\
\text { receives a } 0 .\end{array}$ \\
\hline Religion & $\begin{array}{l}\text { In solution of mining } \\
\text { conflicts between the } \\
\text { community population and } \\
\text { the mining company, how } \\
\text { would you rate the work of } \\
\text { the churches? }\end{array}$ & Dichotomous & $\begin{array}{l}0=(\text { very }) \\
\text { negative; } 1= \\
\text { (very) positive. }\end{array}$ \\
\hline \multicolumn{4}{|c|}{ Demands for Rights } \\
\hline $\begin{array}{l}\text { Environmental } \\
\text { Impacts }\end{array}$ & $\begin{array}{l}\text { What impact will B2Gold's } \\
\text { activity have on the } \\
\text { environment? }\end{array}$ & Dichotomous & $\begin{array}{l}0=\text { Positive and } \\
\text { very positive; } \\
1=\text { Negative and } \\
\text { very negative }\end{array}$ \\
\hline Agricultural Impacts & $\begin{array}{l}\text { Agree or disagree? The } \\
\text { drilling of the land done for } \\
\text { mining activity damages the } \\
\text { environment and agriculture. }\end{array}$ & Dichotomous & $\begin{array}{l}0=\text { Disagree } \\
1=\text { Agree }\end{array}$ \\
\hline \multicolumn{4}{|c|}{ Demands for Services } \\
\hline $\begin{array}{l}\text { Employment } \\
\text { Opportunities }\end{array}$ & $\begin{array}{l}\text { What impact will B2Gold's } \\
\text { activity have on employment } \\
\text { opportunities }\end{array}$ & Dichotomous & $\begin{array}{l}0=\text { Negative and } \\
\text { very negative; } \\
1=\text { Very positive } \\
\text { and positive }\end{array}$ \\
\hline $\begin{array}{l}\text { Educational } \\
\text { Opportunities }\end{array}$ & $\begin{array}{l}\text { Has the mining company } \\
\text { helped improve educational } \\
\text { services in your community? }\end{array}$ & Dichotomous & $\begin{array}{l}0=\mathrm{No} ; \\
1=\text { Yes }\end{array}$ \\
\hline \multicolumn{4}{|c|}{ CONTROL VARIABLES } \\
\hline \multicolumn{4}{|c|}{ Mining Variables } \\
\hline $\begin{array}{l}\text { Importance of } \\
\text { Mining }\end{array}$ & $\begin{array}{l}\text { How important are the } \\
\text { mining companies for the } \\
\text { economic development of } \\
\text { Nicaragua? }\end{array}$ & Continuous & $\begin{array}{l}\text { 1= Very } \\
\text { Important; } \\
2=\text { Some } \\
\text { importance; } \\
\text { 3=Little } \\
\text { importance }\end{array}$ \\
\hline $\begin{array}{l}\text { Knowledge of } \\
\text { Project }\end{array}$ & $\begin{array}{l}\text { Based on the following three } \\
\text { questions: } \\
\text { 1) In what country is } \\
\text { B2Gold's central }\end{array}$ & $\begin{array}{l}\text { Dichotomous } \\
\text { Additive } \\
\text { Index }\end{array}$ & $\begin{array}{l}\text { Index means if a } \\
\text { respondent } \\
\text { knows } \\
\text { B2Gold's } \\
\text { central office is }\end{array}$ \\
\hline
\end{tabular}




\begin{tabular}{|c|c|c|c|}
\hline & $\begin{array}{l}\text { office located? }(1= \\
\text { Canada; } 0=\text { Other } \\
\text { Countries }) \\
\text { 2) Do you know who } \\
\text { Guardines de Yaoska } \\
\text { are in your } \\
\text { community? }(1=\text { Yes; } \\
0=\text { No })\end{array}$ & & $\begin{array}{l}\text { in Canada, if the } \\
\text { respondent } \\
\text { knows who } \\
\text { Guardines de } \\
\text { Yaoksa are than } \\
\text { the respondent } \\
\text { receives a 2. If } \\
\text { the respondent } \\
\text { can provide the } \\
\text { correct answer } \\
\text { for one out of } \\
\text { the two } \\
\text { questions the } \\
\text { respondent } \\
\text { receives a } 1 . \text { If } \\
\text { the respondent } \\
\text { cannot provide } \\
\text { the correct } \\
\text { answer for any } \\
\text { of the two } \\
\text { questions the } \\
\text { respondent } \\
\text { receives a } 0 .\end{array}$ \\
\hline $\begin{array}{l}\text { Proximity to } \\
\text { Extraction }\end{array}$ & $\begin{array}{l}\text { Variable created using the } \\
\text { indicator } \\
\text { "Community/Neighborhood." }\end{array}$ & Dichotomous & $\begin{array}{l}0=\text { All other } \\
\text { communities. } \\
1=\text { Respondents } \\
\text { that live in the } \\
\text { direct vicinity of } \\
\text { the mining } \\
\text { project or } \\
\text { proposed } \\
\text { mining project } \\
\text { because of their } \\
\text { direct impact by } \\
\text { mining. }\end{array}$ \\
\hline \multicolumn{4}{|c|}{ Community Variables } \\
\hline Interpersonal Trust & $\begin{array}{l}\text { Would you say the people in } \\
\text { your community are } \\
\text { trustworthy? }\end{array}$ & Dichotomous & $\begin{array}{l}0=\text { A little } \\
\text { trustworthy and } \\
\text { not trustworthy; } \\
1=\text { Trustworthy } \\
\text { and very } \\
\text { trustworthy }\end{array}$ \\
\hline Community Divided & Is your community divided? & Dichotomous & $0=\mathrm{No} ; 1=$ Yes \\
\hline \multicolumn{4}{|c|}{ Political Variables } \\
\hline Approval of Mayor & $\begin{array}{l}\text { In the solution of mining } \\
\text { conflicts between the local }\end{array}$ & Dichotomous & $\begin{array}{l}0=\text { Positive and } \\
\text { Very Positive; }\end{array}$ \\
\hline
\end{tabular}




\begin{tabular}{|c|c|c|c|}
\hline & $\begin{array}{l}\text { population and the mining } \\
\text { company, how would you } \\
\text { measure the work of the } \\
\text { municipal mayor? }\end{array}$ & & $\begin{array}{l}1=\text { Negative and } \\
\text { Very Negative }\end{array}$ \\
\hline Public Corruption & $\begin{array}{l}\text { Do you know a public } \\
\text { employee that asked for a } \\
\text { bribe from the mining } \\
\text { company? } \\
\text { Do you know a judge that } \\
\text { asked for a bribe from the } \\
\text { mining company? }\end{array}$ & $\begin{array}{l}\text { Dichotomous } \\
\text { Additive } \\
\text { Index }\end{array}$ & $\begin{array}{l}0=\text { No } \\
1=\text { Yes } \\
\text { Index means if a } \\
\text { respondent } \\
\text { knows of a } \\
\text { public employee } \\
\text { AND a judge, } \\
\text { the respondent } \\
\text { receives a } 2 \text {. If a } \\
\text { respondent } \\
\text { knows of a } \\
\text { public employee } \\
\text { OR a judge, the } \\
\text { respondent } \\
\text { receives a } 1 \text {. If a } \\
\text { respondent does } \\
\text { not know of a } \\
\text { public employee } \\
\text { and a judge, the } \\
\text { respondent } \\
\text { receives a } 0 .\end{array}$ \\
\hline Political Interest & $\begin{array}{l}\text { How much interest do you } \\
\text { have in politics? }\end{array}$ & Continuous & $\begin{array}{l}\text { 1=A little } \\
\text { 2=Some } \\
3=\text { A lot }\end{array}$ \\
\hline Political Ideology & $\begin{array}{l}\text { Thinking about the } \\
\text { terminology, "left" and } \\
\text { "right", where do you place } \\
\text { your self on a } 1 \text { (left) and } 10 \\
\text { (right) scale? }\end{array}$ & Continuous & $\begin{array}{l}1=\text { Very left; } \\
5=\text { Neutral; } \\
10=\text { Very right }\end{array}$ \\
\hline \multicolumn{4}{|c|}{ Economic Variables } \\
\hline $\begin{array}{l}\text { Personal Economic } \\
\text { Situation }\end{array}$ & $\begin{array}{l}\text { How would you define your } \\
\text { personal economic situation? }\end{array}$ & Continuous & $\begin{array}{l}1=\text { Worse; } \\
2=\text { Equal; } \\
3=\text { Better }\end{array}$ \\
\hline $\begin{array}{l}\text { National Economic } \\
\text { Situation }\end{array}$ & $\begin{array}{l}\text { How would you define the } \\
\text { economic situation of } \\
\text { Nicaragua, as compared to } 12 \\
\text { months ago? }\end{array}$ & Continuous & $\begin{array}{l}\text { 1= Worse; } \\
2=\text { Equal; } \\
\text { 3= Better }\end{array}$ \\
\hline \multicolumn{4}{|c|}{ Socio-demographic Variables } \\
\hline Income & $\begin{array}{l}\text { In which of the following } \\
\text { ranges do you find your } \\
\text { family's monthly household }\end{array}$ & Continuous & $\begin{array}{l}1=\text { Menos de } \\
1,100 \text { córdobas; }\end{array}$ \\
\hline
\end{tabular}




\begin{tabular}{|c|c|c|c|}
\hline & $\begin{array}{l}\text { income, including } \\
\text { remittances and income from } \\
\text { adults and children? }\end{array}$ & & $\begin{array}{l}\text { 2= Entre 1,100- } \\
\text { 1,650 córdobas; } \\
\text { 3= Entre 1,651- } \\
\text { 1,950 córdobas; } \\
\text { 4= Entre 1,951- } \\
\text { 2,550 córdobas; } \\
\text { 5= Entre 2,551- } \\
\text { 3,000 córdobas; } \\
\text { 6= Entre 3,001- } \\
\text { 3,200 córdobas; } \\
\text { 7= Entre 3,201- } \\
\text { 3,500 córdobas; } \\
\text { 8= Entre 3,501- } \\
\text { 3,950 córdobas; } \\
\text { 9= Entre 3,951- } \\
\text { 4,450 córdobas; } \\
\text { 10= Entre } \\
\text { 4,451-5,100 } \\
\text { córdobas; } \\
\text { 11= Entre } \\
\text { 5,101-5,750 } \\
\text { córdobas; } \\
\text { 12= Entre } \\
\text { 5,751-6,350 } \\
\text { córdobas; } \\
\text { 13= Entre } \\
\text { 6,351-7,700 } \\
\text { córdobas; } \\
\text { 14= Entre } \\
\text { 7,701-9,800 } \\
\text { córdobas; } \\
\text { 15= Entre } \\
\text { 9,801-13,500 } \\
\text { córdobas; } \\
\text { 16= Más de } \\
\text { 13,500 córdobas }\end{array}$ \\
\hline Education & $\begin{array}{l}\text { What is the last level of } \\
\text { education that you achieved? }\end{array}$ & Continuous & $\begin{array}{l}\text { 1= Literate } ; \\
\text { 2= Primary } \\
\text { 3= Secondary; } \\
\text { 4= Technical } \\
\text { 5= University }\end{array}$ \\
\hline Female & What is your gender? & Dichotomous & $\begin{array}{l}0=\text { Male; } \\
1=\text { Female }\end{array}$ \\
\hline Age & What is your age? & Continuous & $\begin{array}{l}1=18-19 ; \\
2=20=39 \\
3=40=69\end{array}$ \\
\hline
\end{tabular}




\begin{tabular}{|l|l|l|l|}
\hline & & & $4=69=82$ \\
\hline
\end{tabular}




\section{CHAPTER 6}

"Santo Domingo's Anti-Mining Resistance Movement Against B2Gold" 
My theoretical framework discussed in Chapter 4 permits me to systematically study the attitudes, beliefs, and characteristics of individuals in highly visible extractive protest cases, like Santo Domingo, by directly asking them what makes them oppose or support resource extraction, as well as understand the micro-level politics that shape individual attitudes towards extraction. The third part of my theoretical framework also permits me to understand what attitudes, beliefs, and characteristics individuals have in highly visible protest cases for successfully overturning mining concessions through sustained protests and social movement resistance. By understanding individual attitudes, beliefs, and characteristics towards mining, scholars of extractive protests and social movements will be able to better understand the individual mechanisms that lead citizens in the extractive frontier to either partake in mining resistance or abstain, as well as what individuals believe makes their protests and social movements more successful. For example, by understanding the reasons individuals in Santo Domingo, a community that strongly resists mining, oppose or support mining, I can better understand the reasons why citizens in Santo Domingo believe they have not yet reached a national-level policy change in overturning B2Gold's mining concession in the community.

In this chapter, I utilize qualitative empirical evidence from the mining community of Santo Domingo from my own field work interviews from January 2017. I utilize interviews I conducted in Santo Domingo and Managua with protest actors, social movement members, community members, researchers and academics from universities and research centers, and environmental organization leaders. I also use existing academic literature and news articles related to protest activity in Santo Domingo. Additionally, I use survey research to ask citizens in Santo Domingo their views and 
perceptions to generalize from empirical data, rather than make inferred assumptions about individuals from aggregate community-level data in order to understand how the attitudes, beliefs, and characteristics of individuals living in Santo Domingo are shaped by the environments succumbed to the extractive frontier. I surveyed approximately 400 citizens in Santo Domingo in April 2018. My survey data offers robust individual-level data that permits me to understand what prompts citizens to participate in protests by understanding what factors lead them to oppose or support mining, as well as what these individuals believe could make their anti-extraction movement against B2Gold more successful. I test my theoretical framework and confirm my theoretical and empirical expectations using my survey data.

\section{Santo Domingo's Resistance to B2Gold's Mining Concession}

The municipality of Santo Domingo is home to another community in Nicaragua that largely opposes B2Gold's mining projects. Santo Domingo is located in the central region of Nicaragua in the Department of Chontales, characterized by having a mountainous relief with a tropical rainy climate. Figure 6.1, below, provides context of where Santo Domingo, Chontales is in comparison to the rest of Nicaragua. It was founded in 1913 by miners from Nueva Segovia, a northern department of Nicaragua. Santo Domingo has a population of around 18,000 inhabitants with the majority of the population living in rural areas and working as farmers, ranchers, or artisanal miners. (Centro Humboldt 2015a; Pérez Soza 2013). 


\section{Figure 6.1: Santo Domingo's Location}

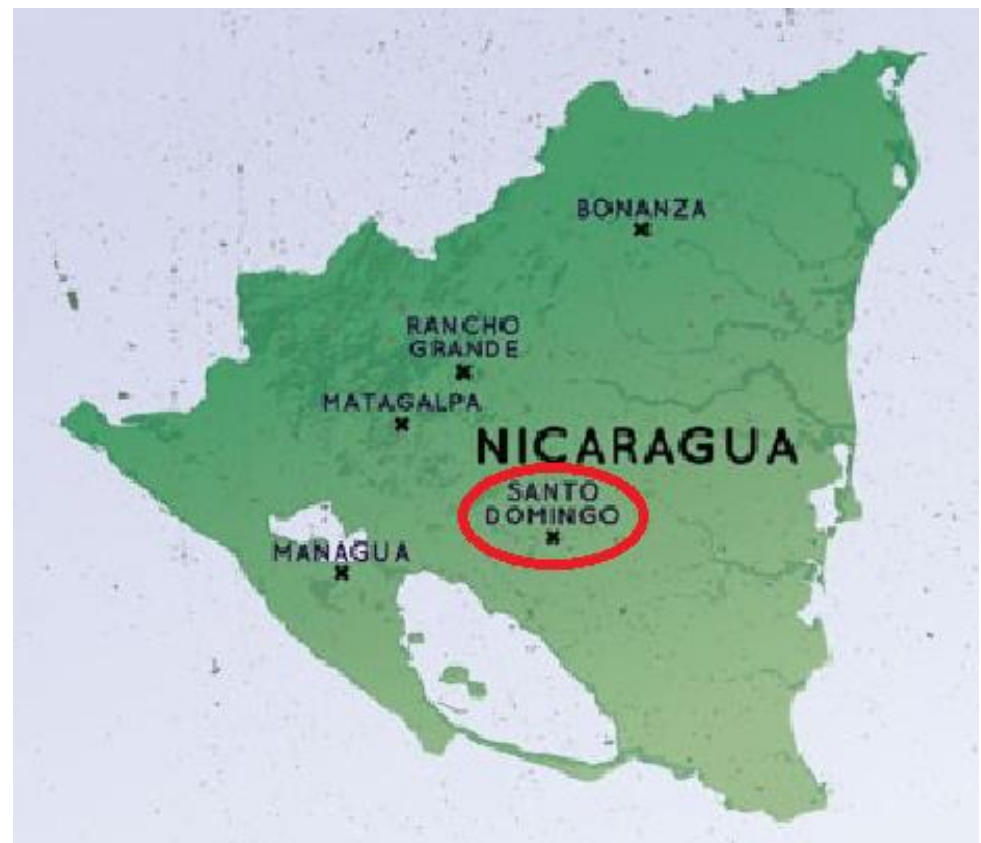

Source: Centro Humboldt (2015b).

Santo Domingo has considerable hydrographic wealth with several rivers and tributaries accumulating around it or through it, with the River Siquia being the most important river with a course of 170 kilometers and the River Artiguas crossing through Santo Domingo's center. The drinking water of Santo Domingo was once considered one of the best-supplied municipalities in the Department of Chontales (INIDE 2005). Pérez Soza (2013) even claims Santo Domingo had the most superb water system throughout all of Nicaragua. It once produced approximately 60 gallons of water per minute and supplied other municipalities throughout the department. The abundance of these water sources combined with Santo Domingo's climate and mountainous terrain have provided it with a rich physical environment that has soil and subsoil nicely suited for the development of productive activities, such as agriculture and livestock. Of the total economically active population, $90.9 \%$ are employed in the three main economic activities of the 
municipality: agriculture, livestock, and small-scale artisanal mining (INIDE 2005; Centro Humboldt 2015a).

The prime economic activity for Santo Domingo is the agricultural sector, which includes an economically active population of $86.3 \%$, predominately living in rural areas and cultivating rice, corn, beans, citrus fruits, yuccas, bananas, and other fruits and vegetables native to Nicaragua. For Santo Domingo, the raising of large cattle serves a double function (milk and meat) because its production is destined for national consumption and export. The majority of the land used for agriculture and livestock in Santo Domingo is marked by forests, meaning that farms combine grazing and planting areas with forest-type trees. Although this forestry condition has contributed to maintaining a strong climate and the flow of streams and rivers in general, agricultural and livestock work requires greater economic efforts and strong agricultural practices to sustain the required productivity. Additionally, the raising of small livestock (pigs and poultry), the cultivation of basic grains, and the selling of clothing and accessories are other economic drivers in Santo Domingo (Centro Humboldt 2015a).

Around 3,600 citizens in Rancho Grande are artisanal miners or "güiriseros, ” as they are known in Nicaragua (Centro Humboldt 2015a; Pérez Soza 2013). Artisanal miners in Santo Domingo extract approximately 18 grams of gold per day at a rate of \$1,500 Córdobas. ${ }^{121}$ Typically, artisanal miners in Santo Domingo extract \$5 million Córdobas a day, which is equivalent to approximately US\$152,000 (Pérez Soza 2013).

\footnotetext{
121 The Córdoba is Nicaragua's currency. \$1,500 Córdobas is equivalent (as of March 28, 2019) to US\$45.68.
} 
Artisanal miners tend to use rudimentary methods to extract and process the gold. ${ }^{122}$ For extraction, artisanal miners use shovels, picks, and buckets. They process gold using hand tools (i.e., mallets), homemade processing machines (i.e., using recycled materials), and mercury and water for the separation of gold from the rest of the minerals and rock (Centro Humboldt 2015a). Even with these methods, the miners can extract 180-200 ounces of gold per month. In Nicaraguan standards, these artisanal miners are living well. Despite all the potential that Santo Domingo has to offer; its environment, its agricultural production, its livestock, its water sources, and its inhabitants' livelihoods have all been threatened for over a decade by B2Gold's mining activities.

In Chapter 2, I discussed Nicaragua's history with mining and how it has grown to become the top producer of gold in Central America, surpassing Guatemala in 2012. Spalding (2016) notes that as international gold prices rose and Nicaragua became an investment friendly country for extractive companies, more and more companies began to invest in Nicaragua and explore previously unexplored parts of the country in search for commercially feasible gold deposits located near water sources that are required for present day gold mining. With knowledge of Santo Domingo's gold deposits through its history with artisanal mining, Santo Domingo was deemed prosperous by the extractive sector. Spalding (2016) suggests that B2Gold has become Nicaragua's lead corporate investor and part of this is due to its acquisition of mining concessions around Nicaragua in places like Santo Domingo.

\footnotetext{
${ }^{122}$ Author's personal observations while conducting field research in Santo Domingo: January 2017. In Figure 6.1A in the Appendix, I provide photos I took while in Santo Domingo that shows both the extraction and processing methods of artisanal miners in Santo Domingo.
} 
B2Gold currently has production, exploitation, and exploration projects in $\mathrm{La}$ Libertad and Santo Domingo, Chontales. Industrial mining in Santo Domingo essentially began in 2008 following a request submitted by the company, Mining Development of Nicaragua S.A., (DESMINIC S.A.) to develop exploration projects in the El Escandal and Jabalí districts of the Santo Domingo—-La Libertad ${ }^{123}$ mining corridor. ${ }^{124}$ However, DESMINIC ended up selling its shares to B2Gold. The company entered the community with no environmental permits, no consent from the local government or community leaders, and essentially violating the following Nicaraguan laws and decrees:

Environmental Law 217, Mining Law 387, Decree 199-2001, and Decree 76-2006 of the Environmental Assessment System (Centro Humboldt 2015a). By Nicaraguan law, both exploration and exploitation activities need to be studied, evaluated, authorized, and monitored separately because the scope and difference of the environmental impacts that each mining activity has (Centro Humboldt 2015a).

B2Gold started mining exploration work of the aforementioned projects on November 23, 2009 (Centro Humboldt 2015a), and by May 2010 President Ortega and Catholic Cardinal Obando visited Santo Domingo for B2Gold's inauguration of exploiting gold in the area. ${ }^{125}$ However, at this time, B2Gold technically only had an exploration concession, not an exploitation concession. It was not until August 2011 that Hilda Espinosa, General Director of the Ministry of Natural Resources and the Environment (MARENA), authorized B2Gold to begin exploiting gold in Santo Domingo without thoroughly conducting environmental assessment studies and

\footnotetext{
${ }^{123}$ La Libertad, Chontales is $7 \mathrm{~km}$ away from Santo Domingo.

${ }^{124}$ Santo Domingo has a "gold vein" that is over three kilometers long and can be seen by satellite imagery.

${ }^{125}$ B2Gold gifted President Ortega an ounce of gold (Pérez Soza 2013).
} 
conducting evaluations, which is largely one of the most important things in her job description (Pérez Soza 2013). ${ }^{126}$ Thus, B2Gold was illegally extracting gold until August of 2011 when Director Espinosa authorized its exploitation concession, although this authorization was illegal as well. Below in Figure 6.2 is a map of B2Gold's concessions in Santo Domingo.

Figure 6.2: B2Gold's Mining Concession in Santo Domingo

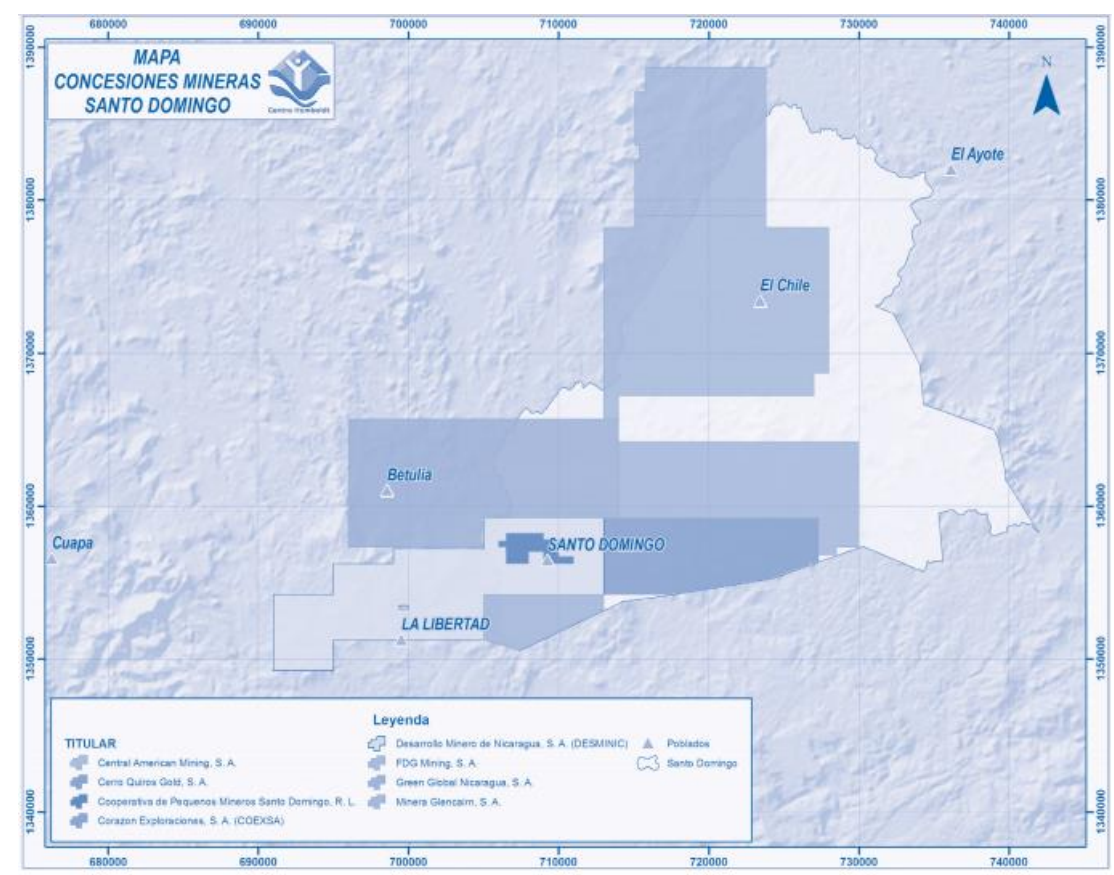

Source: Centro Humboldt (2015b).

B2Gold claims it practices corporate social responsibility (CSR) by providing social programs that benefit the population and by offering employment opportunities and jobs for citizens. Agreeably, the Nicaraguan government continues to "point out that mining companies have executed projects in health, education, investments and, in the case of Santo Domingo, they opened a water purification plant" (Articulo 662018 ). Over 58\% of

\footnotetext{
${ }^{126}$ B2Gold was granted a concession to carry out open-pit exploitation activities of 130,400 tons of accumulated ore in the area of El Coluvio-Jabali (Centro Humboldt 2015a).
} 
Nicaraguans live in poverty, $29 \%$ of the population lives in extreme poverty, and $67 \%$ barely survive on more than $\$ 1.00 /$ day. In Nicaragua, poverty tends to persist in rural areas. Santo Domingo is a very rural area with an economy dependent on agricultural and livestock production. It has $18.5 \%$ of its population living in extreme poverty (Agros International, N.D; OPHI 2011, 5). ${ }^{127}$ Thus, it seems like the offer of jobs, employment opportunities, and economic development by B2Gold would be a benefit to the citizens of Santo Domingo. NGOs, local groups, and government agencies and institutions like the Mayor's Office, the Ministry of Health, the Ministry of Education, and the national police all support B2Gold and its projects because they receive economic benefits from the company. For example, the national police received new motorcycles, the Catholic church was repaired, the Mayor's Office was given new office equipment, the Ministry of Health was given medical equipment, and the Ministry of Education was given notebooks for the children. ${ }^{128}$

However, in 2012, B2Gold exported US\$400 million in gold from Santo Domingo, but only $1 \%$ of this US\$400 million stayed in Nicaragua to be divvied up among the national government and its agencies. The only benefits that the community of Santo Domingo sees and feels from B2Gold are through the gifts that I mentioned earlier, and some employment opportunities for local residents. However, Pérez Soza (2013) claims that the gifts from B2Gold often generate greater costs, more spending, and more corruption for the community and its institutions and organizations. Additionally, Santo Domingo has 18,000 inhabitants, but B2Gold only employs 243 workers, which are not

\footnotetext{
${ }^{127}$ Comparatively speaking, Matagalpa, where Rancho Grande is located, has $18.1 \%$ of its population living in extreme poverty.

${ }^{128}$ Author's personal interview with community members in Santo Domingo: January 2017.
} 
all from Santo Domingo, or even Nicaragua (Pérez Soza 2013). B2Gold only employs approximately 100 workers that are actually from Santo Domingo, and the company does not hire Santo Domingo's artisanal miners because the company does not want to employ them. B2Gold brings in workers from all over that it can hire at a cheap price. Many of B2Gold's workers travel from other Central American countries, like Guatemala, to temporarily live and work for the company. The community believes that B2Gold does not like mixing its business dealings with the business dealings of the locals. ${ }^{129}$

Yet, the majority of Santo Domingo's local organizations and institutions have been coerced, corrupted, and bought by B2Gold, which indicates that those that are engaged in these local organizations and institutions are not likely forming oppositional attitudes towards mining or are fearful to speak out against the company. As Dougherty and Olsen $(2014,191)$ demonstrate, some communities like Santo Domingo "have lower levels of collective-efficacy and experience less relational trust and higher levels of institutional trust" (Dougherty and Olsen 2014, 191). The authors suggest that these types of communities are more vulnerable to outside interests, like those of B2Gold.

Additionally, many other citizens in Santo Domingo tend to support B2Gold because they work for the company, have a family member that works for the company, or have a job that some way interacts with the company. Although these citizens do not necessarily support B2Gold in every aspect, they fear acting against B2Gold due to potential negative repercussions that the company could cause them and their families. Essentially, these citizens do not want to lose the economic benefits and gifts that B2Gold sometimes provides.

${ }^{129}$ Author's personal interviews with community members from Santo Domingo: January 2017. 
However, there is still a large portion of the population that strongly opposes B2Gold and its mining projects because they have harmed Santo Domingo's environment, agricultural production, livestock production, water sources, and the livelihoods of inhabitants for over a decade. The citizens of Santo Domingo did not truly become aware of B2Gold's harmful impact until 2012 when it began using its machines and equipment to extract large quantities of gold colluvium. ${ }^{130}$ (Centro Humboldt 2015a). B2Gold claims that they respect the environment and that the company practices environmentally friendly methods when mining. ${ }^{131}$ However, as Pérez Soza (2013) claims, "[m]ining is built on myths, lies, [and] unrealities." For example, Pérez Soza (2013) discusses how B2Gold flashes around a bogus environmental impact study, and he claims that:

...there's no such thing as an environmentally-friendly mining company. They're all harmful. Whether large or small, mining causes irreversible damage to the environment, with the difference that small-scale miners can exploit the gold for 200 years and make a living at it, causing much less damage ${ }^{132} \ldots$ [B2Gold is] taking away our hills, our lands...In six years there'll be no more gold or anything else, and Santo Domingo will be a desert.

B2Gold's exploration and exploitation of metallic minerals, have different forms of generating contamination by heavy metals in the rivers, streams, lagoons, subterranean aquifers, etc. In March 2014, Centro Humboldt conducted a study in Santo Domingo to

\footnotetext{
${ }^{130}$ Pérez Soza (2013) notes that "[g]old colluvium is superficial, easy to extract; it's very rich gold that doesn't need much treatment."

${ }^{131}$ For example, B2Gold's website "highlights that the responsibility they have with natural resources in Santo Domingo has resulted in the establishment of a Wildlife Refuge" (Articulo 66, 2018).

${ }^{132}$ During a personal interview in Santo Domingo, I learned the methods that artisanal miners use have never harmed the environment or the water. However, the activities the mining company uses are continuously destroying the environment and Santo Domingo's water sources because the company digs very deep down into the earth to the water basin levels and uses chemicals in its extracting processes - the chemicals are leaking into the water basin level.
} 
gather information on farms near the area where B2Gold operates its open-pit mining. The study offered relevant findings, such as the irreversible impact of Rio Artiguas (one of the main rivers in Santo Domingo) and its tributaries. One of the tributaries serves to supply water to about 19 agricultural and livestock farms, where 27 families and around 180 people live permanently (not including the workers and farm owners that live nearby). These farm owners accounted for nearly 40 sources of water for these farms. However, since B2Gold's open-pit mining activities began, 10 of these water sources have disappeared (Centro Humboldt 2015a).

Centro Humboldt conducted several other studies, which show that B2Gold's open-pit mining activities have caused or will cause the following: the total destruction of primary forest; the removal of the plant bark along the banks of several streams and rivers; the deviation and destruction of water sources; the increase of heavy metals and pollutant sediments in water sources adjacent to the exploitation area due to the dumping of materials; negative effects to the local flora and fauna; damage to the access roads to the communities (servitude of passage) and thus impeding the free circulation and the physical integrity of the population; and increase in noise and dust due to the constant circulation of heavy vehicles (Centro Humboldt 2015a). Thus, Santo Domingo's environment, its agricultural production, its livestock, its water sources, and its inhabitants' livelihoods have all been threatened and remained threatened by B2Gold's mining activity.

Several neighborhoods in Santo Domingo feel or fear the impacts that the water contamination from B2Gold's open-mining activities. For example, some community members can no longer use the local waterways, creeks, and rivers to fish because the 
fish are disappearing due to the contaminated water. These community members relied on fishing to feed their families and earn an income in selling the fish in local markets. Additionally, many residents in Santo Domingo need to purchase purified or filter their water for consumption, bathing, and washing clothes and dishes due to the water contamination caused by B2Gold's mining activities. The purchasing of purified water and filtering their water has become increasingly expensive and time consuming for an already impoverished population. ${ }^{133}$

Additionally, community members are extremely concerned about consuming local food products because the areas livestock and crops rely on the contaminated water. The concern regarding the livestock and crops utilizing the contaminated water also worries community members because they are worried that the crops and the livestock will die or distributers and consumers will cease to purchase Santo Domingo's agricultural and livestock products, which harms the community's economic livelihood. Furthermore, many community members in Santo Domingo fear that the water contamination may not cause instant side effects, but may cause harmful side effects in the future; long after B2Gold has left Santo Domingo. The chemicals that Centro Humboldt found in its study are known to cause stomach cancer, kidney failure, and other harmful diseases. These community members are angry because Santo Domingo used to have one of the cleanest sources of drinking water in Nicaragua, but B2Gold's mining activities have destroyed the access to several waterways and contaminated the rest of them with the chemicals the company uses to extract gold, which is threatening the livelihood of citizens in a variety of ways. ${ }^{134}$

\footnotetext{
133 Author's personal interviews with community members from Santo Domingo: January 2017.

${ }^{134}$ Author's personal interviews with community members from Santo Domingo: January 2017.
} 
While visiting Santo Domingo, I witnessed the dense forestry that still exists in Santo Domingo. While getting as close as I could to visit B2Gold's open-pit mine, I was informed that where B2Gold's open-pit mine is located was once filled with thousands of trees. In Figure 6.3, below, I provide a comparison of the forests that still exist in Santo Domingo and B2Gold's open-pit mine to demonstrate the deforestation by B2Gold in order to create its open-pit mine in Santo Domingo. B2Gold practices deforestation in areas of Santo Domingo where it needs to extract gold or where it needs to build highways and roads to transport the gold to its processing plants in La Libertad, Chontales. B2Gold's extractive activities and deforestation have destroyed or polluted a great deal of Santo Domingo's natural waterways, which has directly harmed the community’s agricultural livelihood. ${ }^{135}$

\section{Figure 6.3: Deforestation in Santo Domingo}

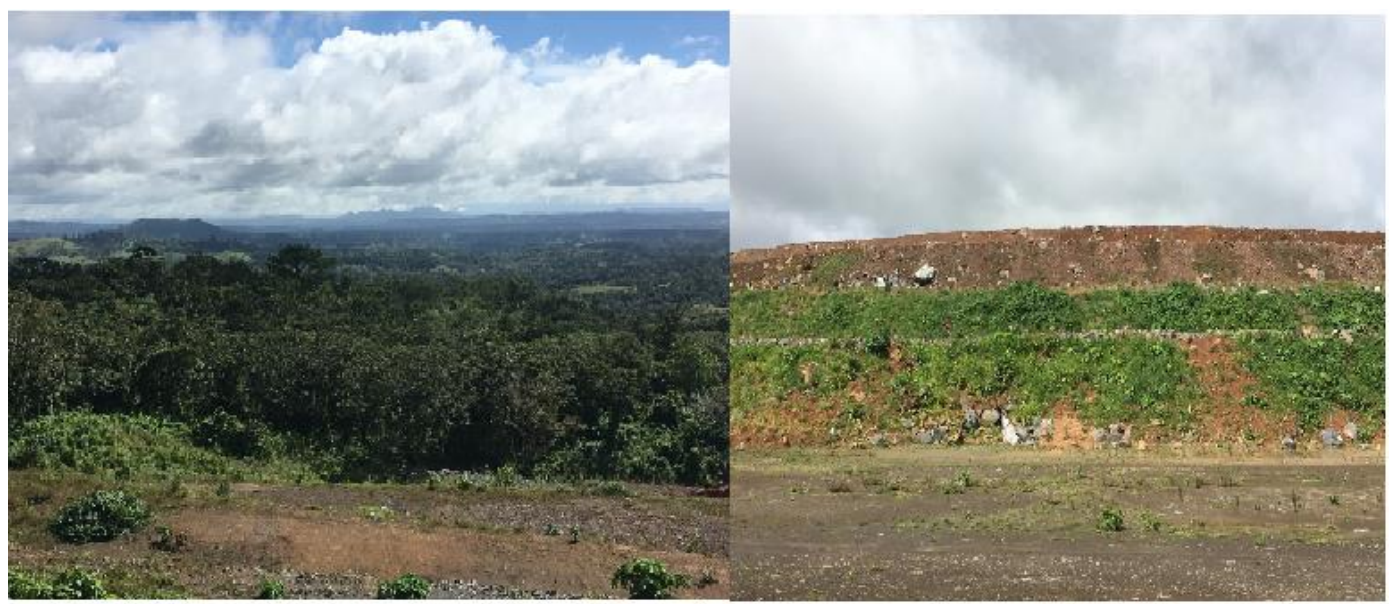

Source: Author's photos.

When B2Gold first began extracting gold in Santo Domingo, it originally mined gold from above the earth through open-pit mining practices, which it still practices. However,

\footnotetext{
${ }^{135}$ Author's personal observations and interviews with members from Santo Domingo: January 2017.
} 
the company is also using tunnels to mine underneath the Santo Domingo community (Pérez Soza 2013). There are several mining tunnels directly underneath Santo Domingo. This is one of the problems that also exists for the community. The gold B2Gold now wants is not outside or on the outskirts of Santo Domingo, but directly underneath the community where everyone lives. Thus, B2Gold is building tunnels underneath Santo Domingo to extract the gold. There is Tunnel 400, Tunnel 500, Tunnel 700, Tunnel 900, Tunnel Azul, and Tunnel Pipilacho. The Nicaraguan government told a leader of Salvemos Santo Domingo that the mining company has every right to tunnel and extract gold from underneath the community. According to Nicaraguan laws, community members only own their house and the land the house is located, but not the land that is underneath the house. Due to B2Gold's tunneling directly underneath homes in Santo Domingo, houses shake continuously. ${ }^{136}$ Pérez Soza (2013) also discusses, how many of the stones and rocks in these tunnels contain arsenic and when B2Gold uses explosives to remove gold from the tunnels; the water is contaminated with arsenic and heavy metals like mercury, lead, and cyanide. Since, these tunnels are directly underneath citizens' homes, these citizens are surely being directly exposed to this contaminated water. Additionally, B2Gold began to purchase farmers' land where it needed to extract gold and where Santo Domingo's artisanal miners had been extracting gold and earning their living for decades. The company paid US\$4 million for 28 hectares and US\$7.7 million in all to buy up land. Nicaraguan Law 387 on mining exploitation concessions, passed in 2001, states that "a company to which a concession is given doesn't own the property. An exploitation concession is different than a property title. The law doesn't

\footnotetext{
${ }^{136}$ Author's personal interviews with leaders from Salvemos Santo Domingo social movement group: January 2017.
} 
say they can buy the property" (Pérez Soza 2013). Law 387 also does not stop the artisanal miners from working the land under B2Gold's concession. No Nicaraguan law that exists that prohibits artisanal miners from continuing to work the land operated by large-scale mining companies.

However, once B2Gold claimed to own the land, it fenced off the property as private property. It protected this land with armed police and would not allow the artisanal miners to continue mining the land that they had worked on for decades. Nicaraguan news media claimed that if the artisanal miners continued to mine on B2Gold's land that they were invading the company's property. However, as Pérez Soza (2013) nicely states, "it's the other way around: the miners actually have a concession to work those lands." In B2Gold's first 20 days of operation in Santo Domingo, the company extracted the amount of gold that would have taken Santo Domingo's artisanal miners 20 years to extract. Additionally, during this same time period, B2Gold cleared 21 hectares of land and extracted 56,000 ounces of gold, which in 2012 was approximately worth US\$106 million. B2Gold approximately extracts 10,200 ounces of gold per day.

If B2Gold continues at its level of capacity for extracting gold, the artisanal miners will have nothing left to mine. The community understands that the company intends to continue to extract the entirety of Santo Domingo's "gold vein" in under a decade. Once B2Gold extracts all of Santo Domingo's gold and leaves the community forever, it will take away the very little jobs and economic benefits it provided to the community. Many in Santo Domingo believe that when B2Gold leaves Santo Domingo, Santo Domingo will be destitute because the small economic benefits B2Gold offers will completely evaporate and the community will be completely contaminated by B2Gold's 
activities. ${ }^{137}$ Essentially, B2Gold and its mining activities are leaving the community with nothing: "no work, no landscape, nothing” (Pérez Soza 2013).

With the negligence of the Nicaraguan government and its institutions, as well as B2Gold's illegal seizure of land and its blatant disregard of the inhabitants' livelihoods; a resistance movement began to form. In 2011, the Salvemos Santo Domingo (Let's Save Santo Domingo), an environmental social movement organization, was formed. The organization consisted mainly of small cooperatives and independent miners, as well as merchants and producers of the main agricultural areas that are affected by B2Gold's exploitation projects. Salvemos Santo Domingo was born out of the common concern for the protection and conservation of Santo Domingo's water sources.

During the period when B2Gold was granted exploitation rights to the Jabalí Center exploitation project, Salvemos Santo Domingo issued a petition with 550 signatures denouncing B2Gold's activities because they were causing the destruction of a nearby stream that contributes as one of Santo Domingo's main sources of water. At the end of the same year, members of different cooperatives of small miners sent a letter to Santo Domingo's City Hall to denounce the eviction of small miners from the areas where they had worked throughout their lives, and for the environmental threats that stem from open-pit mining practices. The social discontent caused by the eviction of the small miners from the exploitation areas intensified because the small miners were unable to earn an income, which affected their family, their livelihoods, and the income of the municipality. Eventually, the first conflict between the community and B2Gold began on September 17, 2012.

${ }^{137}$ Author's personal interviews with community members in Santo Domingo: January 2017. 
Artisanal miners accompanied by citizens and different groups from Santo Domingo, including members of Salvemos Santo Domingo, organized a roadblock that stopped B2Gold from continuing its work in the area. ${ }^{138}$ Nicaragua's government wanted B2Gold to continue its work and urged the protesters to negotiate with the company. B2Gold divided the protesters and negotiated with them separately to create a division among the community. Only members from the Campo de Café (Coffee Grove), Lavadores de Carlos Fonseca (Washers of Carlos Fonseca), and Salvemos Santo Domingo pulled out of negotiations with B2Gold and continued the protest for 105 days, a length of time never before seen in Nicaragua. They used a human roadblock setup two kilometers outside of Santo Domingo that permitted everyone to pass except B2Gold workers (Pérez Soza 2013).

On February 9, 2013, Nicaragua's national government sent the national police to forcefully end the resistance movement against B2Gold. At 4:00 in the morning, over 100 riot police confronted the roadblock, but the protesters did not back down and put up a fight. The Nicaraguan government responded by sending more than 1,000 riot police to Santo Domingo who violently ended the protest with rubber bullets and teargas. Around 12 police officers were injured and 140 Santo Domingo citizens were injured. If the injured went to the local health clinic to be treated, they were turned over to the police. Many of the protesters fled to hilly areas that surround Santo Domingo to hide from the violence and arrest from the police. However, the police still arrested more than 50 people, 14 of whom were jailed in Juigalpa ${ }^{139}$ and 12 taken directly to Managua and

\footnotetext{
${ }^{138}$ Pérez Soza (2013) notes that citizens in Santo Domingo organized under various names: Sector Cuatro, Lavadores de Barrio Pancasán 1, Lavadores de Barrio Pancasán 2, Lavadores de Barrio Carlos Fonseca, and Campo de Café.

${ }^{139}$ Juigalpa is the departmental capital of Chontales.
} 
locked up in "La Loma" or "El Chipote" prison. These two prisons are infamously connected to the Somoza dictatorship in Nicaragua because the Somoza's used the prison to torture and kill political dissidents during their $\sim 40$-year rule. Today, the Nicaraguan government uses them for very dangerous prisoners. ${ }^{140}$ The $12 \mathrm{kept}$ in these prisons were mistreated and isolated from their families for over a month. Eventually released in March 2013, they were not allowed to leave the municipality of Santo Domingo. Below, in Figure 6.4, citizens of Santo Domingo are protesting the "illegal detainment" of the mining protesters.

\section{Figure 6.4: Protesters in Santo Domingo}

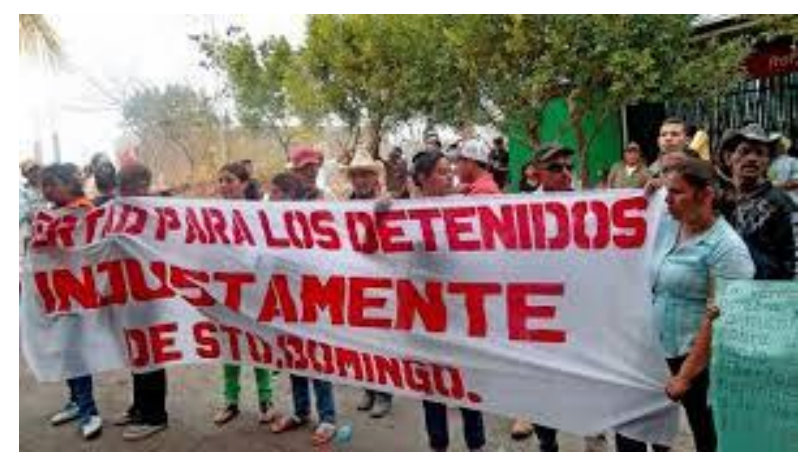

Source: Google images.

The goal of the government was to force them to negotiate with B2Gold and to halt all protests against the company and its activities. The Nicaraguan national police repressed the protesters, its Public Ministry accused the protesters, and the Judicial Branch arbitrarily and unjustly held the protesters in custody. Pérez Soza (2013) mentions how strange it was to "see FSLN political secretary Lenín Gutiérrez in Santo Domingo while the protestors were in prison in Managua. He came looking for the prisoners' relatives,

\footnotetext{
${ }^{140}$ In Latin America, as Svampa (2017) points out, those that protest against their socio-environmental struggles are often criminalized and treated violently by governments and police forces. It appears that Nicaragua's government and police forces follow this practice.
} 
advising them to negotiate with the company. He told them that if they gave up protesting, demonstrating, the prisoners would be released."

The use of threats and intimidation is common in Santo Domingo. For example, Nicaraguan national police visit homes of potential protesters the night before a planned protest to make violent threats to the protesters and their families in order to scare them into not protesting. Many community members continuously have to change their phone numbers and email addresses because the government monitors them and interferes with them in order to stop them from organizing anti-mining activities. Some community members are under constant surveillance. During some of my interviews in Santo Domingo, community members had heightened concerns if someone was listening to the interviews and often whispered. ${ }^{141}$

As I have discussed, those that oppose mining and B2Gold claim that the company does not have the approved environmental impact assessment and the required community consultation that by law should precede extraction. Their resistance is motivated by complaints "about the economic, environmental, and social effects" that industrial mining has on their community and their long term livelihoods (Articulo 66 2018; Spalding 2016; Pérez Soza 2013). Thus, citizens in Santo Domingo largely oppose B2Gold's activities for the same reasons that citizens in Rancho Grande do: to protect their right to land, landscapes, water quantity and quality, and their environment. B2Gold's mining activities have already heavily contaminated the land and the water in Santo Domingo, as well as forced citizens off their properties and destroyed people's homes. However, unlike Rancho Grande, citizens in Santo Domingo have not been able

${ }^{141}$ Author's personal interviews with community members in Santo Domingo: January 2017. 
to successfully overturn B2Gold's concessions to mine gold in the area even after years of establishing a resistance movement against mining.

Yet, the struggle between the citizens of Santo Domingo and B2Gold continues. Salvemos Santo Domingo has practiced and continues to practice forms of resistances like protests, roadblocks, boycotts, and petitions. In 2018, the citizens of Santo Domingo rejected a public consultation in regard to B2Gold's exploration project: Mina Jabalí. Farmers in Santo Domingo assured that if the Mina Jabalí project was to turn in to an exploitation project that it would solidify the environmental destruction of Santo Domingo. The Mina Jabalí project has led citizens to march through the streets while shouting "fuera, fuera, que se vayan" (get out, get out, make them leave) (Articulo 66 2018). Although, a large majority of the population continues to resist mining in Santo Domingo, B2Gold continues to extract gold.

The community organization that is most resistant against mining in Santo Domingo is Salvemos Santo Domingo. However, other NGOs, social groups and organizations, as well as government institutions like the Mayor's Office, the Ministry of Health, the national police, the Ministry of Education, and other governmental organizations do not assist in Santo Domingo's organizational resistance. The local government and its agencies and many local organizations do not assist community members that have been negatively affected by B2Gold's activities. They refuse to meet with them and listen to their grievances. In fact, individuals that are members or a part of these institutions and organizations attempt to stop the protests or report the citizens that plan to protest because they receive monetary benefits and incentives from B2Gold like 
bribes, gifts, jobs, houses, food, etc. ${ }^{142}$ Pérez Soza (2013) provides an example from the first major conflict between Santo Domingo citizens and B2Gold. He states:

The company began to divide them and negotiate separately with each one. And that's when we saw something really strange: the negotiations between the company and the small-scale miners were 'mediated' by none other than Commissioner Major Javier Carrillo, Chontales' police chief. But he spoke more for the company than for the miners. Also present in the negotiations was Lenín Gutiérrez, the FSLN Political Secretary in Chontales, and Wilber Miranda, the FSLN's losing mayoral candidate for Santo Domingo in last year's elections... Then we realized that the mining company had been buying off state and FSLN functionaries and officials to take the company's side. There had been blatant corruption. Just take a look at this: the mining company has given the judicial branch 50 motorcycles and also computers. They are buying consciences, in other words.

Therefore, those that oppose mining in Santo Domingo are likely the citizens that directly experience, feel, and/or witness the detrimental impacts that B2Gold's activities cause to their livelihoods. They may or may not be socially engaged in community organizations, like Salvemos Santo Domingo, and it is not likely these organizations are forming their negative attitudes towards mining but they could be reinforcing them. However, when these organizations are coerced, corrupted, and bribed by the mining company, I do not expect individuals to form negative attitudes against mining. For example, the local government agencies and local organizations do not want to listen or believe the information from Salvemos Santo Domingo and Centro Humboldt about Santo Domingo's water contamination. Their lack of interest to listen and assist those that are negatively impacted by B2Gold and its activities are related to the economic benefits that these individuals and organizations receive from B2Gold (i.e. the national police received

\footnotetext{
142 Author's personal interviews with leaders from Salvemos Santo Domingo social movement group in Santo Domingo: January 2017.
} 
new motorcycles, the Catholic church was repaired; the Mayor's Office was given new office equipment, the Ministry of Education was given notebooks for the children, etc.). ${ }^{143}$ For example, in an interview I held in Managua with a scientist studying the water contamination in Santo Domingo, the scientist stated:

The fact that they are extracting gold directly under the community means that this run off is going directly into the peoples' water supply. When this was brought to the attention of the Mayor's Office, the Ministry of Health, the national police, environmental NGOs, and other organizations in the community, they chose not to believe the scientific study and said that it was false. ${ }^{144}$

Additionally, much of the information and evidence produced by organizations like Centro Humboldt is filtered by the local government, so the full story with the correct information and facts does not reach the population. Many in the community are truly worried that people do not even know what is happening in Santo Domingo, and when they finally do learn it will likely be too late. Some in the community believe that everyone in Santo Domingo should be concerned about the water contamination and environmental pollution caused by B2Gold. Yet, many citizens still do not know the information available about Santo Domingo's water contamination or are persuaded not to believe it because the local government agencies and organizations do not want them to. Currently, only those that know, feel, or directly witness the harmful side effects of mining, oppose B2Gold and mining. However, many citizens in Santo Domingo that are not directly impacted by the harmful side effects from mining do not likely see a reason yet to oppose B2Gold and mining. Furthermore, they are not yet completely aware of the

\footnotetext{
${ }^{143}$ Author's personal interviews with leaders from Salvemos Santo Domingo social movement group in Santo Domingo: January 2017.

${ }^{144}$ I clarified this with the leaders of Salvemos Santo Domingo. They said that this did happen, and it happened because these are the groups that received economic benefits from B2Gold.
} 
harmful effects mining causes their community or they choose not to care because they enjoy the economic benefits from B2Gold. ${ }^{145}$

The resistance movement against mining in Santo Domingo also lacks the economic resources to spread the necessary information. Some community members would like to hold informative workshops in town, pass out flyers, pamphlets, etc. However, they do not have the fiscal capacity to do so, which is allowing for B2Gold to further contaminate the community. The community's struggle is against B2Gold, the local government, and some local organizations, who have endless amounts of resources to suppress any type of resistance against mining. Thus, even those that are leading the resistance movement against B2Gold do not believe in their own capabilities to organize and execute a strong and effective resistance against mining because they lack the resources to inform the entire community about the harmful impacts mining is causing Santo Domingo. Hence, the community lacks self- and community-efficacy because they do not have the organizational resources and capacity to empower themselves and the community to effectively oppose and resist mining. Additionally, Santo Domingo remains divided towards its stance on mining because the community lacks the resources to form a cohesive resistance. ${ }^{146}$

The community of Santo Domingo also lacks unity and cohesion, because it lacks a strong connection to its land and its members. Community members in Santo Domingo, when discussing Rancho Grande's resistance against B2Gold, suggested that citizens in Rancho Grande are native to the area and lived in the community their entire lives. Their

\footnotetext{
145 Author's personal interviews with members from Santo Domingo: January 2017.

146 Author's personal interviews with leaders from Salvemos Santo Domingo social movement group in Santo Domingo.
} 
families lived there their entire lives, and the whole community has strong ties to the land and to each other. However, residents of Santo Domingo are not originally from the community and come from different parts of Nicaragua and Central America for employment purposes. Individuals in Santo Domingo do not have a strong connection to the land or Santo Domingo's community, which makes them less connected to and uninterested in Santo Domingo's resistance against B2Gold and mining. Thus, these types of individuals are not forming oppositional attitudes against B2Gold or mining because they are not concerned with the detrimental impacts mining has on the community. ${ }^{147}$

Santo Domingo's fight against B2Gold and mining is an uphill battle because of how B2Gold was able to coerce, corrupt, and bribe the local government agencies and some local organizations, as well as intimidate and threaten citizens that oppose mining. ${ }^{148}$ There are too many hurdles: monetary and societal that are keeping the community from effectively and sustainably organizing against mining. While I was in Rancho Grande, I was told that "mining companies are a cancer to communities, once they are in the community they are almost impossible to get rid of until the community dies. This is what is happening in Santo Domingo." ${ }^{149}$ Unlike Rancho Grande, the community of Santo Domingo is divided against their stance towards mining and does not have: 1) access to critical organizational tools and information about mining; 2) a high sense of self-efficacy and collective-efficacy empowering it to resist mining; 3 ) and

\footnotetext{
${ }^{147}$ Author's personal interviews with leaders from Salvemos Santo Domingo social movement group in Santo Domingo.

${ }^{148}$ Although some inhabitants of Santo Domingo continue to mobilize and resist B2Gold, they often fear the violence that could be inflicted upon them, which has left some inhabitants to simply avoid resistance and protests against $\mathrm{B} 2 \mathrm{Gold}$ and mining.

${ }_{149}$ Author's personal interview with a leader from the Guardines de Yaoska social movement group in Rancho Grande: January 2017.
} 
a strong community worldview (i.e., community identity and values) contributing to broad-based mobilization and resistance. Community members in Rancho Grande seem to believe that it is almost too late for Santo Domingo to successfully resist B2Gold and mining. ${ }^{150}$ Therefore, for Santo Domingo, I expect null results for my hypothesis related to social engagement in local organizations.

Furthermore, and if one recalls, the negotiation process between the protesters in Santo Domingo and B2Gold that was forced by the government during the community's first conflict with the company (September 2012-February 2013), the protesters and groups (Campo Café, Lavadores de Carlos Fonseca, and Salvemos Santo Domingo) that refused the negotiations demanded that Santo Domingo's local parish priest, César Augusto León, be one of the mediators instead of the Chontales police commissioner. This shows the trust that some of the community members had in this Catholic priest. Additionally, some of the mediation was conducted in a room in the local Catholic church. However, unfortunately, the room was not large enough to hold the majority of the protesters (Articulo 66, 2018). It does appear that the Catholic Church and the local parish priest may have been respected and trusted in assisting with negotiations between the community protesters and B2Gold. However, as I previously discussed, the Catholic Church in Santo Domingo was eventually coerced into supporting B2Gold and its activities because the mining company helped restore the church. Essentially, the Catholic Church of Santo Domingo accepted gifts from the mining company instead of looking out for the interests of the community and the citizens. ${ }^{151}$

\footnotetext{
${ }^{150}$ Author's personal interviews with leaders from Salvemos Santo Domingo social movement group in Santo Domingo.

${ }^{151}$ Author's personal interviews with community members from Santo Domingo: January 2017.
} 
Besides what I just discussed, and unlike Rancho Grande, the role of the Catholic Church and the Evangelical Church was largely absent in Santo Domingo's antiextraction movement. However, community members acknowledged that Rancho Grande's strong organizational capacity and community unity is a result of the Catholic Church and the Evangelical Church's involvement and engagement in its anti-mining resistance movement. The community members understood that the Catholic and Evangelical Churches brought together environmental and agricultural NGOs, governmental agencies and institutions, and other organizations throughout Rancho Grande and the entire Department of Matagalpa. Some citizens in Santo Domingo believe that the Catholic and Evangelical Churches were the unifying factor that brought community cohesion to Rancho Grande and provided the resources and sustenance for the community to effectively organize and successfully overturn B2Gold's mining concession. ${ }^{152}$

Additionally, some individuals in Santo Domingo believe their resistance movement against B2Gold would be successful if it had involvement and assistance from the Catholic and Evangelical Churches in uniting and organizing the community against mining. Nicaragua is a very religious country and the Churches are well respected and trusted institutions. Community members believe if the resistance movement could gain the support of the Churches to assist in its opposition against B2Gold, they believe that individuals involved in the institutions and organizations that support B2Gold for economic benefits would perhaps begin to follow the directive of these Churches in promoting opposition towards B2Gold and mining. However, to date, religion's role in

\footnotetext{
${ }^{152}$ Author's personal interviews with community members from Santo Domingo: January 2017.
} 
Santo Domingo has largely been absent and B2Gold continues to hold power over much of the community while it continues to extract gold and cause harm to a large majority of citizens living in the community. Therefore, I also expect that the absence of religious involvement in Santo Domingo's resistance movement against B2Gold is likely one of the key factors for why Santo Domingo has not been able to achieve a national-level policy change in reversing B2Gold's mining concession. ${ }^{153}$

\section{$\underline{\text { Research Design and Empirical Analysis }}$}

\section{Survey Sampling}

In collaboration with the Socio-Cultural Analysis Center at La UCA in Managua, Nicaragua; I completed public opinion surveys in April 2018 to fulfill a comprehensive database with just under 200 variable indicators related to: the environment, water resources, agricultural activity, security of the land, public services, politics and political beliefs, protest beliefs, economic dynamics, social capital, public institutions, mining activity, and a battery of controls. The data was collected through an application of approximately 400 surveys through personal interviews with residents of Santo Domingo. The surveys were facilitated and supervised by members of the Socio-Cultural Analysis Center. Table 6.1A in the Appendix outlines the survey sample design for Santo Domingo. The municipality of Santo Domingo is composed of 14 neighborhoods and 17 districts. Santo Domingo has a population of 18,000 inhabitants with the majority of the population living in rural areas (Centro Humboldt 2015a). The survey randomly chose

\footnotetext{
${ }^{153}$ Author's personal interviews with community members from Santo Domingo: January 2017.
} 
roughly (+/-) $15 \%$ of individuals living in the 14 neighborhoods and 17 districts that could be surveyed. Out of those individuals randomly chosen, the survey randomly chose roughly (+/-) $15 \%$ of individuals living in the 14 neighborhoods and 17 districts. Roughly 400 surveys were distributed in the districts and neighborhoods in a proportional and randomized manner. These samples are based on data from the 2005 Nicaragua census (INIDE 2005).

With the data from the public opinion surveys, I can understand and study what makes individuals oppose or support resource extraction, as well as understand the microlevel politics (i.e., social engagement in local organizations) that shape individual attitudes, beliefs, and characteristics towards mining. Again, the survey data offers robust individual-level data that permits me to understand what prompts citizens to participate in protests by understanding the factors that lead them to oppose mining. By conducting these surveys with clustering respondents around extractive protest sites like Santo Domingo, I understand what causes some citizens to mobilize and others to abstain against resource extraction; uniquely at the individual level. This survey data also permits me to understand what attitudes, beliefs, and characteristics individuals have in highly visible protest cases for successfully overturning mining concessions through sustained protests and social movement resistance. Therefore, I utilize this data to ask citizens in Santo Domingo their views and perceptions to generalize from empirical data, rather than make inferred assumptions about individuals from aggregate community-level data.

In Figure 6.5 and Figure $6.6^{154}$, based on my survey responses from Santo Domingo, one sees a fairly strong negative community relationship with residents of

\footnotetext{
${ }^{154}$ The survey question for Figure 6.5 that I asked respondents is "How would you classify the relationship between the local population and B2Gold?" The answers were very good, good, average, and very bad. The
} 
Santo Domingo and B2Gold. Figure 6.5 depicts this relationship when the survey was taken in April 2018. The majority of the community members still have negative feelings towards B2Gold, which likely stems from the company's continued activity harming the livelihoods of individuals in the community, and its divisive and deceitful actions, which has caused mistrust with the community members. Just over 150 of the roughly 400 respondents in my survey suggest that the community's relationship with B2Gold is bad. However, just over 150 of the roughly 400 respondents in my survey suggest the community's relationship with B2Gold is average, which likely indicates that some citizens are not entirely opposed to B2Gold's activities and presence in the area because of the possible economic benefits being received from the company. The negative sentiment in Santo Domingo was even higher five years earlier in 2013, which can be seen in Figure 6.6. Around 175 of the roughly 400 respondents in my survey suggest the community's relationship with B2Gold was bad, which likely relates to the timing of Santo Domingo's resistance movement against mining from September 2012-February 2013.

survey question for Figure 6.6 that I asked respondents is "Five years ago, how would you classify the relationship between the local population and B2Gold?" The answers were very good, good, average, and very bad. 
Figure 6.5: Community Relationship with B2Gold

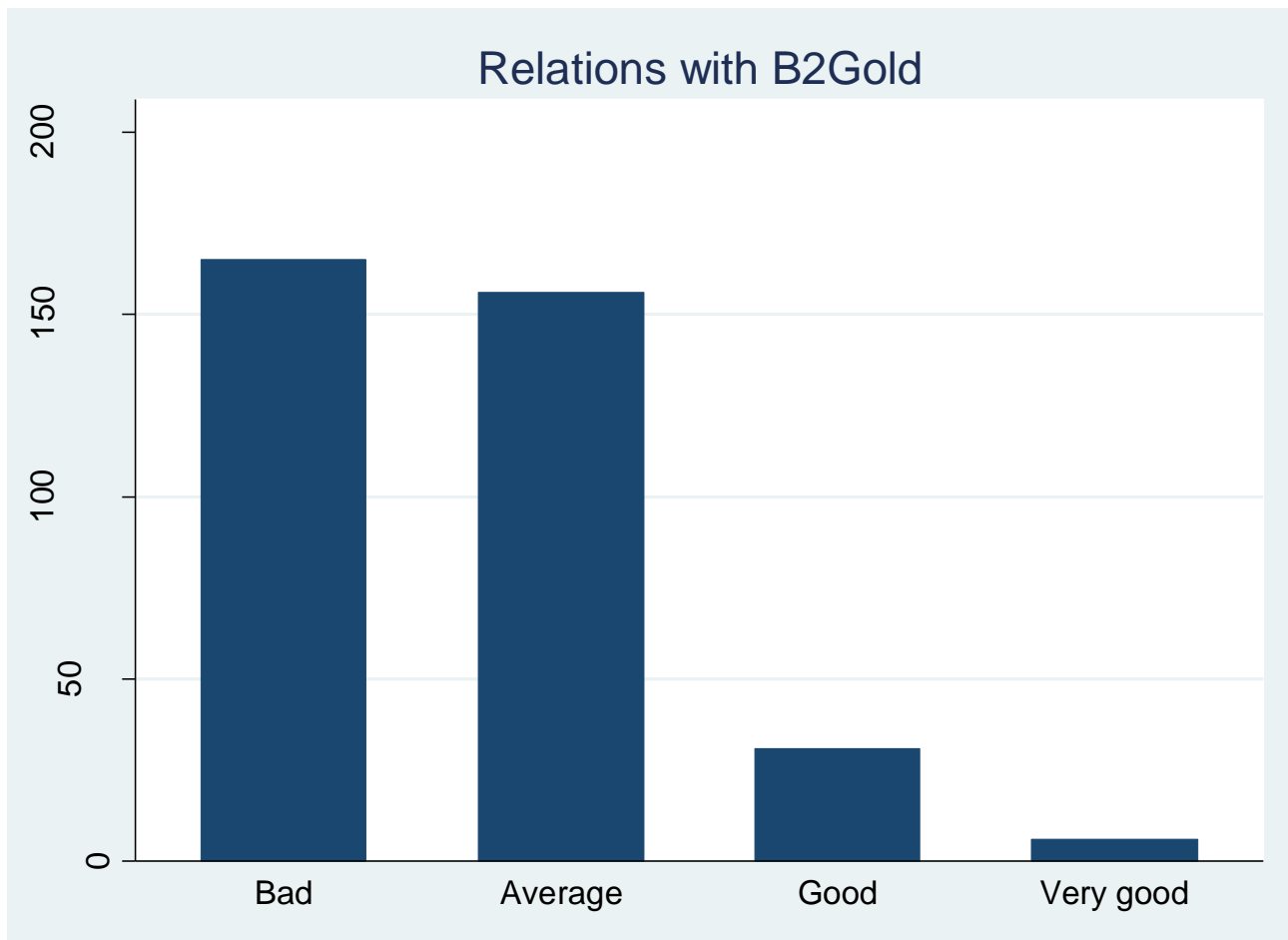

Source: Author's data.

Figure 6.6: Community Relationship with B2Gold 5 Years Ago

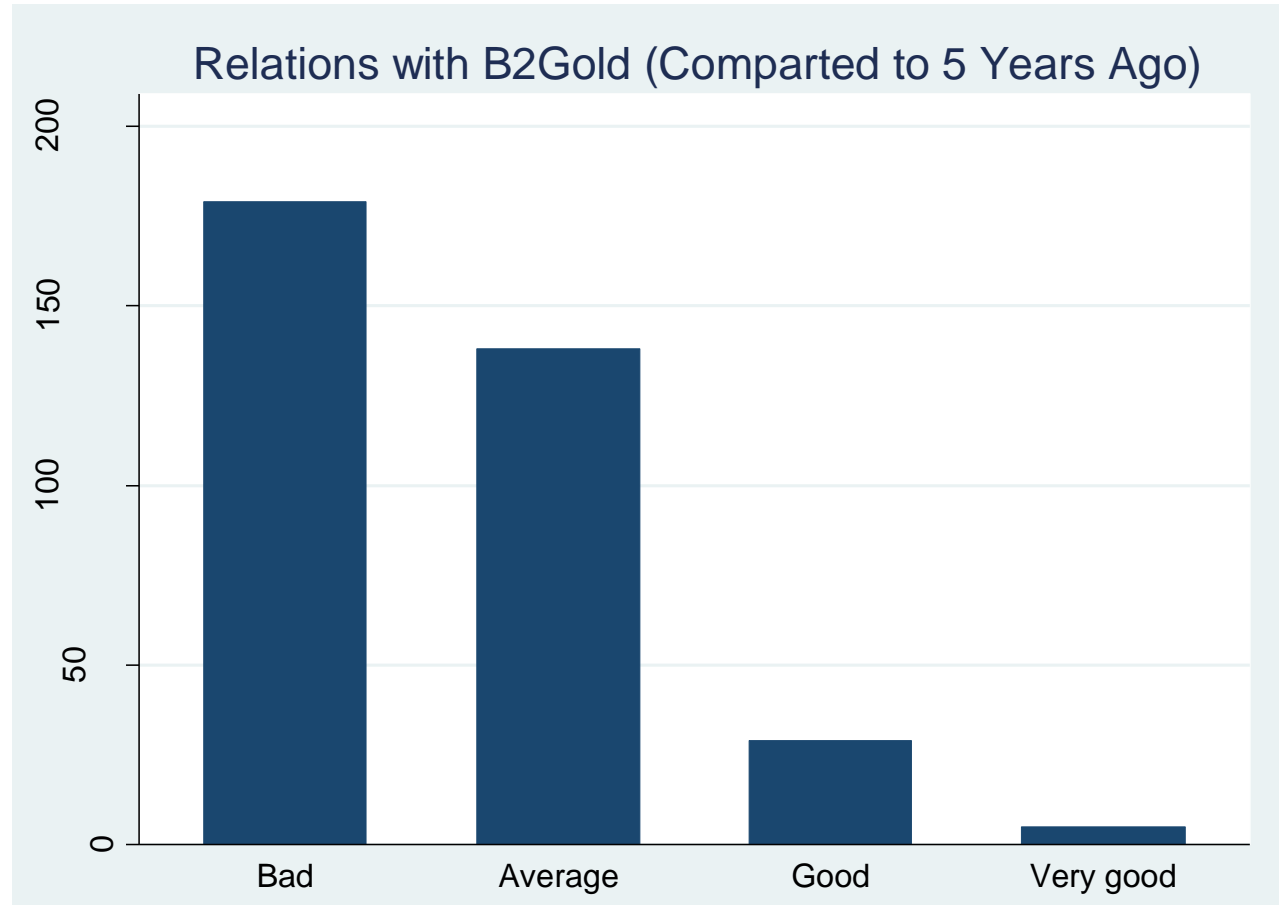

Source: Author's data. 


\section{Dependent Variable and Statistical Model—Support for B2Gold's Mining Activities}

In the first part of my analysis, my first dependent variable—Support for B2Gold's mining activities - is a dichotomous variable that asks an individual if she supports or opposes B2Gold's mining exploration projects. ${ }^{155}$ In the survey, $16.71 \%$ of respondents in Santo Domingo supported the project, while $83.29 \%$ of the respondents opposed it. Given the dichotomous nature of the dependent variable, I use a logistic regression model. Below Figure 6.7 demonstrates the reasons individuals in Santo Domingo support B2Gold's influence in their community. I asked individuals in Santo Doming, "What is the main reason that you support the projects of B2Gold?" There are only $16.71 \%$ (65/389) of respondents from my survey in Santo Domingo who support B2Gold and its activities. Although small, there is still roughly $17 \%$ of the population that supports mining. The top three reasons for support are employment opportunities, economic benefits, and social programs. The other reasons that respondents support B2Gold and its activities are because the company and its activities do not hurt the environment, there is strong state oversight, and B2Gold is a respectful company. However, the top three rated reasons by respondents represent demands for services characteristics.

\footnotetext{
${ }^{155}$ In the Appendix for this chapter, one can find more information about my dependent variable in Table 6.2A ("Variable Coding, Frequency, and Percentages"), Table 6.3A ("Variable Summary Statistics"), and Table 6.4A ("Survey Questions and Variable Explanations").
} 


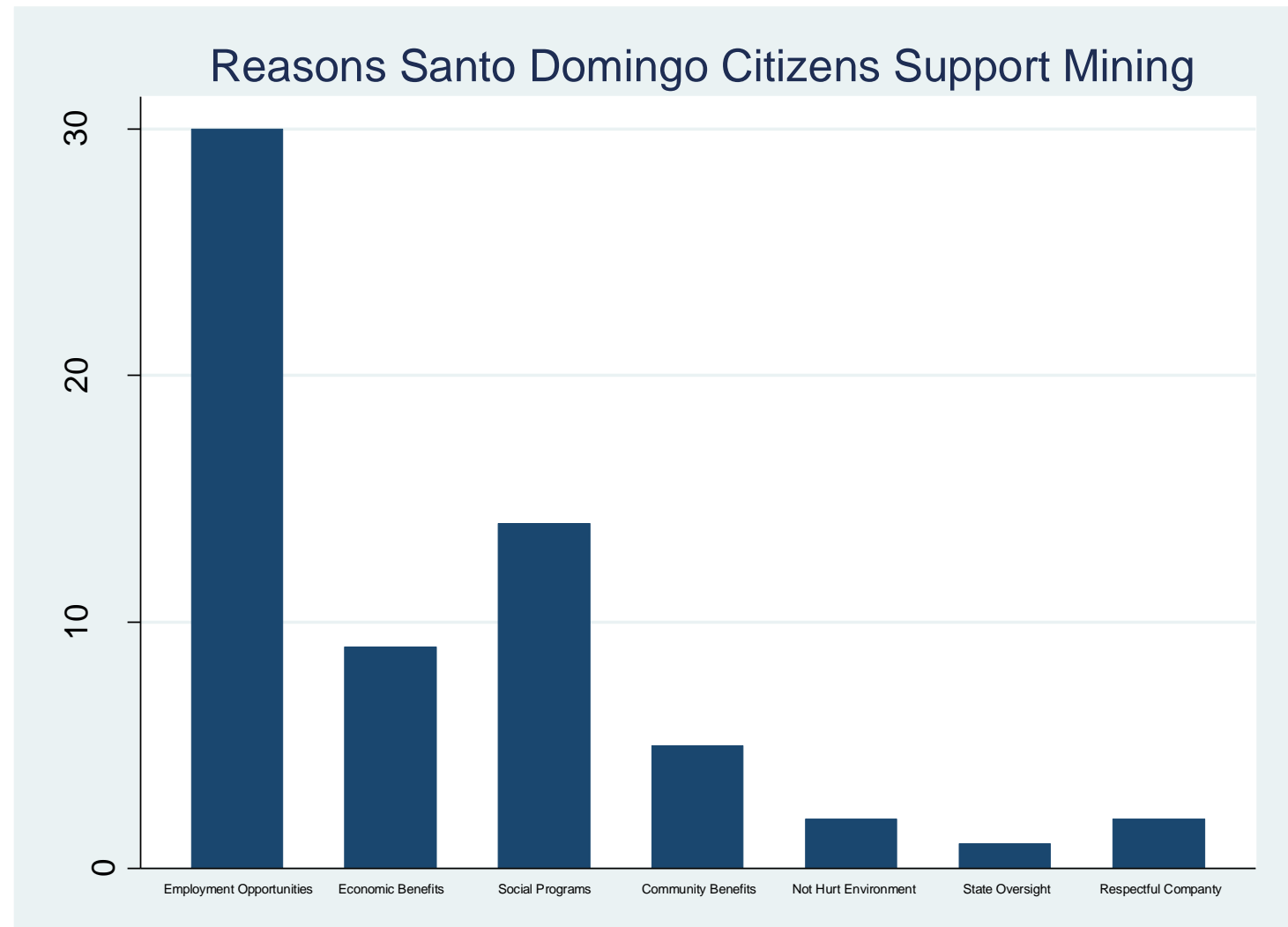

Source: Author's data.

Figure 6.8, below, shows the main reasons respondents from my survey oppose B2Gold and its activities. I asked individuals in Santo Domingo, "What is the main reason that you oppose the projects of B2Gold?" There are $83.29 \%$ of respondents in my survey in Santo Domingo who oppose B2Gold and its activities. The two overwhelming reasons that citizens in Rancho Grande oppose mining and B2Gold's projects is because they believe it hurts the environment (far left bar) and it contaminates the water (far right bar). Over 150 respondents in my survey oppose mining for environmental reasons. The second reason individuals in Santo Domingo oppose mining relates to water contamination. They are fearful that mining and its activities will contaminate its rivers and water sources. Just over 50 respondents from my survey oppose mining because of 
water contamination. It is important to point out that the two main reasons respondents

oppose mining in Santo Domingo are directly related to demand for rights type claims. ${ }^{156}$

\section{Figure 6.8: Reasons Individuals in Santo Domingo Support B2Gold}

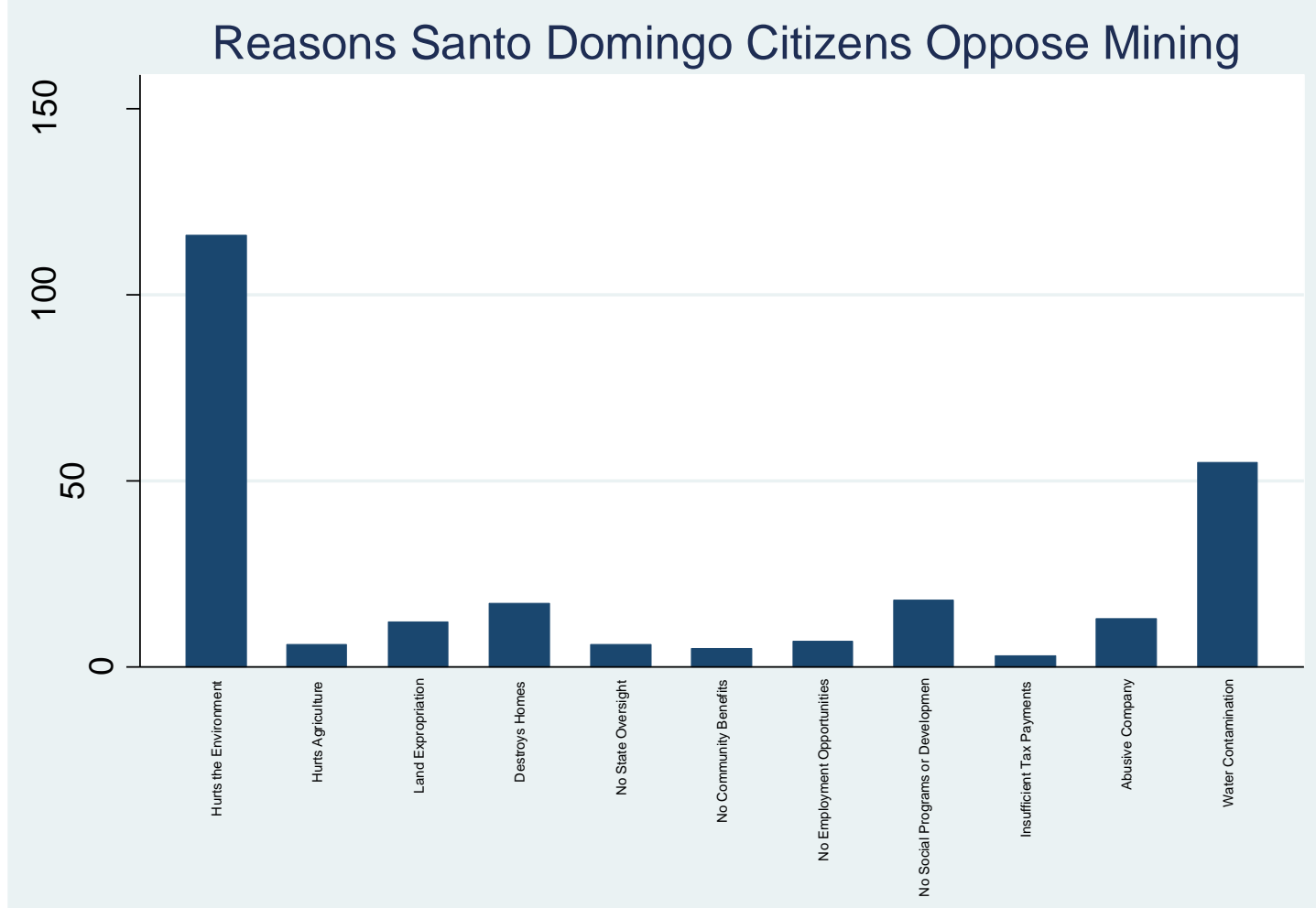

Source: Author's data.

Independent Variables—Demands for Rights, Demands for Services, and Social

\section{Engagement}

My independent variables of interest include two variables measuring demands for rights, two variables gauging demands for services, and a variable measuring individuals' social

\footnotetext{
${ }^{156}$ The other reasons respondents oppose B2Gold and its activities are related to the harmful impacts to agriculture, land expropriation, destruction of homes, lack of state oversight, lack of community input, lack of provisions related to social programs and economic development, and B2Gold is an abusive company. However, the top four related reasons are linked to demands for rights.
} 
engagement in community organizations. ${ }^{157}$ I explain each of these variables in turn. My main independent variables of interest seek to capture the relative importance of rightsand service-based claims, which conceptually can be seen as sources of opposition and support, respectively. With regards to rights-based claims, I asked respondents, "What impact will B2Gold's activity have on the environment? This variable, Environmental Impact is dichotomous ( $1=$ negative; $0=$ positive). I also asked respondents if they agreed or disagreed with the following statement: "The drilling of the land done for mining activity damages the environment and agriculture." This variable, Agricultural Impact, is dichotomous ( $1=$ agree; $0=$ disagree). Turning to service-based claims, I asked respondents, "What impact will B2Gold's activity have on employment opportunities?" This variable, Employment Opportunities, is a dichotomous variable (1=(very) positive; $0=($ very) negative). I also asked respondents, "Has the mining company helped improved education services in your community?" This variable, Educational Opportunities, is dichotomous ( $1=$ yes; $0=$ no).

Below are Figure 6.9 and Figure 6.10. Figure 6.9 illustrates my two demands for rights variables: Environmental Impact and Agricultural Impact. Over 300 respondents in Santo Domingo believe that mining damages the environment and agriculture, while less than 100 respondents believe that mining does not damage the environment and agriculture. Figure 6.10 illustrates my two demands for services variables: Employment Opportunities and Educational Opportunities. Just over 250 respondents in Santo Domingo believe that mining does not create employment opportunities, while

\footnotetext{
${ }^{157}$ In the Appendix for this chapter, one can find more information about my independent variables in Table 5.2A ("Variable Coding, Frequency, and Percentages"), Table 5.3A ("Variable Summary Statistics"), and Table 5.4A ("Survey Questions and Variable Explanations").
} 
approximately 250 respondents in Rancho Grande do not think mining creates

educational opportunities. While just under 100 respondents in Santo Domingo believe that mining creates employment and educational opportunities. Based on these descriptive statistics it is clear that Santo Domingo is clearly more of a "demands for rights" community than it is a "demands for services" communities.

Figure 6.9: Descriptive Statistics for Demands for Rights Variables

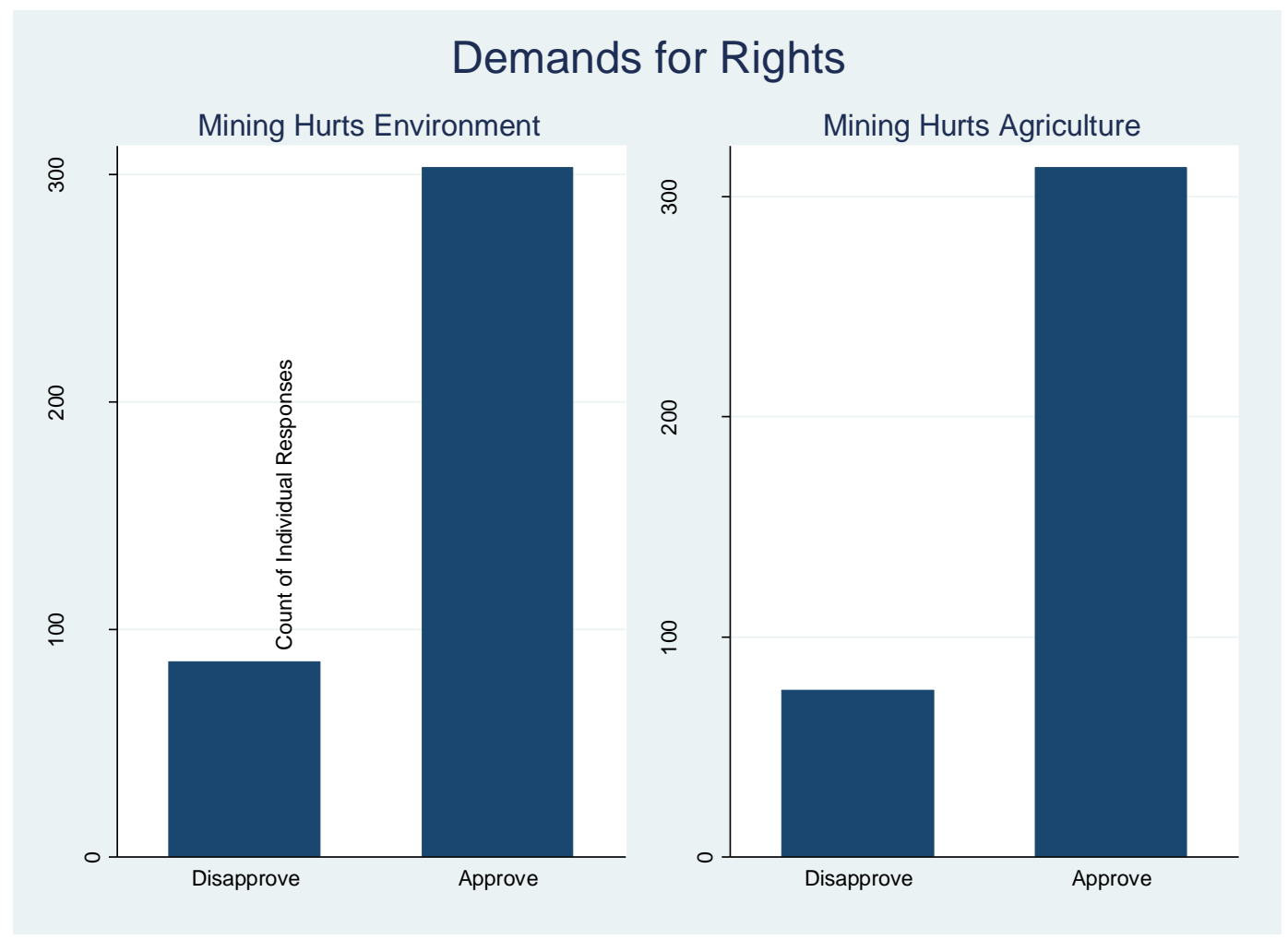

Source: Author's data.

Figure 6.10: Descriptive Statistics for Demands for Services Variables 


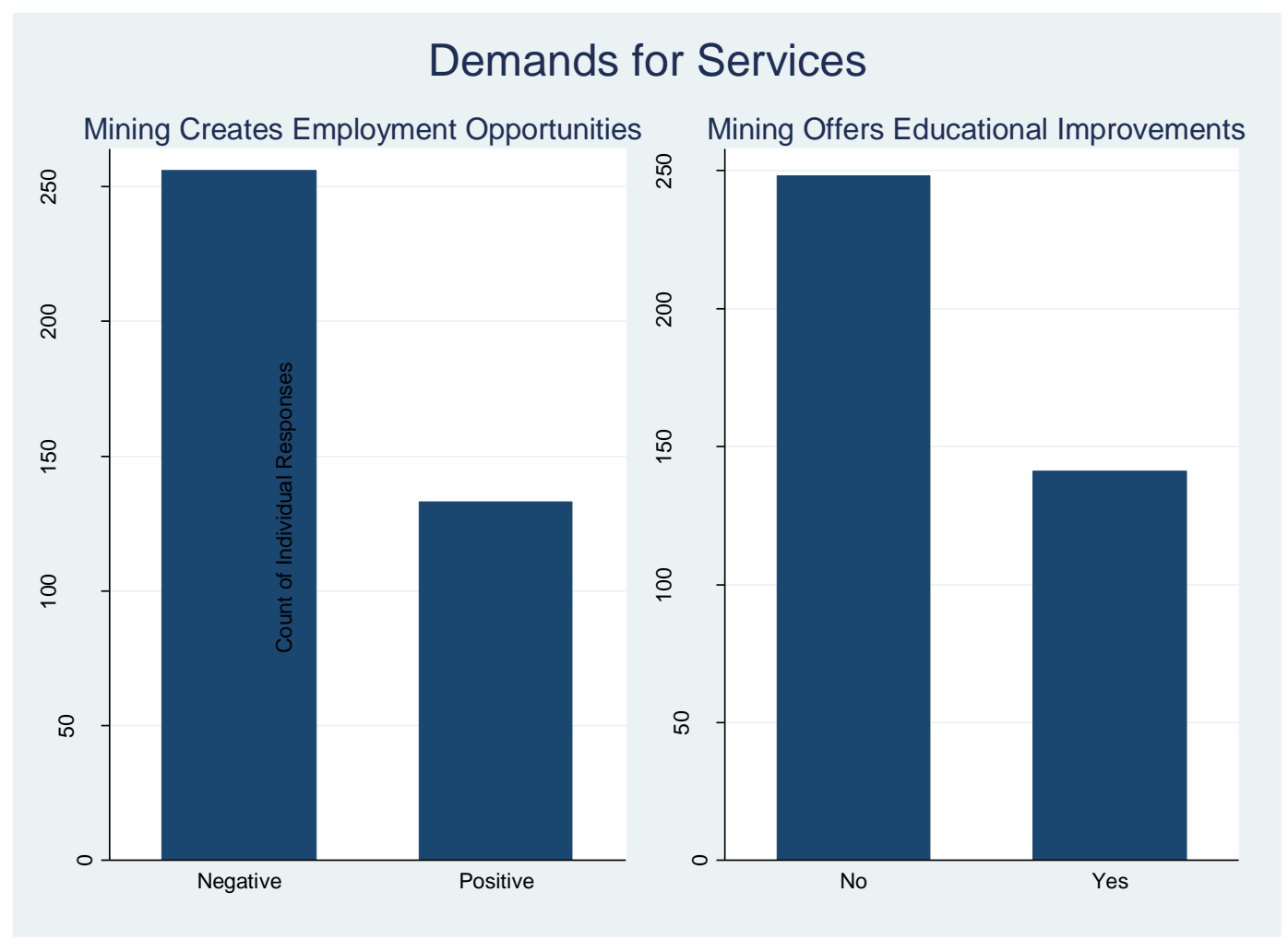

Source: Author's data.

I am also interested in the effects that Social Engagement has on oppositional attitudes towards mining. The question from my survey that I utilized is, "How frequently do you attend an organization meeting?" Although, my survey asked individuals about their participation in various community organizations, I used the following four organizations based on my expectations: 1) general community organization;2) environmental organizations; 3) agricultural organizations; and 4) religious organizations. A respondent received a 0 if he or she never engaged or participated in a community, environmental, agricultural, or religious organization. A respondent received a 1 if he or she participated or engaged in a community, environmental, agricultural, or religious organization once a week, twice a month, or once a month. The Social Engagement variable is an additive index based on a respondent's participation in a community, environmental, agricultural, and/or religious organization. For example, if a respondent participates at least once a 
month in: all four organizations, the respondent receives a 4 ; in three of the four organizations, the respondent receives a 3; in two of the four organizations, the respondent receives a 2 ; in one of the four organizations, the respondent receives a 1 ; and in none of the organizations, the respondent receives a 0 . Thus, this variable ranges from 0-4 and is used to measure individuals' social engagement in community organizations. I find congruence between my measure of social engagement and Moseley’s (2015) indicator of community engagement - an indicator that gauges the frequency with which citizens participate in local organizations and can effectively measure the dense organizational networks that are pivotal to shape and form individual attitudes and beliefs towards mining.

Figure 6.11 and Figure 6.12 below provide some basic descriptive statistics for my Social Engagement variable based on survey respondents from Santo Domingo. Figure 6.11 displays a bar graph that shows respondents that participate in local community organizations in Santo Domingo. There are 122 respondents that do not participate, there are 158 respondents that participate in at least 1 organization, there are 68 respondents that participate in 2 organizations, there are 35 respondents that participate in 3 organizations, and there are 16 respondents that participate in 4 organizations. Remember that the four organizations are general community organizations, environmental organizations, agricultural organizations, and religious organizations. Out of the 389 respondents in my survey from Santo Domingo, 277 individuals are socially engaged, at some level, in local organizations. Figure 6.12 shows the relationship between my Social Engagement variable and Support for B2Gold's mining activities. There are only 30 out of the 158 respondents that participate in 1 
organization that support B2Gold's mining activities. There are only 8 out of the 68 respondents that participate in 2 organizations that support B2Gold's mining activities. There are only 4 out of the 35 respondents that participate in 3 organizations that support B2Gold's mining activities. And, there are just 3 out of the 16 respondents that participate in 4 organizations that support B2Gold's mining activities. There are a lot less respondents that support mining and are socially engaged than respondents that oppose mining and are socially engaged.

\section{Figure 6.11: Social Engagement in Local Organizations}

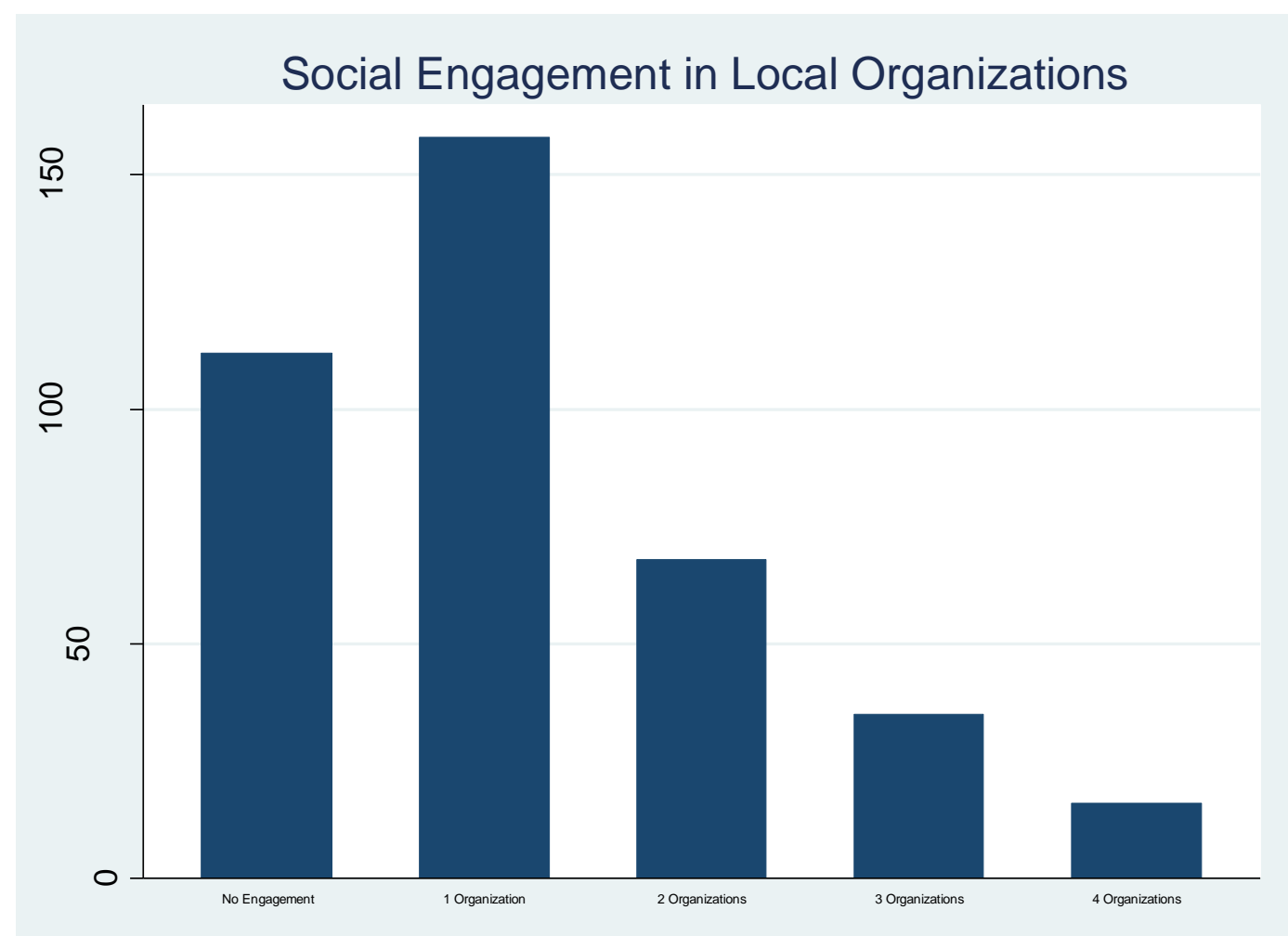

Source: Author's data.

Figure 6.12: Social Engagement and Support for Mining 


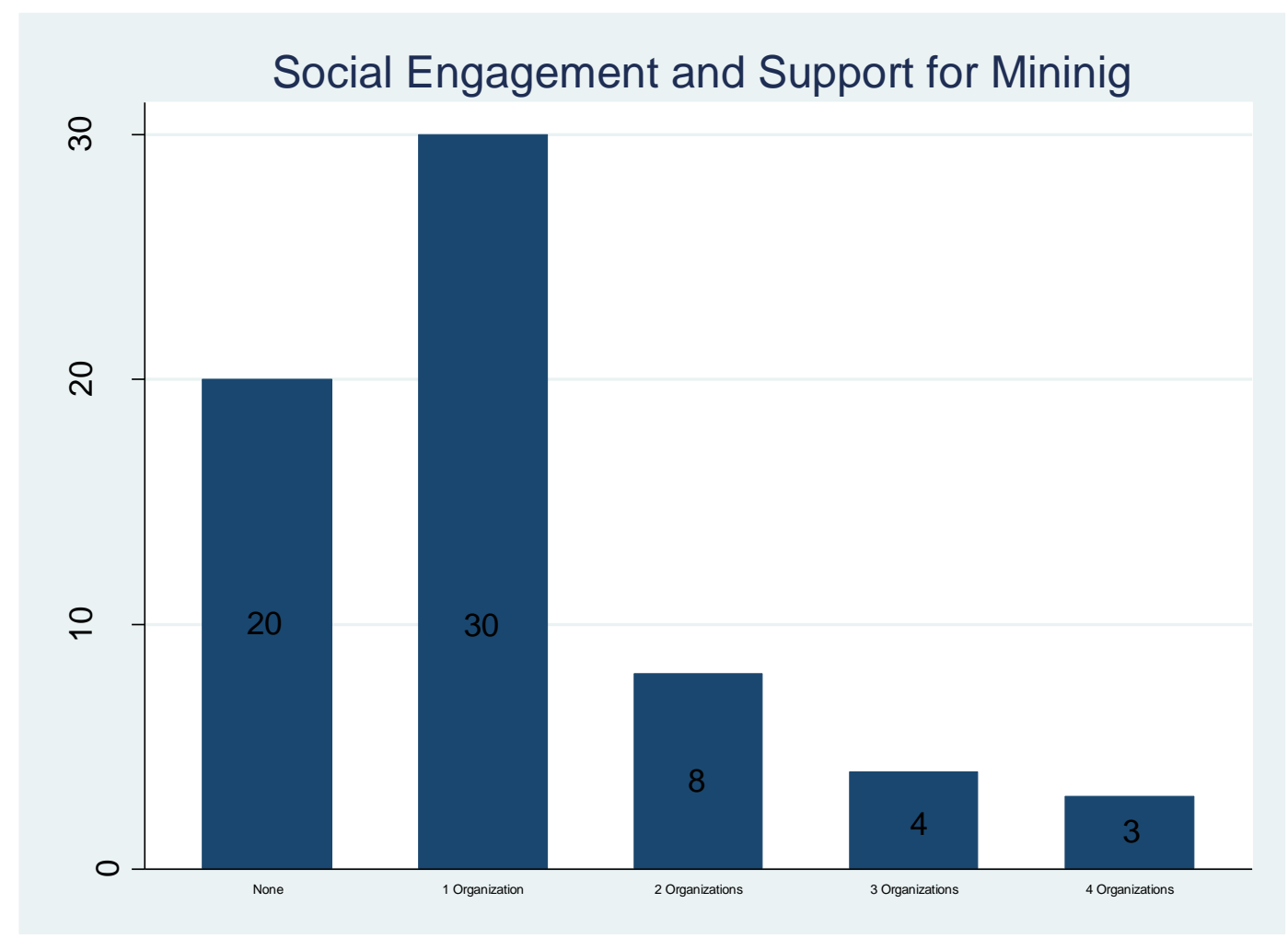

Source: Author's data.

Table 6.1 below provides correlations between individuals who are engaged in local organizations with the components that I argue make socially engaged individuals more likely to oppose mining projects: 1) access to critical organizational tools and information about mining; 2) a higher sense of self-efficacy and collective-efficacy empowering them and their communities to resist mining; 3) and a stronger community worldview contributing to broad-based mobilization. In these crosstab correlation tables, individuals that participated in one, two, three, and/or four organizations at some level received a 1; otherwise individuals received a 0. I utilized my Social Engagement variable specified earlier, and made it dichotomous instead of continuous for ease of comparison purposes. This variable is used in all four of the crosstab tables.

Table 6.1: Social Engagement's Relationship with Knowledge, Efficacy, and Community Worldview 


\begin{tabular}{|c|c|c|c|}
\hline & \multicolumn{3}{|c|}{ Socially Engaged Individuals } \\
\hline Organizational & \multicolumn{3}{|c|}{ Participation in Community Organizations } \\
\hline & $\begin{array}{c}\text { Does Not } \\
\text { Participate }\end{array}$ & Particpates & Total \\
\hline Yes & 90 & 243 & 333 \\
\hline No & 22 & 34 & 56 \\
\hline \multirow[t]{2}{*}{ Total } & 112 & 277 & 389 \\
\hline & \multicolumn{3}{|c|}{ Socially Engaged Individuals } \\
\hline Self-Efficacy & \multicolumn{3}{|c|}{ Participation in Community Organizations } \\
\hline & $\begin{array}{c}\text { Does Not } \\
\text { Participate }\end{array}$ & Particpates & Total \\
\hline Yes & 107 & 262 & 369 \\
\hline No & 4 & 11 & 15 \\
\hline \multirow[t]{2}{*}{ Total } & 111 & 273 & 384 \\
\hline & \multicolumn{3}{|c|}{ Socially Engaged Individuals } \\
\hline \multirow[t]{2}{*}{$\begin{array}{l}\text { Community } \\
\text { Divided }\end{array}$} & \multicolumn{3}{|c|}{ Participation in Community Organizations } \\
\hline & $\begin{array}{c}\text { Does Not } \\
\text { Participate }\end{array}$ & Particpates & Total \\
\hline Not Divided & 47 & 119 & 166 \\
\hline Divided & 59 & 152 & 211 \\
\hline \multirow[t]{2}{*}{ Total } & 106 & 271 & 377 \\
\hline & \multicolumn{3}{|c|}{ Socially Engaged Individuals } \\
\hline $\begin{array}{l}\text { Community } \\
\text { Worldview }\end{array}$ & \multicolumn{3}{|c|}{ Participation in Community Organizations } \\
\hline & $\begin{array}{c}\text { Does Not } \\
\text { Participate } \\
\end{array}$ & Particpates & Total \\
\hline Yes & 86 & 224 & 310 \\
\hline No & 19 & 40 & 59 \\
\hline Total & 105 & 264 & 369 \\
\hline
\end{tabular}

Source: Author's data.

Organizational Tools and Information About Mining is also dichotomous. If survey respondents answered that they know: 1) where B2Gold's headquarters are; 2) who Salvemos Santo Domingo is; 3) who B2Gold's subsidiary company is; and/or 4) B2Gold's mining project; the respondents received a $1(0=$ respondents did not know any of the four categories). Out of the 389 respondents, it appears that the majority of them, 
$243(62.5 \%)$, participate in local organizations and understand the organizational tools and information about mining available to them, which is contrary to the qualitative evidence I provided in the previous section. Self-efficacy is based on a survey question that asked respondents the following question: "Should communities protect their land from mining companies entering them?" The variable is dichotomous ( $1=\mathrm{yes} ; 0=$ no). Out of the 384 respondents, it appears that the majority of them, $262(68.2 \%)$ have a higher sense of self-efficacy and believe that they can resist mining, which is also contrary to the qualitative evidence that I provided in the previous section.

Finally, the last two crosstab tables examine two different variables related to community to gauge respondents' community worldview. The first, Community Divided, is based on a survey question that asked individuals if they believed their community was divided. Respondents received a 1 if they believed Santo Domingo is divided; a 0 otherwise. Only $31.6 \%$ (119/377) of respondents that participate in community organizations do not think Santo Domingo is divided, which is not a strong correlation and could perhaps give credence as to why Santo Domingo has failed to effectively resist mining. Even those who are actively engaged believe that the community is divided, which is not good for the cohesion needed among the community to keep a strong and sustainable resistance movement against mining. Although my proxies for Organizational Tools and Information About and Self-efficacy show strong correlations with socially engaged individuals, Community Divided's correlation with Social Engagement is weak. Based on my qualitative evidence I previously discussed, those that do oppose mining appear to lack self- and community-efficacy because they lack the resources that empower them to effectively organize and resist B2Gold and are constantly 
fighting an uphill battle with local institutions and organizations that have more resources. Thus, the community remains divided on mining and Santo Domingo lacks the cohesion and worldview that would permit it to form a broad-based mobilization and resistance against $\mathrm{B} 2 \mathrm{Gold}$.

The second, Community Development, which is based on a survey question that asked respondents the following: "Do you believe that people are ready to contribute to the development of your community?" It is a dichotomous variable ( $1=y e s ; 0=$ no). It appears that socially engaged individuals are more likely to say yes, $60.7 \%$ (224/369), to the belief that their fellow community members are ready to help with the development of Santo Domingo. Three of the four relationships presented in Table 6.1 show strong correlations between socially engaged individuals and the reasons I theorized on how these individuals form or shape their oppositional attitudes against mining. Although my qualitative evidence does not completely agree with these correlations, these correlations

are not a causal relationship. They simply show that respondents from my survey believe themselves to have the attitudes that reflect the micro-political traits of socially engaged individuals. I still expect null findings related to my social engagement hypothesis for Santo Domingo.

\section{Control Variables}

The predominance of existing literature, one way or another, has utilized both political, economic, and demographic control variables for their impact and influence on mining related resistance. I include a number of these indicators from my survey as control variables. I divided my control variables into four sections. Under the first section, 
"Mining Variables," I include the following variables Importance of Mining for Nicaragua, Knowledge of the Project, and Proximity to Extraction. I created Importance of Mining using the question, "How important are the mining companies for the economic development of Nicaragua?" The variable is continuous (1=very important; 2=some importance; $3=$ little importance). Respondents were also asked to gauge their level of mining by measuring their Knowledge of the Project based on survey questions related to B2Gold and mining. This variable is an additive index. I also created a variable, Proximity to Extraction, that captures a respondent's proximity to B2Gold's proposed mining projects. Those that live in the direct vicinity of the proposed extraction sites were coded as 1 ; otherwise they were coded as 0 .

The second set of control variables are my "Political Variables." Respondents were asked to gauge their Approval of the Local Mayor and their level of Political Interest. My third set of control variables are my "Economic Variables." I control for the evaluations of One's Personal Economic Situation as well as evaluations of the National Economic Situation. Finally, I control for "Socio-demographic Variables." I control for the respondent's Level of Income, Level of Education, gender (Female), and Age; since I am concerned with local-level attitudes towards mining. In the Appendix for this chapter, one can find more information about my control variables in Table 6.2A ("Variable Coding, Frequency, and Percentages"), Table 6.3A ("Variable Summary Statistics"), and Table 6.4A (“Survey Questions and Variable Explanations”).

\section{First Empirical Findings}


In Table 6.2, I present two different models. In Model 1, I present the results of a logistic regression for only the rights-based claims (Environmental Impact and Agricultural Impact) and service-based claims (Employment Opportunities and Educational Opportunities). Model 2 adds the variable Social Engagement. Both models include the same set of mining variables, political variables, economic variables, and sociodemographic variables.

Table 6.2: Logistic Regression Results for Support of B2Gold's Mining Project

\begin{tabular}{|c|c|c|}
\hline VARIABLES & Model 1 & Model 2 \\
\hline \multicolumn{3}{|l|}{ Social } \\
\hline \multicolumn{3}{|l|}{ Engagement } \\
\hline Social & & -0.1504 \\
\hline Engagement & & $(0.190)$ \\
\hline \multicolumn{3}{|l|}{ Demands for } \\
\hline \multicolumn{3}{|l|}{ Rights } \\
\hline Environmental & $-1.2630 * * *$ & $-1.2313 * * *$ \\
\hline Impact & $(0.466)$ & $(0.463)$ \\
\hline Agricultural & $-1.3141 * * *$ & $-1.3225 * * *$ \\
\hline Impact & $(0.456)$ & $(0.461)$ \\
\hline \multicolumn{3}{|l|}{ Demands for } \\
\hline \multicolumn{3}{|l|}{ Services } \\
\hline Employment & $2.1388 * * *$ & $2.1184 * * *$ \\
\hline Opportunities & $(0.423)$ & $(0.428)$ \\
\hline Educational & $1.0938 * *$ & $1.0818 * *$ \\
\hline Opportunities & $(0.427)$ & $(0.428)$ \\
\hline \multicolumn{3}{|l|}{ Mining Variables } \\
\hline Importance of & -0.2014 & -0.1874 \\
\hline Mining & $(0.302)$ & $(0.307)$ \\
\hline Knowledge of & -0.0805 & -0.0434 \\
\hline B2Gold & $(0.351)$ & $(0.352)$ \\
\hline Proximity to & 0.5754 & 0.5114 \\
\hline Extraction & $(0.489)$ & $(0.486)$ \\
\hline \multicolumn{3}{|l|}{$\begin{array}{l}\text { Political } \\
\text { Variables }\end{array}$} \\
\hline Approval of & 0.1650 & 0.2306 \\
\hline Mayor & $(0.394)$ & $(0.405)$ \\
\hline Political Interest & $0.5750 *$ & $0.5722 *$ \\
\hline & $(0.297)$ & $(0.298)$ \\
\hline
\end{tabular}




\begin{tabular}{lcc} 
Variables & & \\
Personal & 0.3426 & 0.2769 \\
Economic & $(0.333)$ & $(0.347)$ \\
Situation & & \\
National & 0.2000 & 0.2081 \\
Economic & $(0.336)$ & $(0.343)$ \\
Situation & & \\
$\begin{array}{l}\text { Socio- } \\
\text { demographic }\end{array}$ & & \\
Variables & & \\
Income & 0.0027 & 0.0075 \\
& $(0.056)$ & $(0.056)$ \\
Education & -0.0054 & -0.0062 \\
& $(0.143)$ & $(0.143)$ \\
Female & -0.3796 & -0.4007 \\
& $(0.436)$ & $(0.438)$ \\
Age & 0.1021 & 0.1277 \\
& $(0.415)$ & $(0.414)$ \\
Constant & $-2.8614 *$ & -2.7421 \\
& $(1.737)$ & $(1.771)$ \\
Observations & & \\
\hline
\end{tabular}

Robust standard errors in parentheses $* * * \mathrm{p}<0.01, * * \mathrm{p}<0.05, * \mathrm{p}<0.1$

My results show that rights-based claims significantly decrease one's likelihood of supporting B2Gold's mining project (Model 1), which is what I expected. I am 99\% confident that Agricultural Impacts and Environmental Impacts decrease one's likelihood of supporting B2Gold's mining project. Conversely, service-based claims positively and significantly influence one's likelihood of supporting B2Gold's mining project (Model 1), which is what I expected. Employment Opportunities is statistically significant at $99 \%$ confidence and Educational Opportunities is statistically significant at $95 \%$ confidence. My results hold when I include Social Engagement in Model 2. I remain 99\% confident that Agricultural Impacts and Environmental Impacts decrease one's likelihood of supporting B2Gold's mining project. Employment Opportunities remains statistically 
significant at $99 \%$ confidence and Educational Opportunities remains statistically significant at $95 \%$ confidence.

As I predicted, Social Engagement (Model 2) is not significant, which is likely because individuals in Santo Domingo are divided on their attitudes towards mining. Some individuals that participate in community organizations in Santo Domingo likely oppose mining for reasons I have discussed throughout this chapter, but others that are actively engaged in community organizations already had their supportive opinions formed on mining or are benefiting from B2Gold's projects. As I have suggested, Rancho Grande's organizational efforts and its efforts to unite the population and the community started very early, early enough so it could get a hold on mining's influence in the community. However, Santo Domingo appears to have been too late on its organizational efforts and its efforts to unify the community against mining, which allowed B2Gold to influence and corrupt different sectors of Santo Domingo like the local government agencies and local organizations. Thus, my results indicate that individuals in Santo Domingo that engage in local-level organizations (i.e., community organizations, environmental organizations, agricultural organizations, and/or religious organizations) are not more likely to oppose or support mining projects.

The coefficients in a logistic regression do not provide the capability of interpreting substantive effects for my variables of interest. Thus, in Figure 6.13 (Model 1) and Figure 6.14 (Model 2), I display the average marginal effects (with $95 \%$ confidence intervals). I estimate marginal effects or changes in mean predicted probabilities taking into account the observed values of control variables. Notice that my approach for estimating marginal effects in mean predicted probabilities does not hold 
constant control variables at their means or other values, but rather takes into account the full variation of the data. I use the margins command in Stata with the default specification (Mitchell 2012). In Figure 6.13, the likelihood of an individual opposing B2Gold's mining project for environmental reasons and agricultural reasons are approximately 14\% and 15\%, respectively. The likelihood of an individual supporting B2Gold's mining project for employment opportunities and educational opportunities is approximately $25 \%$ and $12 \%$, respectively. Turning to Figure 6.14 (Model 2), the likelihood of an individual opposing B2Gold's mining project for environmental and agricultural reasons are approximately $14 \%$ and $15 \%$, respectively. The likelihood of an individual supporting B2Gold's mining project for employment opportunities and educational opportunities is approximately $24 \%$ and $12 \%$, respectively.

\section{Figure 6.13: Average Marginal Effects with 95\% CIs for Model 1}

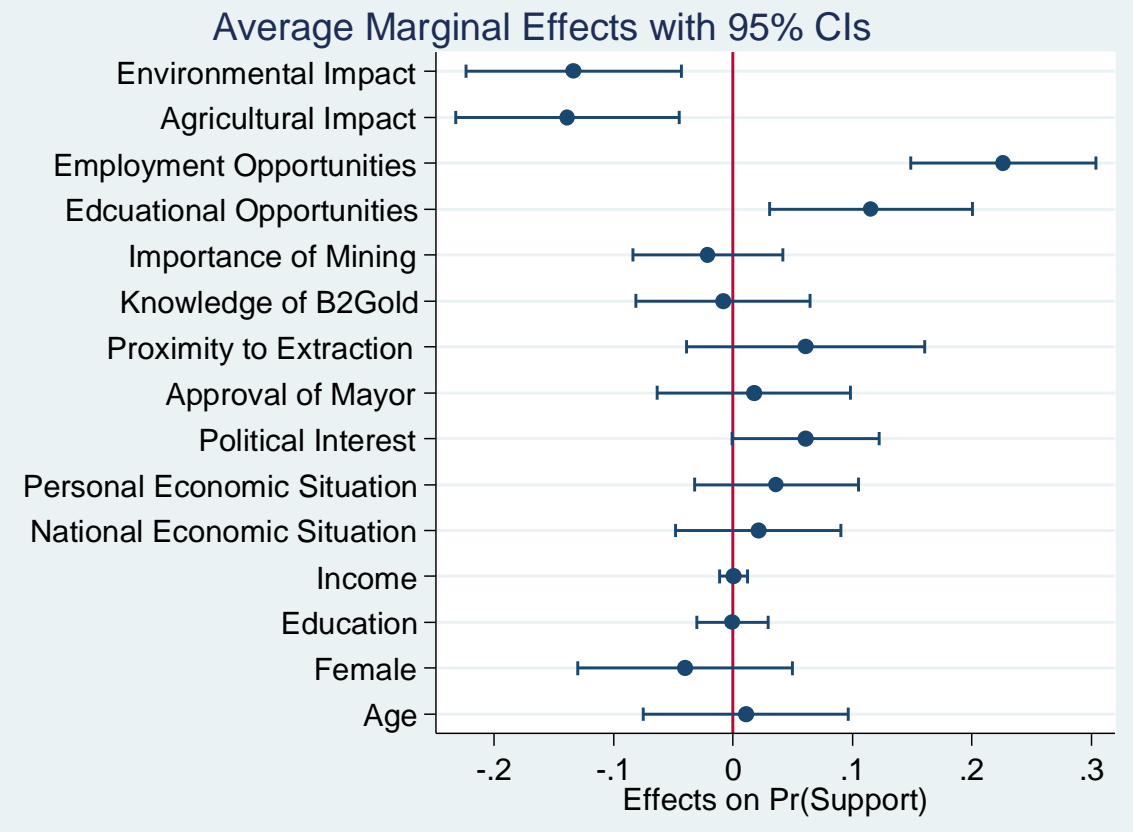

Figure 6.14: Average Marginal Effects with 95\% CIs for Model 2 


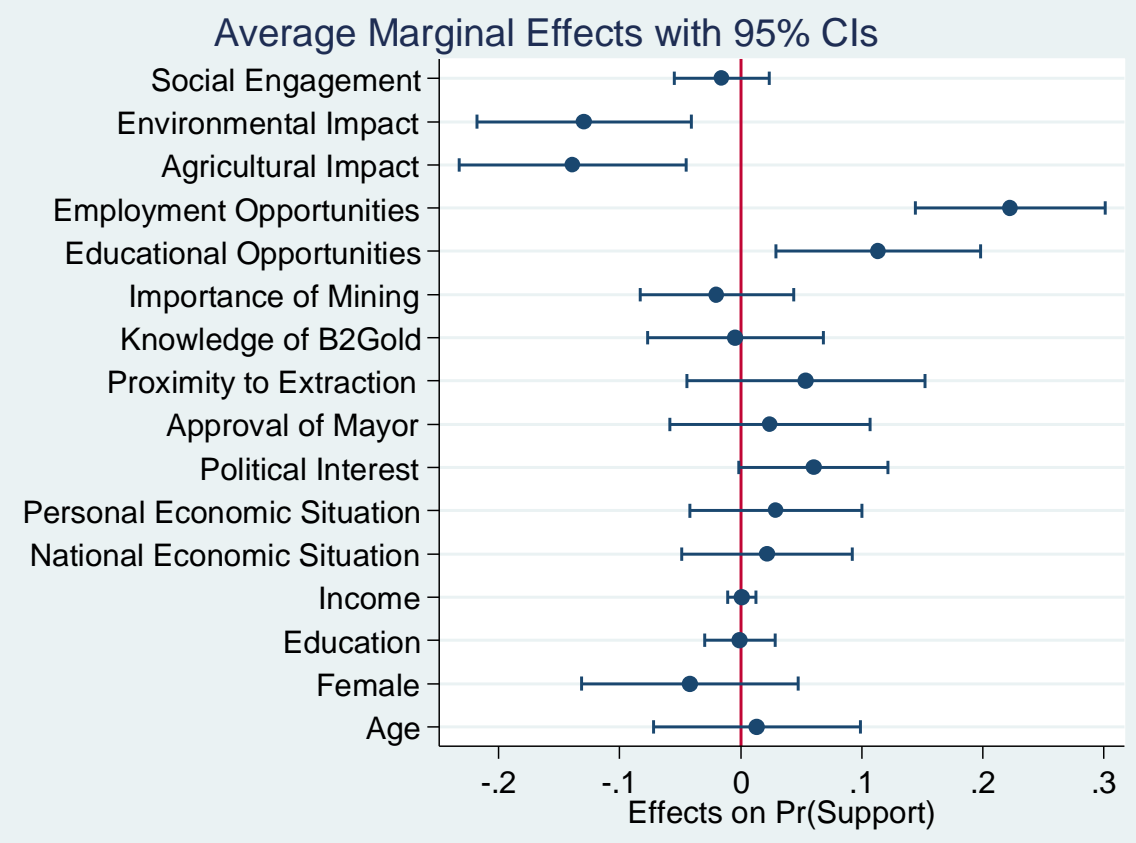

\section{Discussion}

Beyond economic threats (i.e., environmental and agricultural impacts) towards mining in Santo Domingo, there are other possible reasons that can help explain the opposition to B2Gold's mining projects. As I have demonstrated in this chapter, mining companies like B2Gold, tend to be allies with governments, like Nicaragua's, to develop "fraudulent mechanisms and increasingly sophisticated technologies of socio-cultural penetration to ensure the social license needed to operate in the new territories. It's what mining transnationals and their partners do, even knowing that when they enter a territory they always cause damage to the ways of life, cultures and policies that ensure the social reproduction of the populations living there" (Sanchez Gonzalez 2017). In most instances in Santo Domingo, B2Gold has not followed their commitments to environmental stewardship and social responsibility, while the Nicaraguan government, local and 
national, has failed to follow their own mining laws or support the local population of Santo Domingo. Both the negligence of B2Gold and Nicaragua's government, as well as the negative impacts associated with mining have also influenced opposition in Santo Domingo.

Additionally, I provided numerous examples throughout the chapter that demonstrated how B2Gold and the Nicaraguan government and its agencies, local and national, have been coerced, corrupted, and bribed in order to protect B2Gold's investment in Santo Domingo. Sanchez Gonzalez (2017) notes that with the help of its government allies, "extractive companies also resort to violence. Criminalizing protests and manipulating fears are mechanisms of domination to quiet the conflict the companies cause in the communities." I demonstrated in this chapter that community members, members of Salvemos Santo Domingo, and protesters have been subjected to different forms of violence and intimidation by B2Gold and different government officials. In Santo Domingo, the government and B2Gold work together to ensure B2Gold's investment is protected, while they both neglect the well-being of citizens in Santo Domingo. Trying to resist mining when you have a company with unlimited resources and the government forcefully protecting that company leaves the citizens of Santo Domingo with an uneven and unfair disadvantage, which likely makes them oppose mining even more.

There are two additional reasons that I alluded to and briefly discussed throughout the chapter that likely lead to oppositional attitudes towards B2Gold and mining: forced and uneven relocation and the destruction of homes. Many homeowners in Santo Domingo have lived in their homes for decades. However, with B2Gold's interest in 
extracting gold directly underneath the community of Santo Domingo where citizens live, many of these homeowners have been forced to move. B2Gold offers these inhabitants new homes ${ }^{158}$ and some compensation, but the homes were substandard to their existing homes. B2Gold also promised these inhabitants ownership titles to these new substandard homes. However, the majority of these citizens were never granted a title to the home. Thus, many fear that B2Gold could at any time reclaim the new property, since they do not have a title or a claim to the home. ${ }^{159}$

Additionally, many of these homeowners that were forced to relocate, previously operated small businesses (i.e., convenience stores, small restaurants, butcher shops, etc.) in their original homes that were located in or near the town's center. However, the homes were they were forcefully relocated to are a significant distance from Santo Domingo's town center, and very few people live near the neighborhoods were the new homes are located. Thus, these small business that depend on operations in the town center suffered severely, which negatively impacted the livelihoods of those individuals forced to relocated. Officials from B2Gold promised these inhabitants the help they needed to rebuild their home businesses, but the inhabitants never received such help. Based on these conditions, many inhabitants began refusing to move. However, if they refused to move, they were often threatened or forcibly removed by police forces directed by municipal officials. ${ }^{160}$

In some neighborhoods throughout Santo Domingo located near B2Gold's extraction sites, the houses shake due to B2Gold's use of explosives to extract gold.

\footnotetext{
${ }^{158}$ I had the opportunity to visit some of these new homes.

${ }^{159}$ Author's personal interviews with community members in Santo Domingo: January 2017.

${ }^{160}$ Author's personal interviews with community members from Santo Domingo: January 2017.
} 
B2Gold violates an additional Nicaraguan law that prohibits the use of explosives within a certain distance of residential homes. ${ }^{161}$ However, B2Gold continues to use explosives, which has left many of these homes damaged. ${ }^{162}$ Additionally, many residents fear that their homes could cave in because of B2Gold's use of tunnels underneath the entire community of Santo Domingo. As I mentioned earlier, tunneling is technically allowed by law because no one is permitted to own land under a certain depth, so anyone can utilize the land - including B2Gold. However, with the use of tunneling and explosives, residents believe their homes and possibly even their lives are on borrowed time. These residents have sent letters and signed petitions to the Mayor's Office, the City Council, other government institutions, and B2Gold. To no avail, they have never received a response from either of these institutions. The sentiment that I gathered from these residents is helplessness because they have been forgotten by those that are supposed to protect them, all in the name of economic self-interests. ${ }^{163}$ In Figure $6.2 \mathrm{~A}$ in the Appendix, I provide some pictures that I took to show the damages that B2Gold's explosives have caused some homes. It appears that extractive activities, in Santo Domingo, cannot be conducted without the expropriation of a significant number of properties, as well as the destruction of homes. Hence, it is likely that individuals who perceive themselves as vulnerable due to the expropriation of their property or the destruction of their homes from B2Gold's activities will lead to oppositional attitudes towards mining and B2Gold.

Throughout this chapter I have also discussed Santo Domingo's artisanal miners.

\footnotetext{
${ }^{161}$ These homes were within the legal parameter that forbids the use of explosives for mining activities.

${ }^{162}$ I witnessed the damage these homes have. The floors, the walls, and the ceilings are cracked. Some homes have even become separated from their foundations.

${ }^{163}$ Author's personal interviews with community members from Santo Domingo: January 2017.
} 
Besides B2Gold refusing to employ the artisanal miners, the artisanal miners' livelihoods are threatened by B2Gold's extraction of gold. B2Gold has essentially monopolized the extraction of gold in Santo Domingo. Artisanal miners have been prohibited by B2Gold and government officials to mine the land they have used for decades, which is harming their income. Additionally, the shear amount of gold that B2Gold extracts and its plan to extract all of Santo Domingo's gold in under a decade will eventually leave the artisanal miners with no gold left to mine. Essentially, if B2Gold continues its activities, the livelihoods of Santo Domingo's artisanal miners will be completely destroyed. Therefore, B2Gold's presence in Santo Domingo is a threat to community's long history with artisanal mining, which likely leads to opposition towards B2Gold in some sectors of the community.

\section{Dependent Variable and Statistical Model—Religion as a Catalyst for Success}

In the second part of my analysis, my second dependent variable—Successful Protest against B2Gold's mining activities — is a dichotomous variable that asks respondents the following: "Have the protests organized by your community been successful against the mining company?" ${ }^{164}$ In the survey, $70.86 \%$ of respondents in Rancho Grande believed their protest movement against B2Gold's mining activities was unsuccessful, while $29.14 \%$ of the respondents believed that their protest movement was successful. Figure 6.15 displays a bar graph that shows 231 out of 326 of my survey respondents believed that Santo Domingo has been unsuccessful in its resistance against B2Gold in achieving

\footnotetext{
${ }^{164}$ In the Appendix for this chapter, one can find more information about my dependent variable in Table 6.2A ("Variable Coding, Frequency, and Percentages"), Table 6.3A ("Variable Summary Statistics"), and Table 6.4A ("Survey Questions and Variable Explanations").
} 
an overturn in the company's mining concession. Given the dichotomous nature of the dependent variable, I use a logistic regression model.

\section{$\underline{\text { Figure 6.15: Respondent Beliefs About Successful Mining Protest Movement }}$}

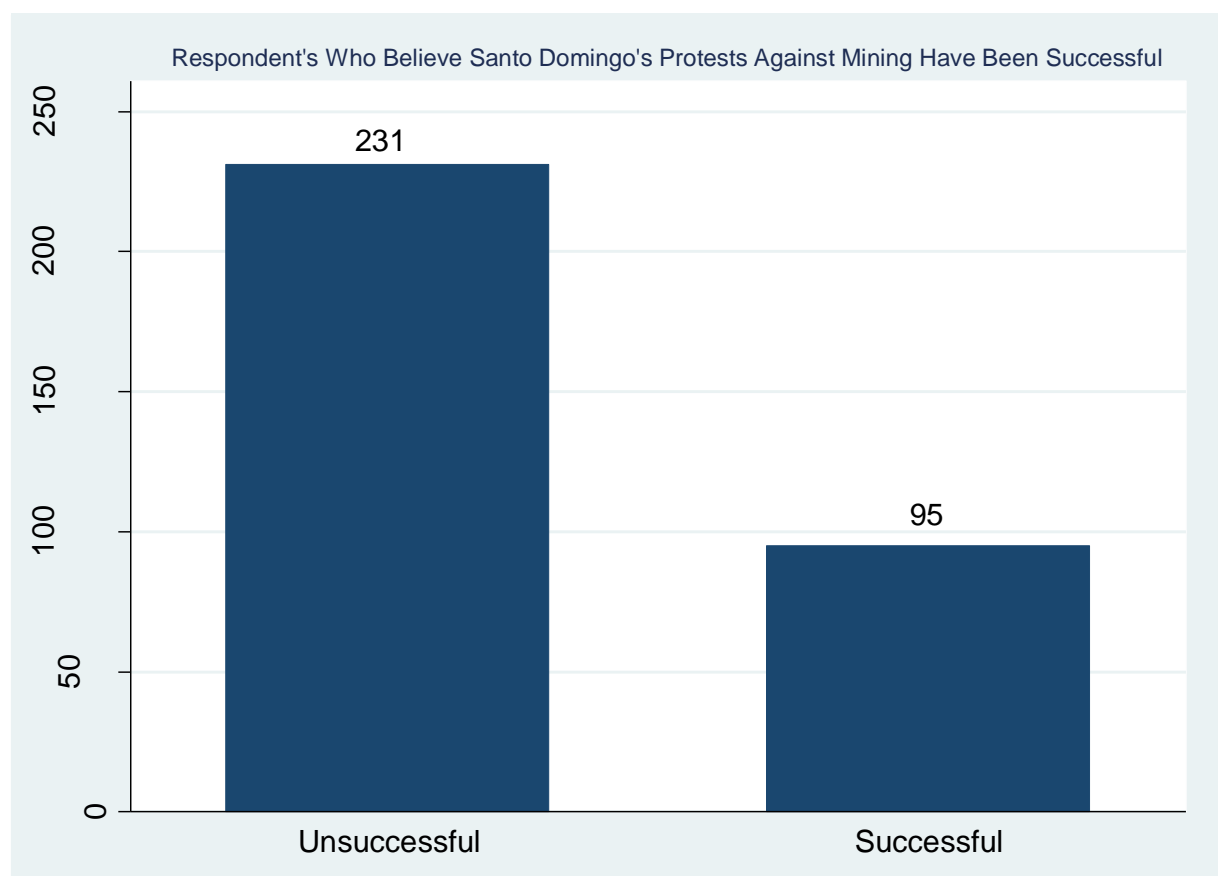

Source: Author's data.

Independent Variables-Demands for Rights, Demands for Services, Social

\section{Engagement, and Religion as a Catalyst}

I am broadly interested in why Santo Domingo is unable to halt B2Gold's mining concession in their community. As previously discussed, Arce (2014b, 2015) and Arce and Hendricks (forthcoming) claim that successful campaigns against mineral extraction are more likely to encompass rights-based claims than service-based claims. Therefore, like in the previous analytical section of this chapter, I use the rights- and service-based variables. Thus, four of my independent variables include the same two variables measuring demands for rights; Environmental Impacts and Agricultural Impacts and the 
same two variables gauging demands for services: Employment Opportunities and

\section{Educational Opportunities.}

Additionally, since I do not show support in my previous analytical section for how Social Engagement provides individuals with: 1) access to critical organizational tools and information about mining; 2) a higher sense of self-efficacy and collectiveefficacy empowering them and their communities to resist mining; 3) and a stronger community worldview contributing to broad-based mobilization; I include Social Engagement in my models in this analytical section as well because I believe the community's lack of Social Engagement in forming oppositional attitudes towards mining is likely influential in Santo Domingo's unsuccessful resistance movement against B2Gold. One should recall that Social Engagement is an additive index that measures the frequency of participation by individuals in community organizations, agricultural organizations, environmental organizations, and religious organizations.

In Table $6.3^{165}$, I disaggregated the components that make up my Social Engagement variable (i.e., participation and engagement in community organizations, environmental organizations, agricultural organizations, and religious organizations) with my dependent variable-Successful Protest. Table 6.3 specifically examines crosstabs between religious social engagement and protest success, environmental social engagement and protest success, agricultural social engagement and protest success, and community social engagement and protest success. From the relationships in the Table 6.3, it appears that individuals in Santo Domingo are more involved in the community religiously than in environmental, agricultural, and community organizations. This is

\footnotetext{
${ }^{165}$ Data for Table 6.3 are from the author's survey data.
} 
likely because individuals in Santo Domingo are still very religious and attend church on a regular basis to practice their faith in God. It is possible that a large sum of individuals in Santo Domingo do not attend the other organizations because they understand that they are corrupted by B2Gold or they have no particular interest in participating because of their beliefs related to mining's economic benefits. The majority of individuals in each crosstab relationship believe that Santo Domingo's protest against B2Gold were unsuccessful. This shows that individuals who believe that Santo Domingo's protests were unsuccessful are not very socially engaged and that religion did not assist the community in achieving protest success.

Table 6.3: Disaggregated Social Engagement Components and Relationship with Protest Success

\begin{tabular}{|c|c|c|c|}
\hline \multirow{2}{*}{$\begin{array}{l}\text { Protest } \\
\text { Successful }\end{array}$} & \multicolumn{3}{|c|}{ Religious Social Engagement } \\
\hline & $\begin{array}{l}\text { Attends a Religious } \\
\text { Organization Regularly }\end{array}$ & $\begin{array}{l}\text { Does Not Attend a } \\
\text { Religious Organization } \\
\text { Regularly }\end{array}$ & Total \\
\hline Yes & 64 & 31 & 95 \\
\hline No & 136 & 95 & 231 \\
\hline Total & 200 & 126 & 326 \\
\hline Protest & \multicolumn{3}{|c|}{ Environmental Social Engagement } \\
\hline & $\begin{array}{l}\text { Attends an Environmental } \\
\text { Organization Regularly }\end{array}$ & $\begin{array}{l}\text { Does Not Attend an } \\
\text { Environmental } \\
\text { Organization Regularly }\end{array}$ & Total \\
\hline Yes & 16 & 79 & 95 \\
\hline No & 35 & 196 & 231 \\
\hline Total & 51 & 275 & 326 \\
\hline \multirow{2}{*}{$\begin{array}{l}\text { Protest } \\
\text { Successful }\end{array}$} & \multicolumn{3}{|c|}{ Agricultural Social Engagement } \\
\hline & $\begin{array}{l}\text { Attends an Agricultural } \\
\text { Organization Regularly }\end{array}$ & $\begin{array}{l}\text { Does Not Attend an } \\
\text { Agricultural Organization } \\
\text { Regularly }\end{array}$ & Total \\
\hline Yes & 14 & 81 & 95 \\
\hline No & 22 & 209 & 231 \\
\hline Total & 36 & 290 & 326 \\
\hline
\end{tabular}




\begin{tabular}{|l|c|c|c|}
\hline $\begin{array}{l}\text { Protest } \\
\text { Successful }\end{array}$ & \multicolumn{3}{|c|}{ Community Social Engagement } \\
\hline & $\begin{array}{l}\text { Attends a Community } \\
\text { Organization Regularly }\end{array}$ & $\begin{array}{l}\text { Does Not Attend a } \\
\text { Community Organization } \\
\text { Regularly }\end{array}$ & Total \\
\hline Yes & 42 & 53 & 95 \\
\hline No & 73 & 158 & 231 \\
\hline Total & 115 & 211 & 326 \\
\hline
\end{tabular}

Source: Author's data.

My main independent variable of interest for this analytical section is Religion, since I theorize that religion is the catalyzing agent that leads to successful protest movements against mining activities. Below, Figure 6.16 displays a bar graph that depicts survey respondents' religion by type. As previously mentioned and consistent with the two most popular religions in Nicaragua, the respondents' in Santo Domingo are overwhelmingly Catholic (264/389) and Evangelical (79/389). Religion is a dichotomous variable that asks respondents the following: "In solution of mining conflicts between the community population and the mining company, how would you rate the work of the Churches?" The variable is coded as 1 if respondents rated Churches as (very) positive; and 0 otherwise. In the survey, $84.48 \%$ of respondents in Santo Domingo rated the Churches positively as useful in assisting the community solve its mining conflict. Although the role of religion and the Churches in Santo Domingo has been absent from Santo Domingo's antiextraction movement, this shows that citizens in Santo Domingo believe if the Churches were involved that they would greatly aid the community in halting B2Gold's mining concession. Only $15.52 \%$ do not think positively of the Churches. In the Appendix for this chapter, one can find more information about Religion in Table 6.2A ("Variable Coding, Frequency, and Percentages"), Table 6.3A ("Variable Summary Statistics"), and Table 6.4A ("Survey Questions and Variable Explanations"). 


\section{Figure 6.16: Respondent's Religion by Type}

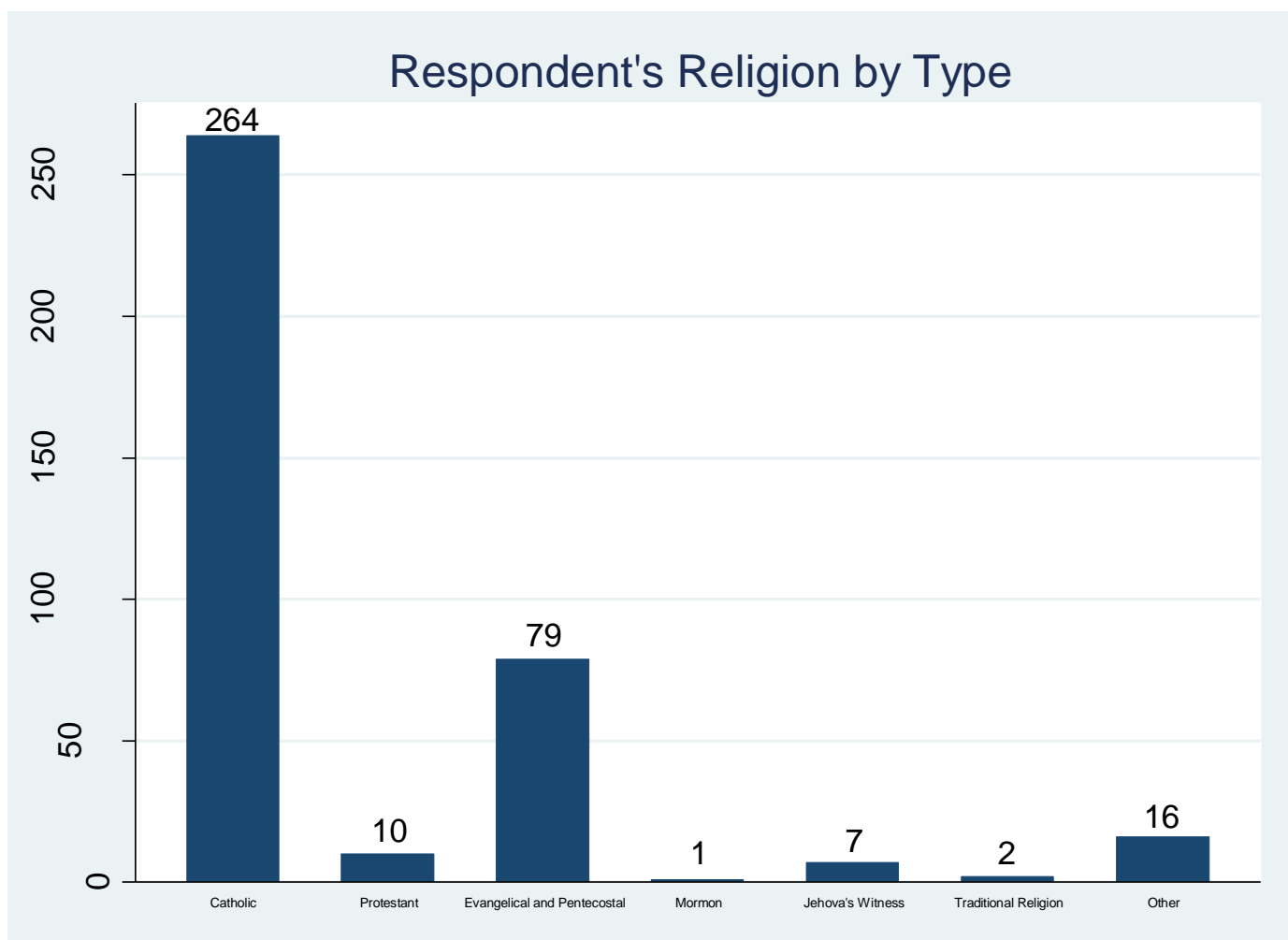

Source: Author's data.

\section{Control Variables}

Similar to the previous analytical section I include indicators from my survey as control variables. Like before, I divided my control variables into sections. I have added a section, "Community Variables." Under the first section, "Mining Variables," I again include the variables Knowledge of the Project and Proximity to Extraction. I exclude Importance of Mining for Nicaragua in this analysis. My "Community Variables" are Interpersonal Trust and Community Divided. Interpersonal Trust is a variable created from the following survey question: "Would you say the people in your community are trustworthy?" The variable is coded as dichotomous $(1=($ very $)$ trustworthy and $0=($ very $)$ 
untrustworthy). Community Divided is a variable that is based on the following survey question: "For you, is your community divided?" The variable is dichotomous (1=yes and $0=$ no).

For my "Political Variables" I continue using Approval of the Local Mayor and level of Political Interest. I also incorporate Public Corruption and Political Ideology. Public Corruption asks respondents the following question: "Have you ever seen a public official accept a bribe?" The variable is dichotomous ( $1=$ yes; $0=$ no). Political Ideology is a continuous variable that asked respondents to rate their political ideology on a left (1) to right (10) scale. For my "Economic Variables", I continue to control for are the evaluations of One's Personal Economic Situation as well as evaluations of the National Economic Situation. Finally, I control for "Socio-demographic Variables." I continue to control for the respondent's Level of Income, Level of Education, gender (Female), and Age. In the Appendix for this chapter, one can find more information about my control variables in Table 6.2A ("Variable Coding, Frequency, and Percentages"), Table 6.3A ("Variable Summary Statistics"), and Table 6.4A ("Survey Questions and Variable Explanations").

\section{Second Empirical Findings}

In Table 6.4, I present three different models. In Model 4, I present the results of a logistic regression for only Religion and my socio-demographic variables. Model 5 adds my rights-based variables (Environmental Impact and Agricultural Impact) and my service-based variables (Employment Opportunities and Educational Opportunities). Model 6 adds the rest of my control variables. 
Table 6.4: Logistic Regression Results for Successful Protest

\begin{tabular}{|c|c|c|c|}
\hline VARIABLES & Model 4 & Model 5 & Model 6 \\
\hline \multicolumn{4}{|l|}{ Religion } \\
\hline Religion & $\begin{array}{c}0.8166^{*} \\
(0.422)\end{array}$ & $\begin{array}{c}0.7436^{*} \\
(0.426)\end{array}$ & $\begin{array}{l}0.5850 \\
(0.533)\end{array}$ \\
\hline \multicolumn{4}{|l|}{$\begin{array}{l}\text { Social } \\
\text { Engagement }\end{array}$} \\
\hline $\begin{array}{l}\text { Social } \\
\text { Engagement }\end{array}$ & & $\begin{array}{c}0.2560 * * \\
(0.126)\end{array}$ & $\begin{array}{c}0.3889 * * \\
(0.172)\end{array}$ \\
\hline \multicolumn{4}{|l|}{$\begin{array}{l}\text { Demands for } \\
\text { Rights }\end{array}$} \\
\hline $\begin{array}{l}\text { Environmental } \\
\text { Impact } \\
\text { Agricultural } \\
\text { Impact }\end{array}$ & & $\begin{array}{l}-0.5917 \\
(0.425) \\
0.0150 \\
(0.365)\end{array}$ & $\begin{array}{l}-1.1662 \\
(0.726) \\
0.3153 \\
(0.452)\end{array}$ \\
\hline \multicolumn{4}{|l|}{$\begin{array}{l}\text { Demands for } \\
\text { Services }\end{array}$} \\
\hline $\begin{array}{l}\text { Employment } \\
\text { Opportunities } \\
\text { Educational } \\
\text { Opportunities }\end{array}$ & & $\begin{array}{l}0.0852 \\
(0.302) \\
-0.2138 \\
(0.308)\end{array}$ & $\begin{array}{c}0.4096 \\
(0.399) \\
-0.8509 * * \\
(0.407)\end{array}$ \\
\hline \multicolumn{4}{|l|}{ Mining Variables } \\
\hline $\begin{array}{l}\text { Knowledge of } \\
\text { B2Gold } \\
\text { Proximity to } \\
\text { Extraction }\end{array}$ & & & $\begin{array}{l}0.1361 \\
(0.392) \\
-0.1182 \\
(0.550)\end{array}$ \\
\hline \multicolumn{4}{|l|}{$\begin{array}{l}\text { Community } \\
\text { Variables }\end{array}$} \\
\hline $\begin{array}{l}\text { Interpersonal } \\
\text { Trust } \\
\text { Community } \\
\text { Divided }\end{array}$ & & & $\begin{array}{l}-0.5879 \\
(0.423) \\
-0.0478 \\
(0.400)\end{array}$ \\
\hline \multicolumn{4}{|l|}{$\begin{array}{l}\text { Political } \\
\text { Variables }\end{array}$} \\
\hline $\begin{array}{l}\text { Approval of } \\
\text { Mayor } \\
\text { Public Corruption }\end{array}$ & & & $\begin{array}{l}0.0703 \\
(0.381) \\
0.2793 \\
(0.429)\end{array}$ \\
\hline Political Interest & & & $\begin{array}{c}0.5014 * \\
(0.275)\end{array}$ \\
\hline Political Ideology & & & $\begin{array}{l}0.0070 \\
(0.064)\end{array}$ \\
\hline \multicolumn{4}{|l|}{$\begin{array}{l}\text { Economic } \\
\text { Variables }\end{array}$} \\
\hline Personal & & & 0.1551 \\
\hline
\end{tabular}




\begin{tabular}{|c|c|c|c|}
\hline Economic & & & $(0.294)$ \\
\hline Situation & & & \\
\hline National & & & 0.2616 \\
\hline Economic & & & $(0.291)$ \\
\hline Situation & & & \\
\hline $\begin{array}{l}\text { Socio- } \\
\text { demographic } \\
\text { Variables }\end{array}$ & & & \\
\hline Income & 0.0052 & -0.0061 & -0.0209 \\
\hline & $(0.034)$ & $(0.035)$ & $(0.051)$ \\
\hline Education & -0.0109 & -0.0094 & -0.0769 \\
\hline & $(0.099)$ & $(0.100)$ & $(0.162)$ \\
\hline Female & -0.1612 & -0.0887 & -0.1338 \\
\hline & $(0.291)$ & $(0.294)$ & $(0.431)$ \\
\hline Age & -0.1355 & -0.1901 & $-0.5636 *$ \\
\hline & $(0.238)$ & $(0.236)$ & $(0.338)$ \\
\hline Constant & -1.1859 & -0.7083 & -0.3689 \\
\hline & $(0.953)$ & $(1.127)$ & $(2.128)$ \\
\hline Observations & 260 & 260 & 163 \\
\hline
\end{tabular}

In Models 3 and 4, Religion is positive and statistically significant at the $90 \%$ confidence level. Although religion's role in Santo Domingo has been absent from Santo Domingo's anti-extraction movement against B2Gold and mining, these results indicate that the community still understands the importance that religion's influence can have in assisting them effectively and successfully overturn B2Gold's mining concession at the national level. As I have discussed, many community members throughout Santo Domingo understood how important religion's role was in Rancho Grande for successfully overturning B2Gold's mining concession at the national level, and believes if they could gain the support of the Catholic and Evangelical Churches in Santo Domingo that the those in support of B2Gold and mining would begin to oppose the company and its activities because the Churches are such respected and trusted institutions. However, after 
incorporating the rest of my control variables in Model 5, Religion is no longer statistically significant.

Surprisingly, Social Engagement in Models 4 and 5 is positive and statistically significant at the $95 \%$ confidence level. Although I have shown that the community of Santo Domingo remains largely divided on its stance against B2Gold and mining, individuals that participate in some local organizations believe and understand their participation in these organizations would likely increase their chances at unifying and organizing the community through the provision of information and resources that empowers them to effectively and successfully resist B2Gold and mining. On the contrary, these results could indicate that individuals that participate in some organizations that have been coerced and corrupted by B2Gold believe that the antiextraction resistance movement against the company and its activities has been successful because B2Gold's mining concession has not been overturned and they can continue to receive the economic benefits and perks that the community offers.

In Model 5, Educational Opportunities is negative and statistically significant, likely indicating that individuals believe that B2Gold's provision of educational services and opportunities leads some in the community to support the company, which divides the community on its stance towards mining and makes its resistance movement against mining ineffective and unsuccessful in overturning B2Gold's mining concession at the national level. My only control variables that are statistically significant in any models are Political Interest and Age. Political Interest is positive and statistically significant in Model 5 at the $90 \%$ confidence level and Age is negative and statistically significant in Model 5 at the $90 \%$ confidence level. 
As I previously discussed, the coefficients in a logistic regression do not provide the capability of interpreting substantive effects of my variables of interest. Thus, in Figure 6.17 (Model 5), I display the average marginal effects (with 95\% confidence intervals). Again, I estimate marginal effects or changes in mean predicted probabilities taking into account the observed values of control variables. Notice that my approach for estimating marginal effects in mean predicted probabilities does not hold constant control variables at their means or other values, but rather takes into account the full variation of the data. Like before, I use the margins command in Stata with the default specification (Mitchell 2012). In Figure 6.17, the likelihood of an individual believing that the protest movement against B2Gold and mining was successful due to engagement in community is approximately $9 \%$. Additionally, the likelihood of an individual believing that the protest movement against B2Gold and mining was unsuccessful due to the company's provision of educational services and opportunities is approximately $15 \%$.

Figure 6.17: Average Marginal Effects with 95\% CIs for Model 2 


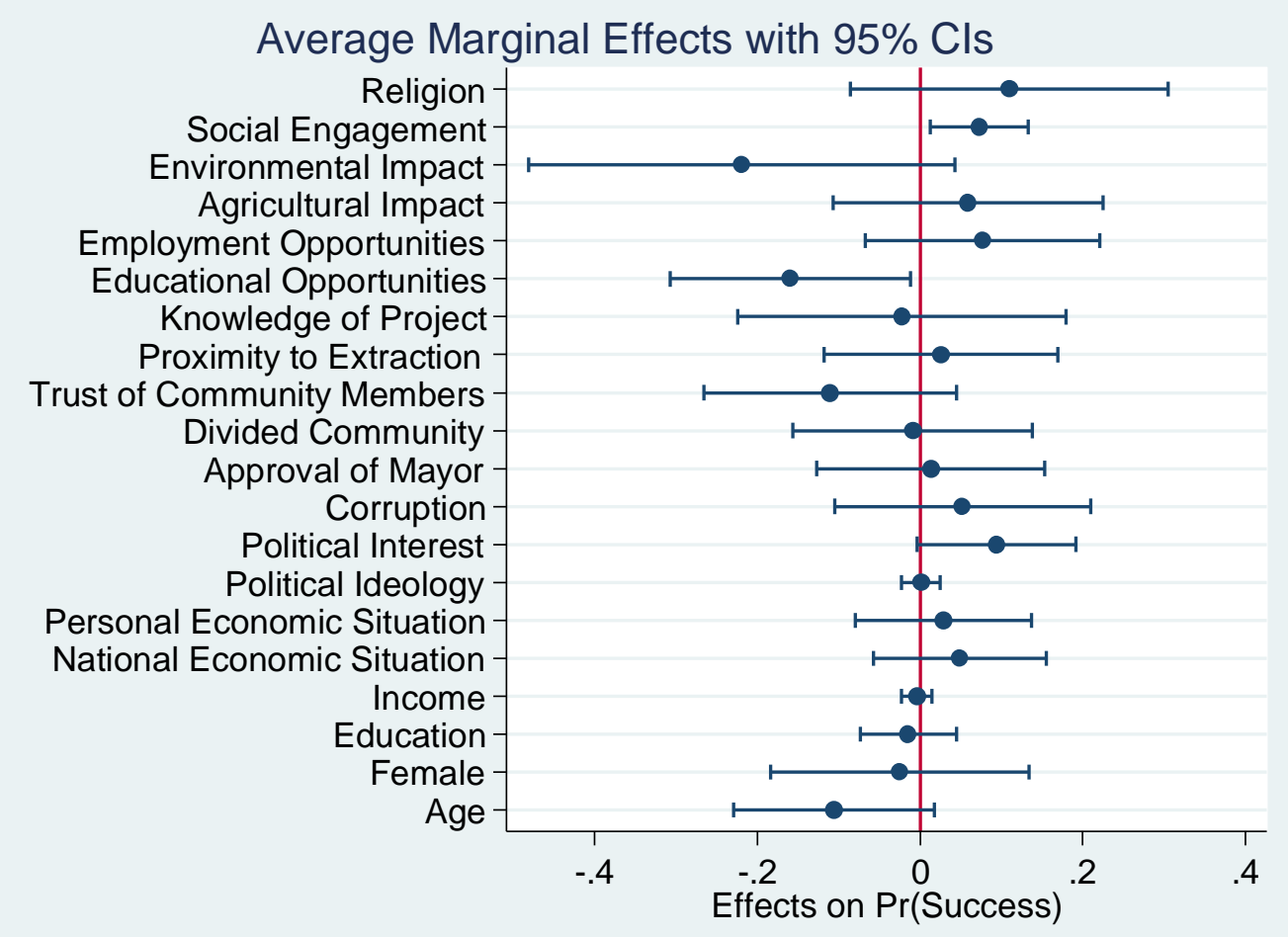

\section{Discussion}

As Arce (2014b) and Bebbington and Bury (2013) have demonstrated, stopping a mining project is very difficult due to power differences between the extractive companies and the local communities. Another key requirement is the amount of time outside of daily routines that needs to be devoted in sustaining mobilizations and movements. Supported by national governments to re-privatize national economies through extractivism, extractive companies like B2Gold diffuse protesters' claims by offering selective material rewards to the leaders of organizations (i.e., bribes or employment opportunities) or by spending on projects in collaboration with local authorities and institutions (i.e. providing the local police force with new motorcycles or repairing the Catholic church). Thus, the goal of an extractive company is to gain or "buy" the local population's support and the 
local authorities and institutions support through a continuous offering of small concessions, which is what happened to the majority of Santo Domingo's local government agencies and organizations, including the Catholic Church.

Rancho Grande's organizational efforts and their efforts to unite people and communities of Rancho Grande against mining started very early, early enough so they could get a good hold on the situation and not allow B2Gold to coercively influence the local government agencies and community organizations like it did in Santo Domingo. The community of Santo Domingo is perhaps too late on their organizational efforts and their efforts to unify the community against mining, which allowed B2Gold to corrupt different sectors of Santo Domingo like the local government agencies and local organizations. B2Gold has used "perks, bribes, blackmail; it has bought people off... The company has been trying to buy everybody off, and has been appropriating everything. It bought the farmers' properties, the ecosystem, the basin; in short, it bought our geography. It doesn't own just the concession; it owns everything” (Pérez Soza 2013).

The sentiment of the residents who oppose B2Gold and mining is that they have no one to rely on or turn to in their struggle. It seems like many residents feel helpless and live in fear. Many citizens in Santo Domingo would like to speak up against mining, but they are fearful of B2Gold and its corrupted followers use of intimidation and violence. The community seems lost in its struggle against B2Gold, and seems unsure on how to unite and effectively organize against B2Gold, since the company is so powerful and has purchased the support of those that are supposed to help the residents. The citizens that oppose B2Gold believe they could overturn B2Gold's mining concession if they had support from local organizations and groups, like the Catholic and Evangelical 
Churches, which my empirical results indicate. They understand the role and influence that the Churches played in Rancho Grande, and believe that if they could gain the support of the Catholic and Evangelical Churches to assist them in their own struggles that other local organizations and government agencies would follow suit, since the Churches are so respected and trusted throughout the community. ${ }^{166}$

\section{Conclusion}

To date, research on the politics of resource extraction focuses on successful campaigns against extraction and emphasizes the sources of opposition to mining. With few exceptions, existing research has rarely explored why some campaigns against resource extraction remain unsuccessful, as well as individual-level attitudes related to resource extraction. Departing from previous scholarship, and based on original data from a 2018 survey in Santo Domingo, Chontales, I trace the sources of opposition and support for resource extraction at the individual level in a context where there is both resistance to and backing for mining in order to understand the attitudes, beliefs, and characteristics of individuals in the context of an unsuccessful resistance movement against mining.

My results reveal that individuals who perceive the impact of mining as an environmental threat that is detrimental to agriculture and the environment are more likely to oppose B2Gold and its mining activities. Additionally, my results show that individuals who perceive the impact of mining for economic opportunities like the generation of employment opportunities and educational opportunities are more likely to support the mining project. My only control variable that showed any level of

\footnotetext{
${ }^{166}$ Author's personal interviews with community members in Santo Domingo: January 2017.
} 
significance was a respondent's interest in politics. Individuals interested in politics are more likely to support mining in Santo Domingo, which makes sense because the majority of individuals that participate in government agencies and institutions, as well as political parties throughout Santo Domingo have all been coerced, corrupted, or bribed by B2Gold. My results remain robust across several models as well as with the inclusion of a host of theoretical and control variables. Ultimately, the future of resource extraction in Nicaragua faces the paradox of individual support and collective resistance.

There is growing divide between those who oppose extraction and those who support it, which is why it is essential that scholars begin to study the rarely explored individual-level attitudes, beliefs, and characteristics related to resource extraction. In doing so, social scientists can start to understand the "variegated individual responses to mining" that underline the aggregate stories of homogenous community resistance (Dougherty 2018, 2). My study demonstrates reasons why and how individuals living in the extractive frontier either support or oppose mining and mining projects. By understanding individual attitudes, beliefs, and characteristics towards mining, scholars of extractive protests and social movements will be able to better understand the individual mechanisms that lead citizens in the extractive frontier to either partake in mining resistance or abstain. In order to understand what makes protests successful or unsuccessful, scholars need to understand what makes individuals oppose or support resource extraction. Opposition and support towards mining are not mutually exclusive from protest success in overturning a mining concession. They build off each other. My study of Santo Domingo demonstrates what individuals believe could make their 
unsuccessful resistance movement against B2Gold more successful by fully understanding what makes them either oppose or support resource extraction.

Although studies are rare on the religion's role and influence in extractive protests, it appears that a trend is growing, not just in the literature, but in application of the church, church leadership, and religious organizations assisting communities with anti-mining movements across Latin America based on environmental activism and protection against the detriments mining causes. I have shown in this chapter, qualitatively and quantitatively, that when religious involvement and engagement is absent from anti-mining movements, one is less likely to see an effectively organized campaign against mining and mining companies that influence the government to overturn its policy allowing for the company's mining concession. Although citizens in Santo Domingo appear to understand the impact that strong religious influence can have in helping them in their struggles against B2Gold, the churches, religious leaders, and religious organizations have not yet accepted their call to environmental activism and assisting those that have succumbed to the detriments of modern day mining.

However, a good portion of Santo Domingo citizens refuse to give up and continue to resist against B2Gold and its activities. In addition to protests, marches, roadblocks, and petitions, citizens of Santo Domingo are pursuing legal avenues of resistance. For example, Pérez Soza (2013) discusses that citizens in Santo Domingo have the necessary documentation to take legal action by filing a civil suit and penal one against B2Gold, and they hope to do so in Nicaragua and/or in international courts. Citizens of Santo Domingo want to file suit against the company for "environmental 
liability and the socioeconomic liability" that have contributed to the demise of their livelihoods (Pérez Soza 2013).

Additionally, the leaders of Salvemos Santo Domingo were willing and eager to talk with me because I was a foreigner, and they believe that their resistance against B2Gold needs international attention and assistance from international organizations in providing the resources needed to fight against the local corruption and B2Gold's mining activities. They were excited to learn that I would conduct a public opinion survey in Santo Domingo because they believed that for those in the community that live in fear; they would finally be able to express their true opinions about mining since the survey findings would remain anonymous. Essentially, they thought that many citizens could finally tell the world how their lives are negatively impacted by mining activities by B2Gold, the government, and the organizations in the community. They urged me to publish this study because they believe a publication from a university in the United States would bring attention to international organizations involved in environmental protection and human rights. They were hopeful that my dissertation would spark the attention of the international community in assisting their struggles through the provision of resources and information they need to effectively and efficiently organize and resist B2Gold. 


\section{$\underline{\text { Appendix }}$}

Table 6.1A: Survey Sample of Santo Domingo, Chontales

\begin{tabular}{|l|l|l|}
\hline Neighborhoods & Households & \# of Surveys \\
\hline Tamagás & 56 & 9 \\
\hline Tapawaisito & 105 & 17 \\
\hline Chester Obando & 141 & 22 \\
\hline Carlos Fonseca & 126 & 20 \\
\hline Jalteva & 159 & 25 \\
\hline Pedro Joaquín Chamorro & 72 & 11 \\
\hline Roldan Paz & 32 & 5 \\
\hline Oscar Lino Paz & 29 & 5 \\
\hline Germán Pomares & 30 & 5 \\
\hline Pancasán & 117 & 18 \\
\hline Sandino & 97 & 15 \\
\hline Jabalí & 64 & 10 \\
\hline La Hermandad & 90 & 14 \\
\hline Revolución & 34 & 5 \\
\hline Districts & & \\
\hline Cuscuas & Households & of Surveys \\
\hline Tapaiwas 2 & 180 & 28 \\
\hline Tapaiwas 3 & 70 & 11 \\
\hline El Chile & 20 & 3 \\
\hline Palmira No 1 & 222 & 35 \\
\hline El Camastro & 120 & 19 \\
\hline El Cilindro & 106 & 17 \\
\hline Dos Bocas & 49 & 8 \\
\hline El Guineal & 176 & 28 \\
\hline El Mono & 58 & 9 \\
\hline Bulún No 1 & 101 & 16 \\
\hline Bulún No 2 & 97 & 15 \\
\hline El Escándalo & 145 & 23 \\
\hline El Salto & 18 & 3 \\
\hline Banadi & 28 & 4 \\
\hline Total & 219 & 41 \\
\hline & 2583 & $\mathbf{4 0 0}$ \\
\hline & & \\
\hline
\end{tabular}


Table 6.2A: Variable Coding, Frequency, and Percentages

\begin{tabular}{|c|c|c|c|c|c|}
\hline Variable & $N$ & Mode & Coding & Frequency & Percentage \\
\hline \multicolumn{6}{|c|}{ DEPENDENT VARIABLES } \\
\hline \multicolumn{6}{|c|}{ Support for Mining } \\
\hline \multirow{2}{*}{$\begin{array}{l}\text { Support for } \\
\text { Mining }\end{array}$} & \multirow[t]{2}{*}{389} & \multirow[t]{2}{*}{0} & 0 & 324 & 83.29 \\
\hline & & & $1=$ Support & 65 & 16.71 \\
\hline \multicolumn{6}{|c|}{ Successful Protest } \\
\hline \multirow{2}{*}{$\begin{array}{c}\text { Successful } \\
\text { Protest } \\
\end{array}$} & \multirow[t]{2}{*}{326} & \multirow[t]{2}{*}{0} & $0=$ Unsuccessful & 231 & 70.86 \\
\hline & & & $1=$ Success & 95 & 29.14 \\
\hline \multicolumn{6}{|c|}{ INDEPENDENT VARIABLES } \\
\hline \multicolumn{6}{|c|}{ Engagement } \\
\hline \multirow{5}{*}{$\begin{array}{c}\text { Social } \\
\text { Engagement }\end{array}$} & \multirow[t]{5}{*}{389} & \multirow[t]{5}{*}{1} & $0=$ No engagement & 112 & 28.79 \\
\hline & & & $\begin{array}{c}1=\text { Engaged in } 1 \\
\text { organization }\end{array}$ & 158 & 40.62 \\
\hline & & & $\begin{array}{c}2=\text { Engaged in } 2 \\
\text { organizations }\end{array}$ & 68 & 17.48 \\
\hline & & & $\begin{array}{c}3=\text { Engaged in } 3 \\
\text { organizations }\end{array}$ & 35 & 9 \\
\hline & & & $\begin{array}{l}4=\text { Engaged in } 4 \\
\text { organizations }\end{array}$ & 16 & 4.11 \\
\hline \multirow[t]{2}{*}{ Religion } & \multirow[t]{2}{*}{335} & \multirow[t]{2}{*}{1} & $0=($ Very) negative & 52 & 15.52 \\
\hline & & & $1=($ Very) positive & 283 & 84.48 \\
\hline \multicolumn{6}{|c|}{ Demands for Rights } \\
\hline \multirow{2}{*}{$\begin{array}{c}\text { Environmental } \\
\text { Impact }\end{array}$} & \multirow[t]{2}{*}{389} & \multirow[t]{2}{*}{1} & 0 & 86 & 22.11 \\
\hline & & & 1=Negative impact & 303 & 77.89 \\
\hline \multirow{2}{*}{$\begin{array}{l}\text { Agricultural } \\
\text { Impact }\end{array}$} & \multirow[t]{2}{*}{389} & \multirow[t]{2}{*}{1} & 0 & 76 & 19.54 \\
\hline & & & $\begin{array}{c}1=\text { Agree that mining } \\
\text { damages }\end{array}$ & 313 & 80.46 \\
\hline \multicolumn{6}{|c|}{ Demands for Services } \\
\hline \multirow{2}{*}{$\begin{array}{l}\text { Employment } \\
\text { Opportunities }\end{array}$} & \multirow[t]{2}{*}{389} & \multirow[t]{2}{*}{0} & 0 & 256 & 65.81 \\
\hline & & & 1=Positive impact & 133 & 34.19 \\
\hline \multirow{3}{*}{$\begin{array}{c}\text { Educational } \\
\text { Opportunities }\end{array}$} & 389 & 0 & 0 & 248 & 63.75 \\
\hline & & & 1=Positive impact & 141 & 36.25 \\
\hline & & & VONTROL VARIABI & & \\
\hline & & & Mining Variables & & \\
\hline Importance of & 375 & 1 & $1=$ Very little & 222 & 59.20 \\
\hline Mining & & & $2=$ Some & 116 & 30.93 \\
\hline & & & $3=\mathrm{A}$ lot & 37 & 9.87 \\
\hline Knowledge of & 389 & 1 & $0=$ No knowledge & 85 & 21.85 \\
\hline B2Gold & & & $\begin{array}{c}1=\text { Knowledge of one } \\
\text { indicator }\end{array}$ & 205 & 52.70 \\
\hline
\end{tabular}




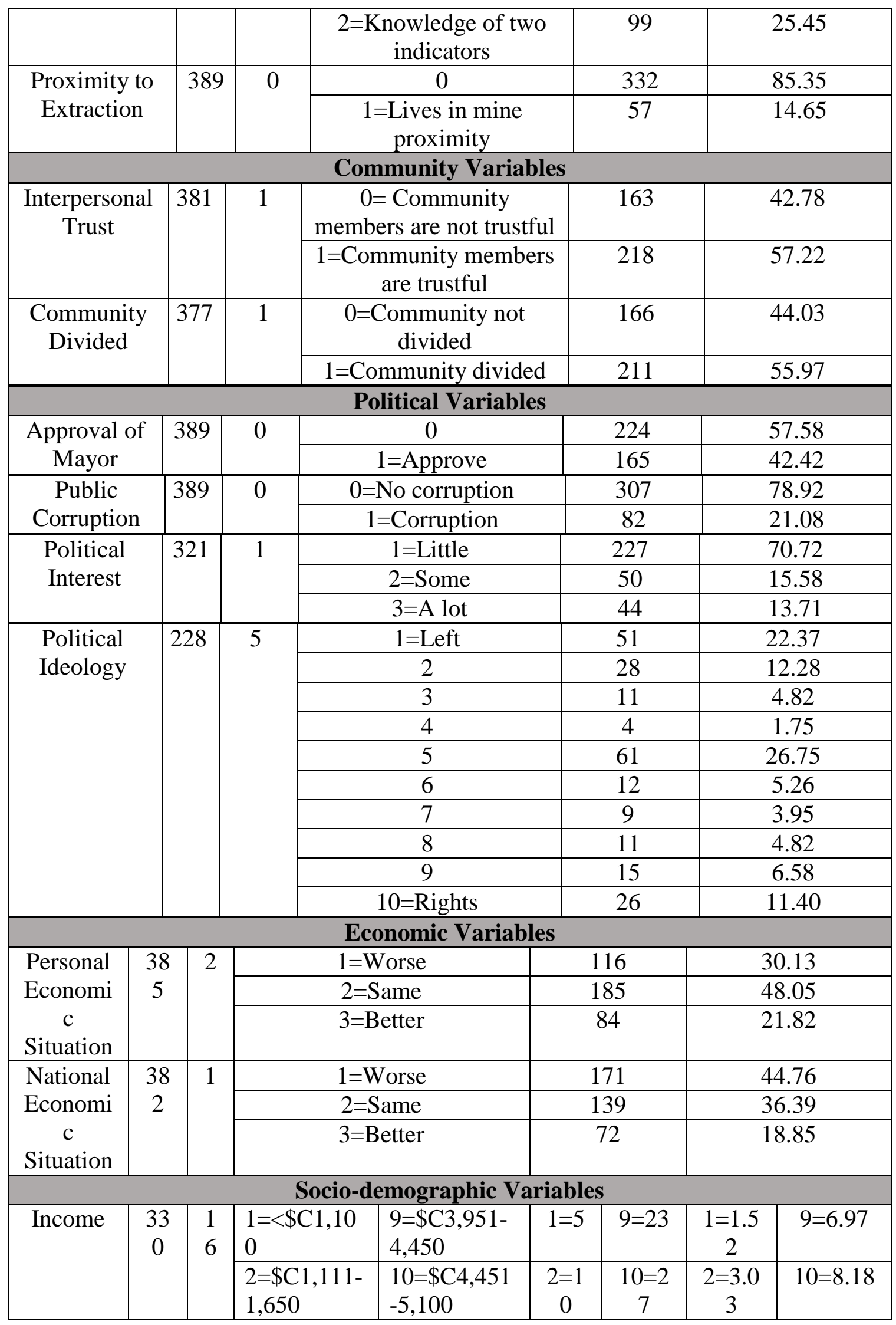




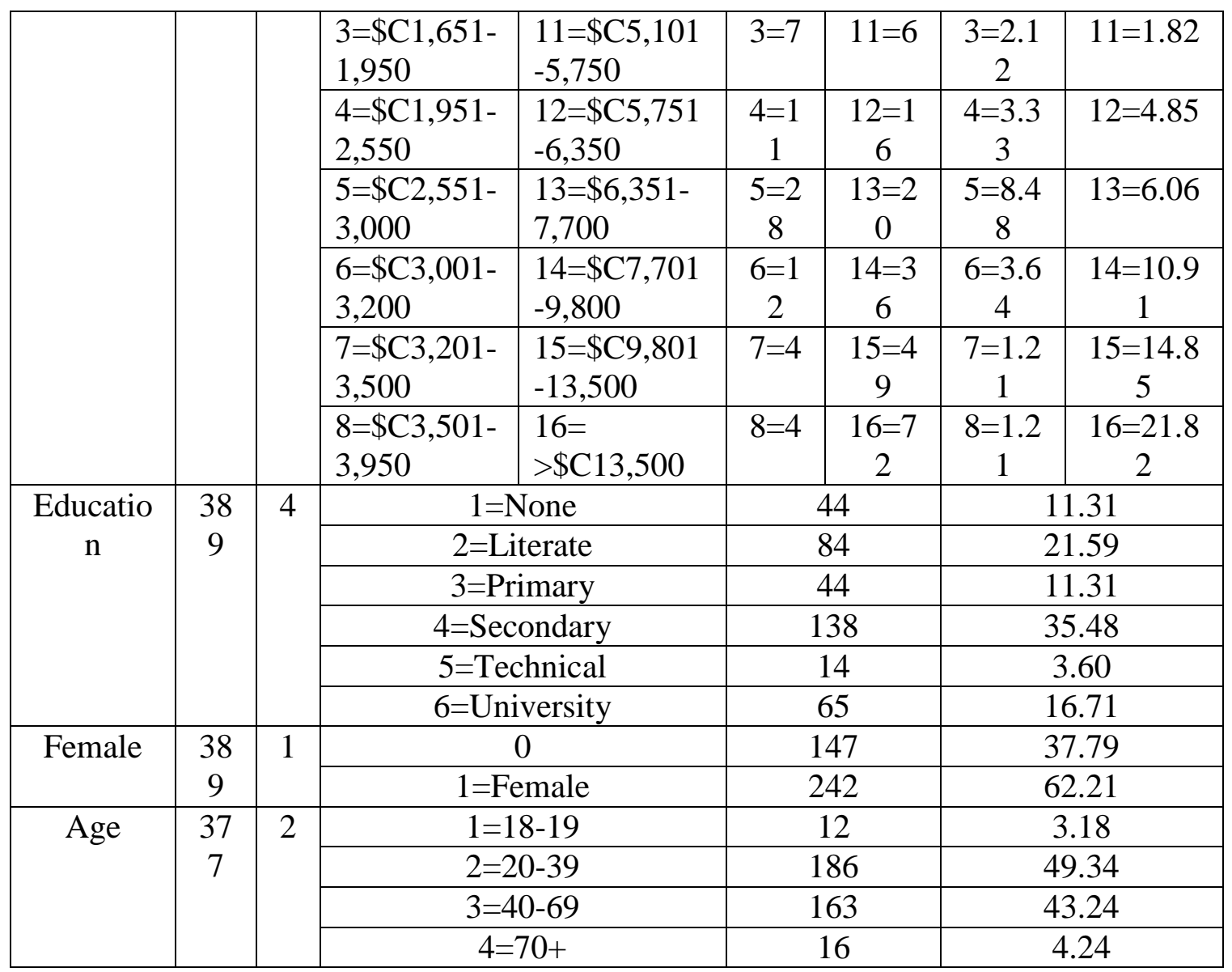


Table 6.3A: Variable Summary Statistics

\begin{tabular}{|c|c|c|c|c|c|}
\hline Variable & $N$ & Mean & $\begin{array}{l}\text { Stan. } \\
\text { Dev. }\end{array}$ & Min. & Max. \\
\hline \multicolumn{6}{|c|}{ DEPENDENT VARIABLES } \\
\hline \multicolumn{6}{|c|}{ Support for Mining } \\
\hline $\begin{array}{l}\text { Support for } \\
\text { Mining }\end{array}$ & 389 & 1670951 & .3735412 & 0 & 1 \\
\hline \multicolumn{6}{|c|}{ Successful Protest } \\
\hline $\begin{array}{c}\text { Successful } \\
\text { Protest }\end{array}$ & 326 & .291411 & .45511 & 0 & 1 \\
\hline \multicolumn{6}{|c|}{ INDEPENDENT VARIABLES } \\
\hline \multicolumn{6}{|c|}{ Engagement } \\
\hline $\begin{array}{c}\text { Social } \\
\text { Engagement } \\
\text { Index }\end{array}$ & 389 & 1.190231 & 1.076845 & 0 & 4 \\
\hline Religion & 335 & .8447761 & .3626597 & 0 & 1 \\
\hline \multicolumn{6}{|c|}{ Demands for Rights } \\
\hline $\begin{array}{l}\text { Environmental } \\
\text { Impact }\end{array}$ & 389 & .7789203 & .4155085 & 0 & 1 \\
\hline $\begin{array}{l}\text { Agricultural } \\
\text { Impact }\end{array}$ & 389 & .8046272 & .396998 & 0 & 1 \\
\hline \multicolumn{6}{|c|}{ Demands for Services } \\
\hline $\begin{array}{l}\text { Employment } \\
\text { Opportunities }\end{array}$ & 389 & .3419023 & .4749579 & 0 & 1 \\
\hline $\begin{array}{c}\text { Educational } \\
\text { Opportunities }\end{array}$ & 389 & .3624679 & .481332 & 0 & 1 \\
\hline \multicolumn{6}{|c|}{ CONTROL VARIABLES } \\
\hline \multicolumn{6}{|c|}{ Mining Variables } \\
\hline $\begin{array}{l}\text { Importance of } \\
\text { Mining }\end{array}$ & 375 & 1.506667 & .6696901 & 1 & 3 \\
\hline $\begin{array}{c}\text { Knowledge of } \\
\text { B2Gold }\end{array}$ & 389 & 1.03599 & .6876978 & 0 & 2 \\
\hline $\begin{array}{l}\text { Proximity to } \\
\text { Extraction }\end{array}$ & 389 & .1465296 & .3540917 & 0 & 1 \\
\hline \multicolumn{6}{|c|}{ Community Variables } \\
\hline $\begin{array}{c}\text { Interpersonal } \\
\text { Trust }\end{array}$ & 381 & .5721785 & .495134 & 0 & 1 \\
\hline $\begin{array}{l}\text { Community } \\
\text { Divided }\end{array}$ & 377 & .5596817 & .497085 & 0 & 1 \\
\hline \multicolumn{6}{|c|}{ Political Variables } \\
\hline $\begin{array}{c}\text { Approval of } \\
\text { Mayor }\end{array}$ & 389 & .4241645 & .494852 & 0 & 1 \\
\hline $\begin{array}{c}\text { Public } \\
\text { Corruption }\end{array}$ & 389 & .2107969 & .4083997 & 0 & 1 \\
\hline
\end{tabular}




\begin{tabular}{|c|c|c|c|c|c|}
\hline $\begin{array}{c}\text { Political } \\
\text { Interest }\end{array}$ & 321 & 1.429907 & .7217013 & 1 & 3 \\
\hline $\begin{array}{c}\text { Political } \\
\text { Ideology }\end{array}$ & 228 & 4.732456 & 3.06801 & 1 & 10 \\
\hline \multicolumn{7}{|c|}{ Economic Variables } \\
\hline $\begin{array}{c}\text { Personal } \\
\text { Economic } \\
\text { Situation }\end{array}$ & 385 & 1.916883 & .716873 & 1 & 3 \\
\hline $\begin{array}{c}\text { National } \\
\text { Economic } \\
\text { Situation }\end{array}$ & 382 & 1.740838 & .755284 & 1 & 3 \\
\hline \multicolumn{7}{|c|}{ Socio-demographic Variables } \\
\hline Income & 330 & 11.35758 & 4.541536 & 1 & 16 \\
\hline Education & 389 & 3.485861 & 1.562423 & 1 & 6 \\
\hline Female & 389 & .622108 & .4854849 & 0 & 1 \\
\hline Age & 377 & 2.485411 & .6319713 & 1 & 4 \\
\hline
\end{tabular}


Table 6.4A: Survey Questions and Variable Explanations

\begin{tabular}{|c|c|c|c|}
\hline Variable Name & Survey Question & $\begin{array}{l}\text { Variable } \\
\text { Type }\end{array}$ & $\begin{array}{l}\text { Variable } \\
\text { Coding }\end{array}$ \\
\hline \multicolumn{4}{|c|}{ DEPENDENT VARIABLES } \\
\hline \multicolumn{4}{|c|}{ Support for Mining } \\
\hline Support for Mining & $\begin{array}{l}\text { Are you for or against the } \\
\text { development of B2Gold's } \\
\text { mining projects? }\end{array}$ & Dichotomous & $\begin{array}{l}0=\text { Not } \\
\text { supportive; } \\
\text { 1=Supportive }\end{array}$ \\
\hline \multicolumn{4}{|c|}{ Successful Protest } \\
\hline Successful Protest & $\begin{array}{l}\text { Have the protests organized } \\
\text { by your community been } \\
\text { successful against the mining } \\
\text { company? }\end{array}$ & Dichotomous & $\begin{array}{l}0=\text { Not } \\
\text { successful; } \\
1=\text { Successful }\end{array}$ \\
\hline \multicolumn{4}{|c|}{ INDEPENDENT VARIABLES } \\
\hline \multicolumn{4}{|c|}{ Engagement } \\
\hline Social Engagement & $\begin{array}{l}\text { How frequently do you } \\
\text { attend a: } \\
\text { 5) Community } \\
\text { Organization; } \\
\text { 6) Environmental } \\
\text { Organization; } \\
\text { 7) Agricultural } \\
\text { Organization; } \\
\text { Religious Organization? }\end{array}$ & $\begin{array}{l}\text { Dichotomous } \\
\text { Additive } \\
\text { Index }\end{array}$ & $\begin{array}{l}0=\text { Not engaged } \\
\text { (If respondents } \\
\text { never } \\
\text { participate); } \\
1=\text { Engaged (If } \\
\text { respondents said } \\
\text { they } \\
\text { participated } \\
\text { once a week, } \\
\text { twice a month, } \\
\text { or once a } \\
\text { month). } \\
\text { Index means if a } \\
\text { respondent } \\
\text { participates at } \\
\text { least once a } \\
\text { month in: all } \\
\text { four } \\
\text { organizations, } \\
\text { the respondent } \\
\text { receives a } 4 ; \text { in } \\
\text { three of the four } \\
\text { organizations, } \\
\text { the respondent } \\
\text { receives a } 3 ; \text { in } \\
\text { two of the four } \\
\text { organizations, } \\
\text { the respondent } \\
\text { receives a } 2 ; \text { in }\end{array}$ \\
\hline
\end{tabular}




\begin{tabular}{|c|c|c|c|}
\hline & & & $\begin{array}{l}\text { one of the four } \\
\text { organizations, } \\
\text { the respondent } \\
\text { receives a } 1 ; \\
\text { and in none of } \\
\text { the } \\
\text { organizations, } \\
\text { the respondent } \\
\text { receives a } 0 .\end{array}$ \\
\hline Religion & $\begin{array}{l}\text { In solution of mining } \\
\text { conflicts between the } \\
\text { community population and } \\
\text { the mining company, how } \\
\text { would you rate the work of } \\
\text { the churches? }\end{array}$ & Dichotomous & $\begin{array}{l}0=(\text { very }) \\
\text { negative; } 1= \\
\text { (very) positive. }\end{array}$ \\
\hline \multicolumn{4}{|c|}{ Demands for Rights } \\
\hline $\begin{array}{l}\text { Environmental } \\
\text { Impacts }\end{array}$ & $\begin{array}{l}\text { What impact will B2Gold's } \\
\text { activity have on the } \\
\text { environment? }\end{array}$ & Dichotomous & $\begin{array}{l}0=\text { Positive and } \\
\text { very positive; } \\
1=\text { Negative and } \\
\text { very negative }\end{array}$ \\
\hline Agricultural Impacts & $\begin{array}{l}\text { Agree or disagree? The } \\
\text { drilling of the land done for } \\
\text { mining activity damages the } \\
\text { environment and agriculture. }\end{array}$ & Dichotomous & $\begin{array}{l}0=\text { Disagree } \\
1=\text { Agree }\end{array}$ \\
\hline \multicolumn{4}{|c|}{ Demands for Services } \\
\hline $\begin{array}{l}\text { Employment } \\
\text { Opportunities }\end{array}$ & $\begin{array}{l}\text { What impact will B2Gold's } \\
\text { activity have on employment } \\
\text { opportunities }\end{array}$ & Dichotomous & $\begin{array}{l}0=\text { Negative and } \\
\text { very negative; } \\
1=\text { Very positive } \\
\text { and positive }\end{array}$ \\
\hline $\begin{array}{l}\text { Educational } \\
\text { Opportunities }\end{array}$ & $\begin{array}{l}\text { Has the mining company } \\
\text { helped improve educational } \\
\text { services in your community? }\end{array}$ & Dichotomous & $\begin{array}{l}0=\mathrm{No} ; \\
1=\text { Yes }\end{array}$ \\
\hline \multicolumn{4}{|c|}{ CONTROL VARIABLES } \\
\hline \multicolumn{4}{|c|}{ Mining Variables } \\
\hline $\begin{array}{l}\text { Importance of } \\
\text { Mining }\end{array}$ & $\begin{array}{l}\text { How important are the } \\
\text { mining companies for the } \\
\text { economic development of } \\
\text { Nicaragua? }\end{array}$ & Continuous & $\begin{array}{l}\text { 1= Very } \\
\text { Important; } \\
2=\text { Some } \\
\text { importance; } \\
\text { 3=Little } \\
\text { importance }\end{array}$ \\
\hline $\begin{array}{l}\text { Knowledge of } \\
\text { B2Gold }\end{array}$ & $\begin{array}{l}\text { Based on the following three } \\
\text { questions: } \\
\text { 3) In what country is } \\
\text { B2Gold's central }\end{array}$ & $\begin{array}{l}\text { Dichotomous } \\
\text { Additive } \\
\text { Index }\end{array}$ & $\begin{array}{l}\text { Index means if a } \\
\text { respondent } \\
\text { knows } \\
\text { B2Gold's } \\
\text { central office is }\end{array}$ \\
\hline
\end{tabular}




\begin{tabular}{|c|c|c|c|}
\hline & $\begin{array}{l}\text { office located? }(1= \\
\text { Canada; } 0=\text { Other } \\
\text { Countries }) \\
\text { 4) Do you know who } \\
\text { Guardines de Yaoska } \\
\text { are in your } \\
\text { community? }(1=\text { Yes; } \\
0=\text { No })\end{array}$ & & $\begin{array}{l}\text { in Canada, if the } \\
\text { respondent } \\
\text { knows who } \\
\text { Guardines de } \\
\text { Yaoksa are than } \\
\text { the respondent } \\
\text { receives a 2. If } \\
\text { the respondent } \\
\text { can provide the } \\
\text { correct answer } \\
\text { for one out of } \\
\text { the two } \\
\text { questions the } \\
\text { respondent } \\
\text { receives a } 1 . \text { If } \\
\text { the respondent } \\
\text { cannot provide } \\
\text { the correct } \\
\text { answer for any } \\
\text { of the two } \\
\text { questions the } \\
\text { respondent } \\
\text { receives a } 0 .\end{array}$ \\
\hline $\begin{array}{l}\text { Proximity to } \\
\text { Extraction }\end{array}$ & $\begin{array}{l}\text { Variable created using the } \\
\text { indicator } \\
\text { "Community/Neighborhood." }\end{array}$ & Dichotomous & $\begin{array}{l}0=\text { All other } \\
\text { communities. } \\
1=\text { Respondents } \\
\text { that live in the } \\
\text { direct vicinity of } \\
\text { the mining } \\
\text { project or } \\
\text { proposed } \\
\text { mining project } \\
\text { because of their } \\
\text { direct impact by } \\
\text { mining. }\end{array}$ \\
\hline \multicolumn{4}{|c|}{ Community Variables } \\
\hline Interpersonal Trust & $\begin{array}{l}\text { Would you say the people in } \\
\text { your community are } \\
\text { trustworthy? }\end{array}$ & Dichotomous & $\begin{array}{l}0=\text { A little } \\
\text { trustworthy and } \\
\text { not trustworthy; } \\
1=\text { Trustworthy } \\
\text { and very } \\
\text { trustworthy }\end{array}$ \\
\hline Community Divided & Is your community divided? & Dichotomous & $0=\mathrm{No} ; 1=$ Yes \\
\hline \multicolumn{4}{|c|}{ Political Variables } \\
\hline Approval of Mayor & $\begin{array}{l}\text { In the solution of mining } \\
\text { conflicts between the local }\end{array}$ & Dichotomous & $\begin{array}{l}0=\text { Positive and } \\
\text { Very Positive; }\end{array}$ \\
\hline
\end{tabular}




\begin{tabular}{|c|c|c|c|}
\hline & $\begin{array}{l}\text { population and the mining } \\
\text { company, how would you } \\
\text { measure the work of the } \\
\text { municipal mayor? }\end{array}$ & & $\begin{array}{l}1=\text { Negative and } \\
\text { Very Negative }\end{array}$ \\
\hline Public Corruption & $\begin{array}{l}\text { Do you know a public } \\
\text { employee that asked for a } \\
\text { bribe from the mining } \\
\text { company? } \\
\text { Do you know a judge that } \\
\text { asked for a bribe from the } \\
\text { mining company? }\end{array}$ & $\begin{array}{l}\text { Dichotomous } \\
\text { Additive } \\
\text { Index }\end{array}$ & $\begin{array}{l}0=\text { No } \\
1=\text { Yes } \\
\text { Index means if a } \\
\text { respondent } \\
\text { knows of a } \\
\text { public employee } \\
\text { AND a judge, } \\
\text { the respondent } \\
\text { receives a } 2 \text {. If a } \\
\text { respondent } \\
\text { knows of a } \\
\text { public employee } \\
\text { OR a judge, the } \\
\text { respondent } \\
\text { receives a } 1 \text {. If a } \\
\text { respondent does } \\
\text { not know of a } \\
\text { public employee } \\
\text { and a judge, the } \\
\text { respondent } \\
\text { receives a } 0 .\end{array}$ \\
\hline Political Interest & $\begin{array}{l}\text { How much interest do you } \\
\text { have in politics? }\end{array}$ & Continuous & $\begin{array}{l}\text { 1=A little } \\
\text { 2=Some } \\
3=\text { A lot }\end{array}$ \\
\hline Political Ideology & $\begin{array}{l}\text { Thinking about the } \\
\text { terminology, "left" and } \\
\text { "right", where do you place } \\
\text { your self on a } 1 \text { (left) and } 10 \\
\text { (right) scale? }\end{array}$ & Continuous & $\begin{array}{l}1=\text { Very left; } \\
5=\text { Neutral; } \\
10=\text { Very right }\end{array}$ \\
\hline \multicolumn{4}{|c|}{ Economic Variables } \\
\hline $\begin{array}{l}\text { Personal Economic } \\
\text { Situation }\end{array}$ & $\begin{array}{l}\text { How would you define your } \\
\text { personal economic situation? }\end{array}$ & Continuous & $\begin{array}{l}1=\text { Worse; } \\
2=\text { Equal; } \\
3=\text { Better }\end{array}$ \\
\hline $\begin{array}{l}\text { National Economic } \\
\text { Situation }\end{array}$ & $\begin{array}{l}\text { How would you define the } \\
\text { economic situation of } \\
\text { Nicaragua, as compared to } 12 \\
\text { months ago? }\end{array}$ & Continuous & $\begin{array}{l}\text { 1= Worse; } \\
2=\text { Equal; } \\
\text { 3= Better }\end{array}$ \\
\hline \multicolumn{4}{|c|}{ Socio-demographic Variables } \\
\hline Income & $\begin{array}{l}\text { In which of the following } \\
\text { ranges do you find your } \\
\text { family's monthly household }\end{array}$ & Continuous & $\begin{array}{l}1=\text { Menos de } \\
1,100 \text { córdobas; }\end{array}$ \\
\hline
\end{tabular}




\begin{tabular}{|c|c|c|c|}
\hline & $\begin{array}{l}\text { income, including } \\
\text { remittances and income from } \\
\text { adults and children? }\end{array}$ & & $\begin{array}{l}\text { 2= Entre 1,100- } \\
\text { 1,650 córdobas; } \\
\text { 3= Entre 1,651- } \\
\text { 1,950 córdobas; } \\
\text { 4= Entre 1,951- } \\
\text { 2,550 córdobas; } \\
\text { 5= Entre 2,551- } \\
\text { 3,000 córdobas; } \\
\text { 6= Entre 3,001- } \\
\text { 3,200 córdobas; } \\
\text { 7= Entre 3,201- } \\
\text { 3,500 córdobas; } \\
\text { 8= Entre 3,501- } \\
\text { 3,950 córdobas; } \\
\text { 9= Entre 3,951- } \\
\text { 4,450 córdobas; } \\
\text { 10= Entre } \\
\text { 4,451-5,100 } \\
\text { córdobas; } \\
\text { 11= Entre } \\
\text { 5,101-5,750 } \\
\text { córdobas; } \\
\text { 12= Entre } \\
\text { 5,751-6,350 } \\
\text { córdobas; } \\
\text { 13= Entre } \\
\text { 6,351-7,700 } \\
\text { córdobas; } \\
\text { 14= Entre } \\
\text { 7,701-9,800 } \\
\text { córdobas; } \\
\text { 15= Entre } \\
\text { 9,801-13,500 } \\
\text { córdobas; } \\
\text { 16= Más de } \\
\text { 13,500 córdobas }\end{array}$ \\
\hline Education & $\begin{array}{l}\text { What is the last level of } \\
\text { education that you achieved? }\end{array}$ & Continuous & $\begin{array}{l}\text { 1= Literate } ; \\
\text { 2= Primary } \\
\text { 3= Secondary; } \\
\text { 4= Technical } \\
\text { 5= University }\end{array}$ \\
\hline Female & What is your gender? & Dichotomous & $\begin{array}{l}0=\text { Male; } \\
1=\text { Female }\end{array}$ \\
\hline Age & What is your age? & Continuous & $\begin{array}{l}1=18-19 ; \\
2=20=39 \\
3=40=69\end{array}$ \\
\hline
\end{tabular}




\begin{tabular}{|l|l|l|l|}
\hline & & & $4=69=82$ \\
\hline
\end{tabular}




\section{Figure 6.1A: Artisanal Mining Methods in Santo Domingo}

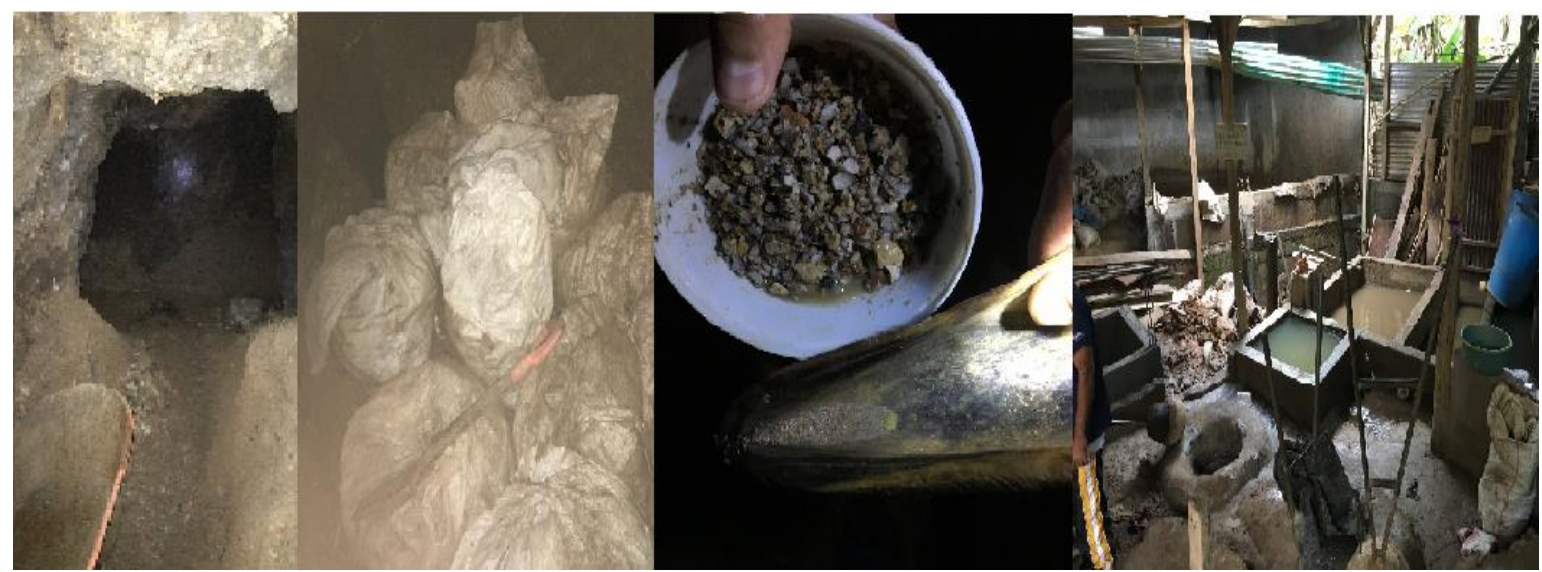

Source: Author's photos.

The first picture on the left is an artisanal miner's tunnel that he and his fellow miners dug with shovels and pickaxes. This particular mining shaft has over 7 miles of tunnels. I was able to explore some of the tunnels while in the mine. The second photo from the left shows bags filled with rocks. When artisanal miners create tunnels they carry out the broken rocks in bags and buckets. In the third photo from left, an artisanal miner demonstrated to me how they sift for gold in the tunnel to see if certain areas have gold. If the area has gold, they will excavate the rocks and bring the rocks to the processing plant. The last photo on the right is what a typical processing plant looks like in Santo Domingo. Workers here break the rocks with rubber mallets into smaller and finer pieces. They use water, rudimentary machinery, and some chemicals to separate the gold from the rocks. 
Figure 6.2A: Destruction of Homes by B2Gold's Explosives

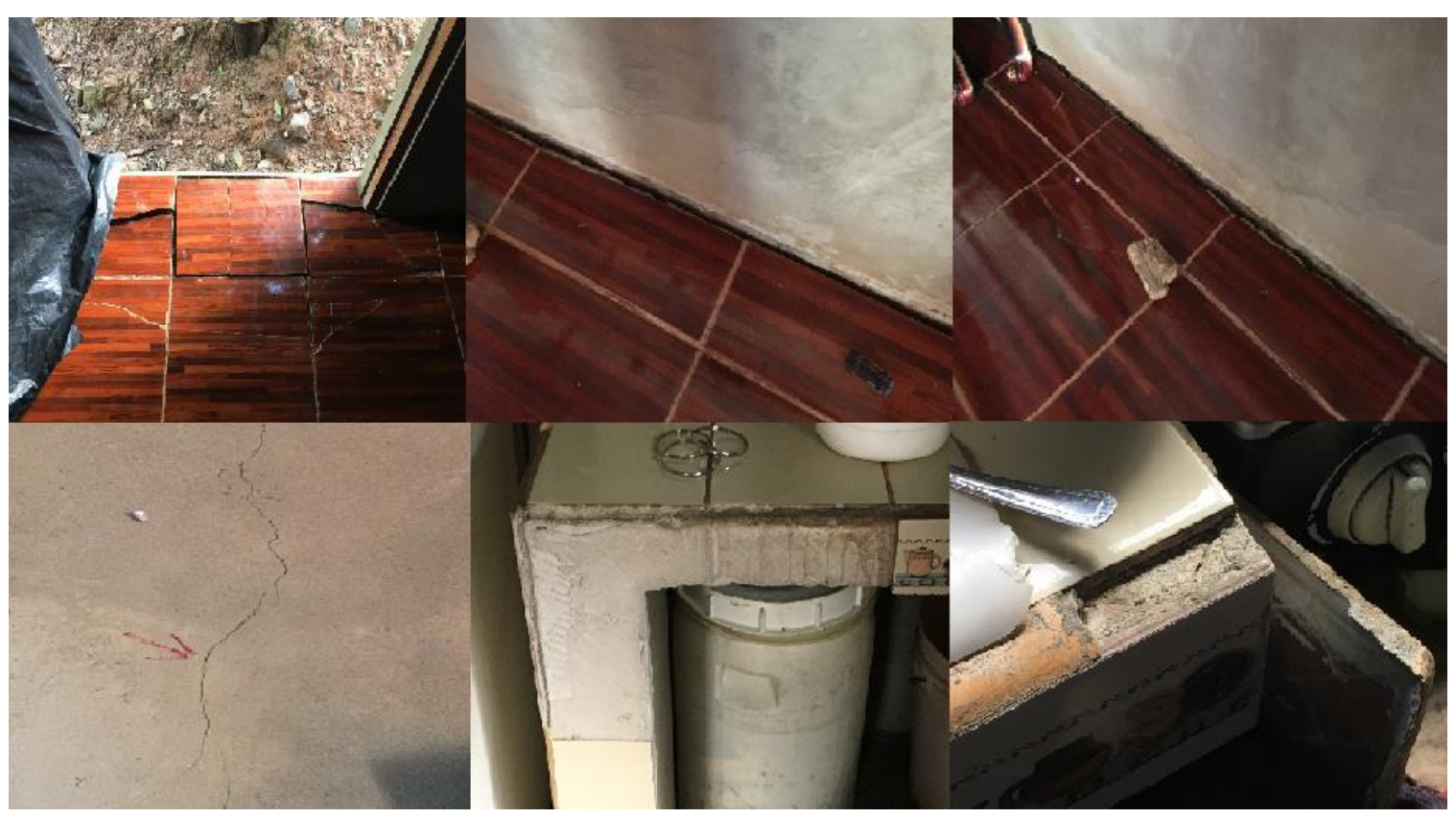


CHAPTER 7

"Comparisons and Conclusion" 
In this final chapter, I analyze my findings and make comparisons between Rancho Grande and Santo Domingo utilizing my individual-level results. The comparison demonstrates the similarities and differences between the two Nicaraguan cases impacted by B2Gold's mining activities. After making these comparisons, I conclude the chapter discussing the contributions from this dissertation and the implications that it has by stressing the utility of understanding individual-level opposition and support through economic opportunities, economic threats, and the micro-politics of social engagement, as well as stressing the rarely studied role of religion in resource extractive conflicts. The implications of my research are important for scholars because work on the attitudes, beliefs, and characteristics of people who oppose or support mineral extraction is relatively uncommon. Additionally, I systematically examine the role that religion has in mobilizations and show that it is an important catalyst for successful challenges against resource extraction and how it ultimately assists in correcting power imbalances between communities, mining companies, and governments.

As Arce (2014b) and Bebbington and Bury (2013) have demonstrated, stopping a mining project is very difficult due to power differences between the extractive companies and the local communities. Another key requirement is the amount of time outside of daily routines that needs to be devoted in sustaining mobilizations and movements. Supported by national governments to re-privatize national economies through extractivism, extractive companies like B2Gold diffuse protesters' claims by offering selective material rewards to the leaders of institutions and organizations or by spending on projects in collaboration with local authorities and institutions. Thus, the goal of extractive companies is to gain or "buy" the local population's support and the 
local authorities and institutions support through a continuous offering of small concessions.

Successful campaigns against mineral extraction are more likely to encompass rights-based claims because mining threatens the environment, agriculture, water, and land, which threatens the livelihoods and existence of individuals living in mining communities and makes them oppose and resist mining until they see policy changes against mining (Arce 2014b, 2015; Arce and Hendricks forthcoming). Both Rancho Grande and Santo Domingo are communities that exemplify rights-based resistance movements against B2Gold. Citizens in Rancho Grande and Santo Domingo have largely opposed and resisted B2Gold's mining activities for nearly a decade for the same reasons: to protect their right to land, landscapes, water quantity and quality, and their environment. However, unlike Rancho Grande's successful overturn of B2Gold's concession, Santo Domingo's organized and sustained rights-based resistance movement against B2Gold has not been successful in overturning B2Gold's operations within the community. In order to understand what makes protests successful or unsuccessful, scholars need to understand what makes individuals oppose or support resource extraction. Opposition and support towards mining are not mutually exclusive from protest success in overturning a mining concession. They build off each other. My findings from Rancho Grande and Santo Domingo demonstrate what individuals, living in extractive areas, believe makes their protests and social movements more successful against mining after fully understanding why and how individuals either oppose or support resource extraction. 
Below, in Table 7.1, I provide comparisons between the rural communities of Rancho Grande and Santo Domingo that largely rely on clean water and healthy environments for agricultural and livestock production that contributes to the livelihood and sustenance of these communities. The agricultural way of live for these communities have been impacted, influenced, and threatened by B2Gold for approximately a decade. In Rancho Grande, B2Gold never began to extract gold through an exploitation concession, but the population understood through the acquiring of information and knowledge from engagement and participation in local organizations that if the company did begin to extract gold that it would be the demise of the community and its existence. While in Santo Domingo, B2Gold has both exploration and exploitation concessions, even though the exploitation concessions are technically illegal under Nicaraguan laws, which has allowed the company to extract gold for nearly a decade. B2Gold's mining activities have already heavily contaminated the land and the water in Santo Domingo, as well as forced citizens off their properties and destroyed people's homes. Many in the community fear once B2Gold leaves Santo Domingo and takes with it the little economic benefits it offers; the community will be so harmed that there will be nothing left for it to sustain its existence. 
Table 7.1: Comparisons Between Rancho Grande and Santo Domingo

\begin{tabular}{|c|c|c|}
\hline Comparison & Rancho Grande & Santo Domingo \\
\hline History of mining & No & Yes \\
\hline Commodity chain & $\begin{array}{l}\text { B2Gold Exploration } \\
\text { Concession }\end{array}$ & $\begin{array}{l}\text { B2Gold Exploration and } \\
\text { Exploitation Concessions }\end{array}$ \\
\hline Geographic location & Rural & Rural \\
\hline Primary threat & Agriculture/Environment & Agriculture/Environment \\
\hline Demands for rights & Yes & Yes \\
\hline Demands for services & Yes & Yes \\
\hline Social Engagement & Yes & No \\
\hline Religion & Yes & No \\
\hline Successful Resistance & Yes & No \\
\hline
\end{tabular}

In both Rancho Grande and Santo Domingo, my findings highlight the reasons why individuals support and oppose B2Gold and its mining project. Individuals in both mining communities oppose B2Gold and its mining projects based on the economic threats from the negative and harmful impacts that mining causes to the environment and 
agricultural production in their communities. Additionally, community members in Rancho Grande and Santo Domingo also support B2Gold and its mining projects based on the economic opportunities that the company and its activities offer to the community, such as social programs, employment, and monetary benefits and gifts.

Throughout this dissertation, I also explored how individuals in extractive areas form or reinforce their attitudes towards mining. I argued that participation and engagement in community organizations help individuals form or reinforce oppositional attitudes towards mining by offering: 1) access to critical organizational tools and information about mining; 2) a high sense of self-efficacy and collective-efficacy empowering it to resist mining; 3) and a strong community worldview (i.e., community identity and values) contributing to broad-based mobilization and resistance. I found support for my argument in Rancho Grande. Individuals that engage in local-level organizations (i.e., community organizations, environmental organizations, agricultural organizations, and/or religious organizations) are more likely to oppose mining projects. The community of Rancho Grande with the assistance of Guardines de Yaoska, the Catholic and Evangelical Churches, and environmental and agricultural NGOs provided the organizational tools and resources to unite the population against mining from the very beginning of B2Gold's influence in the community, which empowered the population to work together in unity and resist mining from harmfully impacting their livelihoods and the community they loved so much. Through their engagement and organization, the community was also able to prohibit B2Gold in coercively influencing local institutions and organizations as it did in Santo Domingo. 
My findings in Santo Domingo indicate that individuals are divided on their attitudes towards mining. Some individuals that participate in community organizations in Santo Domingo likely oppose mining for reasons I have discussed throughout this dissertation, but others that are actively engaged in community organizations already have their supportive opinions formed on mining or are benefiting from B2Gold's projects. As Dougherty and Olsen $(2014,191)$ demonstrate, some communities like Santo Domingo "have lower levels of collective-efficacy and experience less relational trust and higher levels of institutional trust" (Dougherty and Olsen 2014, 191). The authors suggest that these types of communities are more vulnerable to outside interests, like those of B2Gold. Additionally, many other citizens in Santo Domingo tend to support B2Gold because they work for the company, have a family member that works for the company, or have a job that some way interacts with the company. Although these citizens do not necessarily support B2Gold in every aspect, they fear acting against B2Gold due to potential negative repercussions that the company could cause them and their families.

As I have suggested, Rancho Grande's organizational efforts and its efforts to unite the population and the community started very early, early enough so it could get a hold on mining's influence in the community. However, the community of Santo Domingo is perhaps too late on their organizational efforts and their efforts to unify the community against mining, which allowed B2Gold to corrupt different sectors of Santo Domingo like the local institutions and organizations. B2Gold has used "perks, bribes, blackmail; it has bought people off... The company has been trying to buy everybody off, and has been appropriating everything. It bought the farmers' properties, the ecosystem, 
the basin; in short, it bought our geography. It doesn't own just the concession; it owns everything” (Pérez Soza 2013). Thus, unlike my findings in Rancho Grande, my results indicate that individuals in Santo Domingo that engage in local-level organizations are not more likely to oppose or support mining projects. Santo Domingo lacks the informational tools and resources, self-efficacy and collective-efficacy, and the feeling of a community worldview that social engagement provides to empower individuals against mining.

My findings in Rancho Grande also indicate that individuals believe that religion significantly increased their successful achievement in overturning B2Gold's mining concession at the national level. The community believes that the Churches' influence in the social movement against mining was paramount in the national government's decision to overturn B2Gold's mining concession. The Church leaders involved were key actors in providing resources and organizing and unifying the community, which was so impactful for the community's success in overturning B2Gold's mining concession. The Church leaders garnered respect from the people in the community and united everyone to organize against mining. Additionally, the community believes its success is related to its strong religious conviction and its faith in God. The Department of Matagalpa and the community of Rancho Grande is believed to be an area in Nicaragua where one can find the most religious Nicaraguans. Their strong religious conviction allowed them to stay united and to persist through the difficulties they faced during their anti-extraction movement, and continue their resistance until they were successful. ${ }^{167}$

I also find some support for religion in Santo Domingo even though religion's

\footnotetext{
${ }^{167}$ Author's personal interviews with a community member in Rancho Grande and a representative from ADDAC: January 2017.
} 
role and influence was absent from Santo Domingo's resistance movement, and Santo Domingo has not achieved a national-level policy change for reversing B2Gold's mining concession. The sentiment of the residents in Santo Domingo who oppose B2Gold and mining is that they have no one to rely on or turn to in their struggle. It appears that many residents feel helpless and live in fear. Many citizens in Santo Domingo would like to speak up against mining, but they are fearful of B2Gold and its supportive followers use of intimidation and violence. The community seems lost in its struggle against B2Gold, and seems unsure on how to unite and effectively organize against B2Gold, since the company is so powerful and has purchased the support of those that are supposed to help the residents. The citizens that oppose B2Gold believe they could overturn B2Gold's mining concession if they had support from local organizations and groups, like the Catholic and Evangelical Churches, which my findings indicate. They understand the role and influence that the Churches played in Rancho Grande, and believe that if they could gain the support of the Catholic and Evangelical Churches to assist them in their own struggles that other local organizations, institutions, and those supportive of mining would follow suit, since the Churches are so respected and trusted throughout the community. ${ }^{168}$

I have demonstrated throughout this dissertation, qualitatively and quantitatively, when the role and influence of religion is present in anti-mining resistance movements, that one is more likely to see an effectively organized campaign against mining and mining companies that influence national governments in overturning mining concessions. On the contrary, when the role and influence of religion is absent from anti-

\footnotetext{
168 Author's personal interviews with community members in Santo Domingo: January 2017.
} 
mining resistance movements, one is less likely to see an effectively organized campaign against mining and mining companies that influence national governments in overturning mining concessions. Although citizens in Santo Domingo appear to understand the impact that strong religious influence can have in helping them in their struggles against B2Gold; the churches, religious leaders, and religious organizations have not yet accepted their call to environmental activism and assisting those that have succumbed to the harms of modern day mining.

With approximately $49 \%$ of Nicaragua's land available for mining concessions for international extractive companies, many in the communities of Rancho Grande and Santo Domingo would like to see a declaration from Nicaragua's national government that bans mining completely or revise its laws so they are more favorable to communities so future generations of Nicaraguans will not have to live with the destruction that mining and mining companies cause. The community of Rancho Grande would like their resistance movement against B2Gold and mining to be used as a learning process and model for providing the organizational tools, information, and resources that other communities in Nicaragua can use to organize, unite, and resist mining. Ideally, citizens of Rancho Grande would like their resistance movement to be used as a model that assists in generating a National Front with representatives from communities having the ability to defend their communities and represent their communities in an organized, united, and concentrated front against the mining, extractive companies, and local and national governments. ${ }^{169}$

\footnotetext{
${ }^{169}$ Author's personal interviews with community members in Rancho Grande and Santo Domingo: January
} 2017. 
Without a broad-based national movement, Nicaraguan anti-mining mobilizations have tended to be largely local affairs focusing on specific sectoral and community concerns. This pattern could change, particularly with any advancement in the construction of China's investment in the Interoceanic Canal and its potential harms, related to the environment, agriculture, water, and the displacement of people. However, to date, a national movement against environmentally destructive international companies in Nicaragua has had limited reach. Facing political elite cohesion in support of mine development, limited access to the courts and the media, and the sunk costs of a minecentered economy, Nicaraguan activists have been unable to launch a major movement in favor of either a national mining ban or tightened regulations.

However, by studying discrete and well-defined arenas of conflict, and targeting where protests are against extractive companies and their activities; I expect to better understand the dynamics of anti-extraction mobilizations - constituted by group dynamics and individual behaviors. Examining resource extraction and citizens' attitudes towards mining in Nicaragua, the top gold producer in Central America that has seen an increase in protests related to extractive activities over the past decade, makes it an ideal country to study that is applicable to other resource wealthy countries in Central America, Latin America, and even other regions of the world. Thus, understanding why citizens living in the extractive frontier either oppose or support resource extraction in Nicaragua and how these attitudes are formed, shaped, and or reinforced by their social engagement in local organizations leading them to oppose mining should be a generalizable mechanism for citizens living in extractive areas in other resource wealthy countries. It is likely that citizens living in mining areas are more likely to oppose mining activities for 
reasons related to protecting their rights to land, landscapes, water, and the environment. While citizens that support mining are likely to support mining because of the economic benefits that mining companies and extractive activities bring to communities.

To date, research on the politics of resource extraction focuses on successful campaigns against extraction and emphasizes the sources of opposition to mining. With few exceptions, existing research has rarely explored individual-level attitudes related to resource extraction. Departing from previous scholarship, and based on original data from a 2018 survey in Rancho Grande, Matagalpa, Nicaragua, I traced the sources of opposition and support for resource extraction at the individual level in a context where there is both resistance to and backing for mining in order to understand the attitudes, beliefs, and characteristics of individuals in the context of resistance movements against mining. Ultimately, the future of resource extraction in Nicaragua faces the paradox of individual support and collective resistance.

There is growing divide between those who oppose extraction and those who support it, which is why it is essential that scholars begin to study the rarely explored individual-level attitudes, beliefs, and characteristics related to resource extraction. In doing so, social scientists can start to understand different individual responses to mining hat underline the aggregate stories of homogenous community resistance. My study demonstrates reasons why and how individuals living in the extractive frontier either support or oppose mining and mining projects. By understanding individual attitudes, beliefs, and characteristics towards mining, scholars of extractive protests and social movements will be able to better understand the individual mechanisms that lead citizens in the extractive frontier to either partake in mining resistance or abstain. 
Although studies are rare on the church's role in extractive protests, it appears that a trend is growing, not just in the literature, but in application of the church, church leadership, and religious organizations assisting communities with anti-mining movements across Latin America based on environmental activism and protection against the harmful impacts from mining. I have shown, qualitatively and quantitatively, that religion is a key component in the creation and mobilization of social movements and protests, including extractive protests against mining. I have shown how religion (i.e., churches, church leaders, religious organizations, and faith and conviction in God) leads to successful extractive protest movements. Studying religion, in this case Catholicism and Evangelicalism, as a catalyst for sustaining successful protest movements against extraction in Nicaragua should also be generalizable across all of Latin America, a region that is predominately Catholic with an increasing population of Evangelicals. One should also be able to explore my framework for religion as a catalyst for other religions and other types of protests in different regions throughout the world. However, "it is worth stressing that [religion] is most often only one of a host of factors that interact in order to produce and propel groups towards mobilization and action. Hence it is crucial that any analysis of the role of religion in social movements must take into account the interaction of various social and contextual factors alongside religion in their formation and mobilization" (Kirmani 2008, 32) ${ }^{170}$.

\footnotetext{
${ }^{170}$ Kirmani $(2008$, 32-33) also notes that "[w]hile the religious factor may be important in improving understanding of many contemporary social movements, analyses of religion should avoid an essentialist approach and should instead aim to contextualize religion as one amongst many potential mobilizing forces that determine the emergence, operation and impact of social movements."
} 


\section{BIBLIOGRAPHY}

Abuya, Willice O. 2016. "Mining Conflicts and Corporate Social Responsibility:

Titanium Mining in Kwale, Kenya." The Extractive Industries and Society 3(2): 485-493.

Acuña, Roger M. 2015. “The Politics of Extractive Governance: Indigenous Peoples and Socio-environmental Conflicts." The Extractive Industries and Society 2(1): 8592.

Adriance, Madeleine. 1991. “Agents of Change: Priests, Sisters, and Lay Workers in the Grassroots Catholic Church in Brazil.” Journal of the Scientific Study of Religion 30(3): 292-305.

Agencia Nacional de Minería. 2011. "Prior Consultation." https://www.anm.gov.co/sites/default/files/DocumentosAnm/prior_consultation.p df (Accessed April 2, 2019).

Agros International (N.D.). "Nicaragua Regional Project Land." https://www.agros.org/ckfinder/userfiles/files/Land\%20for\%20Nicaragua\%20Proj ect.pdf (Accessed on March 3, 2019).

Aguad, Jhader, “Agro Sí, Mina No: Explaining the Onset of Protest Surrounding Mining Projects in Peru.” 2017). Political Science Honors Projects 61.

Ahmad, Nesar, and Kuntala Lahiri-Dutt. 2006. "Engendering Mining Communities Examining the Missing Gender Concerns in Coal Mining Displacement and Rehabilitation in India." Gender, Technology and Development. 10(3): 313-339. 
Ali, Saleem H., and Andrew S. Grewal. 2006. "The Ecology and Economy of Indigenous Resistance: Divergent Perspectives on Mining in New Caledonia.” The Contemporary Pacific 18(2): 361-392.

Alimonda, Hector. 2008. "Introducción”, en AA.VV. Gestión Ambiental y Conflicto Social en América Latina, Buenos Aires, CLACSO.

Almeida, Paul. 2003. "Opportunity Organizations and Threat-Induced Contention: Protest Waves in Authoritarian Settings.” American Journal of Sociology 109(2): $345-400$.

Almeida, Paul. 2014. Mobilizing Democracy: Globalization and Citizen Protest. Baltimore: Johns Hopkins University Press.

Almeida, Paul. 2016. Neoliberalismo y movimientos populares en C.A. El Salvador. UCA Editores.

Almeida, Paul D. 2018. “The Role of Threat in Collective Action.” In Wiley-Blackwell Companion to Social Movements, edited by David Snow, Sarah Soule, H. Kriesi, and Hanspeter McCammon. Oxford: Wiley-Blackwell. 2nd Ed.

Anaya, James. 2011. "Report of the Special Rapporteur on the Situation of Human Rights and Fundamental Freedoms of Indigenous People. Addendum: Observations on the Situation of the Rights of Indigenous People of Guatemala with Relation to the Extraction Projects, and Other Types of Projects, in Their Traditional Territories. UN General Assembly.

Andreucci, Diego, and Isabella Radhuber. 2015. "Limits to 'Counter-neoliberal' Reform: Mining Expansion and the Marginalisation of Post-extractivist Forces in Evo Morales's Bolivia.” Geoforum 84: 280-291. 
Andrews, Kenneth T., and Charles Seguin. 2015. "Group Threat and Policy Change: The Spatial Dynamics of Prohibition Politics, 1890-1919.” American Journal of Sociology 121(2): 475-510.

Andrews-Speed, Philip, Guo Ma, Bingiia Shao, and Chenglin Liao. 2005. "Economic Responses to the Closure of Small-scale Coal Mines in Chongqing China." Resources Policy 30(1): 39-54.

Anguelovski, Isabelle. 2011. "Understanding the Dynamics of Community Engagement of Corporations in Communities: The Iterative Relationship Between Dialogue Processes and Local Protest at the Tintaya Copper Mine in Peru." Society and Natural Resources 24(4): 384-399.

Arce, Moisés. 2010. "Parties and Social Protest in Latin America's Neoliberal Era." Party Politics 16(5): 669-686.

Arce, Moisés. 2014a. “'Base de Protestas Sociales del Perú Dataset.’ Columbia:

University of Missouri. http://web.missouri.edu/ arcem/.

Arce, Moisés. 2014b. Resource Extraction and Protest in Peru. Pittsburgh: University of Pittsburgh Press.

Arce, Moisés. 2015. "Resource Extraction, Political Fragmentation and Subnational Protest in Peru." In Social Protests and Democratic Responsiveness: Assessing Realities in Latin America and the Caribbean and the European Union. Hamburg: EU-LAC Foundation.

Arce, Moisés, and Michael Hendricks. Forthcoming. "Resource Wealth and Political Decentralization." Oxford Encyclopedia for Latin American Politics. 
Arce, Moisés, and Rebecca E. Miller. 2016. "Mineral Wealth and Protest in Sub-Saharan Africa." African Studies Review 59(3): 83-105.

Arce, Moisés, Rebecca E. Miller, Christopher F. Patane, and Marc S. Polizzi. 2018.

"Resource Wealth, Democracy, and Mobilisation." The Journal of Development Studies, 54 (6): 949-967.

Arce, Moisés, Marc Polizzi, and Bryce Reeder. N.D. "Resource Extraction and Protest Participation in Latin America.”

Arellano-Yanguas, Javier. 2008. “A Thoroughly Modern Resource Curse?: The New Natural Resource Policy Agenda and the Mining Revival in Peru.” Arellano-Yanguas, Javier. 2010. Local Politics, Conflict and Development in Peruvian Mining Regions (Unpublished doctoral dissertation). University of Sussex. Arellano-Yanguas, Javier. 2011. ¿Minería sin Fronteras?: Conflicto y Desarrollo en Regiones Mineras del Perú. Pontificia Universidad Católica del Perú. Arellano-Yanguas, Javier. 2014. "Religion and Resistance to Extraction in Rural Peru: Is the Catholic Church Following the People?" Latin American Research Review 49: 61-80.

Arsel, Murat, Barbara Hogenboom, and Lorenzo Pellegrini. 2016. "The Extractive Imperative and the Boom in Environmental Conflicts at the End of the Progressive Cycle in Latin America.” The Extractive Industries and Society 3(4): 880-887.

Aroca, Javier. 2008. Defendiendo Derechos y Promoviendo Cambios: El Estado, Las Empresas Extractivas y Las Comunidades Locales en el Peru. Vol. 3 OXFAM Internacional. 
Articulo 66. 2018. "Habitantes de Santo Domingo-Chontales rechazan nuevo proyecto de minería industrial.” Alianza Centro Americana Frente a la Mineria, January 16. http://acafremin.org/index.php?option=com_content\&view=article\&id=196:habit antes-de-santo-domingo-chontales-rechazan-nuevo-proyecto-de-mineriaindustrial \&catid=19\&Itemid=101\&lang=en.

Aubynn, Anthony. 2009. "Sustainable Solution or a Marriage of Inconvenience? The Coexistence of Large-scale Mining and Artisanal and Small-scale mining on the Abosso Goldfields Concession in Western Ghana." Resources Policy 34(1): 6470.

Avci, Duygu, and Elena Fernández-Salvador. 2016. “Territorial Dynamics and Local Resistance: Two Mining Conflicts in Ecuador Compared." The Extractive Industries and Society 3(4): 912-921.

Avc1, Duygy, Fikret Adaman, and Begüm Özkaynak. 2010. "Valuation Languages in Environmental Conflicts: How Stakeholders Oppose or Support Gold Mining at Mount Ida Turkey." Ecological Economics 70(2): 228-238.

Baker, Andy, Barry Ames, and Lucio R. Renno. 2006. "Social Context and Campaign Volatility in New Democracies: Networks and Neighborhoods in Brazil's 2002 Elections." American Journal of Political Science 50(2) 382-399.

Baker, Douglas C., and James N. McLelland. 2003. "Evaluation the Effectiveness of British Columbia's Environmental Assessment Process for First Nations' Participation in Mining Development.” Environmental Impact Assessment Review 23(5):581-603 
Ballard, Chris, and Glenn Banks. 2003. "Resource Wars: The Anthropology of Mining." Annual Review of Anthropology 32: 287-313.

Banco Central de Nicaragua. (2015). Anuario de Estadísticas Macroeconómicas (19602016): Sector Real, Empleo y Salarios, Sector Externo. Managua.

Banks, Britt. 2013. "Fostering Dialogue Across Stakeholders in Natural Resource Management in Natural Riches? Perspectives on Responsible Natural Resource Management in Conflict-Affected Countries." World Economic Forum.

Bandura, Albert. 1997. Self-efficacy: The Exercise of Control. New York: Freeman/Times Books/ Henry Holt \& Co.

Bandura, Albert, and Edwin A. Locke. 2003. "Negative Self-efficacy and Goal Effects Revisited.” Journal of Applied Psychology 88(1): 87-99.

Bandura, Albert. 2010. "Self-efficacy." In the Corsini Encyclopedia of Psychology. Hoboken, New Jersey: John Wiley \& Sons.

Barnes, Tiffany D., and Abby Córdova. 2016. "Making Space for Women: Explaining Citizen Support for Legislative Gender Quotas in Latin America." The Journal of Politics 78(3): 670-686.

Barrantes, Roxana. 2005. "Minería Desarrollo y Pobreza en el Perú: o de Cómo Todo Depende del Cristal con que Se Mire.” In: Te Quiero pero No: Minería, Desarrollo y Poblaciones Locales edited by Roxana Barrantes, Patricia, and Anahi Záratey. Instituto de Estudios Peruanos, Lima. Barton, B.D.

Barton, Brooke D. 2005. A Global/Local Approach to Conflict Resolution in the Mining Sector: The Case of the Tintaya Dialogue Table. Boston: Tufts University. 
Bebbington, Anthony. 2007. "Social Movements and the Politicization of Chronic Poverty." Development and Change 38: 793-818.

Bebbington, Anthony J. Denise H. Bebbington, Jeffrey Bury, Jeannet Lingan, Juan Pablo Muñoz, and Martin Scurrah. 2008. "Mining and Social movements: Struggles Over Livelihood and Rural Territorial Development in the Andes." World Development 36(12): 2888-2905.

Bebbington, Anthony. 2009. "Latin America: Contesting Extraction, Producing Geographies.” Singapore Journal of Tropical Geography 30 (1): 7-12.

Bebbington, Anthony, Denise H. Bebbington, and Jeffrey Bury. 2010. "Federating and Defending: Water, Territory and Extraction in the Andes." Out of the Mainstream: Water Rights, Politics and Identity: 307-327.

Bebbington, Anthony J., and Denise H. Bebbington. 2011. "An Andean Avatar: Postneoliberal and Neoliberal Strategies for Securing the Unobtainable. New Political Economy 16(1): 131-145.

Bebbington, Anthony. 2012a. "Social Conflict and Emergent Institutions. Hypotheses from Piura Peru.” In Extractive Industries, Social Conflict and Economic Development: Evidence from South America edited by Anthony Bebbington. London: Routledge.

Bebbington, Anthony. 2012b. "Underground Political Ecologies: The Second Annual Lecture of Cultural and Political Ecology Specialty Group of the Association of American Geographers." Geoforum 43: 1152-1162.

Bebbington, Anthony and Jeffrey Bury. 2013. Subterranean Struggles: New Dynamics of Mining, Oil, and Gas in Latin America. Austin: University of Texas Press. 
Beckford, James. 1985a. Cult Controversies: The Social Response to New Religious Movements. London: Tavistock Publications.

Beckford, James. 1985b. "The Insulation and Isolation of the Sociology of Religion." Sociological Analysis 46(4): 347-354.

Beckford, James. 1990. "The Sociology of Religion and Social Problems.” Sociological Analysis 51: 1-14.

Beckford, James. 2000. "Religious Movements and Globalization.” In Global Social Movements edited by Robin Cohen and Shirin M. Rai. London: Athlone Press.

Beckford, James. 2001. "Social Movements as Free-Floating Phenomena.” In The Blackwell Companion to Sociology of Religion edited by Richard K. Fenn. Malden, Massachusetts: Blackwell Publishing.

Bellinger, Paul T., Jr., and Moisés Arce. 2011. "Protest and Democracy in Latin America’s Market Era," Political Research Quarterly 64(3): 688-704.

Bengoechea, Juan A.S. 1966. "El contrato de ejecución de obra." Revista de Política Social 71.

Berryman, Phillip. 1984. The Religious Roots of Rebellion: Christians in Central American Revolutions. London: SCM Press.

Boas, Taylor C. 2005. "Television and Neopopulism in Latin America: Media Effects in Brazil and Peru." Latin American Research Review 40(2): 27-49.

Boelens, Rutgerd, David Getches, and Armando G. Gil. 2010. Out of the Mainstream: Water Rights, Politics and Identity. London, Washington, DC: Earthscan. 
Bond, Carol, and Phillip Kirsch. 2015. "Vulnerable Populations Affected by Mining: Predicting and Preventing Outbreaks of Physical Violence." The Extractive Industries and Society 2: 552-561.

Bond, Patrick. 2008. "Social Movements and Corporate Social Responsibility in South Africa." Development and Change 39: 1037-1052.

Boulding, Carew. 2014. NGOs, Political Protest, and Civil Society. New York: Cambridge University Press.

Bridge, Gavin. 2004. "Mapping the Bonanza: Geographies of Mining Investment in an Era of Neoliberal Reform." Professional Geographer 56(3): 406-421.

Broad, Robin and John Cavanagh. 2015. "Poorer Countries and the Environment: Friends or Foes?" World Development 72: 419-431.

Bullard, Robert D. 1990. Dumping in Dixie: Race, Class and Environmental Quality. Boulder, Colorado: Westview Press.

Bulmer-Thomas, Victor. 1987. The Political Economy of Central America since 1920. Cambridge: Cambridge University Press.

Burchardt, Hans-Jürgen, and Kristina Dietz. 2014. “(Neo-)extractivism—A New Challenge for Development Theory from Latin America." Third World Quarterly 35(3): 468-486.

Bury, Jeffrey. 2002. "Livelihoods, Mining and Peasant Protests in the Peruvian Andes." Journal of Latin American Geography 1(1): 1-19.

Bury, Jeffrey. 2005. "Mining Mountains: Neoliberalism, Land Tenure, Livelihoods, and the New Peruvian Mining Industry in Cajamarca." Environment and Planning 37(2): 221-239. 
Caballero-Anthony, Mely. 2013. "Community Engagement and Environmental Management in Natural riches? Perspectives on Responsible Natural Resource Management in Conflict-Affected Countries." World Economic Forum.

Cambra, Alvin A. 2016. "Philippines Mining Capitalism: The Changing Terrains of Struggle in the Neoliberal Mining Regime." ASEAS, Australian Journal of SouthEast Asian Studies 9(1): 71-88.

Caren, Neal, Sarah Gaby, and Catherine Herrold. 2017.“Economic Breakdown and Collective Action." Social Problems 64(1): 133-155.

Carstens, Johanna, and Gavin Hilson. 2009. "Mining, Grievance and Conflict in Rural Tanzania." International Development Planning Review 31: 301-326.

Casanova, Jose. 2001. "Civil Society and Religion: Retrospective Reflections on Catholicism and Prospective Reflections on Islam." Social Research 68(4): 10411080.

Cater, Tara, and Arn Keeling. 2013. “'That's Where Our Future Came From': Mining, Landscape, and Memory in Rankin Inlet.” Inuit Studies 37(2): 59-82.

Cederman, Lars-Erik, Kristian Skrede Gleditsch, and Halvard Buhaug. 2013. Inequality, Grievances, and Civil War. Cambridge University Press.

CELAM. 2007. V CELAM Declaration May 13, Section 9.8 "Care for the Environment." www.celam.org/MisionContinental/Documentos/Ingles.pdf (Accessed on February 20, 2019).

Centro Humboldt. 2015a. En Santo Domingo, la ciudadanía promueve la defensa de su Derecho Humano al AGUA. Managua, Nicaragua: IBIS. 
Centro Humboldt. 2015b. Rancho Grande Una herencia natural y productiva amenazada por la minería. Managua, Nicaragua: IBIS.

Centro Humboldt. 2015c. Valoración de Riesgos e Impactos Socio-Ambientales de la Minería Metálica en Nicaragua, 2013-2015. Managua, Nicaragua: IBIS.

Chacón, Karen, and Leonardo Merino. 2014. "Veinte años de conflictividad ambiental en Costa Rica (1994-2013)." Ponencia. Vigésimo Informe Estado de la Nación en Desarrollo Humano Sostenible 2013. San José, Costa Rica: PEN.

Cheng, Christine, and Dominik Zaum. 2013. "Corruption and the Role of Natural Resources in Postconflict Transitions." In Governance, Natural Resources and Post-Conflict Peace Building edited by Carl Bruch, Carroll Muffett, and Sandra Nichols. Routledge.

CIEL. 2010. Inter-American Commission on Human Rights on the Situation of Environmentalists in Mesoamerica.

Clammer, John, Sylvie Poirer, and Eric Schwimmer. 2004. Figured Worlds: Ontological Obstacles in Intercultural Relations. University of Toronto Press.

Clark, Christopher, Matthew Kotchen, and Michael Moore. 2003. "Internal and External Influences on Pro-Environmental Behavior: Participation in a Green Electricity Program." Journal of Environmental Psychology 23(3): 237-246.

Clearly, Edward, and Timothy Steigenga. 2004. Resurgent Voices: Indigenous Peoples, Political Mobilizations, and Religious Change. New Brunswick, New Jersey: Rutgers University Press. 
Cole, Luke, and Sheila Foster. 2001. From the Ground Up: Environmental Racism and the Rise of the Environmental Justice Movement. New York: New York University Press.

Conde, Marta. 2016. "Resistance to Mining. A Review." Ecological Economics 132: 8090.

Conde, Marta, and Giorgos Kallis. 2012. "The Global Uranium Rush and its Africa Frontier: Effects, Reactions and Social Movements in Namibia." Global Environmental Change 22: 596- 610.

Conde, Marta, and Philippe Le Billon. 2017. "Why Do Some Communities Resist Mining Projects While Others Do Not?” The Extractive Industries and Society 4: 681697.

Cook, Andrew J., Geoff Kerr, and Kevin Moore. 2002. “Attitudes and Intentions Towards Purchasing GM Food.” Journal of Economic Psychology 23(5): 557572.

Cordero, Ulate A. 2015. "El Movimiento Social Indígena en Térraba, Costa Rica: La Lucha Contra el Proyecto Diquís," Revista de Estudios Anti-Utilitaristas e Poscolonial, REALIS 5(2): 4-25.

Corning, Alexandra F., and Daniel J. Myers. 2002. "Individual Orientation Toward Engagement in Social Action." Political Psychology 23(4):703-729.

Costanza, Jennifer N. 2016. 'Mining Conflict and the Politics of Obtaining a Social License: Insight from Guatemala. World Development 79: 97-113.

Coumans, Catherine. 2004. “'Beware of Anthropologists': Conflict, Social Acceptability and Anthropological Brokerage in Mining. Working Paper. 
Cuffe, Sandra. 2015. “Nicaragua: Govt. to cancel B2Gold's El Pavón mining project due to environmental impacts after years of community protests." Business and Human Rights Resource Center, October 19. https://www.businesshumanrights.org/en/nicaragua-govt-to-cancel-b2golds-el-pav\%C3\%B3n-miningproject-due-to-environmental-impacts-after-years-of-community-protests

De Groot, Judith I.M., and Linda Steg. 2010. "Relationships Between Value Orientations, Self-Determined Motivational Types and Proenvironmental Behavioural Intentions." Journal of Environmental Psychology 30(4): 368-378.

De la Cadena, Marisol. 2015. Earth Beings: Ecologies of Practice Across Andean Worlds. Durham, North Carolina: Duke University Press.

DeEchave, José. 2005. “Los Procesos de Dialogo y La Administración de Conflictos en Territorios de Comunidades: El Case de la Mina de Tintaya en el Perú.” CooperAccion.

DeEchave, José. 2011. "La Minería Peruana y Los Escenarios de Transición." Transiciones: 61 .

DeEchave, José, Alejandro Diez, Bruno Revesz, Ludwig Huber, Martín Tanaka, and Xavier Ricard Lanata. 2009. Minería y Conflicto Social. Instituto de Estudios Peruanos.

Defensoría del Pueblo de Perú. 2012. "Violencia y Los Conflictos Sociales." Informe Defensorial 156. Gobierno del Perú, Lima, Perú.

della Porta, Donatella, and Mario Diani. 2006. Social Movements: An Introduction. Malden, MA: Blackwell Publishing. 
Díaz Pinzón, Florencio. 2013.“El Movimiento Ambiental Panameño frente al Neoliberalismo: Estudio de Caso Cerro Colorado contra la Minería a Cielo Abierto, Referenciado a la Región Centroamericana, Ano 1989-2010.” Master's thesis, FLACSO, Costa Rica.

Diener, Laura Michelle. 2016. "Meet the Jeans-Wearing, Nature Loving Nuns Who Helped Stop a Kentucky Popeline.” Yes Magazine, (April 7). www.yesmagazine.org/people-power/meet-the-jeans-wearing-nature-loving-nunswho-helped-stop-a-kentucy-pipeline-20160407 (Accessed on January 7, 2019).

Dirección General de Energías y Minas. 2017. Estadísticas Catastrales Mineras. Managua, Nicaragua. www.mem.gob.ni.

Dirección General de Energías y Minas. 2014. 2014. Estadísticas. Managua, Nicaragua. www.mem.gob.ni.

Dodson, Kyle. 2016. "Economic Threat and Protest Behavior in Comparative Perspective." Sociological Perspectives 59(3): 873-891.

Dodson, Michael. 1979. "Liberation Theology and Christian Radicalism in Contemporary Latin America.” Journal of Latin American Studies 11(1): 203-222.

Dougherty, Michael L. 2011. "The Global Gold Mining Industry, Junior Firms, and Civil Society Resistance in Guatemala." Bulletin of Latin American Research 30(4): 403-418.

Dougherty, Michael L. 2018. "How Does Development Mean? Attitudes toward Mining and the Social Meaning of Development in Guatemala." Latin American Perspectives: $1-21$. 
Dougherty, Michael L., and Tricia D. Olsen. 2013. “Taking Terrain Literally: Grounding Local Adaptation to Corporate Social Responsibility in the Extractive Industries." Journal of Business Ethnics 119(3): 423-434.

Dougherty, Michael L., and Tricia D. Olsen. 2014. "They Have Good Devices: Trust, Mining, and the Microsociology of Environmental Decision-making.” Journal of Cleaner Production 84, 183-192.

Downing, Theodore E. 2002. “Avoiding New poverty: Mining-induced Displacement and Resettlement.” Mining, Minerals and Sustainable Development 52.

Duthie, Kaitlyn. 2012. “Local Votes and Mining in the Americas.” Mining Watch. http:// miningwatch.ca/blog/2012/5/14/local-votes-and-mining-americas (Accessed on February 20, 2019).

Economic Commission for Latin America and the Caribbean. 2013. Natural Resources: Status and Trends Toward a Regional Development Agenda in Latin America and the Caribbean. Santiago, Chile: ECLAC.

Edwards, Sebastián. 1995. Crisis and Reform in Latin America: From Despair to Hope. New York: World Bank/Oxford University Press.

Engels, Bettina, and Dietz, Kristina. 2017. Contested Extractivism. Society and the State: Struggles Over Mining and Land. Springer.

Einwohner, Rachel L., and Thomas Maher. 2011. "Threat Assessments and CollectiveAction Emergence: Death Camp and Ghetto Resistance During the Holocaust.” Mobilization 16(2): 127-146.

Eisinger, Peter K. 1973. "The Conditions of Protest Behavior in American Cities." American Political Science Review 67(01):11-28 
Eisenstadt, Todd A., and Karleen Jones West. 2017. "Public Opinion, Vulnerability, and Living with Extraction on Ecuador's Oil Frontier: Where the Debate Between Development and Environmentalism Gets Personal." Comparative Politics 49(2): 231-251.

Emel, Jody, Madoshi Makene, and Esther Wangari. 2012. "Problems with Reporting and Evaluating Mining Industry Community Development Projects: A Case Study from Tanzania." Sustainability 4(2): 257-277.

Engels, Bettina, and Kristina Dietz. 2017. Contested Extractivism. Society and the State: Struggles Over Mining and Land. Springer.

Enríquez, Laura. 2010. Reactions to the Market: Small Farmers in the Economic Reshaping of Nicaragua, Cuba, Russia, and China. University Park, PA: Pennsylvania State University Press.

Erb, Maribeth. 2016. "Mining and the Conflict Over Values in Nursa Tenggara Timur Province, Eastern Indonesia." The Extractive Industries and Society 3(2): 370382.

ERIC. 2016. Impacto socioambiental de la Minería en la Región Noroccidental de Honduras, a la luz de tres estudios de casos: Montaña de Bataderos, Nueva Esperanza (Atlántida) y Locomapa (Yoro). Honduras, Autor.

Escobar, Arturo. 1995. Encountering Development: The Making and Unmaking of the Third World. Princeton, New Jersey: Princeton University Press.

Escobar, Arturo. 2001. "Culture Sits in Places: Reflections on Globalism and Subaltern Strategies of Localization." Political Geography 20: 139-174. 
Estrada, Mica, Anna Woodcock, Paul R. Hernandez, and P. Wesley Schultz. 2011.

“Toward a Model of Social Influence that Explains Minority Student Integration into the Scientific Community. Journal of Educational Psychology 103(1): 206228.

Estrada, Mica, P. Wesley Schultz, Nilmini Silva-Send, and Michael A. Boudrias. 2017. "The Role of Social Influences on Pro-Environment Behaviors in the San Diego Region.” Journal of Urban Health 94: 170-179.

Evans, Sterling. 1999. The Green Republic: A Conservation History of Costa Rica. Austin: University of Texas Press.

Exner, Andreas Christian Lauk, and Werner Zittel. 2015. Sold Futures? The Global Availability of Metals and Economic Growth at the Peripheries: Distribution and Regulation in a Degrowth Perspective." Antipode 47(2): 342-359.

Filer, Colin. 1996. "Participation, Governance and Social Impact: The Planning of the Lihir Gold Mine.” Working Paper.

Firpo Porto, Marcelo, Tania Pacheco, and Jean Pierre Leroy. 2013. Injustiça Ambiental e Saúde no Brasil: o Mapa de Conflitos. Fiocruz.

Fisher, Eleanor. 2007. “Occupying the Margins: Labour Integration and Social Exclusion in Artisanal Mining in Tanzania.” Development and Change 38(4): 735-760.

Fox, Samantha. 2015. “History, Violence, and the Emergence of Guatemala's Mining Sector.” Environmental Sociology 1(3): 152-165.

Franks, Daniel M., Rachel Davis, Anthony J. Bebbington, Saleem H. Ali, Deanna Kemp, and Martin Scurrah. 2014. "Conflict Translates Environmental and Social Risk into Business Costs.” Proc. Natl. Acad. Sci. U.S.A 111(21): 7576-7581. 
Fraser, Nancy. 1998. "Heterosexism, Misrecognition and Capitalism: A Response to Judith Butler.” New Left Review 228.

Fulmer, Amanda, Angelina Godoy, and Philip Neff. 2008. "Indigenous Rights, Resistance, and the Law: Lessons from a Guatemalan Mine.” Latin American Politics and Society 50(4): 91-121.

Fundacion Nicaragüense para el Desarrollo Económico y Social (FUNIDES). 2014. "La minería en Nicaragua: importancia, desafíos y oportunidades." PowerPoint presentation by Juan Sebastián Chamorro, Director Ejecutivo, at Congreso Internacional de Minería, Managua, Nicaragua, August 12-14. www.funides.com/documentos/eventos/2014/agosto/foro_mineria_12_agosto_20 14.pdf. (Accessed on August 16, 2014).

Gamu, Jonathan, Philippe Le Billon, and Samuel Spiegel. 2015. "Extractive Industries and Poverty: A Review of Recent Findings and Linkage Mechanisms." The Extractive Industries and Society 2(1): 162-176.

Geenen Sara. 2014. "Dispossesion, Discplacement and Resistance: Artisanal Miners in a Gold Concession in South-Kivu, Democratic Republic of Congo." Resources Policy 40: 90-99.

Gianotten, Vera, Ton De Wit, and Rodrigo Montoya. 1987. Nicaragua: cuestión agraria y participación campesina. Centro de Estudios y Promocion del Desarrollo, Lima (Peru).

Gil, Vladimir. 2009. Aterrizaje Minero: Cultura, Conflicto, Negociaciones y Lecciones para el Desarrollo desde la Minería en Ancash, Peru. Instituto de Estudios Peruanos. 
Gilberthorpe, Emma, and Glenn Adrian Banks. 2012. "Development on Whose Terms?: CSR Discourse and Social Realities in Papua New Guinea's Extractive Industries Sector.” Resources Policy 37(2): 185-193.

Global Witness. 2015. “¿Cuántos más? El medio ambiente mortal de 2014. Intimidación $\mathrm{y}$ asesinato de activistas ambientales y de la tierra, con Honduras en primer plano."

Göckeritz, Suzanne, P. Wesley Schultz, Tania Rendón, Robert B. Cialdini, Noah J. Goldstein, and Vladas Griskevicius. 2010. "Descriptive Normative Beliefs and Conservation Behavior: The Moderating Roles of Personal Involvement and Injunctive Normative Beliefs." European Journal of Social Psychology 40(3): $514-523$.

Goldstone, Jack, and Charles Tilly. 2001. "Threat (and Opportunity): Popular Action and State Response in the Dynamic of Contentious Action." In Silence and Voice in the Study of Contentious Politics, edited by Ronald R. Aminzade, Jack Goldstone, and Doug McAdam. Cambridge: Cambridge University Press.

González Oliva, Xenia. 2015. “La Minería en el Limbo,” Diario de Hoy (18 December). Goodland, Robert. 2004. "Free, Prior and Informed Consent and the World Bank Group." Sustainable Development Law and Policy 4: 66-74.

Goodwin, Jeff, and James. M. Jasper, eds. 2003. The Social Movements Reader: Cases and Concepts: Oxford: Blackwell Publishers.

Gooren, Henri. 2002. "Catholic and Non-Catholic Theologies of Liberation: Poverty, Self-Improvement, and Ethics Among Small-Scale Entrepreneurs in Guatemala City." Journal for the Scientific Study of Religion 41(1): 29-45. 
Gordillo, Gaston. 2014. Rubble: The Afterlife of Destruction. Durham, North Carolina: Duke University Press.

Guha, Ramachandra, and Joan Martinez-Alier. 1997. Varieties of Environmentalism: Essays North and South. Routledge.

Gurney, Joan Neff, and Kathleen J Tierney. 1982. "Relative Deprivation and Social Movements: A Critical Look at Twenty Years of Theory and Research.” The Sociological Quarterly 23(1): 33-47.

Gurr, Ted Robert. 1970. Why Men Rebel. Princeton, New Jersey: Princeton University Press.

Haarstad, Håvard, and Arnt Fløysand. 2007. "Globalization and the Power of Rescaled Narratives: A Case of Opposition to Mining in Tambogrande, Peru." Political Geography 26: 289-308.

Hall, Ruth, Marc Edelman, Saturnino M. Borras Jr., Ian Scoones, Ben White, and Wendy Wolford. 2015. "Resistance, Acquiescence or Incorporation? An Introduction to Land Grabbing and Political Reactions 'From Below." The Journal of Peasant Studies 42(3-4): 467-488.

Hannigan, John A. "Social Movement Theory and the Sociology of Religion: Towards a New Synthesis.” Sociological Analysis 52(4): 311-331.

Harner, John. 2001. "Place Identity and Copper Mining in Sonora, Mexico." Annals of the Association of American Geographers 91(4): 660-680.

Haslam, Paul Alexander, and Nasser Ary Tanimoune. 2016. "The Determinants of Social Conflict in the Latin American Mining Sector: New evidence with Quantitative Data." World Development 78(16): 401-419. 
Haynes, Jeffrey. 1995. "Religion, Fundamentalism and Ethnicity: A Global Perspective." National Research Institute for Social Development. Geneva, Switzerland.

Helwege, Ann. 2015. "Challenges with Resolving Mining Conflicts in Latin America." The Extractive Industries and Society 2(1): 73-84.

Herbertson, Kirk, Athena R. Ballesteros, Robert Goodland, and Isabel Munilla. 2009.

"Breaking Ground: Engaging Communities in Extractive and Infrastructure Projects." World Resources Institute. Washington D.C.

Hilson, Gavin. 2002. An Overview of Land Use Conflicts in Mining Communities." Land Use Policy 19 1): 65-73.

Hilson, Gavin, and Clive Potter. 2005. "Structural Adjustiment and Subsistence Industry: Artisanal Gold Mining in Ghana." Development and Change 36(1): 103-131.

Hilson, Gavin, and James McQuilken. 2015. "Four Decades of Support for Artisanal and Small-scale mining in Sub-Saharan Africa: A Critical Review.” The Extractive Industries and Society 1(1): 104-118.

Hilson, Gavin, and Natalia Yakovleva. 2007. "Strained Relations: A Critical Analysis of the Mining Conflict in Prestea, Ghana." Political Geography 26: 98-119.

Himley, Matthew. 2013. "Regularizing Extraction in Andean Peru: Mining and Social Mobilization in an Age of Corporate Social Responsibility." Antipode 45: 394416.

Hines, Jody, Harold R. Hungerford, and Audrey N. Tomera. 1987. "Analysis and Synthesis of Research on Responsible Environmental Behavior: A MetaAnalysis." Journal of Environmental Education 18(2): 1-8. 
Holden, William N., and R. Daniel Jacobson. 2009. "Ecclesial Opposition to Nonferrous Mining in Guatemala: Neoliberalism Meets the Church of the Poor in a Shattered Society." Canadian Geographer 53(2): 145-164.

Hollander, Jocelyn A., and Rachel L. Einwohner. 2004. “Conceptualizing Resistance. Sociological Forum 19(4): 533-554.

Horowitz, Leah S. 2010. “'Twenty Years is Yesterday': Science, Multinational Mining, and the Political Ecology of Trust in New Caledonia." Geoforum 41(4): 617-626.

Horowitz, Leah. 2012. "Translation Alignment: Actor-Network Theory Resistance, and the Power Dynamics of Alliance in New Caledonia." Antipode 44: 806-827.

Huckfeldt, Robert, Paul Johnson, and John Sprague. 2004. Political Disagreement: The Survival of Diverse Opinions within Communication Networks. Cambridge University Press.

Inclán, María de la Luz. 2009."Repressive Threats, Procedural Concessions, and the Zapatista Cycle of Protests 1994-2003." Journal of Conflict Resolution 53(5): 794-819.

Instituto Nacional de Información de Desarrollo-INIDE de Nicaragua (INIDES). 2005. Censo 2005.

Instituto de Estudios Estratégicos y Políticas Públicas (IEEPP) y Centro Humboldt. 2017. La Minería Industrial en Nicaragua. Una mirada desde la óptica fiscal. Managua, Nicaragua.

Jahncke Benavente, Javier, and Rocio. Meza. 2010. "Derecho a la Participacion y la Consulta Previa en Latinoamerica." Fedepaz Muqui Miserer CIDSE. Lima, Peru. 
Jasper, James. 1997. The Art of Moral Protest: Culture, Biography, and Creativity in Social Movements. Chicago: University of Chicago Press.

Jenkins, J. Craig. 1983. "Resource Mobilization Theory and the Study of Social Movements." Annual Review of Sociology: 527-553.

Jenkins, Heledd. 2004. "Corporate Social Responsibility and the Mining Industry: Conflicts and Constructs." Corporate Social Responsibility and Environmental Management 11(1): 23-24.

Jenkins, Heledd, and Natalia Yakovleva. 2006. "Corporate Social Responsibility in the Mining Industry: Exploring Trends in Social and Environmental Disclosure.” Journal of Cleaner Production 14: 271-284.

Johnson, Erik W., and Scott Frickel. 2011. "Ecological Threat and the Founding of U.S. National Environmental Movement Organizations, 1962-1998." Social Problems 58(3): 305-329.

Kaiser, Florian, Nina Roczen, and Franz X. Bogner. 2008. “Competence Formation in Environmental Education: Advancing Ecology-Specific Rather than General Abilities." Working Paper.

Kaiser, Florian, and Urhs Fuhrer. 2003. "Ecological Behavior's Dependency on Different Forms of Knowledge.” Applied Psychology 52(4): 598-613.

Keck, Margaret, and Katherine Sikkink 1998. Activists Beyond Borders. Ithaca, New York: Cornell University Press.

Kelman, Herbert C. 1956. "Compliance, Identification, and Internalization: A Theoretical and Experimental Approach to the Study of Social Influence." The Journal of Conflict Resolution 2(1): 51-60. 
Kelman, Herbert C. 1958. "Compliance, Identification, and Internalization: Three Processes of Attitude Change.” The Journal of Conflict Resolution 2(1): 51-60.

Kelman, Herbert C. 2006. "Interests, Relationships, Identities: Three Central Issues for Individuals and Groups in Negotiating Their Social Environment." Annual Review of Psychology 57: 1-26.

Kelman, Herbert C., and V. Lee Hamilton. 1989. Crimes of Obedience. New Haven, Connecticut: Yale University Press.

Kemp, Deanna, and John Owen. 2013. "Community Relations and Mining: Core to Business but Not 'Core Business.” Resources Policy 38(1): 523-531.

Kemp, Deanna, John Owen, Nora Gotzmann, and Carol J. Bond. 2011. “Just Relations and Company - Community Conflict in Mining." Journal of Business Ethics 101(1): 93-109.

Kirmani, Nada. 2008. "The Relationships between Social Movements and Religion in Processes of Social Change: A Preliminary Literature Review." Religions and Development Research Programme Working Paper 23.

Kirsch, Stuart. 2001. "Changing Views of Place and Time Along the Ok Tedi." In From Myth to Minerals: Mining and Indigenous Lifeworlds in Australia and Papua New Guinea edited by James Weiner and Alan Rumsey. Bathurst: Crawford Press.

Kirsch, Stuart. 2007. "Indigenous Movements and Risks of Counterglobalization: Tracking the Campaign Against Papua New Guinea's OK Tedi Mine.” American Ethnologist 34(2): 303-321. 
Kirsch, Stuart. 2014. Mining Capitalism: The Relationship between Corporations and their Critics. University of California Press.

Klandermans, Bert. 1984. "Mobilization and Participation: Social-Psychological Expansions of Resource Mobilization Theory." American Sociological Review 49(5):583-600.

Kohl, Benjamin, and Linda Farthing. 2012. "Material Constraints to Popular Imaginaries: The Extractive Economy and Resource Nationalism in Bolivia." Political Geography 31: 225-235.

Kolstad, Ivar, and Tina Soreide. 2009. "Corruption in Natural Resource Management: Implications for Policy Makers.” Resources Policy 34(4): 214-226.

Kuttschreuter, Margot. 2006. "Psychological Determinants of Reactions to Food Risk Messages." Risk Analysis 26(4): 1045-1057.

Labda, Amani. 2011. Joint Evaluation of Conflict Prevention and Peace Building in the Democratic Republic of Congo. Belgium: Channel Research.

Lange, Siri. 2011. "Gold and Governance: Legal Injustices and Lost Opportunities in Tanzania." African Affairs 110(439): 233-253.

Laplante, J.P., and Catherine Nolin. 2014. "Consultas and Socially Responsible Investing in Guatemala: A Case Study Examining Maya Perspectives on the Indigenous Right to Free, Prior, and Informed Consent. Society \& Natural Resources 27(3): 231-248.

Larsen, Soren C. 2004. "Place Identity in Resource-Dependent Area of Northern British Columbia. Annals of the Association of American Geographers 94(4): 944-960. 
Lawson, Chappel, and James A. McCann. 2005. “Television News, Mexico’s 2000 elections and Media Effects in Emerging Democracies." British Journal of Political Science 35(1): 1-30.

Lay, Jann, Rainer Thiele, and Manfred Wiebelt. 2008. "Resource Booms, Inequality and Poverty: The Case of Gas in Bolivia." Review of Income and Wealth 54(3): 407437.

Lazenby, Henry. 2014. "Nicaragua an attractive mining destination, says 'open for business," Mining Weekly Online, March 11. http://www.miningweekly.com/article/nicaragua-an-attractive-mining-destinationsays-open-forbusiness-2014-03-11, March 6, 2016.

Le Billon, Philippe. 2011. "Extractive Sectors and Illicit Financial Flows: What Role for Revenue Governance Initiatives?" CMII/U4 13.

Le Billon, Philippe. 2014. "Natural Resources and Corruption in Post-War Transitions: Matters of Trust." Third World Quarterly 35(5): 770-786.

Le Billon Philippe, Jonathan Gamu, and Marta Conde. 2016. "Volatile Commodities: A Review of Conflicts and Security Issues Related to Extractive Sectors.” Knowledge Synthesis Report.

Le Billon, Philippe, and Melanie Sommerville. 2016. "Landing Capital and Assembling 'Investable Land' in the Extractive and Agricultural sectors. Geoforum.

Levine, Daniel H. 1988. “Assessing the Impacts of Liberation Theology in Latin America." Review of Politics 50(2): 241-263.

Levine, Daniel H., and Scott Mainwaring. 1989. "Religion and Popular Protest in Latin America: Contrasting Experiences." In Power and Popular Protest: Latin 
American Social Movements edited by Susan Eckstein, Manuel Antonio, and Garretón Merino. University of California Press.

Levitsky, Steven, James Loxton, Brandon Van Dyck, and Jorge I. Domínguez. 2016. Challenges of Party-Building in Latin America. Cambridge University Press. Li, Fabiana. 2015. Unearthing Conflict: Corporate Mining, Activism, and Expertise in Peru. Durham, North Carolina: Duke University Press.

Li, Tania M. 2000. “Articulating Indigenous Identity in Indonesia: Resource Politics and the Tribal Slot. Comparative Studies in Society and History 42(1): 149-179.

Liffman, Paul. 1998. "Indigenous Territorialities in Mexico and Colombia. Cultural Environments and Development Debates, Latin America.” Regional Worlds/Territoriality: 1-35.

López, Petronilo, and Elorgio Dávila. 2014. "We're Going to Defend Our Paradise Against Mining." Envío. http://www.envio.org.ni/articulo/4931 (Accessed on January 20, 2019).

Macintyre, Martha, and Simon Foale. 2004. "Politicized Ecology: Local Responses to Mining in Papua New Guinea." Oceania 74(3): 231-251.

Martin, Deborah G., and Joseph Pierce. 2013. Reconceptualizing Resistance: Residuals of the State and Democratic Radical Pluralism.” Antipode 45(1): 61-79.

Martinez-Alier, Joan. 2003. The Environmentalism of the Poor: A Study of Ecological Conflicts and Valuation. Edward Elgar Publishing.

Martinez Alier, Joan, Isabelle Anguelovski, Patrick Bond, Daniela Del Bene, Federico Demaria, Julien-Francois Gerber, Lucie Greyl, Willi Haas, Hali Healy, Victoria Marín-Burgos, Godwin Ojo, Marcela Firpo Porto, Leida Rijnhout, Beatriz 
Rodríguez-Labajos, Joachim Spangenberg, Leah Temper, Rikard Warlenius, and Ivonne Yánez. 2014. "Between Activism and Science: Grassroots Concepts for Sustainability Coined by Environmental Justice Organizations. Journal of Political Ecology 21: 19-60.

Maher, Thomas V. 2010. “Threat, Resistance, and Mobilization: The Cases of Auschwitz, Sobibór, and Treblinka.” American Sociological Review 75(2): 252272.

Mähler, Annegret, and Jan H. Pierskalla. 2015. "Indigenous Identity, Natural Resources, and Contentious Politics in Bolivia: A Disaggregated Conflict Analysis, 20002011." Comparative Political Studies 48(3): 301-332.

Martin, Andrew, and Marc Dixon. 2010. "Changing to Win? Resistance, Threat and the Role of Unions in Strikes, 1984-2002." American Journal of Sociology 116: 93129.

Martin, Isaac. 2013. Rich People's Movements: Grassroots Campaigns to Untax the One Percent. Oxford: Oxford University Press.

Martin, Joanne, Philip Brickman, and Alan Murray. 1983. "Moral Outrage and Pragmatism: Explanations for Collective Action.” Journal of Experimental Social Psychology (20):484-496.

McAdam, Doug. 1983. "Tactical innovation and the pace of insurgency." American Sociological Review: 735-754.

McAdam, Doug, John D. McCarthy, and Mayer N. Zald. 1996. Comparative Perspectives on Social Movements: Political Opportunities, Mobilizing Structures, and Cultural Framings. Cambridge University Press. 
McAdam, Doug, Sidney Tarrow, and Charles Tilly. 2001. Dynamics of Contention. Cambridge University Press.

McCarthy, John D., and Mayer Zald. 1973. The Trend of Social Movements in America: Professionalization and Resource Mobilization. Morristown, NJ: General Learning Press.

McCarthy, John D., and Mayer Zald. 1977. "Resource Mobilization and Social Movements: A Partial Theory.” American Journal of Sociology 82(6):1212-1241. McCarthy, John D., and Mayer Zald. 2002. "The Enduring Vitality of the Resource Mobilization Theory of Social Movements.” In Handbook of Sociological Theory, ed. Jonathan H. Turner. New York: Kluwer Academic/Plenum Publishers: 533565.

McDonald, Sharyn, and Suzanne Young. 2012. "Cross-sector Collaboration Shaping Corporate Social Responsibility Best Practice Within the Mining Industry." Journal of Cleaner Production 37: 54-67.

McGee, Brant. 2009. “The Community Referendum: Participatory Democracy and the Right to Free Prior and Informed Consent to Development.” Berkeley Journal of International Law 27: 570-635.

McLaughlin, Barry. 1969. Studies in Social Movements: A Social Psychological Perspective. New York: Free Press.

McNeish, John A. 2012. "More than Beads and Feathers: Resource Extraction and the Indigenous Challenge in Latin America.” In New Political Spaces in Latin American Natural Resource Governance edited by Håvard Haarstad. Palgrave Macmillan. 
Meinhold, Jana L., and Amy J. Malkus. 2005. “Adolescent Environmental Behaviors:

Can Knowledge, Attitudes, and Self-Efficacy Make a Difference?” Environmental Behavior 37(4): 511-532.

Meyer, David S. 2004. "Protest and Political Opportunities." Annual Review of Sociology 30: 125-45.

Milfont, Taciano. 2012. “The Interplay Between Knowledge, Perceived Efficacy, and Concern About Global Warming and Climate Change: A One-Year Longitudinal Study.” Risk Analysis 32(6): 1003-1020.

Middeldorp, Nick, Carlos Morales, and Gemma van der Haar. 2016. "Social Mobilisation and Violence at the Mining Frontier: The Case of Honduras." The Extractive Industries and Society 3(4): 930-938.

Mitchell, Michael. 2012. Interpreting and Visualizing Regression Models Using Stata. College Station, TX: Stata Press.

Moffat, Kieren, and Airong Zhang. 2014. "The Paths to Social License to Operate: An Integrative Model Explaining Community Acceptance of Mining.” Resources Policy 39: 61-70.

Montes, Segundo. 1988. "Levantamientos Campesinos en El Salvador." Realidad Económico-Social 1(1).

Mora, María de Jesús, Alejandro Zermeño, Rodolfo Rodríguez, and Paul Almeida. 2017. “Exclusión y Movimientos Sociales en los Estados Unidos.” In Movimientos Sociales en América Latina: Perspectivas, Tendencias y Casos, edited by Paul Almeida and Allen Cordero, 641-669, Buenos Aires: CLACSO. 
Moroz, Peter W., Bob Kayseas, and Robert B. Anderson. 2014. "Using Strategic Alliances to Facilitate Community-Based New Venture Creation.” International Journal of Entrepreneurship and Small Business 22(1): 36-49.

Moseley, Mason Wallace. 2015. "Contentious Engagement: Understanding Protest Participation in Latin American Democracies." Journal of Politics in Latin America 7(3): 3-48.

Moseley, Mason Wallace, and Daniel Moreno. 2010. The Normalization of Protest in Latin America.” Americas Barometer Insights Series, 42. https://www.vaderbilt.edu/lapop/insights/Insights/_Compilation_Volume_II_2010 -2011_V4_W_08.04.16.pdf (Accessed on January 8, 2019).

Mueller, Carol M. 1992. “Building Social Movement Theory.” Frontiers in Social Movement Theory.

Muradian, Roldan, Joan Martinez-Alier, and Humberto Correa. 2003. "International Capital Versus Local Population: The Environmental Conflict of the Tambogrande Mining Project, Peru." Society \& Natural Resources 16(9): 775792.

Muradian, Roldan, Mauricio Folchi, and Joan Martinez-Alier. 2004. “'Remoteness' and Environmental Conflicts: Some Insights from The Political Ecology and Economic Geography of Copper.” International Journal of Sustainable Development 7(3): 321-339.

Newell, Peter. 2005. "Citizenship, Accountability and Community: The Limits of the CSR Agenda.” International Affairs: 81(3): 541-557. 
Newson, Linda. 1987. Indian Survival in Colonial Nicaragua. Norman: University of Oklahoma Press.

Nolan, Jessica M., Wesley Schultz, Robert B. Cialdini, Noah J. Goldstein, and Vladas Griskevicus. 2008. "Normative Social Influences is Underddetected." Personality and Social Psychology Bulletin 34(7): 913-923.

Norris, Pippa, Stefaan Walgrave, and Peter Van Aelst. 2005. "Who Demonstrates? Antistate Rebels, Conventional Participants, or Everyone?" Comparative Politics 37(2): 189-205.

O’Faircheallaigh, Ciaran. 2008. "Negotiating Cultural Heritage? Aboriginal-Mining Company Agreements in Australia." Development and Change 39(1): 25-51. O’Faircheallaigh, Ciaran. 2013. "Community Development Agreements in the Mining Industry: An Emerging Global Phenomenon." Community Development 44(2): 222-238.

O'Faircheallaighm Ciaran, and Saleem Ali. 2008. Earth Matters: Indigenous Peoples, the Extractive Industries, and Corporate Social Responsibility. Sheffield: Greenleaf Publishing.

O’Faircheallaigh, Ciaran, and Tony Corbett. 2005. "Indigenous Participation in Environmental Management of Mining Projects: The Role of Negotiated Agreements.” Environmental Politics 14(5): 629-647.

OCMAL. 2014. Conflictos Mineros en América Latina. Extracción, Saqueo y Agresión. Estado de Situación en 2014.

Olson, Mancur. 1971. The Logic of Collective Action: Public Goods and the Theory of Groups. Cambridge, MA: Harvard University Press. 
Opp, Karl-Dieter. 1988. "Grievances and Participation in Social Movements.” American Sociological Review 53(6): 853-864.

Opp, Karl-Dieter. 2009. Theories of Political Protest and Social Movements: A Multidisciplinary Introduction, Critique, and Synthesis. Routledge.

Ortiz, Isabel, Sara Burke, Mohamed Berrada, Hernán Cortés. 2013. “World Protests 2006-2013.” Working Paper, New York: Initiative for Policy Dialogue and Friedrich-Ebert-Stiftung.

Owen, John, and Deanna Kemp. 2013. "Social License and Mining: A Critical Perspective.” Resources Policy 38(1): 29-35.

Owen, John, and Deanna Kemp. 2014. “'Free Prior and Informed Consent', Social Complexity and the Mining Industry: Establishing a Knowledge Base.” Resources Policy 41, 91- 100.

Owen, John, and Deanna Kemp. 2015. "Mining-induced Displacement and Resettlement: A Critical Appraisal.” Journal of Cleaner Production 87(15): 478-488.

Oxford Poverty and Human Development Initiative (OPHI). 2011. Nicaragua: Country Briefing. Department of International Development, University of Oxford County. www.ophi.org.uk (Accessed March 28, 2019).

Özen, Hayrive, and Şükrü Özen. 2011. "Interactions in and Between Strategic Action Fields: A Comparative Analysis of Two Environmental Conflicts in Gold-mining Fields in Turkey." Organization \& Environment 24: 343-363.

Özen, Hayrive, and Şükrü Özen. 2017. "What Makes Locals Protesters? A Discursive Analysis of Two Cases in Gold-mining Industry in Turkey.” World Development 90: 256-268. 
Özkaynak, Begüm, Beatriz Rodríguez-Labajos, and Cem İskender Aydın. 2015. Towards Environmental Justice Success in Mining Resistances: An Empirical Investigation. EJOLT report 14 (April).

Parajuli, Pramod. 1996. "Ecological Ethnicity in the Making: Developmentalist Hegemonies and Emergent Identities in India." Identities 3(1): 15-29.

Peña, Milagros. 1994. "Liberation Theology in Peru: An Analysis of the Role of Intellectuals in Social Movements." Journal for the Scientific Study of Religion 33(1): 34-45.

Penman, Madeleine. 2016. “Ambivalent Company Attitudes and How They Shape Conflict: Mining Conflicts in Mexico's Ejidos.” The Extractive Industries and Society 3(3): 754-761.

Pérez Rincon, Mario Alejandro. (2015). “Conflictos Ambientales en Colombia: Actores Generadores y Mecanismos de Resistencia Comunitaria.” Ecológica Política 48. Pérez Soza, Nomel. 2013. "In Six Years the Gold Will All Be Gone.” Envío. http://www.envio.org.ni/articulo/4678 (Accessed November 15, 2018).

Perreault, Tom. 2013. "Dispossession by Accumulation? Mining, Water and the Nature of Enclosure on the Bolivian Altiplano. Antipode 45(5): 1050-1069.

Peterson, Nicolas. 2015. "Place Personhood and Marginalization: Ontology and Community in Remote Desert Australia.” Anthropologica 57(2): 491-500.

Peterson St-Laurent, Guillaume, and Philippe Le Billon. 2015. "Staking Claims and Shaking Hands: Impact and Benefit Agreements as a Technology of Government in the Mining Sector." The Extractive Industries and Society 2(3): 590-602. 
Pew Research Center. 2014. "Religion in Latin America: Widespread Change in an Historically Catholic Region.” https://www.pewforum.org/2014/11/13/religion-inlatin-america/ (Accessed on February 20, 2019).

Pinard, Maurice. 2011. Motivational Dimensions in Social Movements and Contentious Collective Action. Montreal: McGill-Queen's University Press.

Pope Benedict XVI. 2010. "If You Want to Cultivate Peace, Protect Creation.” Message for the Celebration of the World Day of Peace, January 1. http://www.vatican.va/holy_father/benedict_xvi/messages/peace/documents/hf_be n- xvi_m... (Accessed on February 20, 2019).

Pope Francis. 2015. 'Laudato Si': On Care for our Common Home. Our Sunday Visitor.

Ponce, Aldo F. and Cynthia McClintock. 2014. "The Explosive Combination of Inefficient Local Bureaucracies and Mining Production: Evidence From Localized Societal Protests in Peru." Latin American Politics and Society 56(3): 118-140.

PRONIcaragua. 2013. Nicaragua: Discover the Mining Opportunities. Managua: PRONicaragua.

PRONicaragua. 2014. Nicaragua: ¡Crezcamos Juntos! PowerPoint presentation by Javier Chamorro, Director Ejecutivo, at Congreso Internacional de Minería, Managua, Nicaragua, (August 12). http://www.congresointernacionaldemineria.com.ni/conferencias/12agosto/Presentacion-General-de-Pais.pdf (Accessed on November 10, 2017).

Putnam, Robert D. 2000. Bowling Alone. The Collapse and Revival of American Community. New York: Simon and Schuster. 
Reenock, Christopher, Michael Bernhard, and David Sobek. 2007. "Regressive Socioeconomic Distribution and Democratic Survival.” International Studies Quarterly 51:677-699.

Resnick, Brian. 2017. "4 Rules for Making a Protest Work, According to Experts.” Vox. (April 23). https://www.vox.com/policy-and-politics/2017/1/31/14430584/protesttrump-strategies-experts (Accessed on December 10, 2018).

Richards, D.P. 2013. Extracting Governance: The Landscape of Cross-Sector Partnerships Between ICMM Companies and Environmental NGOs. Doctoral Dissertation: University of Oxford.

Robertson, Roland. 1986. "Liberation Theology in Latin America: Sociological Problems of Interpretation and Explanation.” In Prophetic Religions and Politics: Religion and the Political Order edited by J.K. Hadden and A. Shupe, 73-102. New York: Paragon House.

Robinson, James A., Ragnar Torvik, and Thierry Verdier. 2006. "Political Foundations of the Resource Curse." Journal of Development Economics 79(2): 447-468.

Rodhouse, Toyah, and Frank Vanclay. 2016. "Is Free, Prior and Informed Consent a Form of Corporate Social Responsibility?" Journal of Cleaner Production 131: 785-794.

Rodríguez Garavito, Cesar, Meghan Morris, Natalia Orduz Salinas, and Paula Buriticá. La Consulta Previa a Los Pueblos Indígenas. Los Estándares del Derecho Internacional. Bogotá, Colombia: Universidad de los Andes

Rogge 1996. “Ecuador’s Oil Region: Developing Community Legal Resources in National Security Zone.” Third World Legal Studies: 233-266. 
Rose, Mitch. 2002. "The Seductions of Resistance: Power, Politics, and a Performative Style of Systems. Environment and Planning D: Society and Space 20(4): 383400.

Ruiz Leotaud, Valentina. 2018. "Hundreds Protest in Veracruz against Mining Development." Mining.Com, (May 27). http://www.mining.com/hundredsprotest-veracruz-mining-development/ (Accessed on February 24, 2019).

Rumsey, Alan, and James Weiner. 2004. Mining and Indigenous Lifeworlds in Australia and Papua New Guinea. Sean Kingston Publishing.

Sanchez Gonzalez, Mario. 2016. Los recursos en disputa. El caso del conflicto minero en Rancho Grande, Nicaragua Anuario de Estudios Centroamericanos, Universidad de Costa Rica, 42: 93-131.

Sanchez Gonzalez, Mario. 2017. "The Rancho Grande Experience: Environmentalism in Rebellion.” Envío. http://www.envio.org.ni/articulo/5383 (Accessed on December 1, 2018).

Sánchez-Vázquez, Luis, Maria Gabriela Espinosa-Quezada, and Maria Beatriz Eguiguren-Riofrío. 2016. “'Golden Reality' or the 'Reality of Gold': Artisanal Mining and Socioenvironmental Conflict in Chinapintza, Ecuador.” The Extractive Industries and Society 3(1): 124-128.

Salas Carreno, Guillermo. 2008. Dinámica Social y Minería: Familias Pastoras de Puna y la Presencia del Proyecto Antamina (1997-2002). Vol. 4 Instituto de Estudios Peruanos. 
Satell, Greg, and Srdja Popovic. 2017. "How Protests Become Successful Social Movements." HBR.ORG, (January 27). https://HBR.ORG/2017/01/How-ProtestsBecome-Successful-Social-Movements (Accessed on December 10, 2018). Scacco, Alexandra. 2008. "Who Riots? Explaining Individual Participation in Ethnic Violence." Working Paper.

Scheyvens, Regina, and Leonard Lagisa. 1998. 'Women, Disempowerment and Resistance: An Analysis of Logging and Mining Activities in the Pacific." Singapore Journal of Tropical Geography 19(1): 51-70.

Schilling-Vacaflor, Almut. 2012. "Democratizing Resource Governance Through Prior Consultations? Lessons from Bolivia's Hydrocarbon Sector.” GIGA Working Papers 184.

Schilling-Vacaflor, Almut, and Riccarda Flemmer. 2013. "Why is Prior Consultation Not Yet an Effective Tool for Conflict Resolution? The Case of Peru." GIGA Working Papers 220.

Scholosberg, David. 2007. Defining Environmental Justice: Theories, Movements and Nature. Oxford University Press.

Schock, Kurt. 2015. "Rightful Radical Resistance: Mass Mobilization and Land Struggles in India and Brazil." Mobilization 20(4): 493-515.

Schultz, P. Wesley. 1999. "Changing Behavior with Normative Feedback Interventions: A Field Experiment on Curbside Recycling." Basic and Applied Social Psychology 22(1): 25-36. 
Schultz, P. Wesley, and Jennifer Tabanico. 2007. "Self, Identity, and the Natural Environment: Exploring Implicit Connections with Nature.” Journal of Applied Social Psychology 37(6): 1219-1247.

Schultz, P. Wesley, and Lynnette C. Zelezny. 1998. "Values and Proenvironmental Behavior: A Five-Country Survey.” Journal of Cross-Cultural Psychology 29(4): 540-558.

Schussman, Alan, and Sarah A. Soule. 2005. "Process and Protest: Accounting for Individual Protest Participation.” Social Forces 84(2): 1083-1108.

Schwartz, Shalom H., Gila Melech, Arielle Lehmann, Steven Burgess, Mari Harris, and Vicki Owens. 2001. "Extending the Cross-Cultural Validity of the Theory of Basic Human Values with a Different Method of Measurement.” Journal of Cross-Cultural Psychology 32(5): 519-542.

Scott, James C. 2014. The Art of Not Being Governed: An Anarchist History of Upland Southeast Asia. New Haven, Connecticut: Yale University Press.

Scott, Rebecca, and Elizabeth Bennett. 2015. "Branding Resources: Extractive Communities, Industrial Brandscapes and Themed Environments.” Work, Employment and Society 29(2): 278-294.

Shriver, Thomas E., Alison E. Adams, and Stefano B. Longo. 2015. "Environmental Threats and Political Opportunities: Citizen Activism in the North Bohemian Coal Basin." Social Forces 94(2): 699-722.

Silva, Eduardo. 2009. Challenging Neoliberalism in Latin America. Cambridge University Press. 
Silva-Macher, Jose-Carlos, and Katharine N. Farrell. 2014. "The Flow/Fund Model of Conga: Exploring the Anatomy of Environmental Conflicts at the Andes-Amazon Commodity Frontier." Environmental Development and Sustainability 16(3): $747-768$.

Simmons, Erica. 2016. Meaningful Mobilization: Market Reforms and the Roots of Social Protest in Latin America. Cambridge: Cambridge University Press.

Simmons, Erica. 2019. “Transnational Protest: 'Going Global' in the Current Protest Cycle Against Economic Globalization.” In Protest and Democracy edited by Moisés Arce and Roberta Rice. University of Calgary Press.

Singer, Olivia. 2013. "Liberation Theology in Latin America." In Modern Latin America, edited by Thomas E. Skidmore, Peter Smith, and James N. Green. Oxford University Press (Eighth Edition).

Smith, Christian. 1991. The Emergence of Liberation Theology: Radical Religion and Social Movement Theory. University of Chicago Press.

Smith, Christian. 1996. Disruptive Religion: The Force of Faith in Social Movements Activism. New York: Routledge.

Snow, David A., E. Burke Rochford Jr., Steven K. Worden, and Robert D. Bendford. 1986. "Frame Alignment Processes, Micromobilization, and Movement Participation.” American Sociological Review 51: 464-481.

Snow, David A., and Catherine Corrigall-Brown. 2005. "Falling on Deaf Ears: Confronting the Prospect of Non-Resonant Frames.” In Rhyming Hope and History: Activism and Social Movement Scholarship, edited by David Croteau, 
Charlotte Ryan, and William Hoynes, 222-238. Minneapolis: University of Minnesota Press.

Snow, David A., Daniel Cress, Liam Downey, and Andrew Jones. 1998. "Disrupting the 'Quotidian': Reconceptualizing the Relationship Between Breakdown and the Emergence of Collective Action." Mobilization 3(1): 1-22.

Snow, David A., and Robert D. Benford. 1988. "Ideology, Frame Resonance, and Participant Mobilization.”International Social Movement Research 1(1): 197217.

Sosa, Irene, and Karyn Keenan. 2001. "Impact Benefit Agreements Between Aboriginal Communities and Mining Companies: Their Use in Canada.” Canadian Environmental Law Association. Ottawa, Canada.

Soto, Yokebec. 2013. La Verdad a Cielo Abierto: Más de 20 Años de Historia de la Mina Crucitas. San José, Costa Rica. Recurso electrónico.

Spalding, Rose J. 2011. “Transnational Activism and National Action: El Salvador's Anti-Mining Movement." Paper presented at workshop on The Domestic Effects of Transnational Activism, Tulane University, New Orleans, LA.

Spalding, Rose J. 2014a. Contesting Trade in Central America: Market Reform and Resistance. Austin: University of Texas Press.

Spalding, Rose J. 2014b. "El Salvador: Horizontalism and the Anti-Mining Movement." In Rethinking Latin American Social Movements, edited by Richard StahlerSholk, Harry Vanden, and Marc Becker. Lanham, Maryland: Rowman and Littlefield: 311-330. 
Spalding, Rose J. 2015a. "Domestic Loops and Deleveraging Hooks: Transnational Social Movements and the Politics of Scale Shift," In Social Movement Dynamics: New Perspectives on Theory and Research From Latin America, edited by Federico M. Rossi and Marisa Von Bülow. London: Ashgate: 181-214. Spalding, Rose J. 2015b. "Mining Booms and Mining Bans: Divergent Outcomes of Anti-Mining Movements in Nicaragua and Costa Rica." Paper presented at the International Congress of the Latin American Studies Association, San Juan, Puerto Rico, May 27-30.

Spalding, Rose. 2016. "Mining and Protest in Central America. Interpreting Alternative Outcomes." Paper presented at the XXXIV International Congress of the Latin American Studies Association, New York, NY.

Spalding, Rose J. Forthcoming. "Los empresarios y el estado en la Nicaragua postrevolucionaria: el reordenamiento de las élites y la nueva estrategia de colaboración" in La Reconfiguración de las Élites y el Poder en Centroamérica. Eric Hershberg and Juan Pablo Pérez Sáinz, eds. Vol. 2, San José: FLACSO.

Spence, Alexa, Wouter Poortinga, Catherine Butler, and Frank Pidgeon. 2011. "Perceptions of Climate Change and Willingness to Save Energy Related to Flood Experience." Nature Climate Change 1(1): 46-49.

Spronk, Susan, and Jeffery R. Webber. 2007. "Struggles Against Accumulation by Dispossession in Bolivia: The Political Economy of Natural Resource Contention." Latin American Perspectives 34(2): 31-47. 
Steg, Linda, and Judith I.M. De Groot. 2012. "Environmental Values." In The Oxford Handbook of Environmental and Conservation Psychology edited by Susan D. Clayton. New York: Oxford University Press.

Stern, Paul C. 2000. "New Environmental Theories: Toward a Coherent Theory of Environmentally Significant Behavior.” Journal of Social Issues 56(3): 407-424.

Stoler, Anna L. 2008. "Imperial Debris: Reflections on Ruins and Ruination.” Cultural Anthropology 23(2): 191-219.

Stüurmer, Stefan, and Bernd Simon. 2009. "Pathways to Collective Protest: Calculation, Identification, or Emotion? A Critical Analysis of the Role of Group-Based Anger in Social Movement Participation.” Journal of Social Issues 65(4): 681-705.

Svampa, Maristella. 2017. "Cuatro Claves para Leer América Latina." Nueva Sociedad 268: 50-64.

Svampa, Maristella, and Mirta A. Antonelli, eds. 2009. Minería Transnacional, Narrativas del Desarrollo y Resistencias Sociales. Buenos Aires: Editorial Biblos. Swyngedouw, Erik. 1997. 'Neither Local nor Global: 'Glocalization' and the Politics of Scale." In Spaces of Globalization: Reasserting the Power of the Local edited by Kevin Cox. New York: Guilford Press.

Szablowski, Daniel. 2007. Transnational Law and Local Struggles: Mining Communities and the World Bank. Bloomsbury Publishing.

Szasz, Andrew. 2007. Shopping Our Way to Safety: How We Changed from Protecting the Environment to Protecting Ourselves. Minnesota: University of Minnesota Press. 
Sztompka, Piotr. 1999. Trust: A Sociological Theory. Cambridge: Cambridge University Press.

Tarrow, Sidney. 1994. Power in Movement: Social Movements and Contentious Politics. New York: Cambridge University Press.

Tarrow, Sidney. 1998. Power in Movement: Social Movements, Collective Action, and Politics. New York: Cambridge University Press.

Temper, Leah, and Joan Martinez-Alier. 2013. "The God of the Mountain and Godavarman: Net Present Value, Indigenous Territorial Rights and Sacredness in a Bauxite Mining Conflict in India. Ecological Economics 96: 79-87.

Teschner, Benjamin. 2012. "Small-scale Mining in Ghana: The Government and the Galamsey." Resources Policy 37(3): 308-314.

Tilly, Charles. 1978. From Mobilization to Revolution. Mcgraw-Hill College.

Trumbo, Craig W., and Katherine A. McComas. 2003. "The Function of Credibility in Information Processing of Risk Perception." Risk Analysis 23(2): 343-353.

Turman, Jinny. 2018. "Religion and Resistance in Appalachia: Faith and the Fight Against Mountaintop Removal Coal Mining by Joseph D. Witt (review)." Journal of Southern History 84(1): 232-233.

Turner, John C., and Penelope J. Oakes. 1986. “The Significance of the Social Identity Concept for Social Psychology with Reference to Individualism, Interactionism and Social Influence.” British Journal of Social Psychology 25(3): 237-252.

Urkidi, Leire. 2010. “A Glocal Environmental Movement Against Gold Mining: PascuaLama in Chile. Ecological Economics 70(2): 219-227. 
Urkidi, Leire. 2011. "The Defense of the Community in the Anti-Mining Movement of Guatemala." Journal of Agrarian Change 11(4): 556-580.

Urkidi, Leire, and Marianna Walter. 2011. "Dimensions of Environmental Justice in Anti-Goldmining Movements in Latin America." Geoforum 42(6): 683-695.

Van der Werff, Ellen, Linda Steg, and Kees Keizer. 2013. "The Value of Environmental Self-Identity: The Relationship Between Biospheric Values, Environmental SelfIdentity and Environmental Preferences, Intentions and Behaviour." Journal of Environmental Psychology 34:55-63.

Van Dyke, Nella Soule, and Sarah Soule. 2002. "Structural Social Change and the Mobilizing Effect of Threat: Explaining Levels of Patriot and Militia Organizing in the United States." Social Problems 49(4): 497-520.

Vélez-Torres, Irene. 2014. “Governmental Extractivism in Colombia: Legislation, Securitization and the Local Settings of Mining Control." Political Geography 38: $68-78$.

Veltmeyer, Henry, and James Petras. 2014. The New Extractivism: A Post-Neoliberal Development Model or Imperialism of the Twenty-First Century? London: Zed.

Vieyra, Juan Cruz, Malaika Masson. 2014. Transparent Governance in an Age of Abundance: Experiences from the Extractive Industries in Latin America and the Caribbean. Inter-American Development Bank.

Villalba-Eguiluz, C.Unai, and, Iker Etxano. 2017. "Buen Vivir vs Development (II): The Limits of (Neo-) Extractivism.” Ecological Economics 138: 1-11.

Villafuerte, Daniel 2014. "Neoextractivismo, Megaproyectos y Conflictividad en Guatemala y Nicaragua." Espiral (Guadalajara) 21(61): 109-141. 
Walsh, Edward, Rex Warland, and Douglas Clayton Smith. 1997. Don't Burn it Here:

Grassroots Challenges to Trash Incinerators. State College, PA: Penn State University Press.

Walter, Knut. 2004. El régimen de Anastasio Somoza. 1936-1956. Managua, Nicaragua: IHNCA.

Walter, Marianna, Joan Martinez-Alier, and Humberto Correa. 2010. "How to Be Heard When Nobody Wants to Listen: Community Action Against Mining in Argentina.” Canadian Journal of Development Studies 30: 281-301.

Walter, Marianna, and Leire Urkidi. 2015. “Community Mining Consultations in Latin America (2002): The Contested Emergence of Hybrid Institution for Participation." Geoforum

Walter, Martin. 2016. Extractivism in Latin America and the Caribbean: The Basics. Inter-American Development Bank Technical Note 907. Washington DC: InterAmerican Development Bank.

Warnaars, Ximena S. 2012. "Why Be Poor When We Can Be Rich? Constructing Responsible Mining in El Pangui, Ecuador.” Resources Policy 37(2): 223-232.

Wayland, Joshua, and Matthew Kuniholm. 2016. "Legacies of Conflict and Natural Resource Resistance in Guatemala." The Extractive Industries and Society 3(2): 395-403.

Weyland, Kurt. 2003. "Economic Voting Reconsidered: Crisis and Charisma in the Election of Hugo Chavez." Comparative Political Studies 36(7): 822-848. Williams, Rhys. 2006. “Collective Action, Everyday Protest, and Lived Religion.” Social Movement Studies 5(1): 83-89. 
Witt, Joseph D. 2016. Religion and Resistance in Appalachia: Faith and the Fight Against Mountaintop Removal Coal Mining. Lexington: University Kentucky Press.

Witt, Joseph D. 2017. "Case Study: Religion and the Twenty-First Century AntiExtraction Movement." In Grounding Religion: A Field Guide to the Study of Religion and Ecology, edited by Whitney Bauman, Richard Bohannon, and Kevin J. O'Brien. New York: Routledge ( $2^{\text {nd }}$ Edition): 26-33.

Wo Ching, Eugenia. 2014. "Costa Rica: The First Latin American Country Free of OpenPit Gold Mining." In The Earth Charter, Ecological Integrity and Social Movements, edited by Laura Westra and Miriam Vilela. New York: Routledge. World Trade Organization. 2013. International Trade Statistics.

Wünderich, Volker .1989. Sandino en la Costa. De las Segovias al Litoral Atlántico. Nicaragua: Editorial Nueva Nicaragua.

Wünderich, Volker. 2010. Sandino. Una biografía política. Nicaragua: Instituto de Historia de Nicaragua y Centroamérica.

Yakovleva, Natalia. 2005. Corporate Social Responsibility in the Mining Industries. Ashgate Publishing Ltd.

Yakovleva, Natalia. 2007. "Perspectives on Female Participation in Artisanal and Smallscale Mining: A Case Study of Birim North Distric of Ghana.” Resources Policy 32(1): 29-41.

Yoder, John. 1990. "The Wider Setting of 'Liberation Theology.” The Review of Politics 52(2): 285-296. 
Zandvliet, Luc, and Mary Anderson. 2009. Getting it Right: Making CorporateCommunity Relations Work. Greenleaf Publishing.

Zepeda-Millán, Chris. 2017. Latino Mass Mobilization: Immigration, Racialization, and Activism. Cambridge: Cambridge University Press. 


\section{VITA}

Michael Hendricks was born on December 8, 1988 in Long Branch, New Jersey. Michael grew up in West Long Branch, New Jersey with his father (Stephen), his mother (Patricia), and his older sister (Caitlin). Michael's father worked in the wine and beverage industry as a sales and businessman for the majority of his career until his retirement. Michael's mother is a teacher and guidance counselor at a Catholic high school in Red Bank, New Jersey. Michael's sister works as a third grade teacher in Stamford, Connecticut where she lives with her husband Brian and her daughter Grace. Michael and his family have always had the spirt of travel and the spirt of volunteerism engrained in their souls.

Michael graduated from Shore Regional High School in West Long Branch, New Jersey in 2007. After graduation, Michael attended the University of Delaware from 2007-2011. During his time at the University of Delaware, Michael studied International Relations with a concentration in development and a specialization in European studies. He also received undergraduate minors in Spanish, Business, and History. While at the University of Delaware, Michael had the opportunity to study abroad in Quito, Ecuador and Granada, Spain. During his study abroad experiences, Michael was able to travel around Ecuador, South America, Spain, and Europe. He learned the local languages and immersed himself in the local cultures and traditions. As an undergraduate student, Michael also traveled to Honduras for a service-learning trip. He volunteered with Students Helping Honduras where he built schools in extremely impoverished areas around Honduras and taught English and math. 
After Michael graduated from the University of Delaware in May of 2011, he was able to combine his love of travel with his love for volunteering that was instilled in him throughout his life. He left for Nicaragua as a Peace Corps Volunteer in August 2011. Michael served as a Peace Corps TEFL Volunteer in Nicaragua from August 2011November 2013. He served for 27 months in the municipality of San Marcos in the department of Carazo. He co-taught and co-planned lessons and co-created teaching materials with several Nicaraguan English teachers in his community. He also conducted monthly English trainings for all of the English teachers in his community. Michael also conducted many secondary projects. The one that he is proudest of is the special needs park and playground that he built with the Special Needs School in his community. The park and playground were inclusive for students with a variety of disabilities. It was a major community effort that Michael will remember for the rest of his life.

Michael loved his work so much in Peace Corps Nicaragua that he extended his service to China for six months. Michael served as a Peace Corps Response Volunteer in Guiyang, Guizhou, China. He taught English at Guizhou Vocational and Technology Institute. He taught English with a specific purpose geared towards students wanting to obtain jobs in hotels, as flight attendants, or as tour guides. Although his service was shorter in China than it was in Nicaragua, he still loved his time in China and wishes to return one day soon.

Michael's Peace Corps' experiences are what motivated him to begin graduate school. During his time in the Peace Corps he found himself asking many questions related to politics, economics, and development of countries and communities. In 2014, he started as an MA student in the Department of Political Science and as a Paul D. 
Coverdell Peace Corps Fellow. After graduating with his master's degree, Michael transitioned into the PhD program in the Department of Political Science. Upon graduation, Michael will leave the University Missouri with a $\mathrm{PhD}$ in Political Science, an MA in Political Science, a graduate minor in International Development, and graduate certificates in Grantsmanship, Global Public Affairs, Nonprofit Management, and Public Management.

Michael also had the wonderful opportunity of meeting his wife Carly during his time in Nicaragua as a Peace Corps Volunteer. His wife was a volunteer in the same group of volunteers, but served as an Environmental Education Volunteer. Carly is originally from Muskegon, Michigan. Michael and Carly were married on July 11, 2015 in Muskegon. The two of them have lived in Columbia, MO since August 2014. Carly teaches third grade at Blue Ridge Elementary School and is a recent MA graduate from the Truman School of Public Affairs. Michael and Carly welcomed their son Walter on November 9, 2017. They also have three dogs: Leo, Dolly, and King.

After graduation, Michael and his family plan to move to Normal, Illinois, where Michael will be starting a position at Illinois State University. He will be an Assistant Professor in Comparative Politics, Community Development, and Project Management with a focus on Latin America in the Department of Politics and Government. 